INSTITUTO DE PESQUISAS ENERGÉTICAS E NUCLEARES

Autarquia associada à Universidade de São Paulo

\title{
DESENVOLVIMENTO DE UMA METODOLOGIA DE CALIBRAÇÃO INDEPENDENTE PARA UM LIDAR RAMAN NA OBTENÇÃO E ESTUDO DE PERFIS DE VAPOR D’ÁGUA ATMOSFÉRICO
}

\section{ANI SOBRAL TORRES}

\author{
Tese apresentada como parte dos \\ requisitos para obtenção do grau de \\ Doutor em Ciências na Área de \\ Tecnologia Nuclear - Materiais. \\ Orientador: \\ Prof. Dr. Eduardo Landulfo
}


INSTITUTO DE PESQUISAS ENERGÉTICAS E NUCLEARES

Autarquia associada à Universidade de São Paulo

\section{DESENVOLVIMENTO DE UMA METODOLOGIA DE CALIBRAÇÃO INDEPENDENTE PARA UM LIDAR RAMAN NA OBTENÇÃO E ESTUDO DE PERFIS DE VAPOR D'ÁGUA ATMOSFÉRICO}

\section{ANI SOBRAL TORRES}

Tese apresentada como parte dos requisitos para obtenção do grau de Doutor em Ciências na Área de Tecnologia Nuclear - Materiais.

Orientador:

Prof. Dr. Eduardo Landulfo 
Autorizo a reprodução e divulgação total ou parcial deste trabalho, por qualquer meio convencional ou eletrônico, para fins de estudo e pesquisa, desde que citada a fonte.

Catalogação na Publicação

Instituto de Pesquisas Energéticas e Nucleares

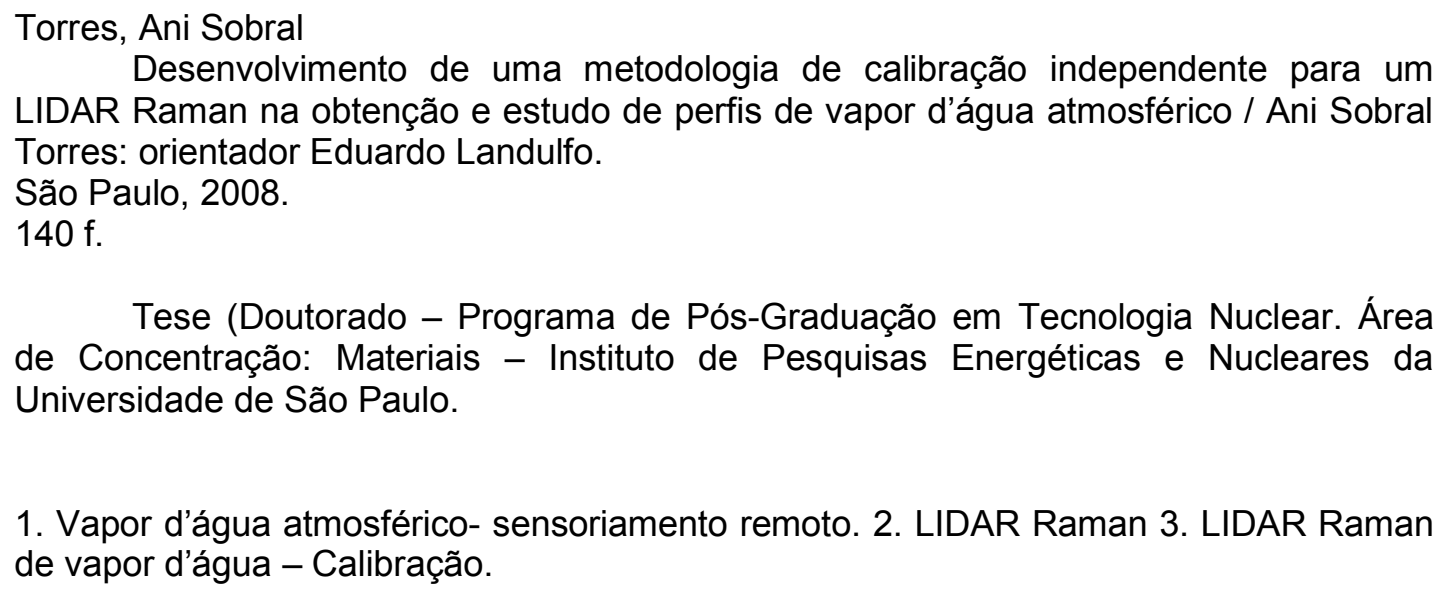

1. Vapor d'água atmosférico- sensoriamento remoto. 2. LIDAR Raman 3. LIDAR Raman de vapor d'água - Calibração. 
Dedico este trabalho ao meu grande incentivador e companheiro, Amir . 


\section{AGRADECIMENTOS}

Porque tudo é fruto de uma equipe!

Quero agradecer àquelas pessoas que, de alguma forma, contribuíram para a realização deste trabalho e me incentivaram de inúmeras formas. A todos vocês quero expressar minha sincera gratidão.

Em especial ao orientador Dr. Eduardo Landulfo pela orientação, apoio e discussões que possibilitaram a realização desse trabalho e tiveram grande impacto no meu conhecimento científico e desenvolvimento profissional.

Ao Dr. David N. Whiteman (NASA-GSFC) e ao Dr. Demetrius Venable (Howard University) pela orientação durante o estágio de doutorado sanduíche, e pelas valiosas reuniões, discussões e idéias que ajudaram no meu aprendizado ao longo do doutorado.

Aos técnicos do CLA pelo auxílio técnico e operacional durante o trabalho, e ao pessoal da oficina do CLA pelas peças usinadas.

A Elsa da secretaria por todo o apoio moral e operacional.

Aos colegas e amigos (Wellington e Renata) do grupo LAAL, do CLA e da Divisão de Ensino do IPEN, que involuntariamente foram omitidos, mas tiveram igual importância para minha vida pessoal e acadêmica.

Aos colegas e amigos da Howard University e da NASA-GSFC que contribuiram muito para o meu crescimento profissional e humano.

À minha família pelo suporte nas horas difíceis, ao meus pais e especialmente ao meu marido Amir, pelo seu amor, apoio incondicional e extrema paciência.

À Deus por permitir que eu trilhasse este caminho com sucesso.

E agradeço ao CNPq, a FAPESP e a CAPES pelo apoio financeiro. 
"Um pouco de ciência nos afasta de Deus. Muito, nos aproxima." 


\section{DESENVOLVIMENTO DE UMA METODOLOGIA DE CALIBRAÇÃO INDEPENDENTE PARA UM LIDAR RAMAN NA OBTENÇÃO E ESTUDO DE PERFIS DE VAPOR D'ÁGUA ATMOSFÉRICO}

\section{Ani Sobral Torres}

\section{RESUMO}

Neste trabalho são apresentados resultados relativos ao desenvolvimento de uma metodologia de calibração independente de um sistema LIDAR Raman para medidas de razão de mistura do vapor d'água, avaliando-se a eficiência total de transmissão óptica do sistema LIDAR Raman. Uma calibração independente ou absoluta de um sistema LIDAR foi possível por meio de medidas e cálculos dos parâmetros relevantes. A metodologia de calibração independente apresentada é baseada na decomposição das equações da razão de mistura do vapor d'água, especialmente na avaliação do fator de calibração e as incertezas relativas à transmissão óptica e secções diferenciais de espalhamento. A eficiência de transmissão incluiu fatores como a refletividade do telescópio, transmissão dos componentes ópticos e filtros. A avaliação da eficiência do sistema foi realizada com do uso de uma lâmpada calibrada de tungstênio em duas configurações distintas de filtros de interferência, (banda larga e banda estreita) instalados no sistema LIDAR Raman da Howard University (HURL). A avaliação da secção diferencial de espalhamento Raman para o vapor d'água foi realizada pelo uso de um modelo téorico descrito na literatura e por uma primeira aproximação experimental.

Os resultados mostraram consistência e que essa metodologia de calibração pode ser usada em uma base rotineira para medidas de vapor d'água atmosférico. 


\title{
DEVELOPMENT OF A METHODOLOGY FOR AN INDEPENDENT WATER VAPOR RAMAN LIDAR CALIBRATION TO STUDY WATER VAPOR ATMOSPHERIC PROFILES.
}

\section{Ani Sobral Torres}

\begin{abstract}
For this study we present the results of the development of an absolute Raman LIDAR calibration methodology for measuring a water vapor mixing ratio. An absolute calibration of the system is possible by measuring or calculating the relevant system parameters based on the decomposition of the calibration instrumental function. The efficiency of the LIDAR system transmission at the laser and Raman produced wavelengths including factors such as reflectivity of the telescope and the transmission of conditioning optics and filters. We have evaluated the efficiency of the system with a calibrated tungsten lamp using two different sets of interference filters (wideband and narrow-band) that were installed at the Howard University Raman LIDAR system. The methodology is based on the decomposition of the water vapor mixing ratio equations, especially on the evaluation of the calibration factor and the instrumental errors involved. Also, the evaluation of the Raman cross section ratio was performed by using a theoretical model and then with an experimental approach.

The results show consistency that this calibration methodology can be used on a regular basis.
\end{abstract}




\section{SUMÁRIO}

Lista de abreviaturas.......................................................................... 12

1. INTRODUÇÃO E JUSTIFICATIVAS ............................................... 14

2. OBJETIVOS.................................................................................... 18

PARTE 1 - CALIBRAÇÃO DO LIDAR RAMAM PARA MEDIDAS DE 19 VAPOR D'ÁGUA.

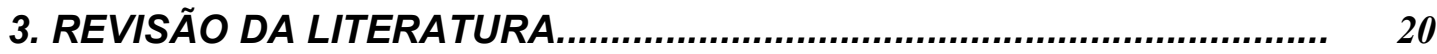

3.1 Sensoriamento Remoto da Atmosfera............................................... 20

3.2 O Efeito Raman .............................................................................. 22

3.3. Estrutura da atmosfera........................................................... 28

3.3.1 Foco na troposfera..................................................................... 30

3.3.2 Composição da atmosfera...........................................................

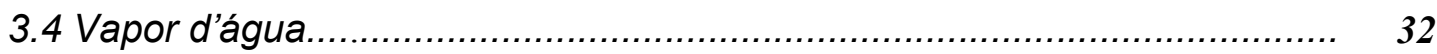

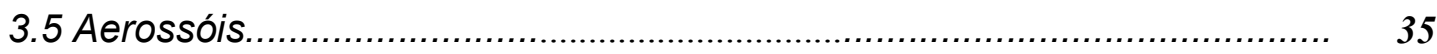

3.6 LIDAR

3.6.1 Aspectos históricos - técnicas LIDAR ……………........................ $\quad 37$

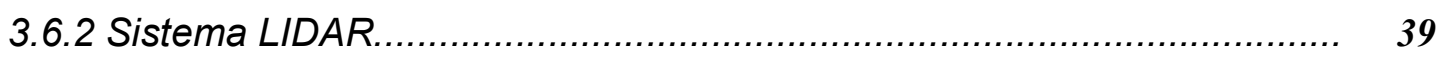

3.7 A equação LIDAR genérica e sua interpretação....................................... 41

3.7.1 Equação de Razão de mistura do vapor d'água obtida por LIDAR 42 Raman

3.7.2 Dependência da temperatura da secção diferencial de espalhamento 45 Raman

3.7.3 Cálculo da secção diferencial de espalhamento Raman.......................... 47

3.7.4 Vibracional-rotacional do nitrogênio................................................. 50

3.7.5 Seç̧ão diferencial de espalhamento Raman do nitrogênio...................... 52

3.7.6 Modelo descrito para o cálculo da secção diferencial de espalhamento 53 Raman do vapor d'água.

4.METODOLOGIA............................................................................ 56

4.1 Aparato Experimental............................................................. 5

4.1.1 O LIDAR Raman da Howard University (HURL).................................. 56

4.1.2 Procedimento para "glue".......................................................... $\quad 60$

4.1.3 Lâmpada calibrada de tungstênio e motor de translação......................... $\quad \mathbf{6 0}$

4.2 Metodologia de calibração................................................................ $\quad 63$ 
5. DETERMINAÇÃO DA EFICIÊNCIA ÓPTICA DE TRANSMISSÃO............

5.1 Simulação do padrão de Intensidade - Ray trace com o "Rayica".......... $\quad 65$

5.2 Testes com a lâmpada de tungstênio ............................................... $\quad 70$

5.3 Análise da irradiância espectral da lâmpada de tungstênio calibrada....... 73

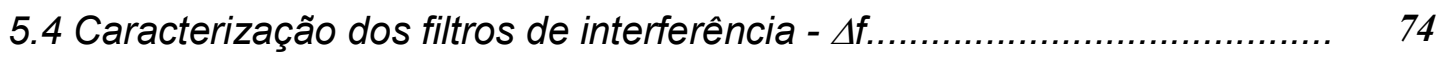

5.4.1 Filtros de Banda estreita............................................................

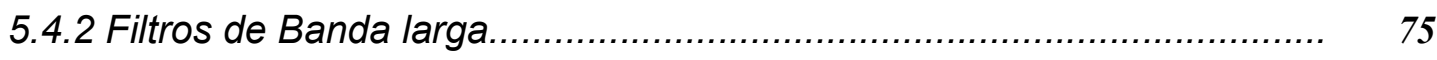

5.4.3 Filtros de Densidade Neutra........................................................

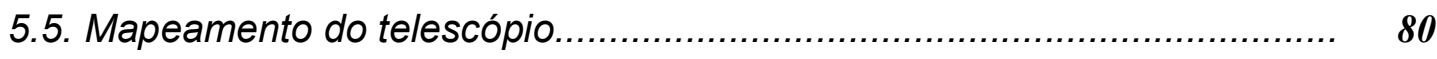

5.5.1 Mapeamento do telescópio em Julho de 2008................................... 83

6. DETERMINAÇÃO DA SECÇÃO DIFERENCIAL DE ESPALHAMENTO 87 RAMAN..

6.1 Secção diferencial de espalhamento Raman teórica................................. 87

6.2 Determinação experimental da razão das secções diferenciais de espalhamento Raman utilizando-se uma configuração de filtros de $\mathbf{9 2}$ interferência de banda larga.

6.3 Cálculo do fator de calibração para várias configurações.......................... 101

7. CÁLCULO DOS ERROS.....................................................................

7.1 Equações para erro na razão de mistura de vapor d'água......................... 103

7.2 Erros calculados para a razão das eficiências de transmissão.................. 104

7.3 Erros relativos e estimados das secções diferenciais de espalhamento Raman para o vapor d'água..................................................................... 105

8. CAMPANHA WAVES - WATER VAPOR VALIDATION EXPERIMENT.... 107

8.1 Dados da WAVES para calibração com outros sensores.......................... 109

9. CONCLUSÕES PARCIAIS.............................................................. 114

PARTE 2 : IMPLEMENTAÇÃO DE UM LIDAR RAMAN NO IPEN, SÃO 116 PAULO.

10. O LIDAR DO MUNICÍPIO DE SÃO PAULO - MSP-LIDAR.................... 117

10.1 Implementação do MSP-Raman LIDAR............................................ 117

10.2 Formalismo na obtenção de perfis de aerossóis por LIDAR

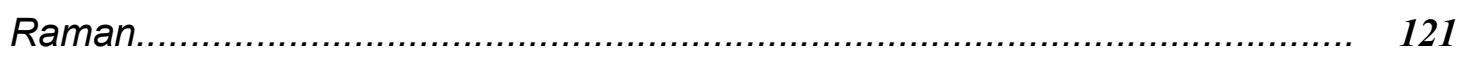

10.2.1 Equação de erros para a razão de espalhamento do aerossol............. 123

10.3 Calibração atmosférica da razão de espalhamento do aerossol............. 124 
10.4 Medidas de aerossóis como MSP-Raman LIDAR.................................... 125

11.CONCLUSÕES FINAIS......................................................................... 130

12. SUGESTÕES PARA TRABALHOS FUTUROS...................................... 132

13. LISTA DE PUBLICAÇÕES............................................................... 134

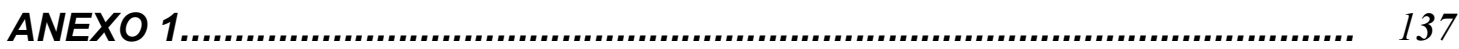

REFERÊNCIAS BIBIOGRÁFICAS........................................................ 139 


\section{LISTA DE ABREVIATURAS}

$A D$ - sinal analógico

AERONET - Aerosol Robotic Network

AOT - Espessura óptica atmosférica

AWEX-G - Airs Water Vapor Experiment - Ground

BS - Beam Splitter

BFP - Band pass filter

CCD - Charge Coupled Detector

CFC - Chlorofluorocarbons

$\mathrm{CFH}$ - Cryogenic Frostpoint Hygrometer

DIAL - Differential Absorption Lidar

ECC - Electrochemical cell ozonesonde

GFSC - Goddard Space Flight Center

GPS - Global Positioning System

HIRDLS - High-Resolution Dynamics Limb Sounder

HU - Howard University

HURL - Howard University Raman Lidar

IPEN - Instituto de Pesquisas Energéticas e Nucleares

LASER - Light Amplifier by Stimulated Emission of Radiation

LIDAR - Light Detection And Ranging

MASER - Microwave Amplifier by Stimulated Emission

MSP - Lidar - Município de São Paulo Lidar

MLS - Microwave Limb Sounder

MR - Razão de mistura

MWR - Microwave radiometer

NOAA - National Oceanic and Atmospheric Administration

ND - Densidade neutra or Neutral density

NASA - National Aeronautis and Space Admnistration

OMI - Ozone Monitoring Instrument

PC - Photon counting

PMT - Photomultiplier tube

RADAR - Radio Detection And Ranging

$\mathrm{RH}$ - Umidade relativa 
SAGE li - Stratospheric Aerosol and Gas Experiment II

STD - Standard deviation ou desvio padrão

TES - Tropospheric emission spectrometer

TOVS - Tiros Operational Vertical Sounder

UMBC - University of Maryland Baltimore County

WMO - World Meteorological Organization 


\section{CAPÍTULO 1}

\section{INTRODUÇÃO E JUSTIFICATIVAS}

A partir da década de 60 , com o surgimento dos lasers, o sensoriamento remoto da atmosfera se desenvolveu o suficiente para se tornar um poderoso instrumento na avaliação da presença de partículas na atmosfera [Clemesha et al, 1966; Fiocco e Smullin, 1963; Cooney, 1968, Vaughan et al, 1993; Ansmann et al,1990; Whiteman, 2003 (I)], na monitoração de emissão de gases de chaminés das indústrias, emanações espontâneas do solo e até sistemas de vigilância militar de armas químicas e biológicas [Troy et al, 1998].

Dada a sua semelhança de operação e princípios físicos com sistemas RADAR, adotou-se o acrônimo LIDAR (Light Detection And Ranging) para denominar essa técnica de sensoriamento remoto a laser.

A técnica LIDAR Raman já está estabelecida há muito tempo [Leonard, 1967; Cooney, 1968 e 1969; Melfi et al, 1969; Ansmann et al,1990; Vaughan et al, 1993; Whiteman, 2001, 2003 (I)] como medida qualitativa de vários constituintes da atmosfera. Entre eles, podemos citar o vapor d'água atmosférico.

A água ocorre na atmosfera nos estados sólido, líquido e gasoso e tem um papel importante em vários processos climatológicos e meteorológicos envolvendo o ciclo hidrológico, o transporte de calor latente, a formação de nuvens, precipitação, crescimento de aerossol, balanço radioativo e química atmosférica. 0 vapor d'água influencia o campo da radiação diretamente por atuar como um gás do efeito estufa pela absorção da parte infravermelha do espectro, participar na formação de nuvens que influenciam o balanço radioativo através do espalhamento da radiação visível incidente e o conseqüente aumento no albedo terrestre [Water Vapor in the Climate System, 1995]. Medidas precisas de razão de mistura do vapor d'água são de considerável importância para entendermos a física atmosférica, incluindo os efeitos do vapor d'água na mudança climática.

Recentemente, avanços tecnológicos permitiram a medida de processos convectivos na camada limite durante o dia [Whiteman, 2003] por Lidar Raman. Aplicações durante o dia aumentaram com o desenvolvimento de transmissores de alta potência e sistemas de detecção com largura de banda estreita que permitem a supressão do ruído de fundo proveniente da luz solar [Vaughan, 1988]. Porém, um 
dos pontos fracos desta técnica é o fato de que as secções diferenciais de espalhamento Raman que são necessárias em primeira aproximação para determinar uma calibração absoluta desta técnica são pouco conhecidas, já que a razão das secções diferenciais de espalhamento Raman possue uma incerteza em torno de 10\% [Penney e Lapp, 1976].

Vários trabalhos [Vaughan et al, 1988; Sherlock et al, 1999; Whiteman (II), 2003; Ferrare et al, 1995; Turner et al, 1999] foram publicados oferecendo opções para calibrar medidas de vapor d'água obtidas por um sistema LIDAR Raman. Entre eles, pode-se citar uma calibração atmosférica, assumindo-se calibração na base de nuvem [Whiteman, 2003 (I)], comparação com radiossondagens [Ferrare et al, 1995] , com um microradiômetro [Turner e Goldsmith, 1999], GPS (Global Positioning System) [Vladutescu et al, 2007; Tarniewicz et al, 2002]. Esse procedimento de validar o perfil de razão de mistura de vapor d água do Raman LIDAR com o de outros sensores torna o erro da medida LIDAR dependente do outro instrumento. Alguns trabalhos [Vaughan et al, 1988; Sherlock et al, 1999; Whiteman (II), 2003] foram propostos no sentido de se realizar uma calibração absoluta do sistema LIDAR Raman sem a necessidade do uso de outros sensores.

Um dos primeiros esforços documentados para realizar uma calibração absoluta ou independente de um LIDAR Raman para o vapor d'água foi feito por [Vaughan et al, 1988], a partir da determinação da transmissão relativa instrumental dos comprimentos de onda Raman combinadas com a determinação experimental da razão das secções diferenciais de espalhamento Raman do $\mathrm{H}_{2} \mathrm{O}$ e do $\mathrm{N}_{2}$ realizadas por [Penney e Lapp,1976] para determinar o coeficiente de calibração. O trabalho de Vaughan resultou em um erro estimado na razão de mistura do vapor d'água de $\sim 12 \%$. Outro método de calibração independente foi proposto por [Sherlock et al,1999] baseado na decomposição da função instrumental, o que permitiu que o coeficiente de calibração fosse expresso como um produto de dois termos: um descrevendo a transmissão instrumental e a eficiência de detecção, e o outro descrevendo a dependência da convolução dos comprimentos de onda da secção diferencial de espalhamento Raman com a função instrumental. O erro total estimado foi de aproximadamente 12-14\%. A maior incerteza em ambos os esforços estava na determinação da razão da secção diferencial de espalhamento Raman para o vapor d'água e nitrogênio. Publicado mais recentemente, [Whiteman, 2003 
(I)] sugere que uma calibração absoluta requer conhecimento da razão de eficiência de transmissão dos canais de vapor d'água e nitrogênio do LIDAR e da razão das secções diferenciais de espalhamento Raman com precisão.

Neste trabalho é apresentada uma metodologia para calibração absoluta para medidas de vapor d'água por um sistema LIDAR Raman. O método é baseado em uma análise cuidadosa da eficiência óptica dos componentes do sistema LIDAR Raman da Howard University (HURL) e na avaliação das secções diferenciais de espalhamento Raman do vapor d'água.

Uma fonte de luz calibrada foi utilizada para o experimento de calibração e a incerteza em sua irradiância espectral foi avaliada, bem como as incertezas envolvidas no sinal LIDAR coletado. Um estudo foi conduzido sobre o desempenho óptico do sistema, além do cálculo dos erros envolvidos na obtenção de transmissão de cada componente ou filtro de interferência. O erro da eficiência óptica total é apresentado.

A partir de novos trabalhos disponíveis na literatura [Avila et al, 1999, 2003, 2004 (I e I)] para o cálculo da secção do vapor d'água, podemos simular os valores das secções diferenciais de espalhamento com relativa acurácia e calcularmos a constante de calibração do sistema HURL.

Este trabalho foi dividido em duas partes: a primeira parte descreve o desenvolvimento da metodologia de calibração independente para razão de mistura de vapor d'água, realizada durante um estágio de doutorado sanduíche na Howard Univeristy em Maryland, EUA e na NASA - Goddard Space Flight Center. A segunda parte descreve o sistema LIDAR disponível em São Paulo no Ipen e sua implementação para medidas de aerosol e vapor d'água por efeito Raman.

No capítulo 2 são expostos os objetivos deste trabalho

No capítulo 3 uma revisão da bibliografia é apresentada, bem como a descrição da técnica LIDAR, do efeito Raman e das equações envolvidas no cálculo da razão de mistura do vapor d'água e no cálculo das secções diferenciais de espalhamento Raman.

No capítulo 4 é apresentada a descrição do sistema LIDAR Raman da Howard University (HURL) utilizado para o desenvolvimento da calibração, bem como a descrição do aparato experimental utilizado para a calibração independente e a metodologia de calibração para medidas de vapor d'água. 
No capítulo 5 é apresentada a determinação da eficiência óptica do sistema por meio do experimento com fonte de luz calibrada e cada etapa desse experimento e desses cálculos é descrita.

No capítulo 6 são apresentados resultados dos métodos experimentais e teóricos adotados para o cálculo das secções diferenciais de espalhamento Raman do vapor d'água e do nitrogênio, importantes na determinação do coeficiente de calibração.

No capítulo 7 são apresentadas as equações de propagação de incertezas dos parâmetros calculados no capítulo 5 e 6 .

No capítulo 8 é descrita uma campanha de campo, realizada em Beltsville, Maryland, EUA de Julho a Agosto de 2006 com o intuito de obtermos perfis de razão de mistura de vapor d'água detectados por diversos sensores, permitindo a validação da metodologia de calibração proposta neste trabalho.

Capítulo 9 apresenta as conclusões parciais sobre a metodologia de calibração do LIDAR Raman para medidas de vapor d'água, encerrando a parte 1 deste trabalho.

No capítulo 10 é descrito o sistema LIDAR do município de São Paulo MSP-LIDAR e sua implementação para se tornar um sistema LIDAR Raman : MSPLIDAR Raman, bem como o formalismo envolvido para medidas de aerossóis e vapor d'água na atmosfera da cidade de São Paulo, representando a parte 2 deste trabalho.

No capítulo 11 são apresentadas as conclusões finais do trabalho e no capítulo 12 são dadas sugestões para trabalhos futuros a serem realizados no IPEN.

Uma lista de publicações é exibida no capítulo 13. 


\section{CAPÍTULO 2}

\section{OBJETIVOS}

Os principais objetivos deste trabalho são:

- Desenvolvimento de uma metodologia de calibração absoluta do sistema LIDAR Raman da Howard University (HURL) realizada durante o estágio de doutorado sanduíche em Maryland,(2005-2006), USA, baseado na análise da eficiência óptica do sistema e no cálculo das secções diferenciais de espalhamento do vapor d'água.

- Cálculo do fator de calibração absoluta do HURL e a tentativa de validação da técnica através de comparação com um fator de calibração extraído de outros sensores (com os dados obtidos durante a campanha WAVES 2006 realizada em Beltsville, Maryland, USA e radiossondagens lançadas na Howard University.

- Implementação de um LIDAR Raman em São Paulo (MSP-Raman LIDAR), no IPEN a partir do LIDAR de espalhamento elástico presente no laboratório (MSPLIDAR). 


\section{PARTE 1 :}

\section{CALIBRAÇÃO DO LIDAR RAMAM PARA MEDIDAS DE VAPOR D'ÁGUA}




\section{CAPÍTULO 3}

\section{REVISÃO DA LITERATURA}

\subsection{Sensoriamento Remoto da Atmosfera}

O sensoriamento remoto é definido por Lillesand \& Kiefer (1987) como " ... a ciência e arte de receber informações sobre um objeto, uma área ou fenômeno pela análise dos dados obtidos de uma maneira tal que não haja contato direto com este objeto, esta área ou este fenômeno". Para obter-se estas informações, usa-se um meio que, neste caso, é a radiação eletromagnética, supondo que esta possa chegar diretamente ao sensor. Isto, no entanto, não é possível em todas as partes do espectro eletromagnético, porque a transmissividade atmosférica é variável para os diversos comprimentos de onda [Lillesand \& Kiefer,1987].

Existem dois tipos de instrumentos para sensoriamento remoto - passivo e ativo. Instrumentos passivos detectam somente radiação emitida pelo objeto sendo observado, ou refletido por um objeto de uma fonte outra que o instrumento. Luz solar refletida é a fonte externa de radiação mais comumente detectada por intrumentos passivos. O olho humano ou um telescópio são sensores remotos passivos: eles precisam de uma fonte externa de radiação. Sensores remotos ativos usam uma fonte de energia, geralmente um laser, na qual a medida é baseada. Radar é conhecido também como um sensor remoto ativo que emite uma microonda e detecta a energia refletida pelo alvo. Como a velocidade das microondas e o tempo entre a emissão e o retorno são conhecidos, a distância do alvo pode ser determinada. O LIDAR (Light Detection and Ranging) é análogo opticamente ao Radar. O LIDAR emite um feixe de luz no alvo e mede a energia refletida ou espalhada pelo alvo no receptor do sistema LIDAR.

Sensores remotos ativos que utilizam uma fonte laser e são usados para deteç̧ão e medidas de gases traçadores no ar o que inclue gases envolvidos no efeito estufa, vapor d'água, etc. A medida desses gases ou vapores na atmosfera é baseada nos seguintes efeitos ópticos: Absorção ressonante, espalhamento Mie/Rayleigh, espalhamento Raman e Raman ressonante, fluorescência, efeito optoacustico e efeito fototérmico [Mansharamani, 2006]. 
Espalhamento atmosférico é uma difusão aleatória de radiação por partículas na atmosfera. Alguns são identificados a seguir e neste trabalho o interesse é no espalhamento Raman.

Espalhamento Rayleigh: Um fóton de luz incidindo sobre uma molécula é espalhado por ela. Se não houver troca de energia, isto é, se a molécula espalhadora não alterar seu estado inicial, o espalhamento é elástico. A grande maioria dos fótons incidentes é espalhada elasticamente. Esse tipo de espalhamento é chamado de espalhamento Rayleigh. Esse espalhamento ocorre quando a radiação interage com moléculas atmosféricas e outras partículas minúsculas que são muito menores em diâmetro do que o comprimento de onda da radiação. O efeito do espalhamento Rayleigh é inversamente proporcional a quarta potência do comprimento de onda. Portanto, existe uma tendência mais forte a este tipo de espalhamento para os comprimentos de onda menores do que para os maiores.

Espalhamento Mie: O espalhamento Mie é o espalhamento por pequenas partículas da atmosfera, i.e., aquelas com tamanho comparável ao comprimento de onda da luz: os aerosóis. É um fenômeno complexo e apresenta uma forte dependência com o ângulo de espalhamento, variando de acordo com o tamanho e forma do aerosol e com a constante dielétrica do meio. Ocorre quando o diâmetro das partículas atmosféricas é da mesma ordem de grandeza ao comprimento de onda da radiação. Este tipo de espalhamento tende a influenciar comprimentos de onda maiores do que o espalhamento Rayleigh.

Espalhamento Raman: Alguns fótons podem excitar um modo de vibração da molécula (ou vários modos), perdendo energia no processo. Depois desse espalhamento inelástico, a molécula passa a vibrar, pois sua energia diminui. Esse é o espalhamento Raman (ou efeito Raman), observado e explicado por Chandrasekhar Raman. Nem todo modo de vibração de uma molécula pode produzir espalhamento Raman, os que podem são chamados de modos ativos para esse tipo de espalhamento. Alguns modos não podem ser excitados por esse tipo de espalhamento e são ditos inativos [Measures, 1984]. 


\subsection{Efeito Raman}

Quando um feixe de luz passa através de um meio, uma certa quantidade é absorvida, outra é transmitida, e o resto é espalhado em todas as direções. A luz espalhada pode ser estudada por observações perpendiculares à direção do feixe incidente (efeito Tyndal). A maior parte da luz é espalhada sem mudança no comprimento de onda (espalhamento Rayleigh), mas há uma pequena parte da luz espalhada, que teve uma mudança no comprimento de onda. Se a luz incidente é monocromática, ou seja, uma linha atômica espectral isolada, o espectro espalhado vai exibir um número de linhas deslocado em relação ao comprimento de onda original. Esse efeito previsto na teoria de Smekal foi primeiramente observado por C.V. Raman e K.S. Krishnam em 1928, e agora é comumente chamado de efeito Raman.

A origem do efeito Raman pode ser explicada brevemente. Considere que um quantum hv de luz incidente atinge uma molécula. Duas soluções estão disponíveis: - se ele é espalhado elasticamente sua energia não muda e a luz espalhada tem a mesma freqüência que a luz incidente, - se é espalhado inelasticamente, pode ocorrer perda ou ganho de energia na interação com a molécula. Essa energia trocada tem que ser, naturalmente, em números inteiros de quanta hv', onde hv'=E1-E2 é a diferença de energia entre dois estados estacionários E1 e E2 da molécula (por exemplo, dois níveis de energia vibracionais). A freqüência da radiação que foi submetida a espalhamento Raman será consequentemente $\quad v "=v \pm v$ '. A freqüência Raman $v^{\prime}$ é geralmente independente da freqüência de luz incidente $v$. Pode-se observar espectros puro rotacional e vibracional-rotacional Raman, os quais são contrapartes do espectro de absorção no infravermelho próximo ou distante. O espectro Raman, contudo, é estudado com fontes de luz no visível ou ultravioleta. Em muitos casos os espectros Raman e infravermelho (IR) de uma molécula se complementam, desde que as vibrações e rotações que não são observáveis no IR sejam no Raman (como a molécula de $\mathrm{O}_{2}$, que não tem espectro no infravermelho).

Sob um ponto de vista teórico, qualquer movimento de um sistema molecular relacionado com a mudança do seu momento de dipólo elétrico conduz a uma absorção ou emissão de radiação. Isto é também o caso para o quadrupólo elétrico 
ou momento de dipólo magnético [Teller and Jahrb, 1934],[Herzberg,1950], mas suas contribuições são normalmente negligenciáveis.

O espalhamento é relacionado com a polarizabilidade molecular a qual se traduz na faculdade do sistema molecular de se deformar e então adquirir um momento de dipólo elétrico sob influência de um campo elétrico. O momento de dipólo induzido (a polarização $P$ ) e o campo elétrico $E$ podem ser ligados por um tensor de segunda ordem (representado por uma matriz $3 \times 3$ ), a polarizabilidade $\alpha$ como:

$$
\vec{P}=\vec{\alpha} \vec{E}
$$

O termo de polarizabilidade $\bar{\alpha}$ é de primeira importância, e seu comportamento para a molécula estudada pode gerar o efeito Rayleigh se é isotrópico (e então o momento dipolar é paralelo ao campo elétrico) ou o efeito Raman, se varia durante a vibração ou rotação da molécula. Para descrever esse efeito é necessária a descrição do quantum da molécula. O estado quântico de um sistema molecular é descrito pela função de onda $\psi$ e leva em consideração: - a translação da molécula, - o modo vibracional dos núcleos atômicos, a rotação dos núcleos atômicos, o movimento dos elétrons em torno do núcleo atômico, o spin eletrônico e nuclear [Lazzaroto, 2001].

A interação de uma onda eletromagnética de campo elétrico $E$ com um sistema molecular é, numa primeira aproximação, a interação com o momento do dipolo elétrico da molécula [Herzberg, 1950]. Se H é o Hamiltoniano do momento de dipolo elétrico $\mathrm{H}$ da transição, a matriz de elementos para uma transição entre dois estados $n$ e $m$ devido a essa interação é

$$
[P]^{m n}=\int \psi_{n} \hat{H} \psi_{m} d \tau
$$

E a probabilidade de transição pode ser deduzida como:

$$
\left.\Pi^{m n} \propto \mid P\right]\left.^{m n}\right|^{2}
$$

Considerando-se como constante (tensor) polarizabilidade, ou seja sem variação durante vibração ou rotação molecular e como as funções de onda $\psi$ são ortogonais pode-se deduzir que as integrais irão desaparecer. Neste caso nenhuma mudança molecular ocorre durante a difusão: o processo é elástico (espalhamento Rayleigh). 
Para uma vibração ou rotação ser ativa no processo Raman, a polarizabilidade deve mudar durante a rotação ou vibração (a polarizabilidade muda durante rotação de qualquer molécula não esférica). Dependendo de qual família a molécula pertence, as regras de seleção podem ser dadas pelo caso Raman [Herzberg, 1950,1945]. Para observar a linha no espectro vibracional-rotacional, a primeira condição é que a transição obedeça as regras de seleção vibracionais, em outros termos, que pertença a banda permitida. Logo a transição tem também que obedecer as regras de seleção rotacionais particulares da banda vibracional considerada.

Por definição, se a molécula está em um nível de energia mais baixo depois da interação, a transição é do tipo Stokes (e a luz espalhada é deslocada para comprimentos de onda maiores). Em caso contrário, a transição é do tipo antiStokes.

Para moléculas diatômicas lineares - como $\mathrm{O}_{2}$ e $\mathrm{N}_{2}$ representadas na Figura 3 por um modo vibracional possível. As transições vibracionais permitidas são $\Delta v=0, \pm 1, \pm 2, \ldots$, onde $v$ é o número quântico vibracional. Todas as transições são permitidas mas suas intensidades diminuem conforme $\Delta v$ aumenta. As bandas Stokes são muito mais intensas que as anti-Stokes (pois a população de nível de energia mais baixo é muito mais importante).

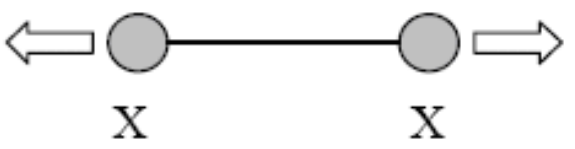

ESTIRAMENTO SIMÉTRICO

$v_{1}$ modo

FIGURA 3 . Modo normal vibracional para uma molécula diatômica.

As transições rotacionais permitidas segundo $\Delta \mathrm{J}=0, \pm 2$ para cada ramo vibracional, onde $\mathrm{J}$ representa o número quântico rotacional, $\Delta \mathrm{J}=-2$ corresponde ao ramo $\mathrm{O}, \Delta \mathrm{J}=0$ para ao ramo $\mathrm{Q}$ e $\Delta \mathrm{J}=+2$ para o ramo $\mathrm{S}$.

Em suma, a transição especificada por $\Delta v=0$ e $\Delta \mathrm{J}= \pm 2$ correspondente ao espalhamento puro Raman rotacional. Os dois ramos correspondentes são chamados ramos $S$. As transições especificadas por $\Delta v= \pm 1, \pm 2, \ldots$ e $\Delta \mathrm{J}=0, \pm 2$ 
correspondem ao espalhamento Raman vibracional-rotacional. $\mathrm{O}$ caso $\Delta v=0$ e $\Delta \mathrm{J}=0$ naturalmente corresponde ao caso Rayleigh.

Para o caso vibracional, como o de moléculas com rotação assimétrica, que possue três átomos, $3 \mathrm{~N}-6=3$ modos normais vibracionais são esperados. Esses modos, representados na Figura 3.1 para a molécula de $\mathrm{H}_{2} \mathrm{O}$, são, numa primeira aproximação, um estiramento e dobramento simétricos do ângulo de valência.

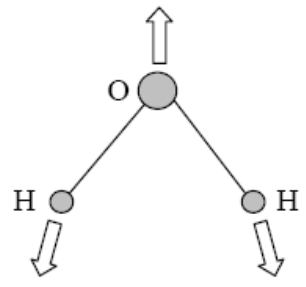

ESTIRAMENTO SIMÉTRICO $v_{1}$ modo

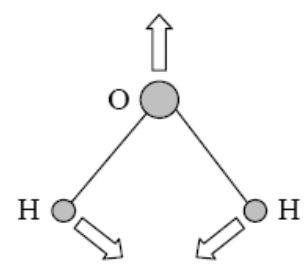

ESTIRAMENTO ANTI-SIMÉTRICO $v_{2}$ modo

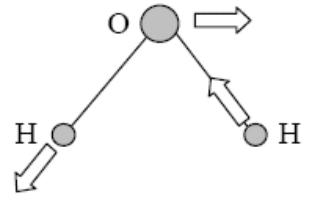

DEFORMAÇÃO

$v_{3}$ modo

FIGURA 3.1 Modos vibracionais para a molécula de $\mathrm{H}_{2} \mathrm{O}$.

Cada um desses modos seguem $\Delta v=0, \pm 1, \pm 2$, mas $\circ$ mais provável e importante modo é o estiramento simétrico, denotado como modo $v 1$. Como para o caso diatômico, todas as transições são permitidas com diminuição das intensidades conforme $\Delta v 1$ aumenta. Novamente, as bandas Stokes são muito mais intensas que as anti-Stokes.

Em suma:

- As transições especificadas por $\Delta v_{i}=0$ e $\Delta \mathrm{J}= \pm 1, \pm 2$ correspondem ao espalhamento puro rotacional Raman.

- As transições especificadas por $\Delta v_{i}= \pm 1, \pm 2, \ldots$ e $\Delta \mathrm{J}= \pm 1, \pm 2$ correspondem ao espalhamento Raman vibracional-rotacional.

- $O$ caso de $\Delta v_{i}=0$ e $\Delta \mathrm{J}=0$ naturalmente corresponde ao caso Rayleigh. 


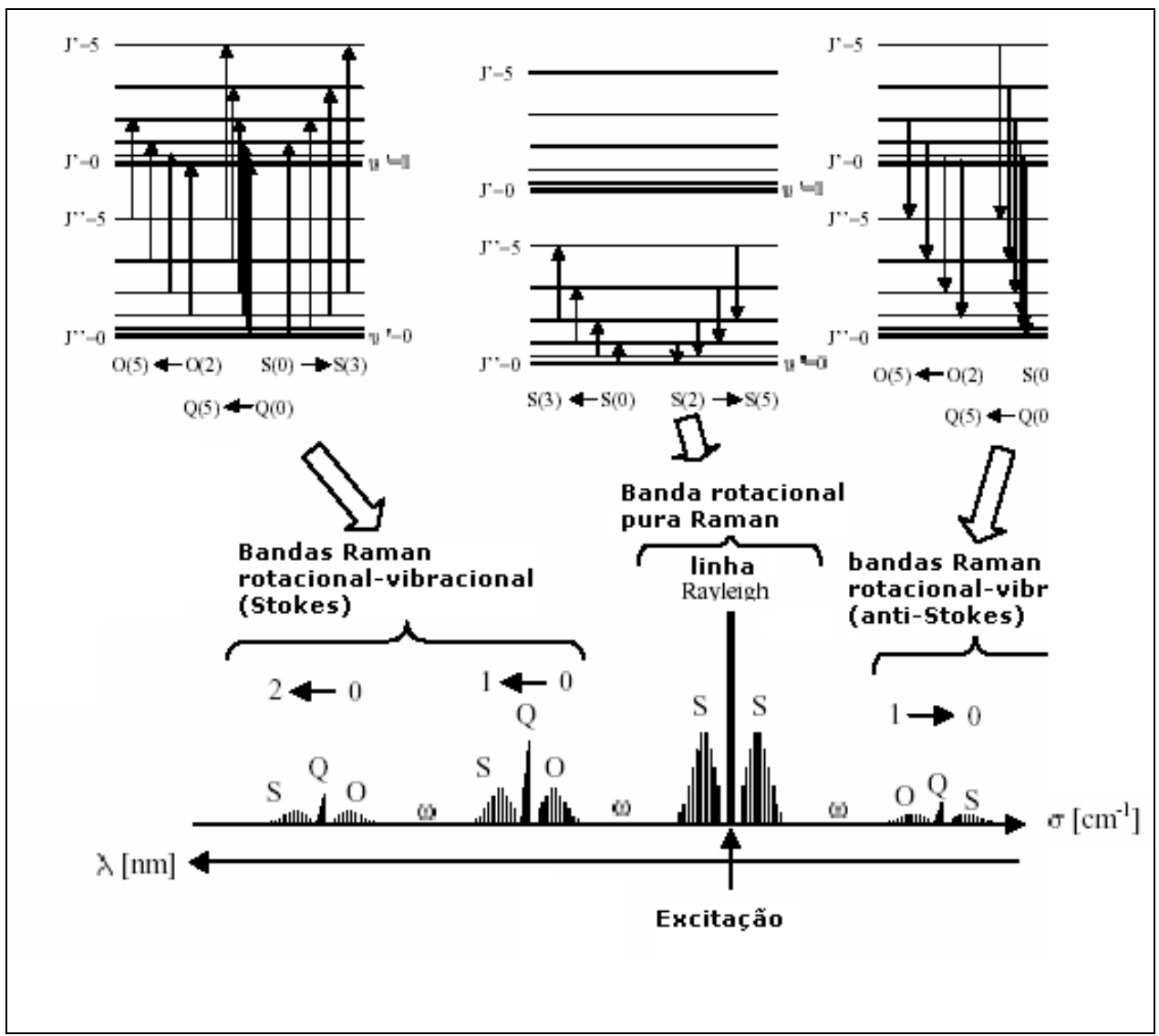

FIGURA 3.2 Esquema para uma molécula diatômica no caso harmônico [Lazzarotto, 2001].

Na Figura 3.2 tem-se uma representação para o caso de moléculas diatômicas onde o termo $\sigma$ representa a razão E/hc.

As Figuras 3.3 e 3.4 representam distribuições relativas a molécula de $\mathrm{N}_{2}$ excitadas a 337,1 nm extraída de [Hinkley, 1976]. Os ramos ("branch") O, S e Q são representados. 


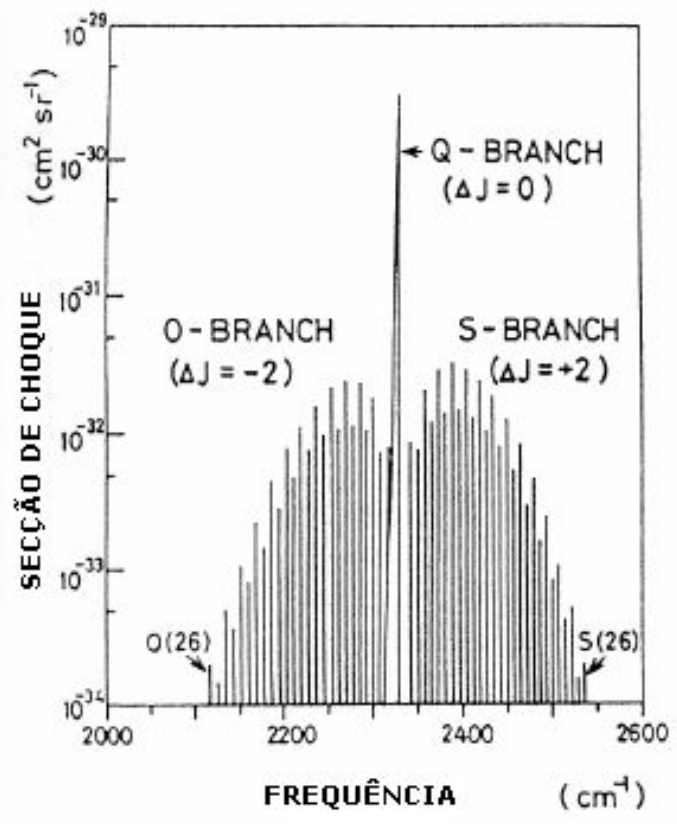

FIGURA 3.3 - Espectro da distribuição vibracional-rotacional Raman calculada a $300 \mathrm{~K}$ mostrando os ramos $\mathrm{O}, \mathrm{S}$ e $\mathrm{Q}$ e a secção de espalhamento diferencial Raman (secção de choque) para a molécula de $N_{2}$ excitada no comprimento de onda de $337.1 \mathrm{~nm}$ [Hinkley, 1976].

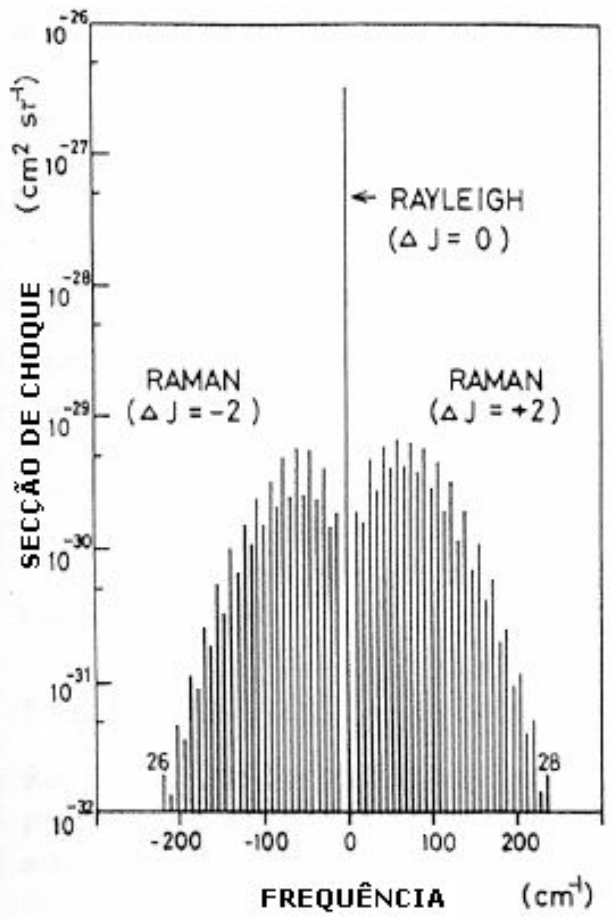

FIGURA 3.4. Espectro da distribuição pura rotacional Raman e Rayleigh calculada a $300 \mathrm{~K}$ mostrando os ramos $\mathrm{O}, \mathrm{S}$ e $\mathrm{Q}$ e a secção espalhamento diferencial Raman (secção de choque) para a molécula de $\mathrm{N}_{2}$ excitada no comprimento de onda de $337.1 \mathrm{~nm}$ [Hinkley, 1976]. 
Os deslocamentos de freqüência do espectro Raman vibracional-rotacional dos ramos $Q$ são resumidos na tabela 1 para um grupo de moléculas de interesse em trabalhos de poluição do ar envolvendo sensoriamento remoto [Measures, 1984].

TABELA 1 - Deslocamentos do número de onda Raman e seção diferencial de espalhamento Raman apropriados para excitação de $337.1 \mathrm{~nm}$.

\begin{tabular}{|c|c|c|c|c|}
\hline Molécula & $\begin{array}{l}\text { Deslocamento } \\
\text { Raman }\left(\mathrm{cm}^{-1}\right)\end{array}$ & $\begin{array}{l}\text { Comprimento de } \\
\text { onda do des. } \\
\text { Raman (nm) }\end{array}$ & $\begin{array}{c}\text { Secção diferencial } \\
\text { de espalhamento } \\
\text { Raman } \\
\left(10^{-30} \mathrm{~cm}^{-2} \mathrm{sr}^{-1}\right)\end{array}$ & $\begin{array}{c}\text { Secção } \\
\text { diferencial de } \\
\text { espalhamento } \\
\text { relativa a Q de } \\
\mathbf{N}_{2}\end{array}$ \\
\hline $\mathrm{O}_{3}$ & 1103,3 & 350,2 & 6,4 & 2,3 \\
\hline $\mathrm{O}_{2}$ & 1556 & 355,9 & 4,6 & 1,6 \\
\hline $\mathrm{CO}$ & 2145 & 363,5 & 3,6 & 1,3 \\
\hline $\mathrm{N}_{2}$ & 2330,7 & 365,9 & 3,5 & 1,3 \\
\hline $\mathrm{H}_{2} \mathrm{O}$ & 3651,7 & 384,4 & $7,8(\mathrm{Q})$ & $2,8(\mathrm{Q})$ \\
\hline $\mathrm{H}_{2}$ & 4160,2 & 392,2 & 8,7 & 3,1 \\
\hline
\end{tabular}

\subsection{Estrutura da atmosfera}

Derivada do grego $\alpha \tau \mu \mathrm{o} \zeta$ (para vapor ) e $\sigma \varphi \alpha \iota \rho \alpha$ (para esfera), a palavra atmosfera descreve a camada, essencialmente gasosa, que engloba a Terra. A atmosfera pode ser vista como um fluido em movimento, logo, todas as teorias relacionadas a isso tentam explicar seu comportamento e junto a sua estrutura vertical, os ventos, meteorologia em geral e problemas relacionados a poluição [Lazzarotto, 2001].

Várias classificações têm sido definidas, mas a mais comumente utilizada é baseada na estratificação vertical da temperatura proposta e aceita em 1960, pela Geodesy and Geophysics International Union in Helsinki e em 1962 pelo comitê executivo da World Meteorological Organization (WMO). A Figura 3.5 representa o esquema dessa nomenclatura baseada na temperatura.

A atmosfera está estruturada em três camadas com temperaturas mais altas, separadas por duas camadas relativamente frias. Os contatos entre essas camadas são áreas de descontinuidade, e recebem o sufixo "pausa", após o nome da camada subjacente (Figura 3.5). 
A Troposfera é a primeira camada e é o interesse de nosso trabalho. É a camada atmosférica que se estende da superfície da Terra até a base da estratosfera $(0-7 / 17 \mathrm{~km})$. Esta camada responde por oitenta por cento do peso atmosférico e é a única camada em que os seres vivos podem respirar normalmente. A sua espessura média é de aproximadamente $12 \mathrm{~km}$, atingindo até 17 km nos trópicos e reduzindo-se para em torno de sete quilômetros nos pólos.

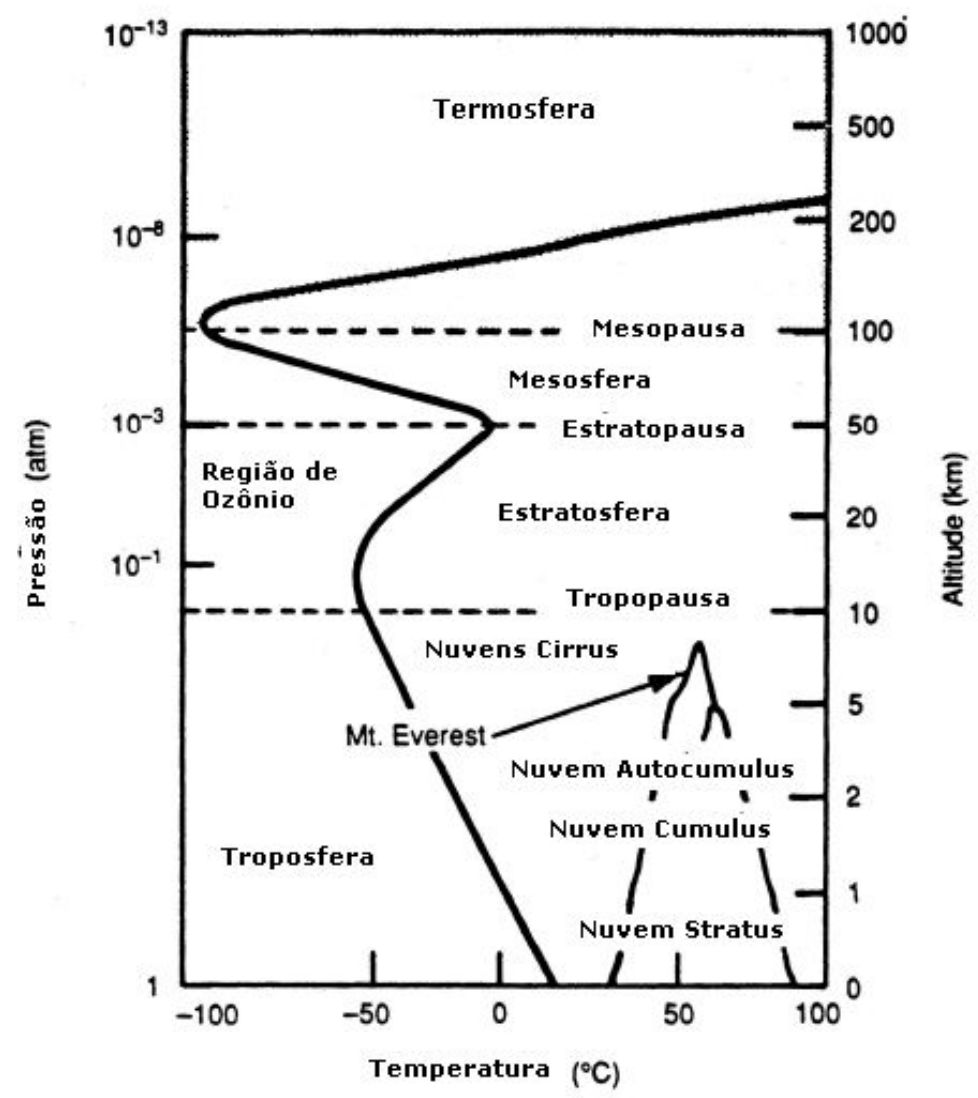

FIGURA 3.5 - Camadas da atmosfera em função da altitude.

A tropopausa é o nome dado à camada intermediária entre a troposfera e a estratosfera, situada a uma altura média em torno de $17 \mathrm{~km}$ no equador. A distância da Tropopausa em relação ao solo varia conforme as condições climáticas da troposfera, da temperatura do ar, a latitude entre outros fatores. Se existe na troposfera uma agitação climática com muitas correntes de convecção, a tropopausa tende a subir. Isto se deve por causa do aumento do volume do ar na troposfera, empurrando a tropopausa para cima, aumentando o seu volume. Ao subir a tropopausa esfria, pois o ar acima dela está mais frio. 
$\mathrm{Na}$ estratosfera a temperatura aumenta com a altitude e se caracteriza pelos movimentos de ar em sentido horizontal, fica situada entre 7 e 17 até $50 \mathrm{~km}$ de altitude aproximadamente, sendo a segunda camada da atmosfera , compreendida entre a troposfera e a mesosfera, a temperatura aumenta à medida que aumenta a altura. Apresenta pequena concentração de vapor de água e temperatura constante até a região limítrofe, denominada estratopausa. Muitos aviões a jato circulam na estratosfera porque ela é muito estável. É nesta camada que existe a camada de ozônio e onde começa a difusão da luz solar (que origina o azul do céu).

É próximo a estratopausa que a maior parte do ozônio da atmosfera situa-se. Isto é em torno de 22 quilômetros acima da superfície, na parte superior da estratosfera.

$\mathrm{Na}$ mesosfera a temperatura diminui com a altitude, esta é a camada atmosférica onde há uma substancial queda de temperatura chegando até a $-90^{\circ} \mathrm{C}$ em seu topo. Está situada entre a estratopausa em sua parte inferior e mesopausa em sua parte superior, entre 50 a $85 \mathrm{~km}$ de altitude. É na mesosfera que ocorre o fenômeno da aeroluminescência das emissões da hidroxila e é nela que se dá a combustão dos meteoróides [Measures, 1984].

A mesopausa é a região da atmosfera que determina o limite entre uma atmosfera com massa molecular constante de outra onde predomina a difusão molecular. Na termosfera $(80 / 85 \mathrm{~km})$ a temperatura aumenta com a altitude e está localizada acima da mesopausa, sua temperatura aumenta rápida e monotonicamente com a altitude até onde a densidade das moléculas é tão pequena e se movem em trajetórias aleatórias tal, que raramente se chocam. lonosfera é a região que contém íons: compreendendo da mesosfera até termosfera que vai até aproximadamente $550 \mathrm{~km}$ de altitude.

\subsubsection{Foco na troposfera}

O foco deste trabalho é no estudo do vapor d'água presente na troposfera. A troposfera é caracterizada por um gradiente negativo de temperatura versus altitude de aproximadamente $0,65^{\circ} \mathrm{C} / 100 \mathrm{~m}$ (para ar seco o valor é de $\sim 1^{\circ} \mathrm{C} / 100 \mathrm{~m}$ ). Isso é devido principalmente à absorção, pelo $\mathrm{CO}_{2}$ e $\mathrm{H}_{2} \mathrm{O}$, da radiação infravermelho 
refletida na superfície terrestre. Ao contrário da estratosfera que tem um gradiente de temperatura positivo e então uma mistura vertical baixa em altitude, a troposfera é caracterizada pela rápida mistura vertical. Essa característica causa dois importantes fenômenos. Primeiro, a alta presença de vapor d'água é importante para circulação geral e mudanças do tempo. O segundo está ligado a problemas de poluição. Com os padrões pré mencionados para a troposfera e para a estratosfera pode-se deduzir que os poluentes emitidos na superfície da Terra possuem um ciclo de vida longo o bastente para atingir a tropopausa, e serão espalhados na estratosfera e permanecerão lá por longo tempo, devido ao lento processo de mistura vertical (Figura 3.6). Esse caso é conhecido como nos exemplos de CFCs [Lazzarotto, 2001].

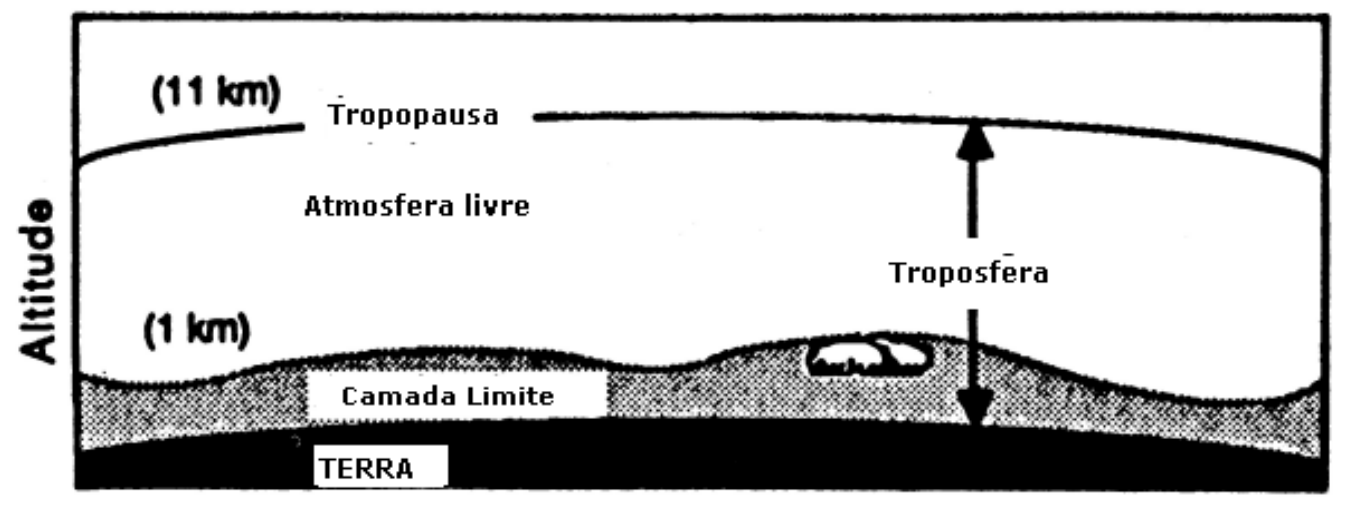

FIGURA 3.6. Vista com foco na altitude das diferentes partes da troposfera como camada limite, atmosfera livre e tropopausa.

Na figura 3.6 a troposfera está dividida em duas partes. Uma é a camada limite, região de mistura rápida e turbulenta onde reações de elementos com tempo de vida curta ocorrem, e a região menos turbulenta chamada atmosfera livre onde reações de elementos de vida longa ocorrem.

\subsubsection{Composição da Atmosfera}

A atmosfera é uma mistura de gases contendo algumas partículas sólidas e líquidas em suspensão. A parte gasosa pode ser dividade em duas: - a primeira com a maioria dos constituintes, que segue a distribuição vertical em acordo com o estado dinâmico e energético da atmosfera global; - a segunda com a minoria dos 
constituintes que possuem comportamento diferente dependendo da produção, destruição ou mecanismos de transporte.

Segundo [Barry e Chorley, 1998], a composição da atmosfera (Tabela 2) e sua estrutura vertical possibilitaram o desenvolvimento da vida no planeta. Sua composição, quando seca e abaixo de 25 km, é: Nitrogênio $\left(\mathrm{N}_{2}\right) 78,08$ \%, atua como suporte dos demais componentes, de vital importância para os seres vivos, fixado no solo pela ação de bactérias e outros microrganismos, é absorvido pelas plantas, na forma de proteínas vegetais; Oxigênio $\left(\mathrm{O}_{2}\right)$ 20,94 \% do volume da atmosfera, sua estrutura molecular varia conforme a altitude em relação ao solo, é responsável pelos processos respiratórios dos seres vivos; e os demais resumidos na tabela 2;

TABELA 2 - Composição média da atmosfera até $25 \mathrm{~km}$.

\begin{tabular}{|l|c|c|}
\hline Nome Gás & Fórmula química & Volume Percentual \\
\hline Nitrogênio & $\mathrm{N}_{2}$ & $78,08 \%$ \\
\hline Oxigênio & $\mathrm{O}_{2}$ & $20,95 \%$ \\
\hline *Vapor d'água & $\mathrm{H}_{2} \mathrm{O}$ & $0 \mathrm{a} 4 \%$ \\
\hline Argônio & $\mathrm{Ar}$ & $0,93 \%$ \\
\hline${ }^{*}$ Dióxido de Carbono & $\mathrm{CO}_{2}$ & $0,0360 \%$ \\
\hline Neonio & $\mathrm{Ne}$ & $0,0018 \%$ \\
\hline Hélio & $\mathrm{He}$ & $0,0005 \%$ \\
\hline *Metano & $\mathrm{CH}_{4}$ & $0,00017 \%$ \\
\hline Hidrogênio & $\mathrm{H}_{2}$ & $0,00005 \%$ \\
\hline *Óxido nitroso & $\mathrm{N}_{2} \mathrm{O}$ & $0,00003 \%$ \\
\hline *Ozônio & $\mathrm{O}_{3}$ & $0,000004 \%$ \\
\hline
\end{tabular}

* variáveis.

A temperatura da atmosfera da Terra varia entre camadas em altitudes diferentes, portanto, a relação matemática entre temperatura e altitude também varia, sendo uma das bases da classificação das diferentes camadas da atmosfera.

\subsection{Vapor d'água}

O vapor d'água varia em concentração na atmosfera espacialmente e temporalmente. As maiores concentrações de vapor d'água são encontradas perto 
da linha do Equador nos oceanos e em florestas tropicais úmidas. Áreas polares frias e desertos continentais subtropicais são locais onde o volume de vapor d'água pode se aproximar a $0 \%$. O vapor d'água tem várias funções importantes em nosso planeta:

- Redistribuir energia térmica na Terra por meio da troca de energia de calor latente.

- A condensação do vapor d'água cria precipitação que cai na superfície da terra fornecendo água para plantas e animais.

- Ajuda no aquecimento da Terra através do efeito estufa.

Vapor d'água e aerossol são dois parâmetros atmosféricos acessíveis por sensoriamento remoto. A razão de mistura de vapor d'água é conservada em processos atmosféricos que não envolvem evaporação ou condensação. Assim, a razão de mistura é útil como um delineador de camadas de ar e no entendimento no transporte de energia dentro da atmosfera.

O acúmulo de conhecimento da concentração e movimento de vapor d'água leva ao melhor entendimento da formação de nuvens, desenvolvimento de tempestades convectivas, e o do ciclo hidrológico.

O clima na Terra é responsável por suportar vida em grande parte devido ao efeito estufa atmosférico e o ciclo hidrológico. A água na fase gasosa, vapor d'água, é um elemento chave em ambos os casos. O ciclo hidrológico descreve o movimento da água, nas três fases, dentro e entre a atmosfera terrestre, oceanos e continentes. Na fase gasosa, a água se move rapidamente através da atmosfera e redistribui a energia associada a sua evaporação e recondensação. O movimento do vapor d'água no ciclo hidrológico é fortemente acoplado à precipitação e umidade do solo, o que tem implicações práticas [Water Vapor in the Climate System, 1995].

Existem vários gases do efeito estufa, alguns ocorrendo naturamente e alguns resultantes de atividades industriais, mas provavelmente o mais importante gas do efeito estufa é o vapor d'água.

O vapor d'água é água no estado gasoso. Meteorologistas têm definido vários termos diferentes para expressar a quantidade de vapor d'água no ar. Alguns 
referem-se a quantidade atual, ou concentração de vapor d'água no ar, e algum relacional a quantidade atual com a quantidade que poderia saturar o ar. Ar é dito saturado quando contém a máxima quantidade possível de vapor d’água sem ocorrer condensação.

Umidade específica é a razão entre a massa de vapor d'água em uma amostra e a massa total de ar úmido, incluindo ambos ar seco e vapor d'água. A razão de mistura é a razão da massa de vapor d'água com a massa de ar seco em um dado volume. Com razões de massa, ambos umidade específica e razão de mistura não possuem números em unidades. Contudo, em função da concentração de vapor d'água tender a ser alguns poucos percentuais da quantidade de ar seco (bastante baixa), eles são usualmente expressos em unidades de gramas de vapor d'água por quilograma de ar (seco e úmido) [Water Vapor in the Climate System, 1995].

Existem diversas técnicas de sensoriamento remoto que medem perfis de vapor d'água atmosférico.Na tabela 3 é apresentada uma comparação entre as técnicas de medida de vapor d’água na atmosfera.

TABELA 3. Comparação entre algumas técnicas de sensoriamento para o vapor d'água atmosférico.

\begin{tabular}{|c|c|c|c|}
\hline $\begin{array}{ll}\text { Plataforma } & \text { de } \\
\text { observação } & \end{array}$ & $\begin{array}{ll}\text { Sistema } & \text { de } \\
\text { sensoriamento } & \end{array}$ & Vantagens & Problemas \\
\hline $\begin{array}{l}\text { Superfície } \\
\text { Terrestre }\end{array}$ & $\begin{array}{l}\text { Rotina de } \\
\text { observação } \\
\text { meteorológica. } \\
\text { Instrumentos incluem } \\
\text { psicrômetro de bulbo } \\
\text { seco e molhado e } \\
\text { higrômetro de } \\
\text { orvalho pontual. }\end{array}$ & $\begin{array}{l}\text { Grandes arquivos com dados } \\
\text { de qualidade global alta } \\
\text { razoáveis estão disponíveis. } \\
\text { A freqüência de observações } \\
\text { é no mínimo, diária. }\end{array}$ & $\begin{array}{l}\text { Cobertura espacial } \\
\text { não é uniforme. Os } \\
\text { dados são na } \\
\text { superfície da Terra } \\
\text { apenas. }\end{array}$ \\
\hline Balões & $\begin{array}{l}\text { Rotina de } \\
\text { observações de } \\
\text { Radiossondagens } \\
\text { (balão } \\
\text { meteorológico). } \\
\text { Sensores de } \\
\text { umidade. }\end{array}$ & $\begin{array}{l}\text { Instrumentos são caros, } \\
\text { tornando observações caras. } \\
\text { Método em uso desde os } \\
\text { anos } 30 \text {, tal que muitos } \\
\text { arquivos de dados estão } \\
\text { disponíveis. Rede global de } \\
\text { aproximadamente } 800 \\
\text { estações fazendo de uma a } 4 \\
\text { observações por dia em cada } \\
\text { estação. Dados tem } \\
\text { resolução vertical } \\
\text { relativamente boa na } \\
\text { troposfera baixa. }\end{array}$ & $\begin{array}{l}\text { A qualidade dos } \\
\text { dados varia na } \\
\text { troposfera alta e é } \\
\text { pobre na extratosfera. } \\
\text { A qualidade das } \\
\text { observações é pobre } \\
\text { em umidades muito } \\
\text { altas e muito baixas. } \\
\text { Diferenças entre } \\
\text { instrumentos } \\
\text { utilizados em } \\
\text { diferentes países e } \\
\text { mudanças tornam os } \\
\text { dados difíceis de } \\
\text { analisar. A cobertura } \\
\text { espacial é limitada. }\end{array}$ \\
\hline
\end{tabular}




\begin{tabular}{|c|c|c|c|}
\hline & $\begin{array}{l}\text { Sondas de pesquisa } \\
\text { (utilizando por } \\
\text { exemplo o ponto de } \\
\text { congelamento de } \\
\text { hidrômetros) }\end{array}$ & $\begin{array}{l}\text { Qualidade das observações } \\
\text { de umidade é alta. Dados } \\
\text { estendem-se além dos limites } \\
\text { de altitudes de radiossondas. }\end{array}$ & $\begin{array}{l}\text { Instrumentos são } \\
\text { caros, tal que as } \\
\text { sondagens são } \\
\text { realizadas com pouca } \\
\text { freqüências em } \\
\text { poucas localidades. }\end{array}$ \\
\hline & $\begin{array}{l}\text { Radiossondas de } \\
\text { referência }\end{array}$ & $\begin{array}{l}\text { Observações de alta } \\
\text { qualidade poderiam ser } \\
\text { utilizadas para comparação } \\
\text { com sistemas de } \\
\text { sensoriamento operacionais } \\
\text { e para experimentos em } \\
\text { campo. }\end{array}$ & $\begin{array}{l}\text { Em desenvolvimento. } \\
\text { Instrumentos são mais } \\
\text { caros do que as } \\
\text { caríssimas } \\
\text { radiossondas. }\end{array}$ \\
\hline \multirow[t]{4}{*}{ Satélites } & $\begin{array}{l}\text { Sensores de } \\
\text { Infravermelho } \\
\text { (TOVS) }\end{array}$ & $\begin{array}{l}\text { Sensores fornecem a coluna } \\
\text { de vapor d'água total e } \\
\text { alguma informação do perfil } \\
\text { vertical em algumas áreas }\end{array}$ & $\begin{array}{l}\text { Dados são limitados } \\
\text { as regiões livres de } \\
\text { nuvens e podem exibir } \\
\text { ligações regionais. } \\
\text { Resolução vertical é } \\
\text { pobre. }\end{array}$ \\
\hline & $\begin{array}{l}\text { Sensores de } \\
\text { Microondas }\end{array}$ & $\begin{array}{l}\text { Sensores fornecem dados do } \\
\text { total da coluna de vapor } \\
\text { d'água sobre regiões grandes } \\
\text { e são pouco influenciados por } \\
\text { nuvens }\end{array}$ & $\begin{array}{l}\text { Dados são limitados a } \\
\text { regiões do oceano } \\
\text { livres de gelo e a } \\
\text { resolução vertical é } \\
\text { pobre. }\end{array}$ \\
\hline & $\begin{array}{lr}\text { Métodos } & \text { de } \\
\text { Ocultação } & \text { Solar } \\
\text { (SAGE II) } & \end{array}$ & $\begin{array}{l}\text { Dados de umidade global em } \\
\text { altitudes muito altas na } \\
\text { extratosfera e acima. Alta } \\
\text { precisão e resolução vertical. }\end{array}$ & $\begin{array}{l}\text { Cobertura é limitada } \\
\text { por nuvens. A } \\
\text { amostragem é pobre } \\
\text { em regiões tropicais. }\end{array}$ \\
\hline & $\begin{array}{ll}\text { Sistema } & \text { de } \\
\text { Posicionamento } & \\
\text { Global (GPS) } & \end{array}$ & $\begin{array}{l}\text { Sondagens de vapor d'água } \\
\text { global usariam o sistema de } \\
\text { navegação de satélites } \\
\text { existente. }\end{array}$ & $\begin{array}{l}\text { Métodos estão em } \\
\text { pesquisa e estado de } \\
\text { desenvolvimento. }\end{array}$ \\
\hline Aeronaves & $\begin{array}{l}\text { Instrumentos } \\
\text { montados sobre } \\
\text { aviões de pesquisa } \\
\text { especiais ou } \\
\text { aeronaves } \\
\text { comerciais. Os } \\
\text { instrumentos de } \\
\text { pesquisa incluem } \\
\text { LIDAR de absorção } \\
\text { diferencial, e } \\
\text { sensores } \\
\text { capacitivos. }\end{array}$ & $\begin{array}{l}\text { Aeronaves de pesquisa } \\
\text { podem fazer medidas em } \\
\text { quase todas as localizações } \\
\text { em qualquer momento. } \\
\text { Medidas com aeronaves } \\
\text { comerciais poderiam fornecer } \\
\text { dados de boa cobertura } \\
\text { sobre o globo. }\end{array}$ & $\begin{array}{l}\text { Missões de pesquisa } \\
\text { são caras e a coleta } \\
\text { de dados é limitada. } \\
\text { Programas } \\
\text { envolvendo aeronaves } \\
\text { comerciais não são } \\
\text { muito comuns. }\end{array}$ \\
\hline $\begin{array}{l}\text { Sensoriamento } \\
\text { Remoto }\end{array}$ & $\begin{array}{l}\text { Raman LIDAR, } \\
\text { LIDAR de absorção } \\
\text { diferencial. }\end{array}$ & $\begin{array}{l}\text { Sensores fornecem dados de } \\
\text { alta qualidade com alta } \\
\text { resolução vertical e temporal. }\end{array}$ & $\begin{array}{l}\text { Os sistemas são caros } \\
\text { e requerem } \\
\text { operadores altamente } \\
\text { habilidosos. A } \\
\text { utilidade é limitada ao } \\
\text { período do dia e } \\
\text { condições de } \\
\text { nebulosidade. }\end{array}$ \\
\hline
\end{tabular}

\subsection{Aerossóis}

Aerossol é definido como "uma suspensão de sólidos finos ou partículas líquidas em um gás" [Seinfeld e Pandis, 1998). Eles podem surgir diretamente como 
partículas (aerossol primário) ou devido a processos de conversão gás-partícula (aerossol secundário). As fontes naturais de aerossóis são o solo, rochas (poeira terrestre), atividades vulcânicas, queima de biomassa e reações entre emissões de gases naturais. Emissões de material particulado são atribuídas as atividades humanas primeiramente separadas em quatro categorias: queima de combustível, processos industriais, fontes como construção, erosão e meios de transporte (veículos) [Seinfeld e Pandis, 1998]. A faixa de tamanho de aerossóis vai de alguns nanometros a dezenas de micrometros. Aerossóis finos tem diâmetros menores que 2,5 $\mu \mathrm{m}$ enquanto que partículas grossas apresentam um diâmetro maior que 2,5 $\mu \mathrm{m}$. Essas partículas grossas são formadas por processos mecânicos e podem ser naturais ou feitas pelo homem. As partículas finas são divididas em duas categorias: a faixa de núcleos transientes ou núcleos Aitken (de 0,005 até 0,1 $\mu \mathrm{m}$ ) e a faixa de acumulação (de 0,1 até 2,5 $\mu \mathrm{m}$ ). Os primeiros são formados da condensação de vapores quentes durante processos de combustão e da nucleação de espécies atmosféricas para formar partículas. Os últimos são formados da coagulação de partículas no modo nuclear e da condensação de vapores em aerossóis existentes, fazendo-os crescer nessa faixa de tamanho. Os mecanismos de remoção são menos eficientes, causando acumulação de partículas [Larchevêque, 2002].

Com o uso de sensoriamento remoto, especialmente da técnica LIDAR, pode-se medir o sinal retroespalhado referente aos aerossóis presentes na troposfera e obter parâmetros como espessura ótica, coeficientes de extinção e retroespalhamento atmosféricos. O impacto dos aerossóis na saúde humana justificam o estudo e monitoramento do mesmo. Apesar do foco deste trabalho ser nas medidas de vapor d'água, algumas medidas foram efetuadas bem como a implementação de medidas de aerossol no IPEN, com o uso de um Raman LIDAR (MSP-LIDAR).

\subsection{LIDAR}

LIDAR é um acrônimo para Light Detection And Ranging. Os sistemas LIDAR consistem de um laser e um telescópio os quais possuem os eixos ópticos alinhados paralelamente ou coaxiais de tal forma que o campo de visão do telescópio inclua o feixe laser conforme ele se propaga através da atmosfera. As 
diferenças nos sistemas de LIDAR estão na seleção do comprimento de onda do laser, no comprimento de onda coletado e na interpretação e análise de dados.

\subsubsection{Aspectos históricos - Técnicas LIDAR}

Em 1917 Albert Einstein estudou as transições quânticas entre dois níveis de energia; ele explicou a emissão espontânea e previu o fenômeno de emissão estimulada. Algumas décadas mais tarde, nos anos 50, o físico Aldred Kastler obteve a primeira inversão de população por bombeamento óptico. Em 1954 Townes construiu o primeiro MASER (Microwave Amplifier by Stimulated Emission of Radiation), baseado na transição da molécula de amoníaco o qual é o precursor do laser. Depois de investigações teóricas, Townbes and Schawlow concluíram em 1958, que seria possível construir um sistema MASER de alta freqüência, isto é, na região do vísivel [Schcawlow e Townes, 1958] e Maiman foi o primeiro em 1960 a construir um Maser óptico com rubi [Maiman, 1960]. A partir daí houve um crescimento exponencial em pesquisa e aplicações nessa área, e o nome foi mudado para LASER (Light Amplification by Stimulated Emission of Radiation).

A era de "sensoriamento a laser" não foi iniciada, por causa da indisponibilidade de lasers, até que algumas tentativas foram realizadas em 1952 [Elterman, 1954] utilizando uma sondagem da luz para registrar temperatura,

pressão e densidade da atmosfera, seguida em 1962 por experimentos com uma técnica similar de altos frequência de pulsos [Mc Clung e Hellworth, 1962].

Os primeiros monitoramentos de aerossóis foram realizados na estratosfera com um laser de rubi [Fiocco e Smullin, 1963] para estudar componentes vulcânicos. Essa técnica então chamada LIDAR, tem se expandido e estimulado pesquisas nos campos de fontes de lasers, óptica, eletrônica, química atmosférica, etc. A principal vantagem dessa técnica é a habilidade para prover uma distribuição de perfil temporal e espacial em tempo real de componentes atmosféricos. Até a atualidade nenhum outro sistema pode competir com essa característica. Esse sistema tem algumas limitações devido ao conceito óptico, como nuvens e chuva.

Desde os anos 60 diversas técnicas foram investigadas para detecção, com mais altas resoluções, mais tipos de moléculas, poluentes, nuvens, processos físicos como o vento. Entre elas, pode-se citar: 
- Rayleigh LIDAR que é usada normalmente para determinar temperatura acima de $30 \mathrm{~km}$ [Hauchecorne et al, 1991], bem como para medidas de aerossol [Landulfo, 2003]. A possibilidade de medidas de temperatura atmosférica abaixo até $1 \mathrm{~km}$ tem também sido demonstrada [She et al, 1993].

- LIDAR DIAL padrão; baseado em uma absorção diferencial do feixe bombeado, pela molécula estudada. Essa tecnologia é clássica mas o sistema de emissão um pouco mais complexo. Ele permite a medida de vários constituintes [Uchiumi et al, 1994]. O vapor d'água é muito difícil com esse método [Browell et al, 1979].

- LIDAR Raman na forma vibracional [Renaut e Capitini, 1988] (vapor d'água na camada limite), [Arshinov et al, 1983] (temperatura abaixo de $1 \mathrm{~km}$ ), ou na forma ressonante [Rosen et al, 1975] (concentração de $\mathrm{NO}_{2}$ e $\mathrm{SO}_{2}$ abaixo de $1 \mathrm{~km}$, com considerações em segurança para os olhos) [Hochenbleicher, et al, 1976].

- LIDAR de Fluorescência, usada para medidas de temperatura na mesosfera, onde a extinção é pequena [She et al, 1993].

A idéia de usar o efeito Raman para um LIDAR, ocorreu em 1967 [Leonard, 1967], quando os primeiros deslocamentos Raman de oxigênio e nitrogênio atmosférico foram observados, e a vantagem dessa nova técnica foi mostrada. Vários grupos pioneiros trabalhavam nesse caminho, Cooney [Cooney, 1968] mediu perfis de densidade atmosférica de $\mathrm{N}_{2}$, Inaba [Inaba e Kobayasi, 1969] mostraram teoricamente que era possível monitorar gases atmosféricos ou poluentes e propuseram um diagrama para a construção do LIDAR. A primeira observação do vapor d'água por essa técnica foi feita por Melfi [Melfi et al. 1979].

Em medidas LIDAR, um laser pulsado é incidido na atmosfera. Fótons retroespalhados são coletados por um telescópio receptor e contados com um tubo fotomultiplicador (PMT). A altitude $z$ onde o evento de retroespalhamento ocorre é dada pelo tempo de chegada do fóton t em uma aproximação de espalhamento simples $z=c t / 2$ [Sherlock (I), 1999], onde $\mathrm{c}$ é a velocidade da luz. Nos comprimentos de onda considerados, os fótons emitidos em um pulso de laser podem ser espalhados elasticamente (espalhamento Rayleigh e Mie) ou inelasticamente (espalhamento Raman). No caso do espalhamento Raman ocorre uma mudança no estado rotacional-vibracional da molécula espalhadora, e um deslocamento no comprimento de onda no sinal retroespalhado fornece informação para identificarmos a molécula responsável. Uma análise temporal e espectral dos 
sinais retroespalhados pode prover informação de distribuições verticais dos constituintes moleculares ativos Raman atmosféricos.

No LIDAR Raman o receptor é sensível, através do uso de um filtro de interferência ou um espectrômetro, a comprimentos de onda deslocados Raman. Muitas moléculas espalham radiação eletromagnética não somente nos comprimentos de onda excitantes, mas também em comprimentos de ondas específicos deslocados pelo fenômento chamado espalhamento Raman. A magnitude do deslocamento é única para a molécula espalhadora, e a intensidade da banda Raman é proporcional à concentração de moléculas espalhadoras. LIDAR Raman têm sido usado para medidas de várias moléculas atmosféricas, includindo $\mathrm{H}_{2} \mathrm{O}, \mathrm{SO}_{2}$, e $\mathrm{CO}_{2}$. A maior limitação da técnica está na baixa secção diferencial de espalhamento para o espalhamento Raman. Assim, seu uso requer lasers de alta potência, grandes telescópios, maior tempo de integração e é normalmente limitado a medidas onde altas concentrações estão presentes [Torres, 2008].

\subsubsection{Sistema LIDAR}

Na sua forma mais genérica, o LIDAR emprega um laser como fonte pulsada de energia e duração adequadas (Figura 3.7). Em geral, os picos de energia atingem dezenas de $\mathrm{J}$ e tem durações de 10 a 20 nanosegundos. Pulso com tais energias, cerca de 1 Joule, são direcionados por sistemas ópticos ou telescópios, para a atmosfera. O esquema a seguir mostra um sistema e seus elementos mais relevantes. 


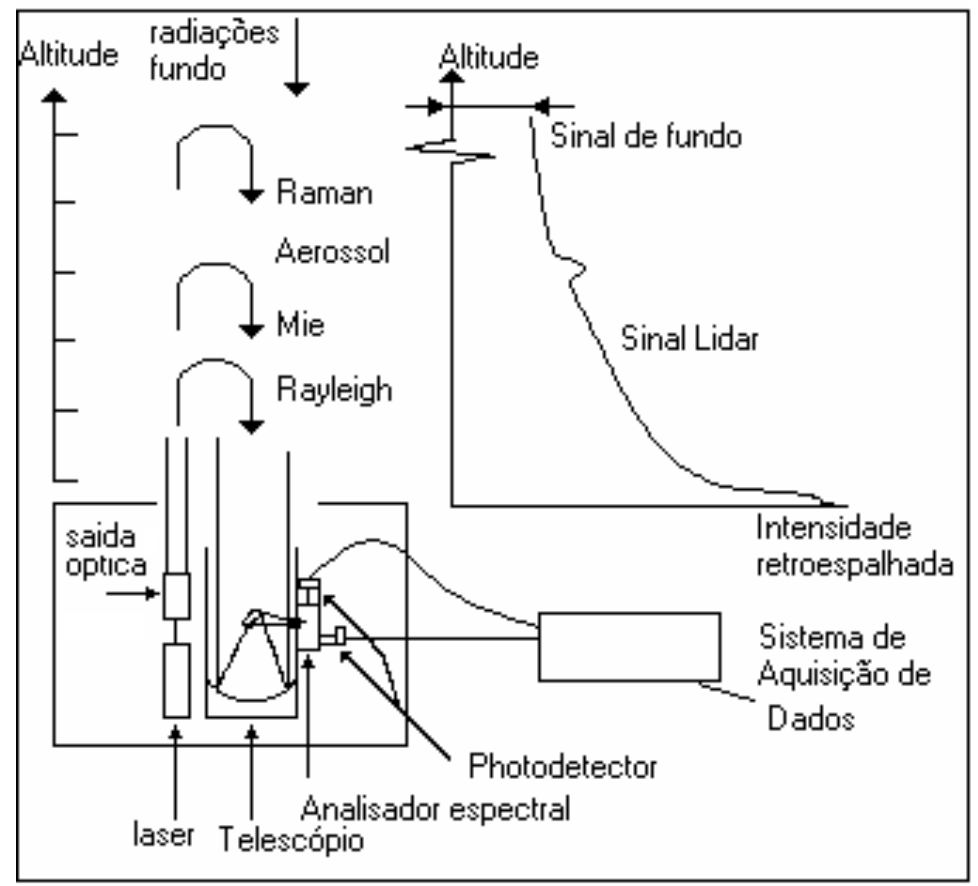

FIGURA 3.7 - Diagrama ilustrativo dos componentes de um sistema LIDAR genérico.

Conforme o feixe laser se propaga pela atmosfera, o mesmo é espalhado pelas moléculas de gás e partículas ou gotículas encontradas no caminho. Uma pequena fração do feixe é retroespalhada na direção de coleta de dados, o receptor. A parte do feixe que se espalha para fora do caminho de propagação ou é absorvida pelos gases e partículas, corresponde a uma atenuação da intensidade, essa atenuação ocorre antes e depois do feixe atingir a região de retroespalhamento.

$\mathrm{Na}$ chegada ao sistema de coleta, os fótons atingem o receptor de óptica refrativa ou reflexiva, e a seguir são transferidos a um detector de resposta rápida, uma fotomultiplicadora ou detector de estado sólido, onde se gera um sinal elétrico cuja intensidade em qualquer instante é proporcional à potência óptica recebida. Como a velocidade de propagação da luz é conhecida, a distância do volume espalhador que produz o sinal é determinada a partir do instante de tempo da transmissão do pulso. A magnitude do sinal recebido é determinada pelas propriedades de retroespalhamento da atmosfera em distâncias sucessivas e pela atenuação no caminho de ida e volta. O retroespalhamento atmosférico, por sua vez, depende do comprimento de onda do laser, e do número, tamanho, forma e propriedades de refração das partículas ou gotículas (ou moléculas) interceptadas 
pela luz incidente. Embora o fenômeno de espalhamento em um ensemble de elementos seja complicado, em primeira aproximação o retroespalhamento aumenta com a concentração de partículas.

Um fator de considerável importância na técnica LIDAR é a intensidade do mínimo sinal detectável que é limitada pelo nível de ruído do sistema, tanto de fontes internas, que são controláveis, como de fontes externas, que são incontroláveis, como por exemplo o ruído térmico dos circuitos elétricos envolvidos, ruídos intrínsecos dos detectores utilizados, e o ruído de origem solar, presente logicamente durante o dia. Dado o alto grau de monocromaticidade do laser, a luz externa pode ser substancialmente eliminada pela utilização de filtros de banda passante estreita, centrada no comprimento de onda do laser.

\subsection{A Equação LIDAR genérica e sua interpretação}

A atmosfera determina o sinal recebido pelo LIDAR, via retroespalhamento da luz através de dois fatores: o coeficiente de retroespalhamento $\beta$ e o coeficiente de atenuação (ou extinção) $\alpha$. Estes fatores são considerados na apresentação da equação de LIDAR de retroespalhamento simples [Russel et al, 1974] :

$$
P_{r}(R)=P_{o}\left(\frac{c \tau}{2}\right) \beta(R) A_{r} R^{-2} \exp \left[-2 \int_{0}^{R} \alpha(r) d r\right]
$$

Onde $P_{r}$ é a potência recebida num instante $t, P_{o}$ é a potência transmitida no instante $t_{0}, c$ é a velocidade da luz, $\tau$ é a duração do pulso, $R$ é a distância, $A_{r}$ é a área efetiva do receptor. Assim, as medidas com LIDAR fornecem informações sobre as características de espalhamento e atenuação da atmosfera, observandose que os efeitos relacionados possam ser de alguma maneira separados. Por outro lado, em algumas aplicações há interesse em se saber também o número de partículas ou concentração em massa a partir das propriedades ópticas da atmosfera. Nesse sentido é necessário ter disponível um modelo atmosférico, e a partir daí extrair uma relação entre $\alpha$ e $\beta$ antes da solução da equação ser encontrada.

A obtenção dos parâmetros físicos da atmosfera a partir das medidas com um sistema LIDAR requerem, primeiro, a separação das características ópticas das 
interações com gases e material particulado, e posteriormente, o conhecimento apropriado das razões entre esses parâmetros, por exemplo: razão de retroespalhamento pelo número de partículas, extinção-massa, etc. Freqüentemente, por razões de simplificação, uma interação é descartada conforme a região da atmosfera a ser estudada, isto é, na atmosfera mais elevada (estratosfera), o retroespalhamento por particulado é mínimo comparado com o retroespalhamento gasoso, enquanto que nas atmosferas sobre centros urbanos 0 contrário é verdadeiro [Flamant,1997].

Ao se processar o sinal LIDAR de um sistema de um comprimento de onda apenas, encontram-se ambigüidades no que diz respeito à determinação da distribuição do tamanho de partículas, e considera-se um 'ensemble' a ser iluminado pelo feixe. Uma maneira de se eliminar tais ambigüidades seria a introdução de mais de um comprimento de onda ao sistema [Cooney, 1969]. De fato, se o número de comprimentos de onda a serem usados não for maior que quatro, as incertezas das medidas ficarão entre 10 e 15\%, dependendo do modelo de inversão a ser utilizado [Zuev, 1982]. Uma outra forma seria medir o sinal LIDAR em diferentes ângulos, mas em uma configuração biestática [Zuev,1982], viável em lugares com relevo livre de edifícios e outras construções.

\subsubsection{Equações de Razão de Mistura do vapor d'água obtidas por LIDAR Raman}

No contexto de um sistema que se baseie no uso de um laser Nd:YAG, operando no comprimento de onda de 1064 nm, no segundo harmônico (532 nm) e no terceiro harmônico (355 nm), observar-se-ão os espalhamentos elásticos desses comprimentos de onda, e os espalhamentos Raman, gerados pelo espalhamento inelástico das moléculas de nitrogênio e oxigênio, que apesar de serem três ordens de magnitude menor que o espalhamento Rayleigh, estão ainda dentro de um limite de detecção do sistema já que as espécies em questão são abundantes na atmosfera. No espalhamento Raman o sinal espalhado sofre um deslocamento em freqüência que é característico dos estados de energia estacionários de uma molécula irradiada [Measures,1984]. Com a inclusão do sinal Raman é possível eliminar a ambigüidade a respeito da razão de LIDAR, sendo assim a equação 
LIDAR, tipicamente dependente de duas incógnitas, os coeficientes de extinção e de retroespelhamento, respectivamente, passa a ter uma solução determinada.

Logo, para o caso de um sinal Raman, a equação LIDAR pode ser representada por:

$$
P\left(\Delta \lambda_{x}, r\right)=\frac{O_{x}(r) P_{0}\left(\lambda_{L}\right) F_{R}(T) A \xi\left(\lambda_{x}\right) N_{x}(r)\left[d \sigma_{x}\left(\lambda_{L}, \pi\right) / d \Omega\right]}{r^{2}} \exp \left\{-\int_{0}^{r}\left\{\alpha\left(\lambda_{L}, r^{\prime}\right)+\alpha\left(\lambda_{X}, r^{\prime}\right) d r^{\prime}\right\}\right\}
$$

Onde $\mathrm{P}\left(\Delta \lambda_{x}, r\right)$ é a potência de retroespalhamento recebida no comprimento de onda $\lambda_{x}$ em função daaltura $r . O_{x}(r)$ é a função de overlap para o canal $x$, e $P_{0}\left(\lambda_{L}\right)$ é a potência de saída do laser no comprimento de onda $\lambda_{L} . F(T)$;e a função que descreve a dependência das secções de choque Raman com a temperatura. A é a área do receptor e $\xi\left(\lambda_{x}\right)$ é a eficiência do sistema para o canal x. $\left(N_{x}(r)\right.$ é o número de densidade de espécies moleculares $x$ que está sendo excitado, e $d \sigma_{x}\left(\lambda_{L}, \pi\right) / d \Omega$ é a secção diferencial de espalhamento Raman pertinente. A função de transmissão atmosférica inclue um termo no comprimento de onda do laser $\lambda_{\mathrm{L}}$, para a transmissão ao longo do caminho e outro termo para o sinal retroespalhado no comprimento de onda $\lambda_{x}$, que foi deslocado do comprimento de onda do laser incidente para um espalhamento inelástico Raman por espécies moleculares $\mathrm{x}$.

A função de transmissão atmosférica para a equação Raman LIDAR $\exp \left\{\left[-\int_{0}^{t}\left(\alpha\left(\lambda_{L}, r^{\prime}\right)+\alpha\left(\lambda_{x}, r^{\prime}\right)\right) d r^{\prime}\right]\right\}$ leva em conta o fato de que os fótons são transmitidos na atmosfera pelo comprimento de onda $\lambda_{L}$ e retorna com um comprimento de onda Raman deslocado $\lambda_{x}$ por espécies $x$. A extinção que ocorre a um certo comprimento de onda é devido, em geral, a ambos espalhamento e absorção de aerossóis e moléculas na atmosfera e é uma função do comprimento de onda. O coeficiente de extinção total é devido a contribuições moleculares e de aerossóis:

$$
\alpha(\lambda, r)=\alpha_{\text {aer }}(r)+\sum_{i=1}^{M} N_{i}(r)\left[\sigma _ { i } \left(\lambda \lambda+\eta_{i}(\lambda \lambda]\right.\right.
$$

$\mathrm{Na}$ equação $3.5, \alpha(\lambda, r)$ é a extinção total no comprimento de onda $\lambda$ e faixa $r$, $\alpha_{a e r}(r)$ é a extinção devido ao espalhamento e absorção do aerossol, $N_{i}(r)$ é o número de densidade molecular da espécie molecular espalhadora-absorvedora, 
$\sigma_{i}(\lambda)$ é a secção diferencial de espalhamento total de espalhamento para a nézima espécie molecular, e $\eta_{i}(\lambda)$ é a secção diferencial de espalhamento Raman de absorção para a espécie molecular i. M é o número total de moléculas sendo consideradas para medidas Rayleigh-Mie ou Raman de oxigênio, nitrogênio ou vapor d'água. Com um laser XeF excimer ou um Nd:YAG, no $3^{\circ}$ harmônico para medirmos o sinal Raman ou Rayleigh-Mie abaixo da estratosfera com o segundo harmônico, a componente molecular do coeficiente de extinção atmosférica $\alpha(\lambda, r)$ é devida somente ao espalhamento por várias moléculas na atmosfera. A equação 3.5 se torna:

$$
\alpha(\lambda, r)=\alpha_{a e r}(\lambda)+N_{a r}(r) \sigma_{a r}(\lambda)
$$

Para a extinção atmosférica quando absorção não é um problema.

Para se avaliar a função de transmissão atmosférica é necessário avaliar separadamente as contribuições que são devido a extinção molecular e de aerossóis. O cálculo da extinção molecular e da profundidade ótica, incluindo os efeitos de dispersão de polarização têm sido discutidos na literatura [Whiteman, 2003, Measures, 1984]. Contudo, algumas fórmulas comuns para extinção Rayleigh que são tipicamente usadas no campo LIDAR, não levam em conta a depolarização ou negligenciam a dispersão com comprimentos de onda, então foi revisado o cálculo da extinção molecular aqui, e depois o da extinção do aerossol.

Na ausência de absorção, a extinção do feixe laser é devida inteiramente ao espalhamento. Equações 3.7-3.9 são usadas para calcular a secção diferencial de espalhamento por molécula para o espalhamento Rayleigh [Bates, 1984]:

$$
\begin{gathered}
\sigma(\lambda)=\frac{24 \pi^{3}\left[n_{s}^{2}(\lambda)-1\right]^{2}}{\lambda^{4} N_{s}^{2}\left(n_{s}^{2}+2\right)^{2}} F_{K}(\lambda) \\
n_{s}(\lambda)=10^{-8}\left[\frac{5791817}{38.0185-(1 / \lambda)^{2}}+\frac{167909}{57.362-(1 / \lambda)^{2}}\right]+1 \\
F_{K}(\lambda)=\left[\frac{6+3 \rho_{0}^{t}(\lambda)}{6-7 \rho_{0}^{t}(\lambda)}\right]
\end{gathered}
$$

Onde $\sigma(\lambda)$ é a secção diferencial de espalhamento por molécula no comprimento de onda $\lambda ; \mathrm{n}_{\mathrm{s}}(\lambda)$ é uma fórmula empírica [Peck and Reeder, 1972] para o índice de 
refração real para ar seco a temperatura e pressão padrão para comprimentos de onda maiores que $230 \mathrm{~nm}$; $\mathrm{N}_{\mathrm{s}}$ é o número de densidade molecular para o ar para a mesma condição $\left(2.54710^{19} \mathrm{~cm}^{-3}\right)$; e $F_{k}(\lambda)$ é o fator King, definido em termos de $\rho_{0}{ }^{t}$, a depolarização da fonte de luz natural (Rayleigh mais o rotacional Raman) [Bates, 1984], valor que é determinado pelas magnitudes das componentes paralelas e perpendiculares da polarizabilidade dinâmica [Measures, 1984], $\alpha^{\|}(\lambda)$ e $\alpha^{\perp}(\lambda)$.

$F_{X}(T)$ é o termo que descreve a dependência de temperatura do espalhamento rotacional-vibracional na equação Raman LIDAR [Whiteman, 2003 (I)]. Pode-se definir $F_{x}(T)$ como :

$$
F_{X}(T)=\frac{\sum \frac{d \sigma\left(\lambda_{x, i}, T, \pi\right)}{d \Omega} \xi\left(\lambda_{x, i}\right)}{\frac{d \sigma_{t}\left(\lambda_{x}, \pi\right)}{d \Omega} \xi\left(\lambda_{x}\right)}
$$

O índice i refere-se a somatória em toda a faixa espectral do filtro de interferência. $\xi\left(\lambda_{x}\right)$ é a eficiência de transmissão do filtro para comprimentos de onda puro vibracional $(354,7 \mathrm{~nm}$, ou nos deslocamentos Raman Stokes 386,7 nm e 407,5 nm para $\mathrm{N}_{2}$ e vapor d'água respectivamente) ou elástico. O $\mathrm{F}_{\mathrm{x}}(\mathrm{T})$ é adimensional com valores de 0 a 1 .

\subsubsection{Dependência da temperatura da secção diferencial de espalhamento Raman}

Com o uso de um filtro estreito (largura a meia altura menor que $1 \mathrm{~nm}$ ) em sistemas LIDAR deve-se considerar a dependência de temperatura das linhas rotacionais puras Raman bem como das linhas vibracionais-rotacionais dos canais de nitrogênio e vapor d'água [Whiteman,2003, Sherlock,1999, Adam,2007]. Os coeficientes de retroespalhamento molecular são dependentes da temperatura, e ignorar essa dependência induz erros nas medidas de LIDAR que usam filtros de interferência estreitos [Whiteman, 2003].

Enquanto a secção diferencial de espalhamento total Raman do vapor d'água não possue dependência com a temperatura, as linhas individuais rotacionais de estiramento no espectro Raman são dependentes e isso deve ser 
considerado quando utilizam-se filtros estreitos permitindo a transmissão de somente uma das partes dos sinais rotacionais e vibracionais [Adam,2007].

Para calcular a função que descreve a dependência com a temperatura, a secção diferencial de espalhamento Raman espectral das moléculas envolvidas no retroespalhamento da radiação tem que ser calculada ou medida. [Adam et al, 2007] apresentaram um trabalho enfatizando o processo de cálculo da secção diferencial de espalhamento para o ar e nitrogênio o qual considera o espectro puro rotacional Raman e o vibracional-rotacional.

A equação que inclue o fator de dependência com a temperatura para o sinal Raman de espécies $X$ pode ser definida como:

$$
\begin{aligned}
& P\left(\lambda_{L}, \Delta \lambda_{X}, r\right)=\frac{O_{X}(r) P_{0}\left(\lambda_{L}\right) N_{X}(r) A \int_{\Delta \lambda_{X}}\left[d \sigma_{X}\left(\lambda^{\prime}, \pi, T\right) / d \Omega\right] \xi\left(\lambda^{\prime}\right) d \lambda^{\prime}}{r^{2}} \\
& \times \exp \left\{-\int\left[\alpha\left(\lambda_{L}, r^{\prime}\right)+\alpha\left(\lambda_{X}, r^{\prime}\right)\right] d r^{\prime}\right\}
\end{aligned}
$$

Onde $\Delta \lambda_{x}$ refere-se a banda $H$ sobre a qual o sinal vibracional Raman é detectado. Note aqui a ausência do termo de espalhamento do aerossol pois somente a radiação espalhada inelasticamente por interações moleculares estão presentes neste sinal.

Considere o caso de um sinal Raman espalhado vibracionalmente pelo vapor d'água expresso pela equação 3.12 com $X$ substituído por $H$. A integral em $\Delta \lambda_{H}$ pode ser expressa como

$$
\int_{\Delta \lambda_{H}} \frac{d \sigma_{H}\left(\lambda^{\prime}, \pi, T\right)}{d \Omega} \xi\left(\lambda^{\prime}\right) d \lambda^{\prime}=F_{H}(T) \frac{d \sigma_{H}(\pi)}{d \Omega} \xi\left(\lambda_{H}\right)
$$

Logo $F_{H}(T)$ torna-se

$$
F_{H}(T)=\frac{\int_{\Delta \lambda_{H}}\left[d \sigma_{H}\left(\lambda^{\prime}, \pi, T\right) / d \Omega\right] \xi\left(\lambda^{\prime}\right) d \lambda^{\prime}}{\left[d \sigma_{H}(\pi) / d \Omega\right] \xi\left(\lambda_{H}\right)}
$$

Essa nova função $F_{H}(T)$ [Whiteman, 2003] contém toda a dependência de temperatura da equação de LIDAR. Contém os efeitos da mudança da eficiência de transmissão do sistema $\xi(\lambda)$, dentro da banda do filtro $\Delta \lambda_{H} . \xi\left(\lambda_{H}\right)$ é a eficiência de transmissão em $\lambda_{H}$. A notação $\left[d \sigma_{H}(\pi) / d \Omega\right]$ é usada para indicar a secção diferencial de espalhamento total de espalhamento Raman para o vapor d'água para o comprimento de onda simulado. Para o terceiro harmônico do laser Nd:YAG 
$(354,7 \mathrm{~nm})$ esse valor é aproximadamente igual a $6,2 \times 10^{-34} \mathrm{~m}^{2} \mathrm{sr}^{-1}$ [Measures, 1984] e é praticamente constante com a temperatura. Em um sistema LIDAR típico, mudanças na transmissão que ocorrem dentro do intervalo $\Delta \lambda_{H}$ são determinadas primariamente pelo filtro de interferência e mudanças menores são devidas a outros componentes ópticos como (beam splitters ) divisores de feixe. Embora a função de transmissão que descreve a largura de banda espectral de um sistema LIDAR seja devido a características de todos os componentes ópticos que interceptam o sinal recebido, o filtro de interferência tipicamente determina a maioria das variações de transmissão dentro da banda espectral de interesse. Seria mais conveniente avaliar $\xi(\lambda$ ') como um produto da transmissão do filtro de interferência, determinado por exemplo, através do uso de uma fonte de luz calibrada ou através de modelamento atmosférico. O produto $\mathrm{F}_{\mathrm{H}}(\mathrm{T})\left[d \sigma_{H}(\pi) / d \Omega\right]$ pode ser visto como a secção diferencial de espalhamento molecular efetiva que é consistente com o uso do termo de eficiência óptica monocromática $\xi\left(\lambda_{H}\right)$ na equação LIDAR.

\subsubsection{Cálculo da secção diferencial de espalhamento}

O cálculo da função $F x(T)$ requer o cálculo da secção diferencial de espalhamento diferencial para uma dada eficiência de transmissão do filtro de interferência.

\subsubsection{Rayleigh e rotacional-rotacional}

A secção diferencial de espalhamento diferencial pode ser definida (no sistema CGS) como:

$$
\left[\frac{\partial \sigma}{\partial \Omega}\right]_{J}=(2 \pi)^{4}\left(v_{0}-\Delta v\right)^{4} F_{M B, J} \Phi_{J}
$$

Onde $v_{0}$ é o número de onda $\left[\mathrm{cm}^{-1}\right]$ correspondente ao comprimento de onda excitante; $\Delta v$ é o deslocamento de freqüência Raman $\left[\mathrm{cm}^{-1}\right]$ (2331 para o $\mathrm{N}_{2}$ e 3546 para o vapor d'agua); $F_{M B, J}$ é a funçao de distribuição de Maxwell-Boltzman no caso rotacional: 


$$
F_{M B, J}=\frac{g_{n, J}(2 J+1) \exp \left(\frac{E_{r o t, J}}{K_{B} T}\right)}{Q_{r o t}}
$$

Onde $\mathrm{J}$ é o número quântico rotacional atômico; $K_{B}$ é a constante de Boltzmam $[\mathrm{J} / \mathrm{K}]$; T é a temperatura $[\mathrm{K}]$.

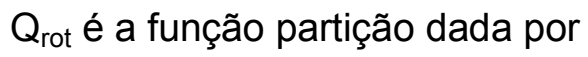

$$
Q_{r o t}=\sum_{J} g_{n, J}(2 J+1) \exp \left[-\frac{E_{r o t, J}}{K_{B} T}\right]
$$

$E_{\text {rot,J }}$ é a energia no estado fundamental, e quando a molécula é considerada um rotacionador rígido, pode ser expressa como:

$$
E_{\text {rot, }}=h \text { c J }(J+1) B_{0}
$$

Onde h é a constante de Planck [J.s], c é a velocidade da luz e $B_{0}$ é a constante de rotação $\left[\mathrm{cm}^{-1}\right]$.

$\mathrm{B}_{0}$ é difinido como

$$
B_{0}=\frac{h}{8 \pi^{2} c I_{b}}
$$

$\mathrm{I}_{\mathrm{b}}$ é o momento de inércia da molécula no eixo através do seu centro de gravidade e perpendicular ao eixo internuclear [Adam,2007, Long, 2002].

\begin{tabular}{|c|c|c|c|c|c|}
\hline gás & $\mathrm{I}$ & $\begin{array}{l}T_{J}=2 \mathrm{I}, \\
2 \mathrm{l}-1,0\end{array}$ & $\begin{array}{c}\mathrm{g}_{\mathrm{n}, \mathrm{J}}=\sum(2 \mathrm{TJ}+1) \\
\mathrm{J} \text { par }\end{array}$ & $\begin{array}{c}\mathrm{g}_{\mathrm{n}, \mathrm{J}}=\Sigma(2 \mathrm{TJ}+1) \\
\mathrm{J} \text { ímpar }\end{array}$ & $B_{0}\left(\mathrm{~cm}^{-1}\right)$ \\
\hline $\mathrm{N}_{2}$ & 1 & $2,1,0$ & 6 & 3 & 1,98957 \\
\hline $\mathrm{O}_{2}$ & 0 & 0 & 0 & 1 & 1,43768 \\
\hline
\end{tabular}

Finalmente $g_{n, J}$ é o fator de peso estatístico o qual depende do spin nuclear I, mostrado na tabela 4 [Herzberg ,1950].

TABELA 4. Peso Estatístico para moléculas de $\mathrm{N}_{2}$ e $\mathrm{O}_{2}$.

| -> spin nuclear |

$\mathrm{T}_{\mathrm{J}}>>$ spin nuclear total

$\mathrm{g}_{\mathrm{n}, \mathrm{J}}->$ fator de peso estatístico

O deslocamento Raman é computado para bandas Q, S e O [Berhrendt,2005] como:

Q: $\Delta v=0$

S: $\Delta v_{\text {stokes }}(\mathrm{J})=-\mathrm{B}_{0} 2(2 \mathrm{~J}+3), \mathrm{J}=0,1,2$

O: $\Delta v_{\text {anti-stokes }}(\mathrm{J})=\mathrm{B}_{0} 2(2 \mathrm{~J}-1), \mathrm{J}=2,3,4$ 
Considerando-se a energia, a função partição pode ser escrita como uma integral (para T grande o suficiente ou B pequeno [Herzberg, 1950] para energia no estado fundamental, a função partição é dada por:

$$
Q_{r o t}=\frac{(2 J+1)^{2} K_{B} T}{2 h c B_{0}}
$$

O termo $\Phi J$ para os ramos $Q$, S e O são:

$$
\begin{aligned}
& \text { S: } \phi_{J}=\frac{7}{45} \frac{3(J+1)(J+2)}{2(2 J+1)(2 J+3)} \gamma^{2}, J=0,1,2, \ldots \\
& \text { O: } \phi_{J}=\frac{7}{45} \frac{3 J(J-1)}{2(2 J+1)(2 J-1)} \gamma^{2}, J=2,3,4 \ldots
\end{aligned}
$$

TABELA 5. Tensor polarizabilidade [Long, 2002].

\begin{tabular}{ccccc}
\hline Molécula & $\mathbf{a}^{2}\left[\mathbf{m}^{6}\right] \mathbf{1 0 ^ { - 6 0 }}$ & $\gamma^{2}\left[\mathbf{m}^{6}\right] \mathbf{1 0 ^ { - 6 0 }}$ & $\mathbf{a}^{, 2}\left[\mathbf{m}^{4} / \mathrm{Kg}\right]$ & $\gamma^{\prime 2}\left[\mathbf{m}^{4} / \mathbf{K g}\right]$ \\
\hline $\mathrm{N}_{2}$ & 3,17 & 0,52 & $2,6210^{-14}$ & $4,2310^{-14}$ \\
\hline $\mathrm{O}_{2}$ & 2,66 & 1,26 & - & - \\
\hline
\end{tabular}

Logo, podemos reescrever:

$$
\left(\frac{\partial \sigma}{\partial \Omega}\right)_{J}=(2 \pi)^{4}\left(v_{0}+\Delta v\right)^{4} \frac{2 h c B_{0}}{(2 I+1)^{2} K_{B} T} g_{n, J}(2 J+1) \exp \left[\frac{-h c J(J+1) B_{0}}{K_{B} T}\right] \Phi_{J}
$$

As linhas individuais para os ramos $Q, S$ e $O$ são:

Q:

$$
\left(\frac{\partial \sigma}{\partial \Omega}\right)_{J}=\frac{112 \pi^{4}}{45}\left(v_{0}\right)^{4} \frac{2 h c B_{0}}{(2 I+1)^{2} K_{B} T} g_{n, J}(2 J+1) e^{\frac{h c J(J+1) B_{0}}{K_{B} T}}\left(\frac{45}{7} a^{2}+\frac{J(J+1)}{(2 J-1)(2 J+3)} \gamma^{2}\right), J=0,1,2, \ldots
$$

S:

$$
\left(\frac{\partial \sigma}{\partial \Omega}\right)_{J}=\frac{112 \pi^{4}\left(v_{0}-\Delta v\right)^{4}}{45} \frac{2 h c B_{0}}{(2 I+1)^{2} K_{B} T} g_{n, J}(2 J+1) e^{-\frac{h c J(J+1) B_{0}}{K_{B} T}}\left(\frac{3(J+1)(J+2)}{2(2 J+1)(2 J+3)} \gamma^{2}, J=0,1,2, \ldots\right.
$$

O:

$$
\left(\frac{\partial \sigma}{\partial \Omega}\right)_{J}=\frac{112 \pi^{4}\left(v_{0}-\Delta v\right)^{4}}{45} \frac{2 h c B_{0}}{(2 I+1)^{2} K_{B} T} g_{n, J}(2 J+1) e^{-\frac{h c J(J+1) B_{0}}{K_{B} T}}\left(\frac{3 J(J-1)}{2(2 J+1)(2 J-1)} \gamma^{2}, J=2,3,4, \ldots\right.
$$


A secção diferencial de espalhamento total para as ramos $Q$ e $S+O$ pode ser obtida assumindo-se uma soma sobre todo $\mathrm{J}$ (até 30 para $\mathrm{N}_{2}$ e até 40 para $\mathrm{O}_{2}$ ) ou usando-se as expressões a seguir obtidas acima para $\mathrm{J} \rightarrow \infty$ (cobrindo o limite clássico) [Inaba, 1976, Weitkamp, 2005]. Inaba usa 26-28 linhas para o cálculo do rotacional-rotacional e vibracional-rotacional para $\mathrm{N}_{2}$, logo:

$$
\begin{aligned}
& \mathrm{Q}:\left(\frac{\partial \sigma_{t}}{\partial \Omega}\right)=(2 \pi)^{4}\left(v_{0}\right)^{4}\left(a^{2}+\frac{7}{180} \gamma^{2}\right) \\
& \text { e } S+O:\left(\frac{\partial \sigma_{t}}{\partial \Omega}\right)=(2 \pi)^{4}\left(v_{0}\right)^{4}\left(\frac{7}{60} \gamma^{2}\right)
\end{aligned}
$$

A secção diferencial de espalhamento de retroespalhamento total sobre $Q, S$ e O:

$$
\mathrm{Q}+\mathrm{S}+\mathrm{O}:\left(\frac{\partial \sigma_{t}}{\partial \Omega}\right)=(2 \pi)^{4}\left(v_{0}\right)^{4}\left(a^{2}+\frac{7}{45} \gamma^{2}\right)
$$

Considerando que o ar é composto primariamente de $79 \%$ de $\mathrm{N}_{2}, 21 \%$ de $\mathrm{O}_{2}$ [Adam, 2007] e a secção diferencial de espalhamento total retroespalhada para o ar é 0,79 vezes a secção diferencial de espalhamento total retroespalhada do $\mathrm{N}_{2}$ mais 0,21 vezes a secção diferencial de espalhamento retroespalhada do $\mathrm{O}_{2}$.

\subsubsection{Vibracional-rotacional do nitrogênio}

No caso do vibracional-rotacional Stokes, a freqüência de deslocamento vai ser $-v_{\text {vib }}+\Delta v$. A equação (3.26) para o cálculo da secção diferencial de espalhamento pode ser representada por:

$$
\left(\frac{\partial \sigma}{\partial \Omega}\right)=(2 \pi)^{4}\left(v_{0}-v_{v i b}+\Delta v\right)^{4} F_{M B} \phi_{J}^{\prime}
$$

A função de distribuição Maxwell-Boltzmann depende de ambas transições rotacional e vibracional. No caso vibracional, a polarizabilidade depende da função de distribuição de Maxwell-Boltzmann:

$$
F_{M B, v i b}=\frac{\exp \left[\frac{-h c v_{v i b}}{K_{B} T}\left(v+\frac{1}{2}\right)\right]}{Q_{v i b}(T)}
$$

Onde $v$ é o número quântico vibracional e $Q_{\text {vib }}$ é a função partição para estados vibracionais, dada por 
$Q_{v i b}(T)=\sum_{v} \exp \left[-\frac{h c v_{v i b}}{K_{B} T}\left(v+\frac{1}{2}\right)\right]=\exp \left(\frac{-h c v_{v i b}}{2 K_{B} T}\right) \sum_{v} \exp \left(-\frac{h c v_{v i b} v}{K_{B} T}\right)=\exp \left(\frac{-h c v_{v i b}}{2 K_{B} T}\right) \frac{1}{1-\exp \left(\frac{-h c v_{v i b}}{K_{B} T}\right)}$

Para transições Stokes a polarizabilidade (e consequentemente 0 espalhamento), depende da soma de $b v^{2}(v-1)$ FMB, vib [Long,1977]. A amplitude da energia vibracional de ponto zero $b v^{2}$ é dada por

$$
b v^{2}=\frac{h}{8 \pi^{2} c v_{v i b}}
$$

Logo ,

$$
b v^{2} \sum_{v}(v+1) F_{M B, v i b}=b v^{2} \frac{1}{1-\exp \left(\frac{-h c v_{v i b}}{K_{B} T}\right)}
$$

Assim:

$\left(\frac{\partial \sigma}{\partial \Omega}\right)_{J}=(2 \pi)^{4}\left(v_{0}-v_{v i b}+\Delta v\right)^{4} \frac{2 h c B_{0}}{(2 I+1)^{2} K_{B} T} \frac{h}{8 \pi^{2} c v_{v i b}\left[1-\exp \left(\frac{-h c v_{v i b}}{K_{B} T}\right)\right]} g_{n, J}(2 J+1) \exp \left[-\frac{h c J(J+1) B_{0}}{K_{B} T}\right] \phi_{J}^{\prime}$

Agora para o caso vibracional, as invariáveis nos termos $\phi \mathrm{J}$ serão diferentes e representadas com uma prima ' (Tabela 5). As linhas individuais espectrais Q, S e O são dadas por

Q:

$$
\begin{aligned}
& \left(\frac{\partial \sigma}{\partial \Omega}\right)_{J}=\left(\frac{112}{45} \pi\right)^{4}\left(v_{0}-v_{v i b}+\Delta v\right)^{4} \frac{2 h c B_{0}}{(2 I+1)^{2} K_{B} T} \frac{h}{8 \pi^{2} c v_{v i b}\left[1-\exp \left(\frac{-h c v_{v i b}}{K_{B} T}\right)\right]} g_{n, J}(2 J+1) \\
& \exp \left[-\frac{h c J(J+1) B_{0}}{K_{B} T}\right]\left(\frac{45}{7} a^{\prime 2}+\frac{J(J+1)}{(2 J-1)(2 J+3)} \gamma^{\prime 2}\right), J=0,1,2, \ldots
\end{aligned}
$$

S:

$$
\left(\frac{\partial \sigma}{\partial \Omega}\right)_{J}=\left(\frac{112}{45} \pi\right)^{4}\left(v_{0}-v_{v i b}+\Delta v\right)^{4} \frac{2 h c B_{0}}{(2 I+1)^{2} K_{B} T} \frac{h}{8 \pi^{2} c v_{v i b}\left[1-\exp \left(\frac{-h c v_{v i b}}{K_{B} T}\right)\right]} g_{n, J}(2 J+1)
$$

$$
\exp \left[-\frac{h c J(J+1) B_{0}}{K_{B} T}\right]\left(\frac{3(J+1)(J+2)}{2(2 J+1)(2 J+3)} \gamma^{\prime 2}\right), J=0,1,2, \ldots
$$


O:

$$
\begin{aligned}
& \left(\frac{\partial \sigma}{\partial \Omega}\right)_{J}=\left(\frac{112}{45} \pi\right)^{4}\left(v_{0}-v_{v i b}+\Delta v\right)^{4} \frac{2 h c B_{0}}{(2 I+1)^{2} K_{B} T} \frac{h}{8 \pi^{2} c v_{v i b}\left[1-\exp \left(\frac{-h c v_{v i b}}{K_{B} T}\right)\right]} g_{n, J}(2 J+1) \\
& \exp \left[-\frac{h c J(J+1) B_{0}}{K_{B} T}\right]\left(\frac{3 J(J-1)}{2(2 J+1)(2 J-1)} \gamma^{\prime 2}\right), J=2,3,4 \ldots
\end{aligned}
$$

A secção diferencial total de retroespalhamento para $Q, S+O$ e $Q+S+O$ pode

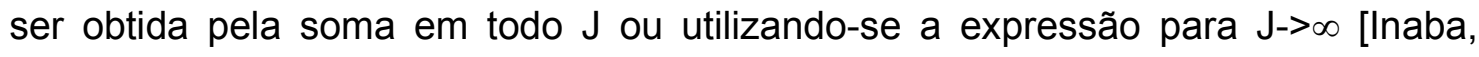
1976] assim, temos:

$$
\begin{aligned}
& \mathrm{Q}:\left(\frac{\partial \sigma}{\partial \Omega}\right)=(2 \pi)^{4}\left(v_{0}-v_{v i b}\right)^{4} \frac{h}{8 \pi^{2} c v_{v i b}\left[1-\exp \left(\frac{-h c v_{v i b}}{K_{B} T}\right)\right]}\left(a^{\prime 2}+\frac{7}{180} \gamma^{\prime 2}\right) \\
& \mathrm{S}+\mathrm{O}:\left(\frac{\partial \sigma}{\partial \Omega}\right)=(2 \pi)^{4}\left(v_{0}-v_{v i b}\right)^{4} \frac{h}{8 \pi^{2} c v_{v i b}\left[1-\exp \left(\frac{-h c v_{v i b}}{K_{B} T}\right)\right]}\left(\frac{7}{60} \gamma^{\prime 2}\right) \\
& \mathrm{Q}+\mathrm{S}+\mathrm{O}:\left(\frac{\partial \sigma}{\partial \Omega}\right)=(2 \pi)^{4}\left(v_{0}-v_{v i b}\right)^{4} \frac{h}{8 \pi^{2} c v_{v i b}\left[1-\exp \left(\frac{-h c v_{v i b}}{K_{B} T}\right)\right]}\left(a^{\prime 2}+\frac{7}{45} \gamma^{\prime 2}\right)
\end{aligned}
$$

\subsubsection{Secção diferencial de espalhamento Raman do nitrogênio}

A secção diferencial de espalhamento vibracional Raman para o nitrogênio pode ser definida, de forma simplificada como [para mais detalhes, ver [Herzberg,1945 ; Inaba, 1976]:

$$
\left(\frac{\partial \sigma}{\partial \Omega}\right)=(2 \pi)^{4}\left(v_{0}-v_{v i b}+\Delta v\right)^{4} F_{M B} \phi_{J}^{\prime}
$$

Onde $v_{v i b}-\Delta v$ é a freqüência de deslocamento no caso do vibracional-rotacional Stockes , $v_{0}$ é o número de onda $\left[\mathrm{cm}^{-1}\right]$ correspondente ao comprimento de onda excitante; $\Delta v$ é o deslocamento de freqüência Raman $\left[\mathrm{cm}^{-1}\right.$ ] (2331 para o $\mathrm{N}_{2}$ e 3546 para o vapor d'agua);, $F_{\mathrm{MB}, \mathrm{J}}$ é a funçao de distribuição de Maxwell-Boltzman no caso é dependente das transições rotacionais e vibracionais, e o termo $\Phi J$ para as ramos $Q$, S e O pode ser:

$$
\begin{aligned}
& \text { Q: } \phi_{J}=a^{2}+\frac{7}{45} \frac{J(J+1)}{(2 J-1)(2 J+3)} \gamma^{2}, J=0,1,2 \ldots \\
& \text { S: } \phi_{J}=\frac{7}{45} \frac{3(J+1)(J+2)}{2(2 J+1)(2 J+3)} \gamma^{2}, J=0,1,2, \ldots
\end{aligned}
$$




$$
\mathrm{O}: \phi_{J}=\frac{7}{45} \frac{3 J(J-1)}{2(2 J+1)(2 J-1)} \gamma^{2}, J=2,3,4 \ldots
$$

Onde a e $\gamma$ são invariantes do tensor de polarizabilidade [Long, 2002] indicando a polarizabilidade isotrópica e anisotrópica, frações de termos contendo $\mathrm{J}$ (número quântico rotacional) (sem o termo 7/45) são chamados coeficiente Placzek-Teller [Long, 2002, Penney et al, 1974].

\subsubsection{Modelo descrito para o cálculo da secção diferencial de espalhamento Raman do vapor d'água}

O espectro de absorção do vapor d'água tem sido estudado. [Avila et al, 1999] e apresentaram resultados dispostos em tabelas com forças de espalhamento e atribuições rotacionais-vibracionais da molécula de água, de onde o espectro Raman da água na região de estiramento $\mathrm{OH}$ pode ser simulado com confiança em uma larga faixa de temperaturas de 0 a aproximadamente $1000 \mathrm{~K}$. Sua fórmula para o cálculo da secção diferencial de espalhamento Raman do vapor d'água será utilizada neste trabalho.

A equação apresenta o cálculo da secção diferencial de espalhamento Raman da água para uma transição rotacional-vibracional particular que contribui para o que Avila [Avila, 1999] chama de pico nas tabelas mostradas em seu artigo [Avila, 1999, 2004].

A secção diferencial de espalhamento Raman pode ser definida [Avila et al, 2004] como:

$$
\left(\frac{\partial \sigma}{\partial \Omega}\right)_{\left(O j K a K c->V^{\prime} J^{\prime} K a^{\prime} K c^{\prime}\right)}^{[M N]}=\left(v_{0}-v\right)^{4} \frac{e^{-E i / k_{B} T}}{Q(T)} A_{\left(0 J K a K c->V^{\prime} K a^{\prime} K c^{\prime}\right)}^{[M N]}
$$

Onde $\Delta v$ é o deslocamento $\left(3654 \mathrm{~cm}^{-1}\right)$ e $A^{X X}$ e $A^{X Y}$ são os coeficientes de polarizabilidade perpendicular. $Q(T)$ é a função partição. $O$ termo exponencial multiplicado com $2 \mathrm{~J}+1$ dividido pela função partição, representa a distribuição rotacional da função de Maxwell-Boltzmann. $E_{i}$ é o estado de energia fundamental, $\mathrm{K}_{\mathrm{B}}$ é a constante de Boltzmann $\left[\mathrm{cm}^{-1} \mathrm{~K}^{-1}\right.$ ] e T a temperatura [K]. [Avila et al, 2004] fornece tabelas com energia de estado fundamental, coeficientes $A^{X X}$ e $A^{X Y}$ bem como a função partição. A equação 3.49 permite o cálculo, usando os dados 
fornecidos por [Avila, 2004], da secção diferencial de espalhamento diferencial absoluta das transições rotacionais-vibracionais Raman (0Jkakc->V'J'ka'kc') do $\mathrm{H}_{2} \mathrm{O}$ na região de estiramento $\mathrm{OH}$ em qualquer temperatura e número de onda $\left[\mathrm{cm}^{-}\right.$ ${ }^{1}$ ] excitante $v_{0}$.

Para a seç̧ão diferencial de espalhamento integrada calculada de $v_{1}$ do vapor d'água fornecido em [Avila,2004], erro relativo foi de $8 \%$ com relação aos cálculos feitos por Penney e Lapp. Os valores absolutos são derivados por refinados cálculos $a b$ initio, testados exaustivamente por experimentos Raman como apresentado no três isótopos $\left(\mathrm{H}_{2} \mathrm{O}, \mathrm{HDO}, \mathrm{D}_{2} \mathrm{O}\right)[$ Avila, 2003,2004]. Contudo, é uma estimativa indireta do erro.

A razão de mistura do vapor d'água $\omega$ é uma grandeza conveniente da quantidade de vapor d'água na atmosfera dada pela razão da massa de vapor d'água sobre a massa de ar seco de um dado volume.

A eficiência de transmissão $\xi(\lambda)$ descreve a eficiência ótica total do receptor LIDAR a um comprimento de onda $\lambda$ e inclui fatores tais como reflectividade do telescópio, a transmissão da ótica condicionante, a transmissão dos filtros, e a eficiência quântica dos detectores.

A partir da equação (3.4), a razão dos espalhamentos simples Raman medidos para água e nitrogênio pode ser representada como:

$$
\frac{P\left(\Delta \lambda_{H}, r\right)}{P\left(\Delta \lambda_{N}, r\right)}=\frac{O_{H}(r) F_{H}[T(r)] N_{H}(r)\left[d \sigma_{H}(\pi) / d \Omega\right] \xi\left(\lambda_{H}\right)}{O_{N}(r) F_{N}[T(r)] N_{N}(r)\left[d \sigma_{N}(\pi) / d \Omega\right] \xi\left(\lambda_{N}\right)} \times \exp \left\{-\int_{0}^{r}\left[\alpha\left(\lambda_{H}, r^{\prime}\right)-\alpha\left(\lambda_{N}, r^{\prime}\right)\right] d r\right\}
$$

Considerando que o $\mathrm{N}_{2}$ forma uma fração constante $(\sim 0,78)$ de ar seco na baixa atmosfera, temos:

$$
w=\frac{M W_{\mathrm{H}_{2} \mathrm{O}}}{M W_{\text {DryAir }}} \frac{N_{H}(r)}{N_{\text {DryAir }}(r)} \cong \frac{M W_{\mathrm{H}_{2} \mathrm{O}}}{M W_{\text {DryAir }}} \frac{N_{H}(r)}{N_{N}(r) / 0.78} \cong 0.485 \frac{N_{H}(r)}{N_{N}(r)}
$$

Onde $\mathrm{MW}_{\mathrm{H} 2 \mathrm{O}}$ é o peso molecular do vapor d'água $(\sim 18 \mathrm{~g} / \mathrm{mol})$ e $M W_{\text {dry air }}$ é o peso molecular do ar seco $(\sim 28,94 \mathrm{~g} / \mathrm{mol})$. Substituindo-se na equação 3.50 , a equação da razão de mistura do vapor d'água pode ser expressa com o uso de um fator de calibração dado por:

$$
\omega=k^{*}(r) \frac{F_{N}[T(r)] P\left(\lambda_{H}, r\right)}{F_{H}[T(r)] P\left(\lambda_{N}, r\right)} \exp \left\{-\int_{0}^{r}\left[\alpha\left(\lambda_{H}, r\right)-\alpha\left(\lambda_{N}, r^{\prime}\right)\right] d r^{\prime}\right\},
$$

onde $k^{*}(r)$ é o fator de calibração do sistema representado: 


$$
k^{*}(r) \cong 0.485 \frac{O_{N}(r)\left[d \sigma_{N}(\pi) / d \Omega\right] \xi\left(\lambda_{N}\right)}{O_{H}(r)\left[d \sigma_{H}(\pi) / d \Omega\right] \xi\left(\lambda_{H}\right)} .
$$

No contexto de uma calibração da razão de mistura do vapor d'água, a obtenção da razão das eficiências ópticas de transmissão foi realizada através de um experimento com uma fonte de luz calibrada que será descrito no próximo capítulo. Nesse contexto, a equação da razão de eficiência total é definida como:

$$
\frac{\xi\left(\lambda_{N}\right)}{\xi\left(\lambda_{\mathrm{H}}\right)}=\frac{C_{\text {out }}\left(\lambda_{H}\right) I_{\text {in }}\left(\lambda_{N}\right)}{C_{\text {out }}\left(\lambda_{N}\right) I_{\text {in }}\left(\lambda_{H}\right)}
$$

onde $\mathrm{C}_{\text {out }}\left(\lambda_{x}\right)$ é a taxa de contagem coletada pelos detectores (fotomultiplicadoras), x é um índice que representa os canais $\mathrm{N}$ para nitrogênio e para $\mathrm{H}$ para vapor d'água, $I_{i n}\left(\lambda_{x}\right)$ é a irradiância spectral emitida pela lâmpada de tungstênio para uma faixa de comprimentos de onda no canal $x$ vezes o fator de correção do filtro, definido pelo perfil de transmissão dos filtros de interferência utilizados. 


\section{CAPÍTULO 4}

\section{METODOLOGIA}

\subsection{Aparato Experimental}

\subsubsection{O sistema LIDAR Raman da Howard University (HURL)}

O HURL está situado em Beltsville, Maryland, Estados Unidos e foi projetado para realizar medidas de vapor d'água atmosférico durante o dia e durante a noite e medidas de razão de espalhamento de aerossóis. Os componentes básicos no sistema são representados no diagrama de bloco da Figura 4.3. O modelo de laser deste sistema LIDAR de três canais é o Continuum Lasers Precision II 9030. Ele opera no terceiro harmônico do Nd:YAG e fornece uma potência média de saída de $48 \mathrm{~W}$ no comprimento de onda fundamental e é capaz de trabalhar no segundo, terceiro ou quarto harmônicos. Esse sistema foi projetado para operar no terceiro harmônico $(354,7 \mathrm{~nm})$ e fornece uma potência média máxima de $14 \mathrm{~W}$ para esse comprimento de onda. A potência média de operação é de $10 \mathrm{~W}$. A divergência do feixe é de $0,5 \mathrm{mrad}$ e o perfil do feixe é próximo de uma gaussiana no campo distante (coeficiente de correlação de 0,9 quando comparado com um perfil Gaussiano utilizando-se de análises de raiz quadrada [Venable et al, 2005]). O resfriamento do laser é realizado por um sistema de refrigeração de $4 \mathrm{~kW}$ da Affinity. Filtros de banda estreitos são utilizados para medir os sinais retroespalhados elásticos e os puros rotacionais Raman a $354,7 \mathrm{~nm}$, os fótons espalhados por Raman das moléculas de nitrogênio a $386,7 \mathrm{~nm}$, e os fótons espalhados Raman pelo vapor d'água a 407,5 nm. Uma das principais funções desse sistema é caracterizar a distribuição temporal e vertical do vapor d'água e processos dinâmicos na camada limite para avaliação de modelos de mesoscala [Venable et al, 2005]. Um resumo das especificações do sistema HURL é apresentado na tabela 6. 


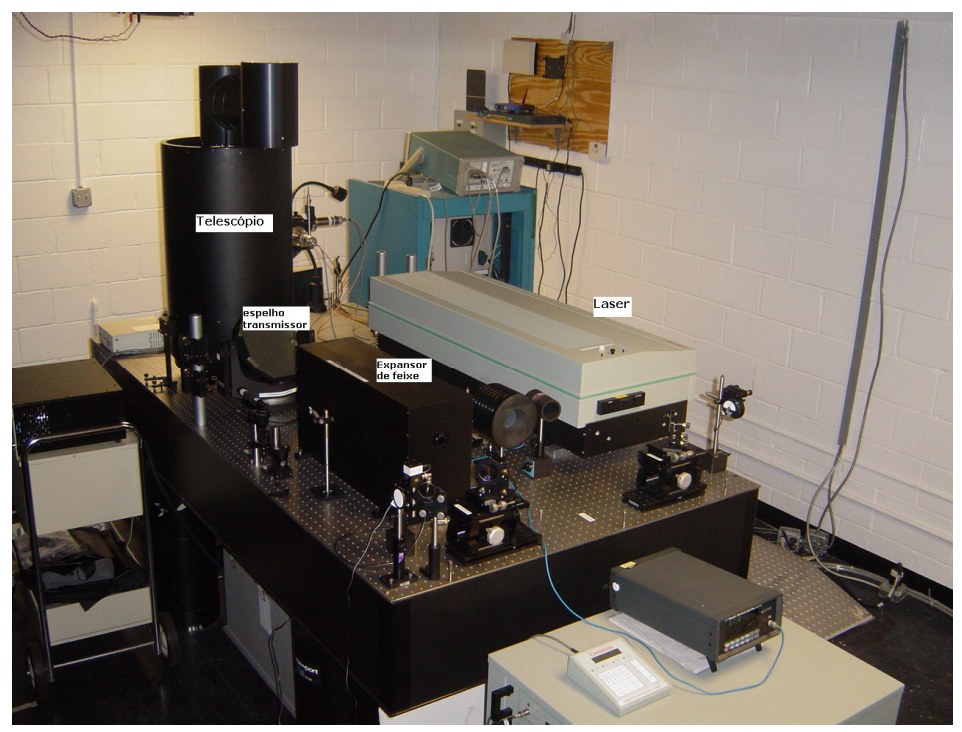

FIGURA 4. System LIDAR Raman da Howard University (HURL)

TABELA 6 . Parâmetros básicos do sistema.

\begin{tabular}{|c|c|}
\hline Geometria & $\begin{array}{l}\text { Apontando no zenith, geometria coaxial com periscópio, e uma janela de } \\
\text { tempo está sendo implementada. }\end{array}$ \\
\hline Laser & $\begin{array}{l}3^{\circ} \text { harmônico do Nd:YAG, } 354.7 \mathrm{~nm}, 30 \mathrm{~Hz}, 0.5 \mathrm{mrad} \text { divergência, } 9.5 \mathrm{~mm} \\
\text { diâmetro do feixe, Continuum Model } 9500,350 \mathrm{~mJ} / \text { pulso }\end{array}$ \\
\hline Telescópio & $\begin{array}{l}400 \mathrm{~mm} \text { diâmetro CA, f/2.3, } 920 \mathrm{~mm} \text { EFL, parábola, } 250 \text { mrad nominal de } \\
\text { campo de vista }\end{array}$ \\
\hline $\begin{array}{l}\text { Expansor de } \\
\text { Feixe }\end{array}$ & $\begin{array}{l}\text { Seguro aos olhos para um pulso simples através de um expansor de feixe } \\
\text { 15X, com difração limitada a } 25,4 \mathrm{~mm} \text { de diâmetro, } 500 \mathrm{~mm} \text { de distância } \\
\text { focal das lentes de entrada e duas lentes de saída com } 150 \mathrm{~mm} \text { de } \\
\text { diâmetro, com } 1000 \mathrm{~mm} \text { de distância focal cada. }\end{array}$ \\
\hline $\begin{array}{l}\text { Espelho } \\
\text { Transmissor }\end{array}$ & $\begin{array}{l}15 \times 20 \mathrm{~cm}^{2} \text {, melhor que } 1 \text { mrad de precisão, overlap completo no campo } \\
\text { de vista do telescópio e laser para } z>3.5 \mathrm{~km} \text {; faixa de medida } \sim 0.8 \mathrm{~km}- \\
\sim 15 \mathrm{~km} \text {; Motor de Controle Newport ESP } 300 \text {. }\end{array}$ \\
\hline $\begin{array}{l}\text { Acoplamento } \\
\text { Óptico }\end{array}$ & $\begin{array}{l}\text { Fibra ótica -acoplada no design do telescópio receptor.Fibra: silica, multi- } \\
\text { modo, } 300 \mathrm{~mm} \text { diâmetro, core, } 0,22 \mathrm{NA} \text {, posicionada no plano focal do } \\
\text { telescópio. }\end{array}$ \\
\hline Módulo separador & $\begin{array}{l}\text { Sistema de } 3 \text { canais com filtros de interferência : } 354.7,386.7 \text {, and } 407.5 \\
\text { nm, Lentes colimadoras: } 2 \text {-Melles LQF066, } 50 \mathrm{~mm} \text { diâmetro, } 75 \mathrm{~mm} \text { EFL, } \\
\text { silica. Filtros de Banda Estreita DI } \sim 0.25 \mathrm{~nm}, \mathrm{~T} \sim 40 \% \text {, Divisor de feixe: } \mathrm{T}> \\
90 \% 380-420, \mathrm{R}>99 \% \text { fora da banda; } \mathrm{T}>90 \% 405, \mathrm{R}>99 \% 387\end{array}$ \\
\hline $\begin{array}{l}\text { PMT - } \\
\text { fotomultiplicadora }\end{array}$ & $\begin{array}{l}\text { Hamamatsu R1942P, } 20 \mathrm{~mm} \text { diâmetro, sensibilidade do catodo }>60 \mathrm{~mA} / \mathrm{lm} \text {, } \\
\text { tempo de ascensão } \sim 2 \mathrm{~ns}\end{array}$ \\
\hline $\begin{array}{l}\text { Licel Transient } \\
\text { Recorders }\end{array}$ & $\begin{array}{l}\text { Modo contagem de fótons e analógico, } 7.5 \mathrm{~m} \text { resolução minima do raio, } \\
\text { Modo analógico; signals abaixo de } 10 \mathrm{MHz} \text { processados com conversor de } \\
12 \mathrm{Bit} \mathrm{A} / \mathrm{D} \text {, somado em } 24 \text { bit RAM; Modo contagem de fótons: sinais } \\
\text { acima de } 10 \mathrm{MHz} \text { são detectados com discriminador rápido de } 200 \mathrm{MHz} \text {, } \\
\text { somado em } 16 \text { bit RAM }\end{array}$ \\
\hline CPU & $\begin{array}{l}\text { Processador } 3.06 \mathrm{GHz}, 3.00 \mathrm{~GB} \text { RAM, } 112 \mathrm{~GB} \text { HD, Windows XP } \\
\text { Professional }\end{array}$ \\
\hline $\begin{array}{l}\text { Software } \\
\text { aplicativo }\end{array}$ & $\begin{array}{l}\text { Licel/LabView Control Package via placa PCI-DIO32HS; rotinas de análise } \\
\text { customizadas em Mathematica, HTBasic. }\end{array}$ \\
\hline
\end{tabular}


Nas Figuras 4, 4.1 e 4.2 são mostrados o sistema HURL, o sistema de aquisição e a unidade separadora de comprimento de onda, respectivamente.

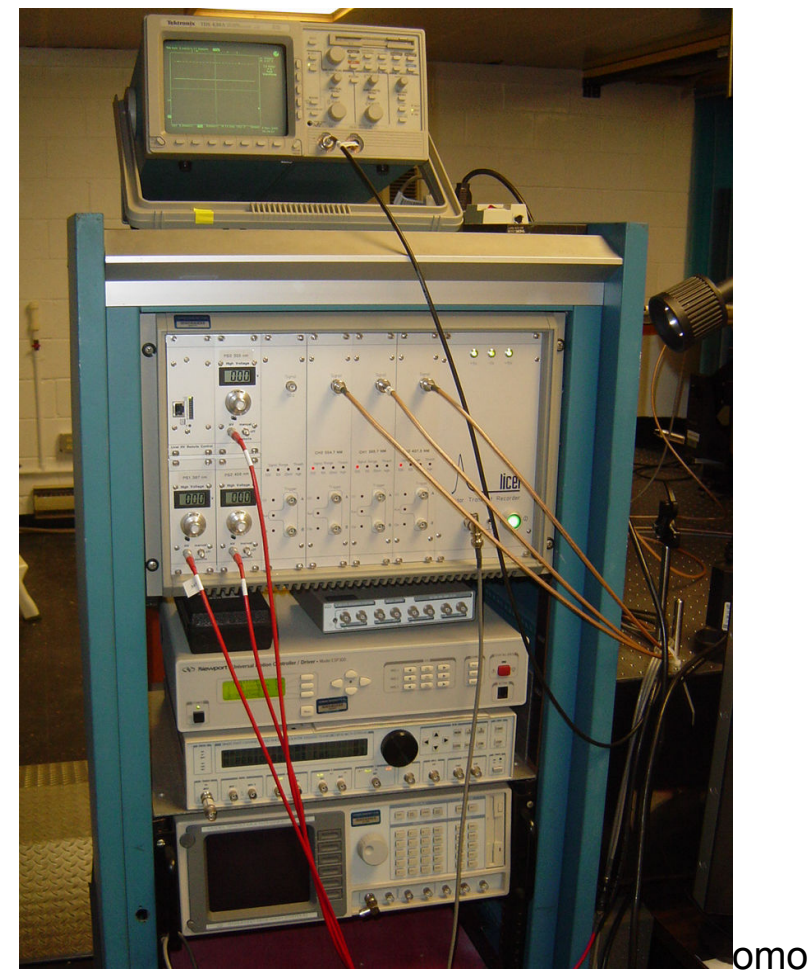

FIGURA 4.1 - Sistema de Aquisição de dados.

O sistema de aquisição de dados consiste de um Registrador de Transientes ópticos da Licel Corporation o qual é capaz de registrar aquisições simultâneas de sinal analógico e modo contagem de fótons (PC). Uma vez que não-linearidades nas taxas de contagem de fótons podem ser significantes em certas taxas de contagem, a detecção combinada de contagem analógica-PC pode aumentar o intervalo dinâmico significativamente. O modo contagem de fótons utiliza um estágio triplo rápido pré amplificador e um discriminador com 64 nívels de "threshold" e opera a $250 \mathrm{MHz}$. O sistema inteiro é controlado via uma placa PCI-DIO32HS de Interface Labview. Um software particular foi desenvolvido pelo Dr. Venable para analisar os dados coletados, realizar uma rotina de "glue", plotar os sinais analógicos e digitais. Um rotina em mathematica foi desenvolvida pelo Dr. D. Whiteman para calcular a razão de mistura do vapor d'água. 

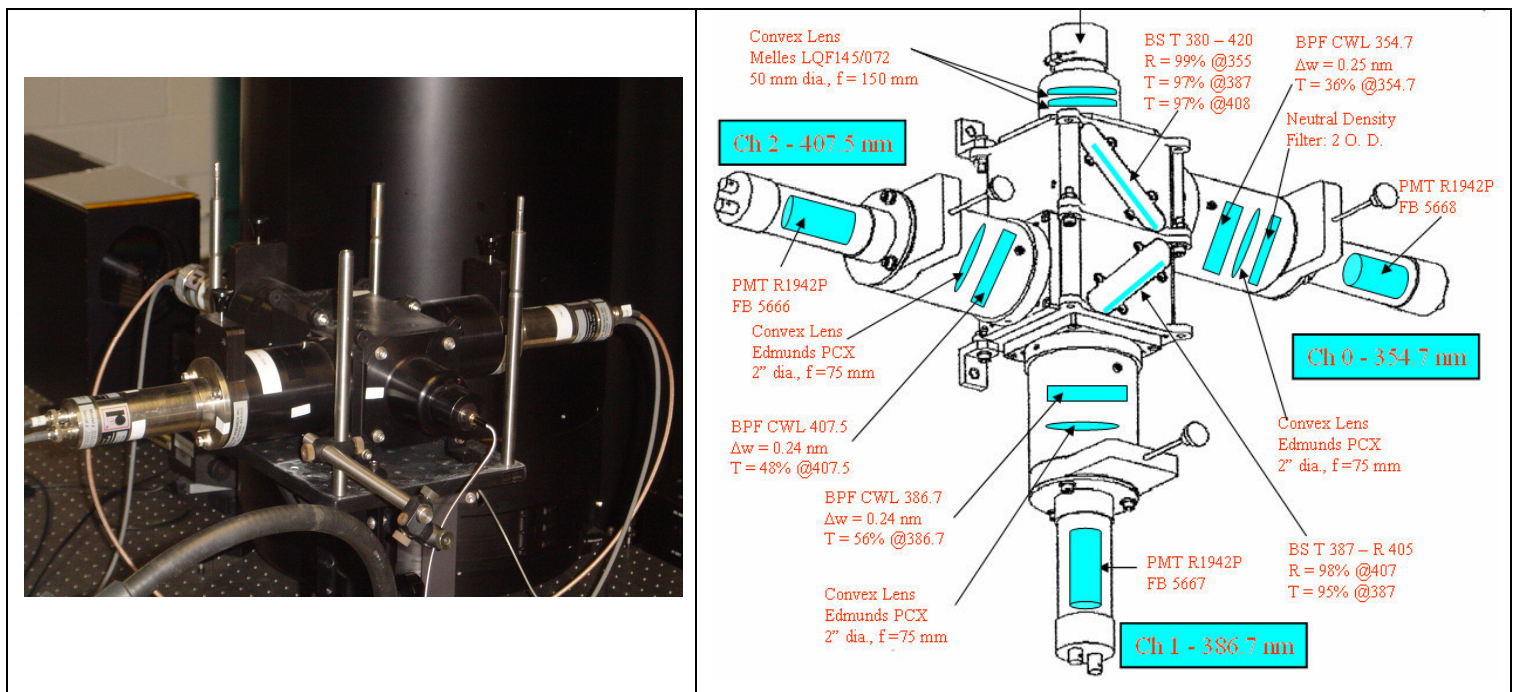

FIGURA 4.2 - Unidade separadora de comprimento de onda (foto à esquerda). Detalhes e especificações de lentes (convex lens), divisores de feixe (BS), filtro de banda passante (BPF) e filtros de densidade neutra e fotomultiplicadoras (PMT) utilizados em cada canal $(\mathrm{CH})$.

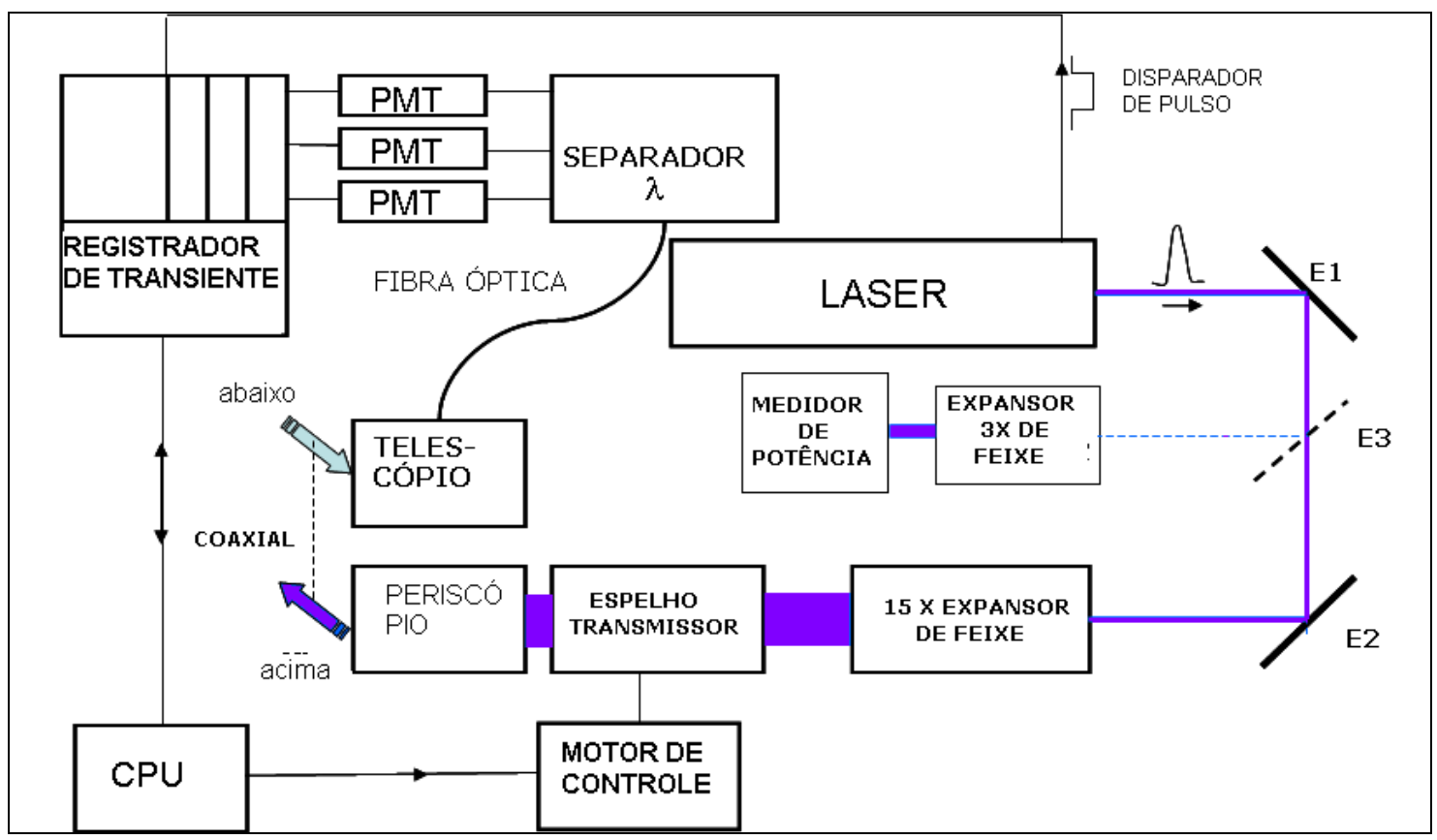

FIGURA 4.3 - Diagrama de blocos do HURL.

Ao se processar os dados do LIDAR, várias correções são aplicadas para se obter melhores resultados. Essas correções incluem correção do tempo de resolução, corrente escura, subtração de ruído de fundo (correção do $r^{2}$ ), correção da função de overlap, correção para a absorção diferencial e correção de efeitos da 
temperatura. Outro tratamento que é realizado nos dados é o procedimento de glue, descrito a seguir.

\subsubsection{Procedimento de "glue" para dados LIDAR}

A combinação dos sinais analógicos (AD) e contagem de fótons (PC) nos permite usar dados analógicos nas regiões de sinais fortes e dados $P C$ nas regiões de sinais fracos [Adam, 2007]. A idéia é formar pares ordenados de dados (AD,PC) em uma região onde ambos são considerados razoavelmente lineares e realizar uma regressão [Adam et al, 2007]. Antes da regressão, os dados em modo contagem de fótons são corrigidos em relação ao efeito "pulse-pileup" [Whiteman, 2003 (I)] assumindo-se um sistema não paralizavel. A regressão determina o coeficiente de ganho que é usado para converter a escala $A D$ em uma escala de contagens de fótons "virtual ". Primeiramente, os coeficientes de glue são determinados perfil por perfil através de regressão (pelo menos 25 pontos são utilizados na regressão) depois de subtração de ruído de fundo. Num segundo passo, os coeficientes médios de glue (para o aerosol, nitrogênio e vapor d'água) são determinados. Alguns critérios estão envolvidos na determinação dos coeficientes médios de glue. Primeiro, somente perfis com um coeficiente de correlação com a regressão $R^{2}$ maior que 0,99 (aerossol), 0,99 (nitrogênio) e 0,97 (vapor d'água) são selecionados. A média e o desvio padrão (STD) são calculados para $R^{2}$. Perfis fora dos limites definidos pela média \pm STD para coeficientes de glue são eliminados. Para os perfis restantes, a média e o STD são computados os coeficientes de glue. Novamente, perfis que estão fora dos limites da média \pm STD para coeficientes de glue são excluídos. O set de perfis restante determina os coeficientes finais médios de glue. Esse procedimento é sempre adotado na análise do sinal LIDAR Raman coletado.

\subsubsection{Lâmpada calibrada de tungstênio e motor de translação}

No visível, infravermelho próximo, uma lâmpada padrão é usada para calibrar a radiação de sensoriamento remoto [Manual Optronics, 2005]. Uma lâmpada halogênea de quartzo (Figura 4.4) de $1000 \mathrm{~W}$, com filamento de tungstênio padrão de irradiância espectral conhecida (OL200M) da Optronics Laboratories, modelo S- 
990 acompanhada de uma fonte OL83A foi utilizada. A calibração é determinada pela resposta dos detectores irradiados por essa fonte de luz. A irradiância espectral da lâmpada é dada em $W / \mathrm{cm}^{2} \mathrm{~nm}$.

A calibração de lâmpadas de tungstênio para irradiância total é baseada na radiação de corpo negro como definida pela lei de Stefan-Boltzman. Para os valores de irradiância total para cada comprimento de onda fornecido pelo manual do fabricante, as incertezas seriam da ordem de $1 \%$. Contudo, um estudo de sensibilidade foi realizado para se verificar o comportamento da lâmpada calibrada como um corpo negro.

Um motor de translação da Arrick X-Y foi usado (Figura 4.5) para instalarmos a lâmpada e permitir a mobilidade da mesma em cada ponto do telescópio (mapeamento).

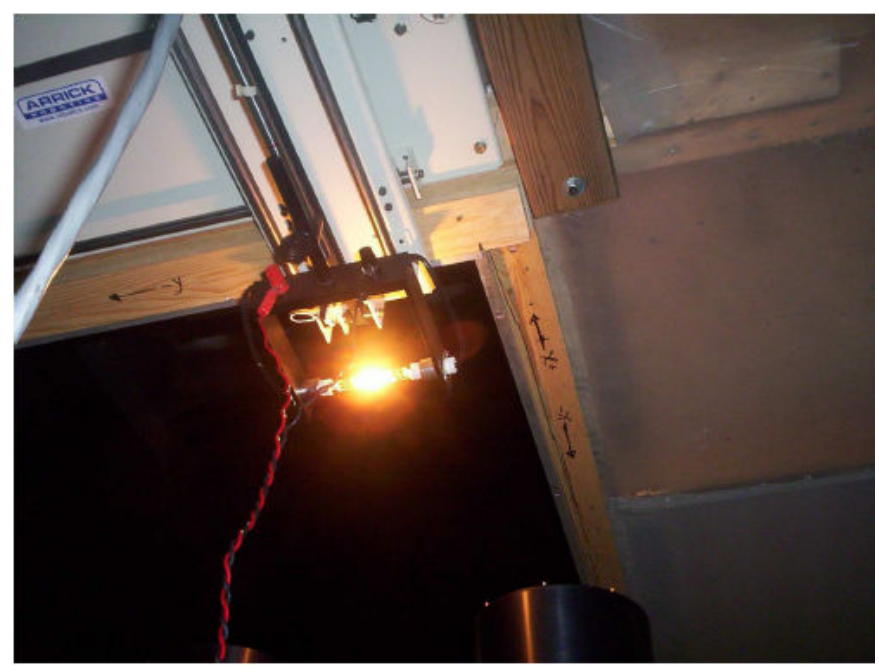

FIGURA 4.4. Lâmpada de tungstênio ligada. 


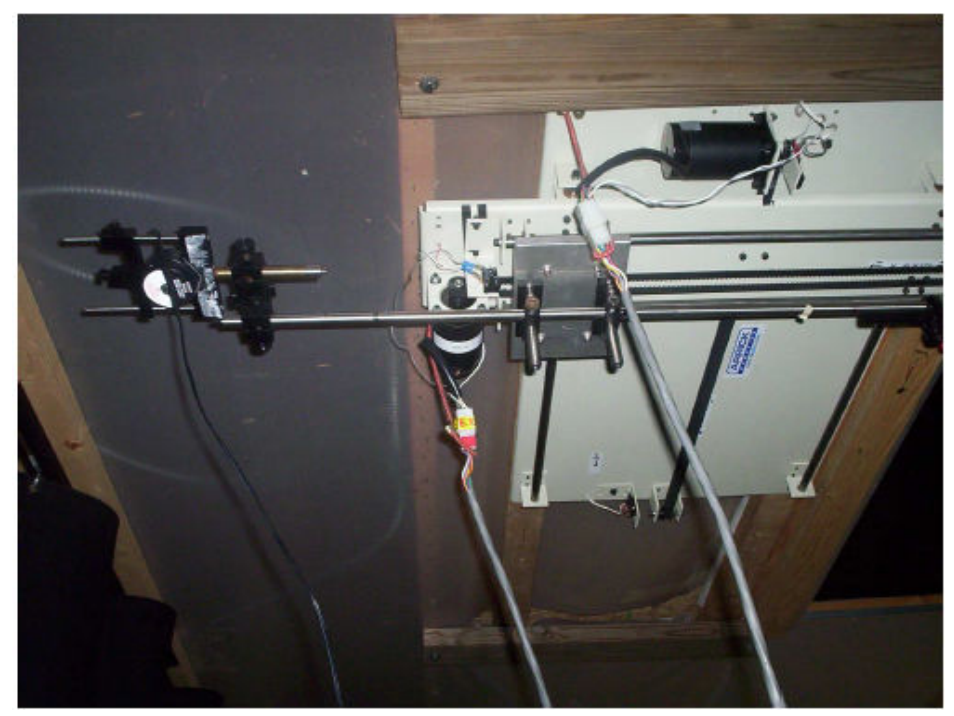

FIGURA 4.5. Motor de translação utilizado para realização do mapeamento do telescópio.

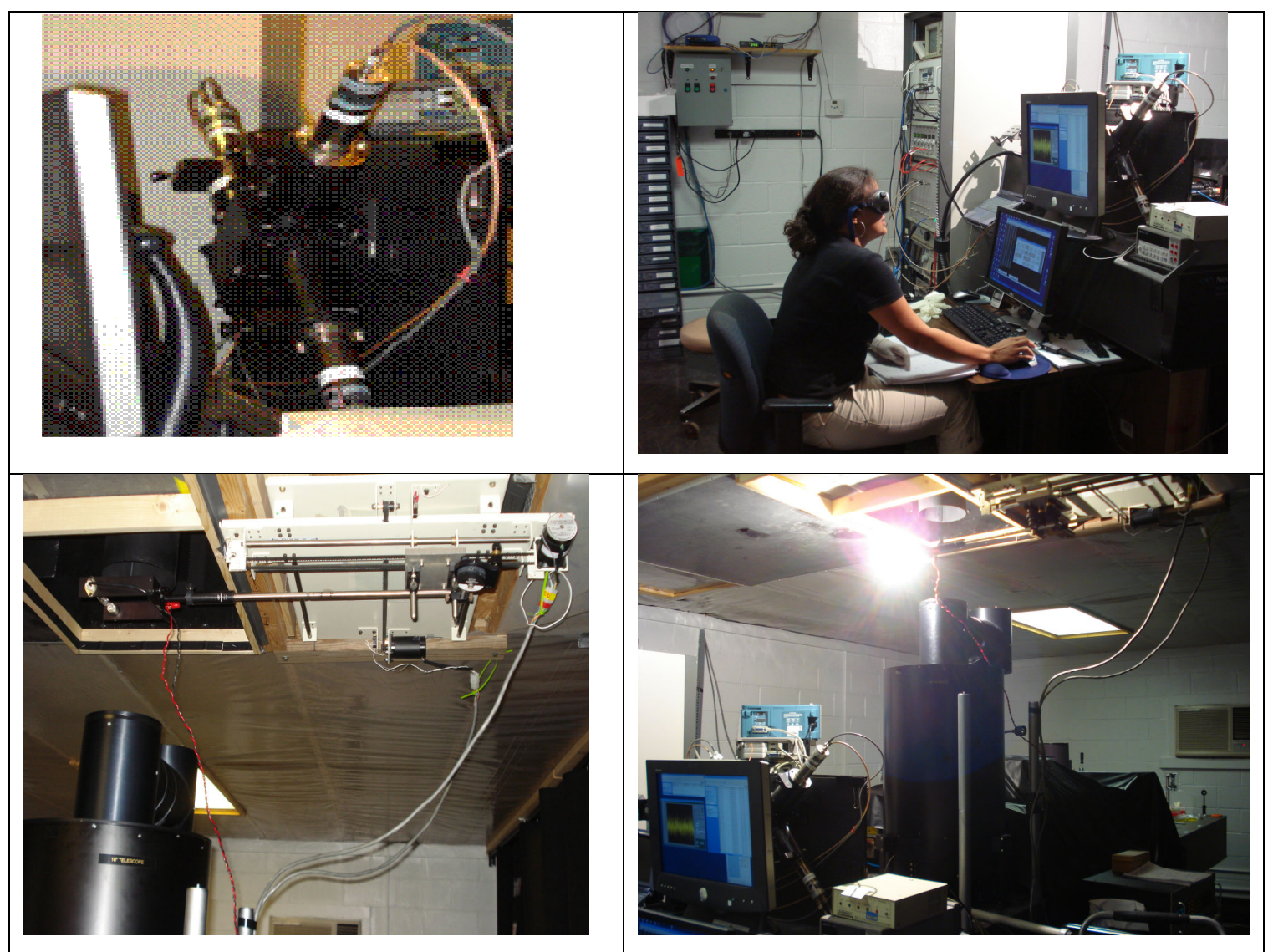

FIGURA 4.6 Montagem do sistema HURL para a calibração com o uso da lâmpada de tungstênio. No alto, à esquerda, unidade separadora de comprimento de onda. $\dot{A}$ direita, sistema de aquisição de dados. Abaixo é mostrado o motor de translação com a lâmpada desligada (à esquerda) e ligada (à direita) em Julho de 2008. 


\subsection{Metodologia de calibração}

Uma análise da equação da razão de mistura do vapor d'água indica que uma calibração absoluta requer conhecimento da razão das transmissões dos canais do vapor d'água e do nitrogênio, a razão das secções diferenciais de espalhamento Raman do nitrogênio e do vapor d'água, a função que descreve a temperatura e a transmissão diferencial. Para melhorarmos o método de calibração, é necessário quantificar a razão das transmissões dos canais LIDAR e a razão das secções diferenciais de espalhamento com acurácia. A razão das eficiências $\xi\left(\lambda_{N}\right) / \xi\left(\lambda_{H}\right)$ pode ser determinada com acurácia com o uso de uma lâmpada de calibração. O conhecimento da razão das secções diferenciais de espalhamento é limitado pelo fato de que a melhor medida de laboratório disponível das secções diferenciais de espalhamento do vapor d'água data de 1976 e tem uma incerteza de 10\% [Penney e Lapp, 1976; Murphy, 1981]. Recentemente [Avila et al,1999, 2003 e 2004 (I e II)] publicaram um modelo para o cálculo das secções diferenciais de espalhamento do vapor d'água que é utilizado no cálculo desse trabalho.

De forma sucinta, o diagrama apresentado na Figura 4.7 ilustra a metodologia empregada para o cálculo do fator de calibração $(k)$ baseado nas equações 3.10 e 3.11 . 


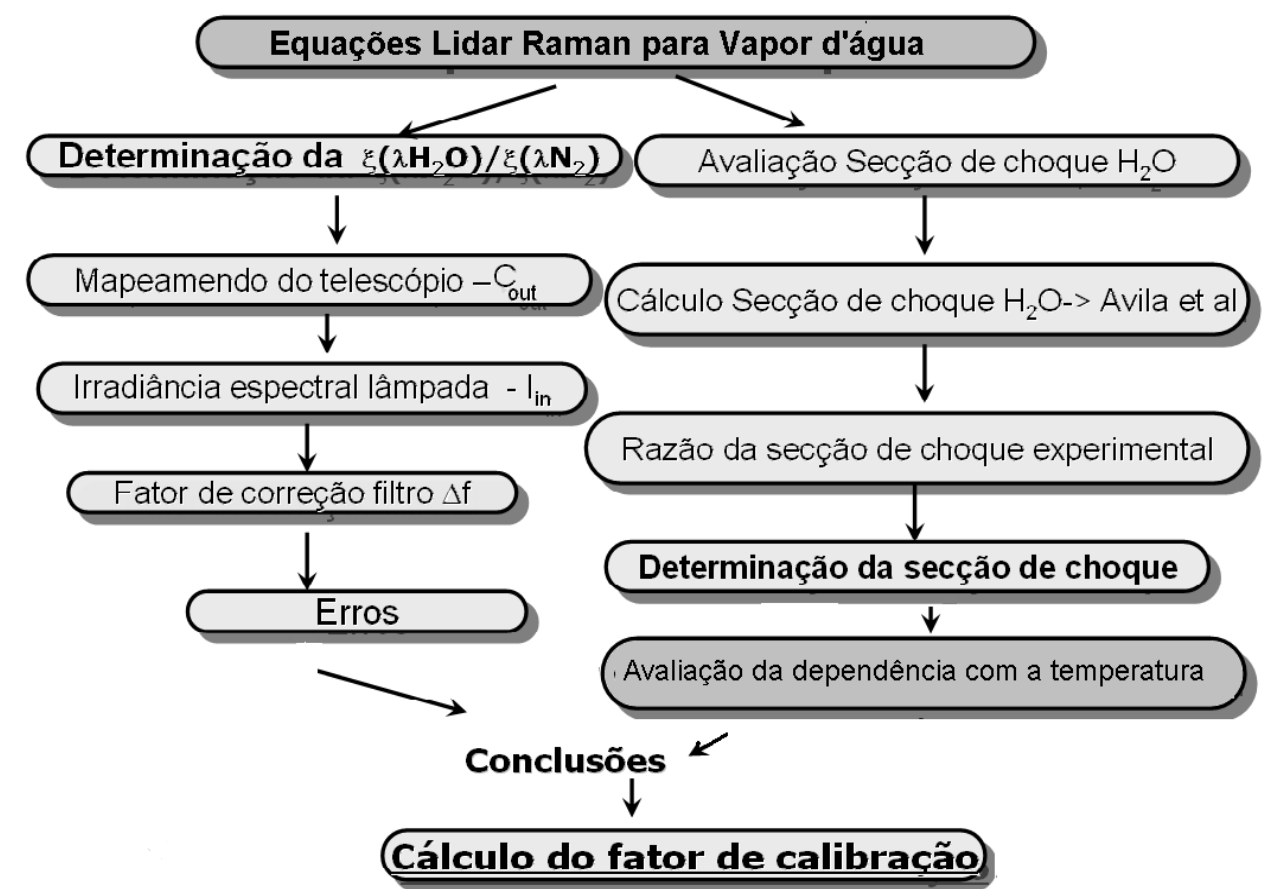

FIGURA 4.7. Diagrama ilustrando a metodologia de calibração do LIDAR Raman de vapor d'água.

No capítulo 5 é apresentado o desenvolvimento de cada etapa do fluxograma acima (lado esquerdo), para o cálculo da razão das eficiências óticas do sistemas, através do mapeamento do telescópio com uma lâmpada calibrada, da avaliação da irradiância espectral da lâmpada, das medidas de transmissão dos filtros de interferência utilizados e dos cálculos das incertezas envolvidas.

No capítulo 6 são apresentados os resultados referentes a determinação da razão das secções diferenciais de espalhamento Raman (lado direito do fluxograma). Isto inclui o modelo teórico escolhido para o cálculo da secção diferencial de espalhamento Raman do vapor d'água e a do nitrogênio e uma estimativa experimental da razão das secções diferenciais de espalhamento. As incertezas são avaliadas e o fator de calibração é calculado descrevendo a última etapa do fluxograma acima. 


\section{CAPÍtULO 5}

\section{DETERMINAÇÃo DA EFICIÊNCIA ÓPTICA DE TRANSMISSÃo}

A eficiência de transmissão ótica $\xi(\lambda)$ descreve a eficiência ótica total do receptor LIDAR a um comprimento de onda laser e inclui fatores como reflectividade do telescópio, transmissão dos componentes óticos, transmissão de qualquer filtro e a eficiência quântica dos detectores. Esse termo é apresentado na equações de LIDAR Raman (capítulo 3) e sua determinação é representada no diagrama de blocos da Figura 3.5.

A razão de eficiência $\xi\left(\lambda_{N}\right) / \xi\left(\lambda_{H}\right)$ pode ser determinada com acurácia através de um experimento com $\mathrm{o}$ uso de uma lâmpada calibrada que obedece $\mathrm{O}$ comportamento de corpo negro, e pela análise da reposta do sistema LIDAR a essa fonte de luz. A equação 3.9 foi definida considerando-se as radiações incidentes da lâmpada calibrada, os perfis de transmissão dos filtros de interferência e densidade neutra e a taxa de contagem coletada pelo detector. Neste caso não é necessário considerarmos secções diferenciais de espalhamento, transmissão atmosférica, função de overlap e dependência com a temperatura, uma vez que foi utilizada uma radiação incidente conhecida.

Alguns testes preliminares foram realizados antes de se obter os resultados de irradiância espectral da lâmpada, taxa de contagem do sistema LIDAR e análise dos filtros. Esses testes consistiam de uma simulação do padrão de intensidade visto pelo detector, e um experimento para se verificar a influência de mudança de altura da lâmpada em relação a taxa de contagem do telescópio. Tais testes são descritos das duas seções subsequentes.

\subsection{Simulação do Padrão de Intensidade - "Ray Trace" com o Rayica}

Para se adquirir mais conhecimento sobre o sistema utilizado, um design do Raman LIDAR da Howard University (HURL) foi simulado com a ferramenta "Rayica" usando capacidades do sofware Mathematica. As capacidades do Rayica abrangem componentes ópticos e traçadores de feixes de luz com precisão. Um sistema compreende um conjunto de componentes ópticos e fontes. Os 
componentes são lentes, espelhos, prismas ou outros objetos ópticos que interagem com os raios. A fonte é uma luz que emite raios. Finalmente, os raios ou feixes carregam informação a respeito de intersecções de superfície, comprimentos de caminho óptico, comprimentos de caminho físico e intensidade de luz [Óptica software, 2006].

A simulação pelo "ray trace" do sistema óptico foi realizada com o intuito de entender qual a influência no padrão de intensidade coletado pelo fotodetector quando mudamos a posição de uma fonte de luz calibrada considerada pontual. As Figuras 5 e 5.1 apresentam o design óptico para o sistema HURL sem inclusão dos filtros de interferência.

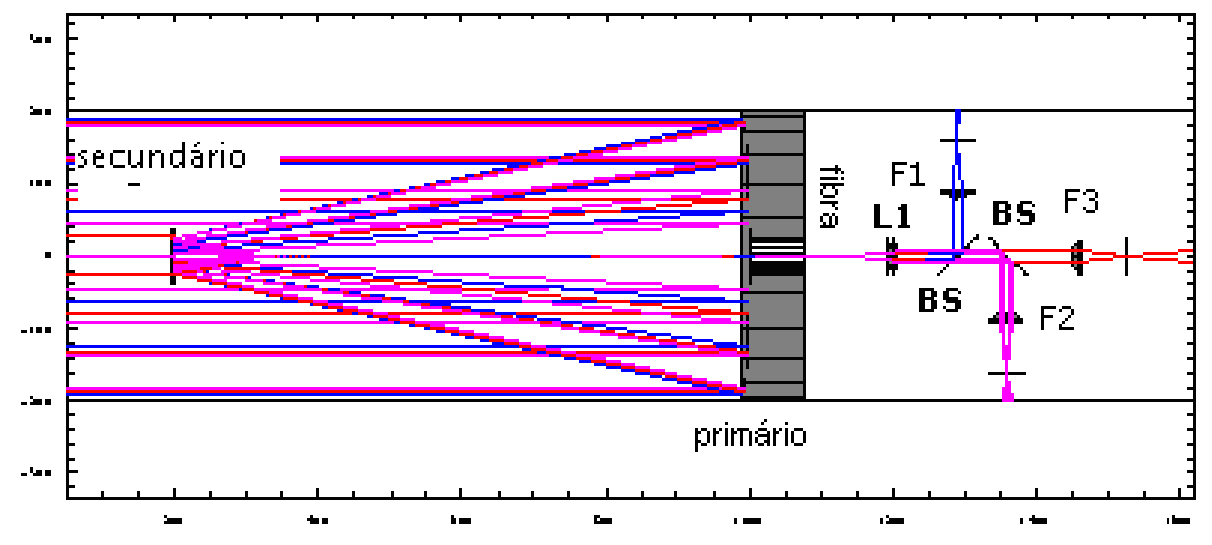

FIGURA 5. Design óptico do sistema HURL e um "ray trace" preliminar, para deteç̧ão de 3 comprimentos de onda diferentes.

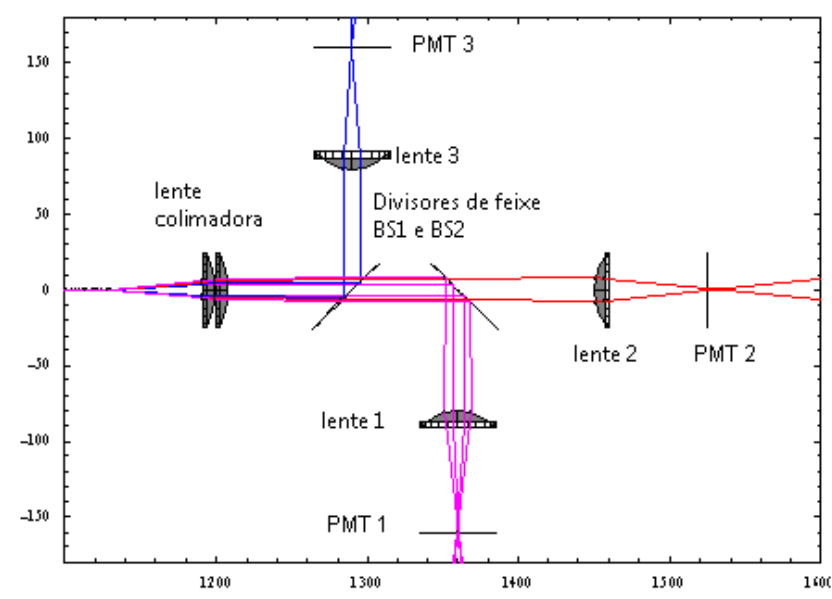

FIGURA 5.1 - Unidade separadora de comprimentos de onda do sistema HURL simulada com o Rayica. 
Uma vez definida a configuração do telescópio, uma fonte de luz simulada foi definida baseada na lâmpada de tungstênio utilizada experimentalmente. Em suma, se deseja ver o padrão de intensidade da lâmpada de tungstênio coletado pela fotomultiplicadora (PMT). Para isso, define-se uma fonte de luz, ( com alguns feixes, para simularmos em tempo razoável) e coloca-se um ponto de observação na posição correspondente a PMT respresentado na Figura 5.1. A posição da lâmpada foi deslocada e uma simulação do padrão de intensidade foi realizada.

Nas Figuras 5.2 e 5.3 são apresentados os padrões de intensidade obtidos para algumas posições da fonte de luz sobre o telescópio, representado na Figura 5.4, simulados com o Rayica. Várias posições da lâmpada sobre o telescópio foram consideradas, e os sinais foram coletados em função disso. 


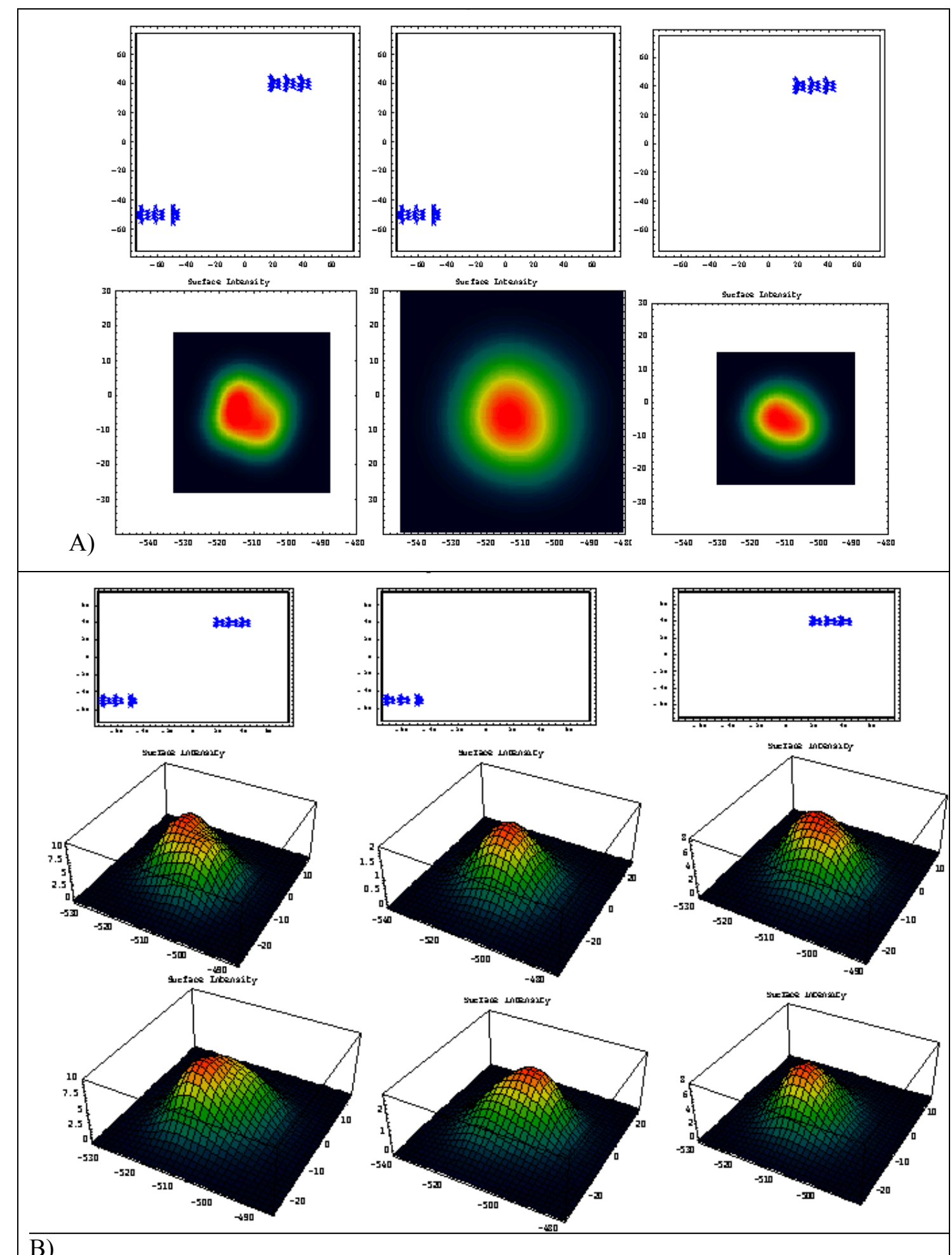

FIGURA 5.2. A) Três situações simuladas (Lâmpada representada por pontos azuis) e respectivos padrões $2 D$ de intensidade e $B$ ) padrões de intensidade $3 D$ para respectivas posições. 
A Figura 5.3 mostra diferentes posições para uma ou mais fontes de luz e o padrão de intensidade simulado pelo Rayica.

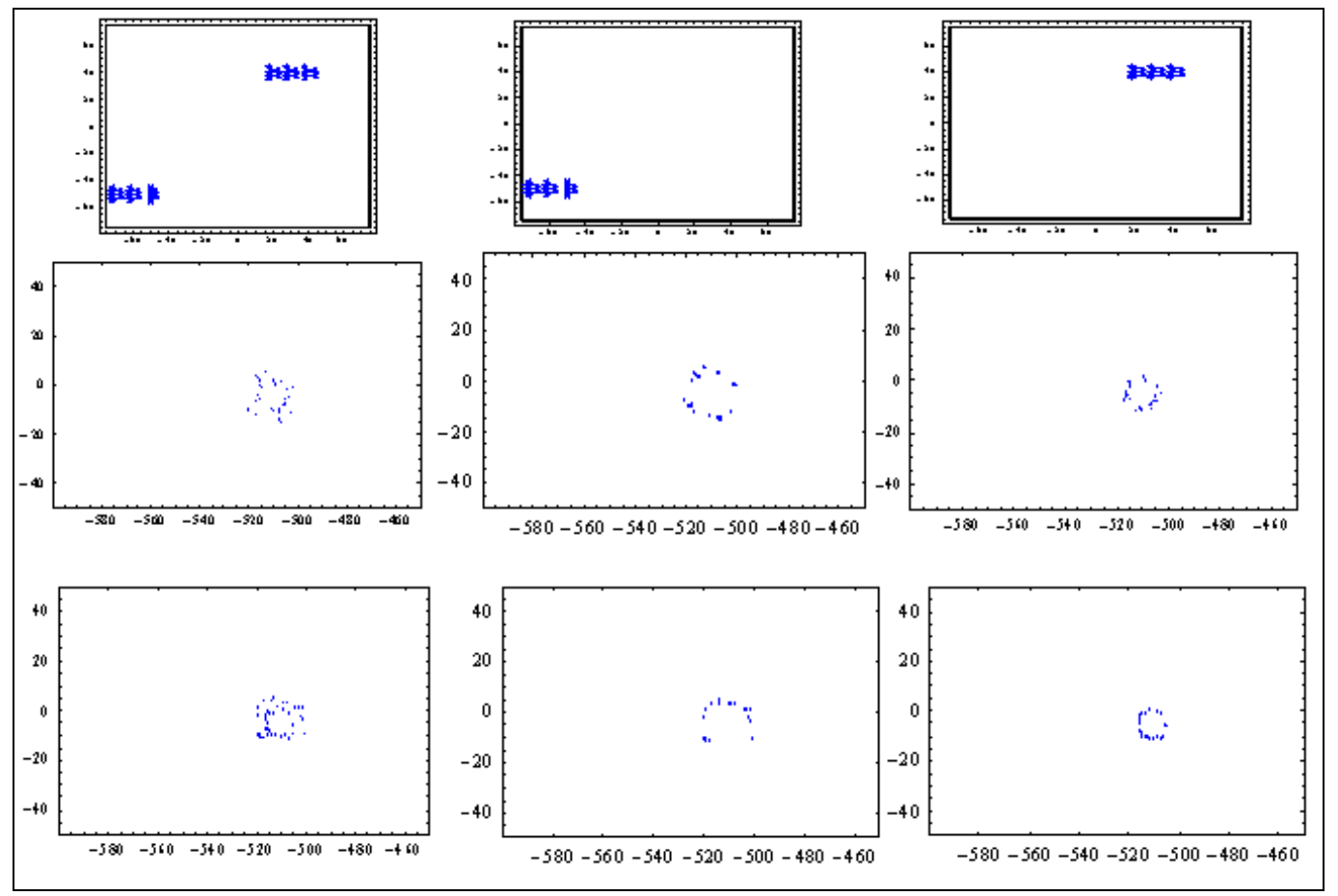

FIGURA 5.3. Tamanho do ponto visto pelo ponto de observação para diferentes posições da lâmpada a $408 \mathrm{~nm}$.
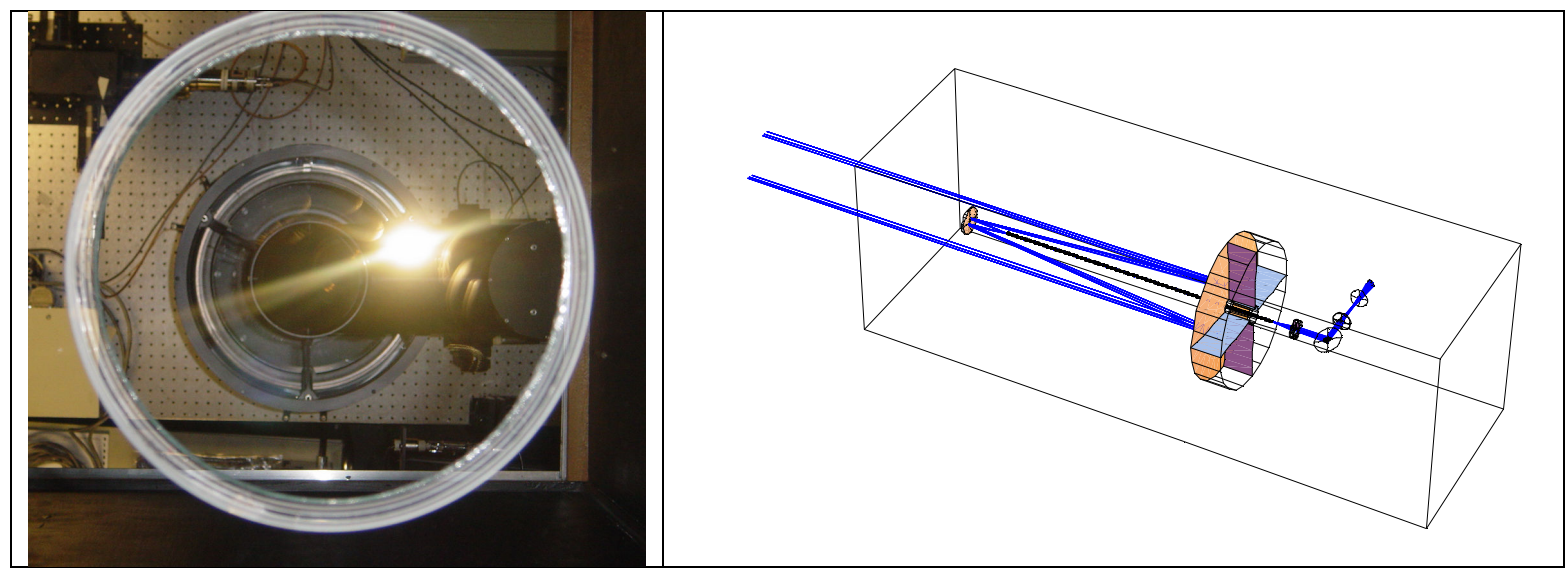

FIGURA 5.4. Topo do telescópio (representação experimental) com a lâmpada à esquerda e simulação do experimento (à direita) com o Rayica considerando duas posições da lâmpada.

O objetivo era tentar estimar a sensibilidade do sistema óptico ao movimento da fonte de luz. Contudo, se fez necessário testar a viabilidade e a confiabilidade do simulador. Uma câmera CCD, modelo LCL-903K Monochrome camera Edmund, foi usada para esse fim. Variou-se a posição da lâmpada sobre a área do telescópio e observou-se os padrões de intensidade mostrados pela CCD. As simulações não 
coincidiam com os padrões observados pela CCD. O software Rayica não se mostra eficiente para simular fibras óticas, apesar de ajudar a entender melhor o sistema óptico, não foi eficiente para simular os padrões de intensidade com a confiabilidade e nível de relevância necessária.

\subsection{Testes preliminares com a lâmpada de tungstênio}

Depois do modelamento com o [Rayica], um experimento preliminar foi realizado. Uma ênfase é dada à sensibilidade do sistema à mudança de distância da lâmpada do telescópio. A Figura 5.5 representa o arranjo experimental onde 3 alturas diferentes para o posicionamento da lâmpada foram escolhidas $(A, B$ e $C)$ na posição centro ou deslocada em relação ao espelho secundário (tabela 7). Uma estimativa da radiação proveniente de ruído e de outras fontes também foi realizada.

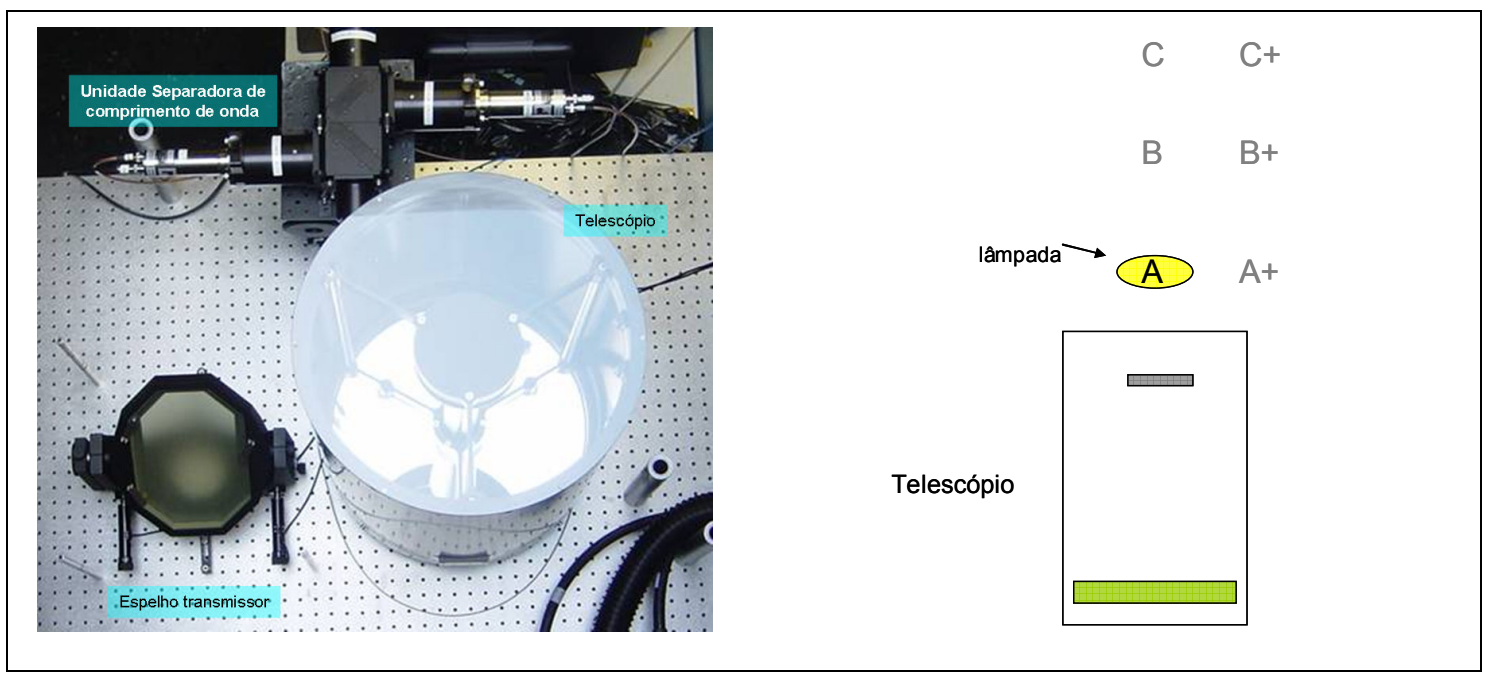

FIGURA 5.5. Arranjo experimental com posições $A, B$ e $C$ da lâmpada e respectivos valores especificados na tabela acima.

TABELA 7. Distâncias da lâmpada em relação ao topo do telescópio.

\begin{tabular}{|c|c|}
\hline Posição & Distância do topo do telescópio \\
\hline A & $43,6 \mathrm{~cm}$ \\
B & $A+25,3 \mathrm{~cm}$ \\
C & $A+43,5 \mathrm{~cm}$ \\
\hline
\end{tabular}


Nas Figuras 5.6 e 5.7 são exibidos os perfis de contagens obtidos para os três canais do sistema HURL para as posições da lâmpada descritas na Figura 5.5. Neste projeto o interesse está em avaliar o número de contagens para os canais $387 \mathrm{~nm}$ e $\sim 408 \mathrm{~nm}$ neste projeto.

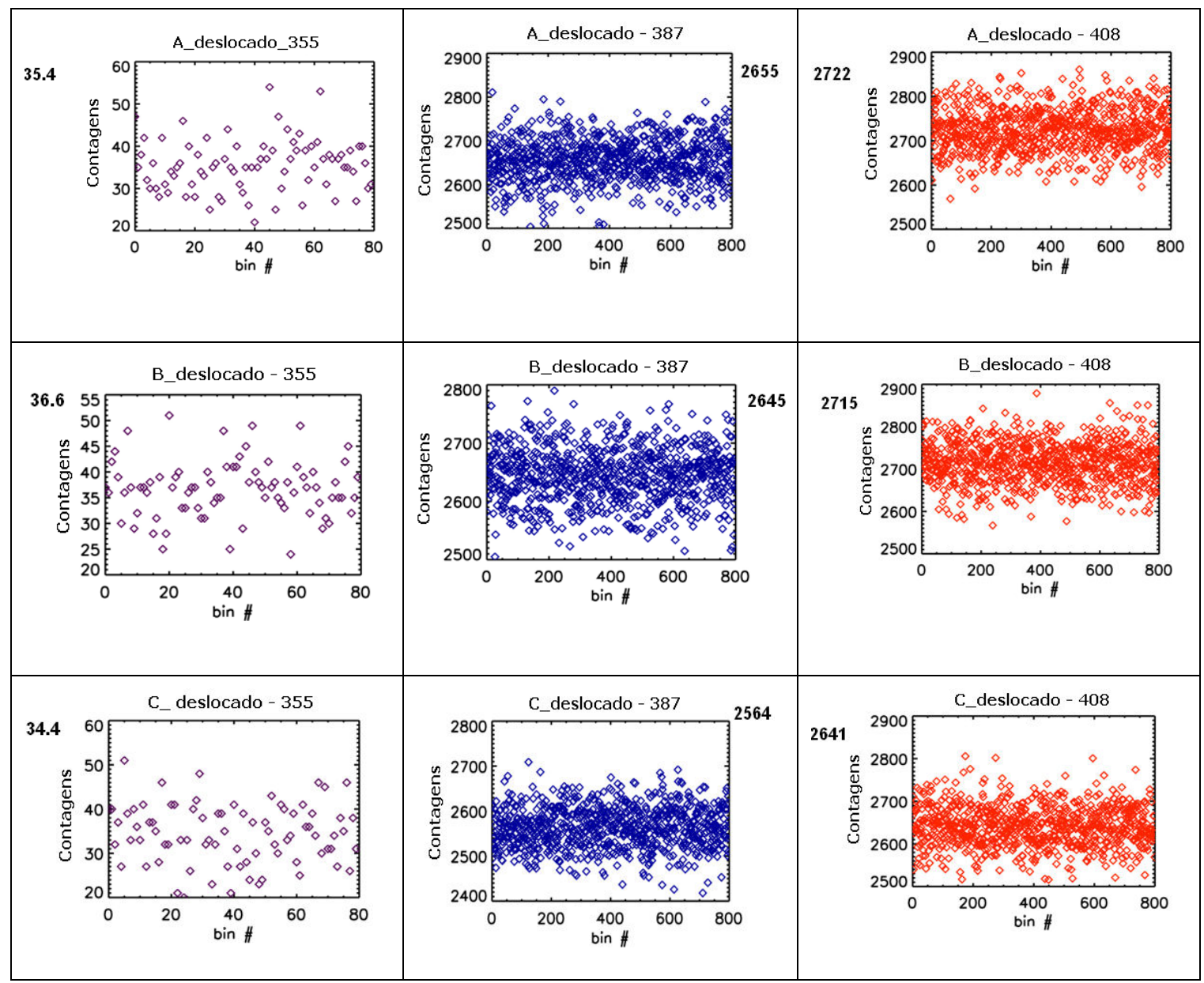

FIGURA 5.6. Contagens medidas para 3 alturas diferentes na posição da lâmpada deslocada segundo figura 5.5. Os valores apresentados no alto ao lado esquerdo das figuras ou ao lado direito no caso das figuras centrais são os valores médios de contagens.

Observa-se que quando a lâmpada está posicionada no centro do telescópio (Figura 5.7), logo acima do espelho secundário, as taxas de contagem caem drasticamente devido ao espelho secundário bloquear a luz incidente da lâmpada de tungstênio. Nota-se um baixo número de contagens no canal de $355 \mathrm{~nm}$, devido a ausência de um filtro de densidade neutra, saturando o detector. 


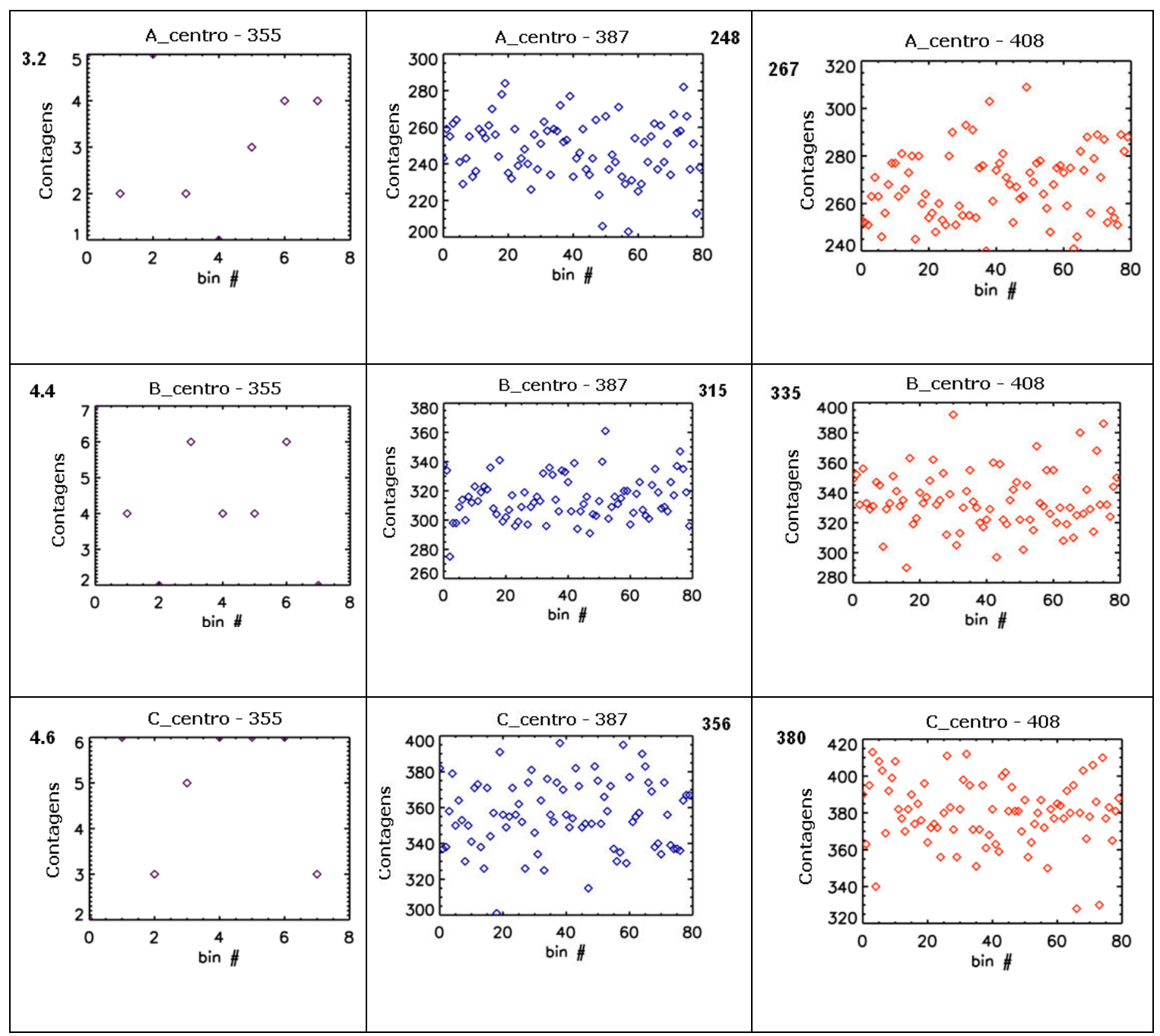

FIGURA 5.7 - Contagens para 3 alturas diferentes da lâmpada em relação ao telescópio na posição centro, ou seja, logo acima do espelho secundário. Os valores ao alto, no lado esquerdo ou direito da figura correspondem as médias de contagens.

De acordo com os erros experimentais (Tabela 8) calculados, nota-se uma independência do valor da intensidade em relação a altura da lâmpada, não seguindo a lei do inverso quadrado. Isso pode ser explicado pelo fato de que a área do detector não é fixa ao variar-se a distância da lâmpada do telescópio, e somente os raios com divergência igual ao campo de vista do telescópio são coletados pela fibra ótica. 
TABELA 8 Taxa de contagem em MHz para diferentes alturas da lâmpada e para 3 comprimentos de onda em $\mathrm{nm}$.

\begin{tabular}{|l|l|c|c|c|c|c|}
\hline & \multicolumn{3}{|c|}{ Centro } & \multicolumn{3}{c|}{ Deslocado } \\
\hline Posição & $\mathbf{3 5 5} \mathbf{~ n m ~ ( \mathbf { 1 0 } ^ { - 4 } )}$ & $\mathbf{3 8 7}$ & $\mathbf{4 0 8}$ & $\begin{array}{c}\mathbf{3 5 5} \mathbf{~ n m} \\
\left(\mathbf{1 0 ^ { - 2 }}\right)\end{array}$ & $\mathbf{3 8 7} \mathbf{~ n m}$ & $408 \mathbf{n m}$ \\
\hline A & $2,1 \pm 0,9$ & $0,16 \pm 0,01$ & $0,17 \pm 0,01$ & $2,3 \pm 0,4$ & $17,3 \pm 0,3$ & $17,8 \pm 0,3$ \\
\hline$B$ & $2,8 \pm 1,2$ & $0,20 \pm 0,01$ & $0,22 \pm 0,01$ & $2,4 \pm 0,4$ & $17,4 \pm 0,3$ & $17,9 \pm 0,3$ \\
\hline$C$ & $3,0 \pm 1,1$ & $0,23 \pm 0,01$ & $0,25 \pm 0,01$ & $2,3 \pm 0,5$ & $17,4 \pm 0,3$ & $18,0 \pm 0,3$ \\
\hline
\end{tabular}

A irradiância espectral da lâmpada é dada em W/cm². Contudo, constatou-se que essa configuração não obedece a lei do inverso quadrado. Por causa disso, não é viável converter a irradiância espectral da lâmpada em taxa de contagens uma vez que não se pode estimar a área efetiva iluminada do detector. Essa conversão seria útil para cálcular perdas dentro do sistema óptico baseado na transmissão dos componentes ópticos.

Nas próximas seções, serão avaliados os termos necessários para calcularmos a razão das eficiências ópticas do HURL através de um experimento de mapeamento.

\subsection{Análise espectral da lâmpada de tungstênio calibrada}

Uma lâmpada halogênea de quartzo de $1000 \mathrm{~W}$, com filamento de tungstênio padrão de irradiância espectral (OL200M) da Optronic Laboratories, modelo S-990 acompanhada de uma fonte OL83A foi utilizada.

Para os valores de irradiância total para cada comprimento de onda fornecido pelo manual do fabricante, as incertezas dadas pelo mesmo são da ordem de $1 \%$. Contudo um estudo foi realizado para se verificar o comportamento de corpo negro da lâmpada. Como mostrado a seguir (Figura 5.8), a lâmpada de tungstênio apresentou um comportamento de "quase corpo negro" devido a função de Planck não coincidir perfeitamente com os valores nominais de irradiância espectral dados pelo fabricante.

Devido a esse comportamento de "quase corpo negro", uma função polinomial foi usada para ajustar os valores de irradiância spectral fornecidos pelo fabricante na faixa de comprimentos de onda do filtro de interferência utilizado. Um estudo de sensibilidade concluiu que uma mudança de $1 \%$ na temperatura da lâmpada pode resultar em $0,5 \%$ de mudança na razão das irradiâncias espectrais 
do vapor d'água e do nitrogênio. Na Figura 5.8 são apresentadas as 3 curvas referentes aos três casos mencionados acima.

Função de Planck a $3220.71 \mathrm{~K}$

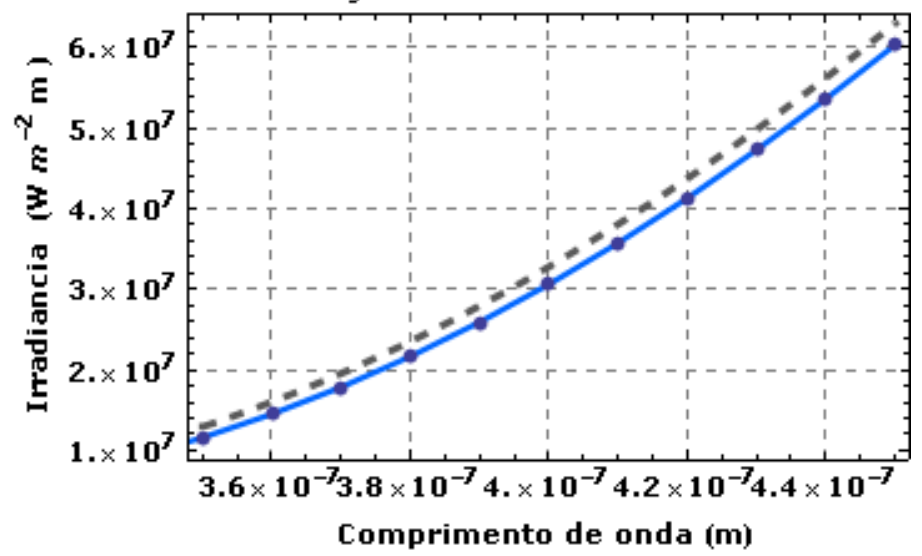

FIGURA 5.8. Função de Planck (linha tracejada) plotada com a curva do fabricante (linha pontilhada) e o ajuste de uma função polinomial (linha contínua) para um "quase corpo negro" a 3220,71 K.

A luz incidente no sistema LIDAR $I_{\text {in }}\left(\lambda_{x}\right)$, calculada a partir da irradiância espectral (L) da lâmpada calibrada extrapolada da curva função de Planck, correspondente ao intervalo do filtro de interferência. Um fator de correção $\Delta f$, foi calculado baseado na área das curvas de transmissão dos filtros. Logo:

$$
\mathrm{I}_{\mathrm{in}}\left(\lambda_{x}\right)=\int_{\lambda_{1}}^{\lambda_{2}} L_{x}(\lambda) \cdot \Delta f(\lambda) d \lambda
$$

\subsection{Caracterização dos filtros de interferência - $\Delta f$}

Duas configurações diferentes de filtro de interferência foram utilizadas: a primeira com filtros de banda estreita, para reduzir a influência da radiação solar sem reduzir substancialmente os sinais de retorno Raman, com centróide a 407,54 $\pm 0,25 \mathrm{~nm}$ e 386,70 \pm 0,25 nm instalados no canal do vapor d'água e nitrogênio respectivamente. A transmissão dos sinais Raman é conhecida por exibir uma dependência de temperatura para esses filtros [Whiteman, 2003 (II)]. A segunda configuração, com o objetivo de se avaliar a razão das secções diferenciais de espalhamento experimental sem a dependência de temperatura, foi instalada utilizando-se filtros de banda larga (largura de banda $\sim 5 \mathrm{~nm}$ para o canal do nitrogênio e $\sim 19 \mathrm{~nm}$ para o vapor d'água). 


\subsubsection{Filtros de interferência de banda estreita}

Filtros de interferência de banda estreita fornecem melhor seleção dos comprimentos de onda em medidas atmosféricas relativas as bandas do vapor d'água e nitrogênio [Bisson, 1999]. Curvas de transmissão foram obtidas do fabricante (Barr Associates) para os filtros com largura a meia altura de 0,25 nm, exibidas na Figura 5.9. A área das curvas foi calculada para se obter o fator de correção definido da equação 5 , usada para corrigir a irradiância espectral da lâmpada.

Um estudo de sensibilidade avaliou as incertezas para essas curvas. Se o centróide é deslocado de $0,05 \mathrm{~nm}$ para a direita, ocorre $0,1 \%$ de mudança na razão $\mathrm{N}_{2} / \mathrm{H}_{2} \mathrm{O}$ de correção do filtro. Se o deslocamento é para a esquerda, a mudança na razão dos fatores é de $0,27 \%$. Essa discrepância é provavelmente devido a assimetria das curvas de transmissão dos filtros.

A)

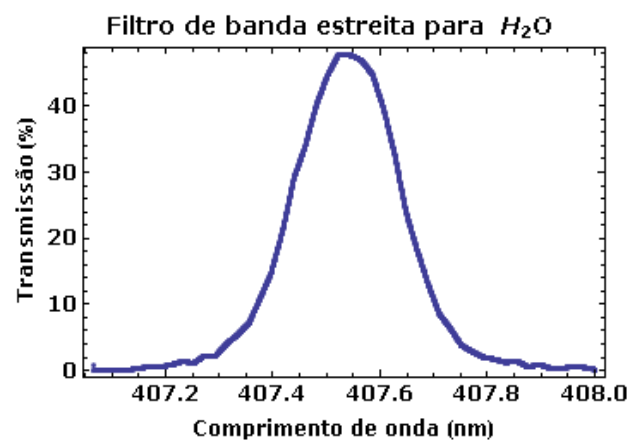

B)

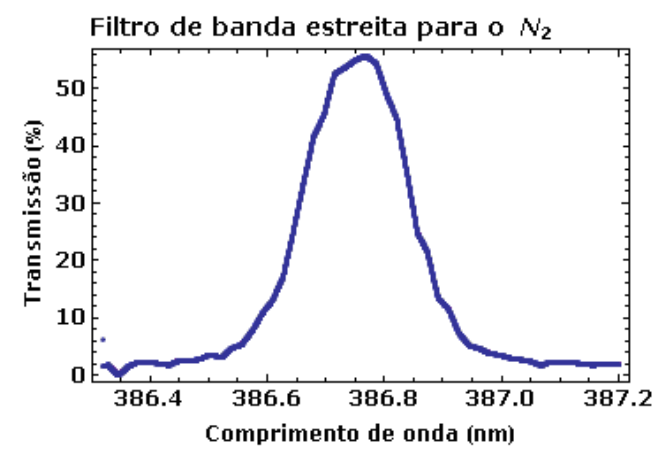

FIGURA 5.9. Curvas de transmissão para os filtros de interferência de banda estreita para o sinal: A) do vapor d'água a 407,54 $\mathrm{nm}$ e B) para o sinal do nitrogênio a $386,7 \mathrm{~nm}$.

\subsubsection{Filtros de interferência de banda larga}

Filtros de banda larga (do fabricante CVI) foram usados para evitar-se a dependência de temperatura das secções diferenciais de espalhamento Raman transmitindo uma maior faixa de comprimentos de onda. Com o uso de filtros de banda larga no HURL, a intensidade de luz é muito maior que na configuração de banda estreita, saturando a fotomultiplicadora. Filtros de densidade neutra são necessários para colocar a taxa de contagem no regime linear e próxima da obtida numa configuração de banda estreita. Baseado na correção "photon pile-up" 
[Whiteman, 2003 (I)], filtros de densidade neutra igual a 2,3 foram escolhidos para o canal do vapor d'água e para o canal do nitrogênio foram utilizados filtros com densidade neutra igual a 2. Assim, mais um filtro é adicionado no cálculo do fator de correção do filtro $\Delta \mathrm{f}$. Um espectrômetro Perkin Elmer Lambda 900 localizado no GSFC-NASA, Maryland, USA foi utilizado para obtenção das curvas de transmissão dos filtros de densidade neutra.

Algumas dificuldades foram encontradas para a determinação de erros envolvidos na transmissão dos filtros pois o espectrômetro usado não forneceu uma incerteza direta. Fatores como manuseio, alinhamento e localização do filtro também são fontes extras de erros. Outro espectrômetro da Varian, modelo CARY D17 foi escolhido devido ao fato de seu fabricante fornecer informações sobre incertezas relacionadas com a resolução do sistema. As curvas obtidas são exibidas na Figura 5.10.

A)

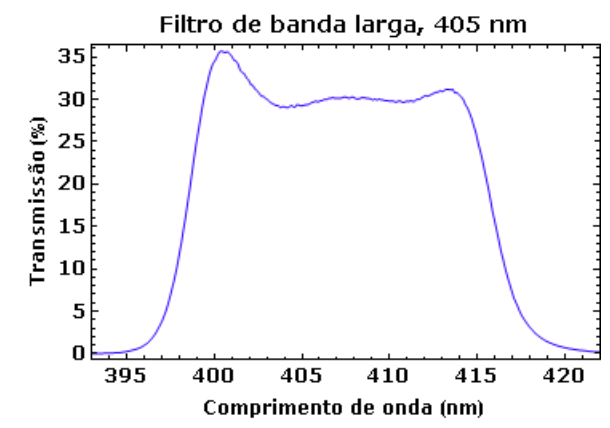

B)

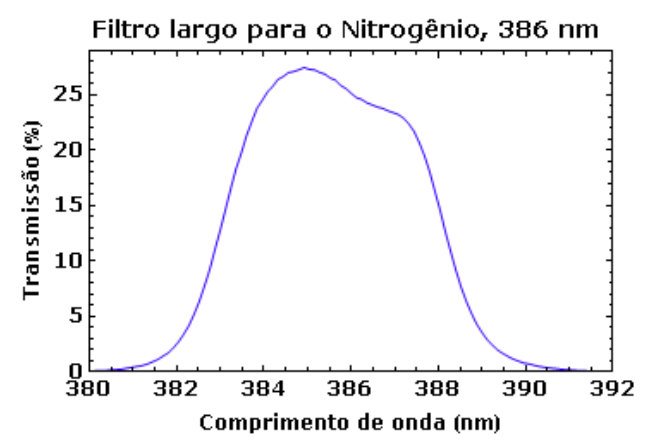

FIGURA 5.10. Curva de transmissão obtida com o CARY D17 para os filtros de banda larga : A) do sinal do vapor d'água e B) para o sinal do nitrogênio.

O erro envolvido (ER) na transmissão afeta a intensidade de luz coletada. Para o erro na transmissão a relação sinal-ruído foi considerada:

$$
E R=\frac{\mathrm{N}}{S} 100
$$

Onde $\mathrm{N}$ é a média da transmissão para a corrente escura no intervalo do filtro de interferência, e S é a média da transmissão obtida no intervalo do filtro. Um erro relativo de $0,04 \%$ foi encontrado para o filtro correspondente ao vapor d'água e de $0,06 \%$ para o filtro do sinal de nitrogênio. 


\subsubsection{Filtros de Densidade Neutra}

Quando filtros de interferência de banda larga são utilizados no sistema HURL, a intensidade da luz é maior que em uma configuração de banda estreita, saturando as fotomultiplicadoras. Logo, um filtro de densidade neutra é necessário para trazer a taxa de contagens a um regime linear e com intensidade de luz proporcional a uma configuração de banda estreita. Filtros de densidade neutra atenuam, dividem ou combinam feixes em uma grande faixa de irradiância sem dependência com o comprimento de onda, tendo vasta aplicação como atenuadores de luz. Uma grandeza importante no que se refere a um filtro de densidade neutra é a densidade óptica $D$, definida como o logarítmo de base 10 da transmitância $T$ recíproca:

$$
\begin{aligned}
& \mathrm{D}=\log (1 / \mathrm{T}) \\
& \mathrm{T}=10^{-\mathrm{D}}
\end{aligned}
$$

Um sistema de contagem não paralizável é um no qual o tempo de resposta $\tau$ é independente do tempo de chegada de contagens adicionais. Ou seja, esse sistema irá fazer uma aproximação para a taxa de contagem máxima conforme a taxa de contagem aumenta [Whiteman, 2003]. Para implementar essa correção de saturação de contagem (também conhecida como "pulse pille-up", deve-se determinar o tempo de resposta eletrônica, o qual para esse sistema é de 5 ns. Para uma taxa de contagem observada de $\mathrm{N}_{\mathrm{m}}$, a fração de tempo durante o qual a unidade de contagem é incapaz de responder a contagens é $\tau \mathrm{N}_{\mathrm{m}}$, pois cada contagem observada produzirá um período de tempo morto. A taxa de contagem medida pode ser expressa como [Whiteman, 2003]:

$$
\mathrm{N}_{\text {real }}=\mathrm{N}_{\mathrm{m} /\left(1-\tau \mathrm{N}_{\mathrm{m}}\right)}
$$

A Figura 5.11 mostra a evolução da taxa de contagens em função do $N_{\text {real }}$ para nosso sistema para 5 ns. 


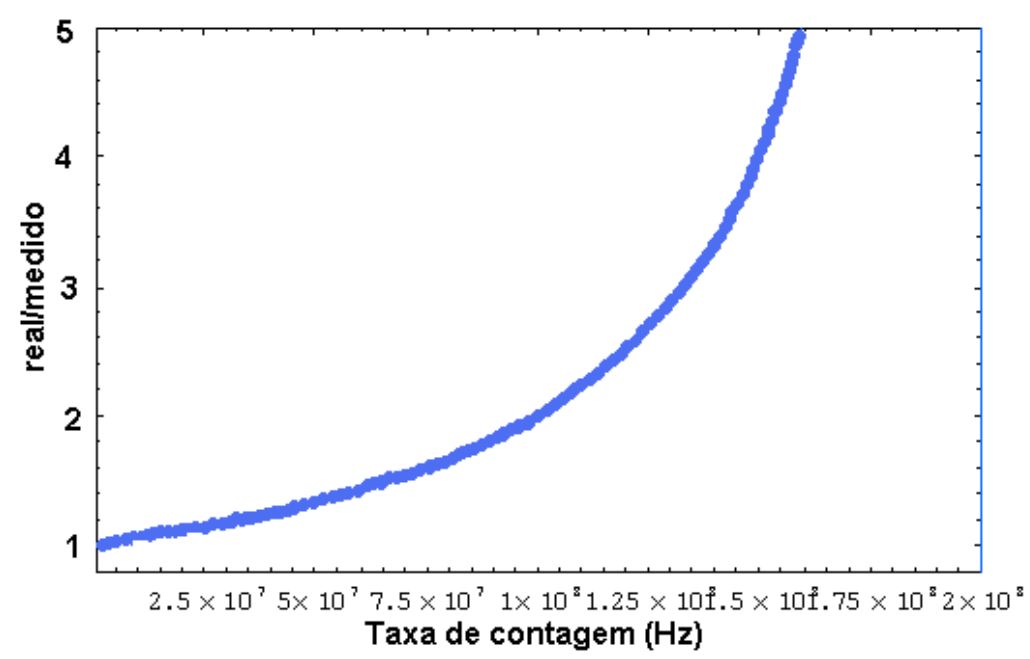

FIGURA 5.11. Taxa de contagem para 5 ns de tempo de integração em função da razão entre a taxa de contagem real e medida.

Para se obter uma diferença de $1 \%$ na razão, é necessária ter uma taxa de contagem em torno de $2 \mathrm{MHz}$. A partir da equação 5.4 para a taxa de contagem de $18 \mathrm{MHz}$ medida, obtem-se um valor de densidade neutra de 0,9. O filtro de densidade neutra vai induzir o regime linear no sistema de contagem.

Um segundo filtro de densidade neutra tem que ser escolhido para certificar que a luz transmitida após o filtro largo e no regime linear terá a intensidade proporcional a medida com um filtro estreito. Para isso, utilizamos a equação 5.3, considerando a transmitância igual a razão da irradiância espectral da lâmpada de tungstênio corrigida por cada filtro (estreito e largo). Estima-se que o filtro deva ter uma densidade óptica em torno de 1,57.

Baseado nos filtros de densidade neutra disponíveis no laboratório, um experimento foi realizado para escolher os filtros com valores de densidade óptica próximos do apresentado acima. Uma descrição desse experimento é apresentada no Apêndice $A$.

Várias técnicas foram empregadas para se obter o perfil de transmissão para esses filtros de densidade neutra disponíveis no laboratório da Howard University. O objetivo era de obtermos um perfil proveniente de uma técnica confiável. O primeiro equipamento utilizado foi um espectrômetro Digikron disponível no GSFC-NASA no laboratório do LIDAR group. Esse espectrômetro apresentou problemas para medidas em comprimentos de onda em torno de $387 \mathrm{~nm}$, impossibilitando-se a 
extração de perfis para esse filtro. Contudo, os perfis para os filtros de vapor d'água $(\sim 407 \mathrm{~nm})$ foram viáveis.

O segundo equipamento utilizado foi um espectrômetro Perkim Elmer 900, que forneceu perfis mais otimistas e sem correções a serem realizadas pois são calibrados automaticamente, apresentados abaixo. Figura 5.12 mostra os perfis de densidade neutra dos nossos filtros em função do comprimento de onda.
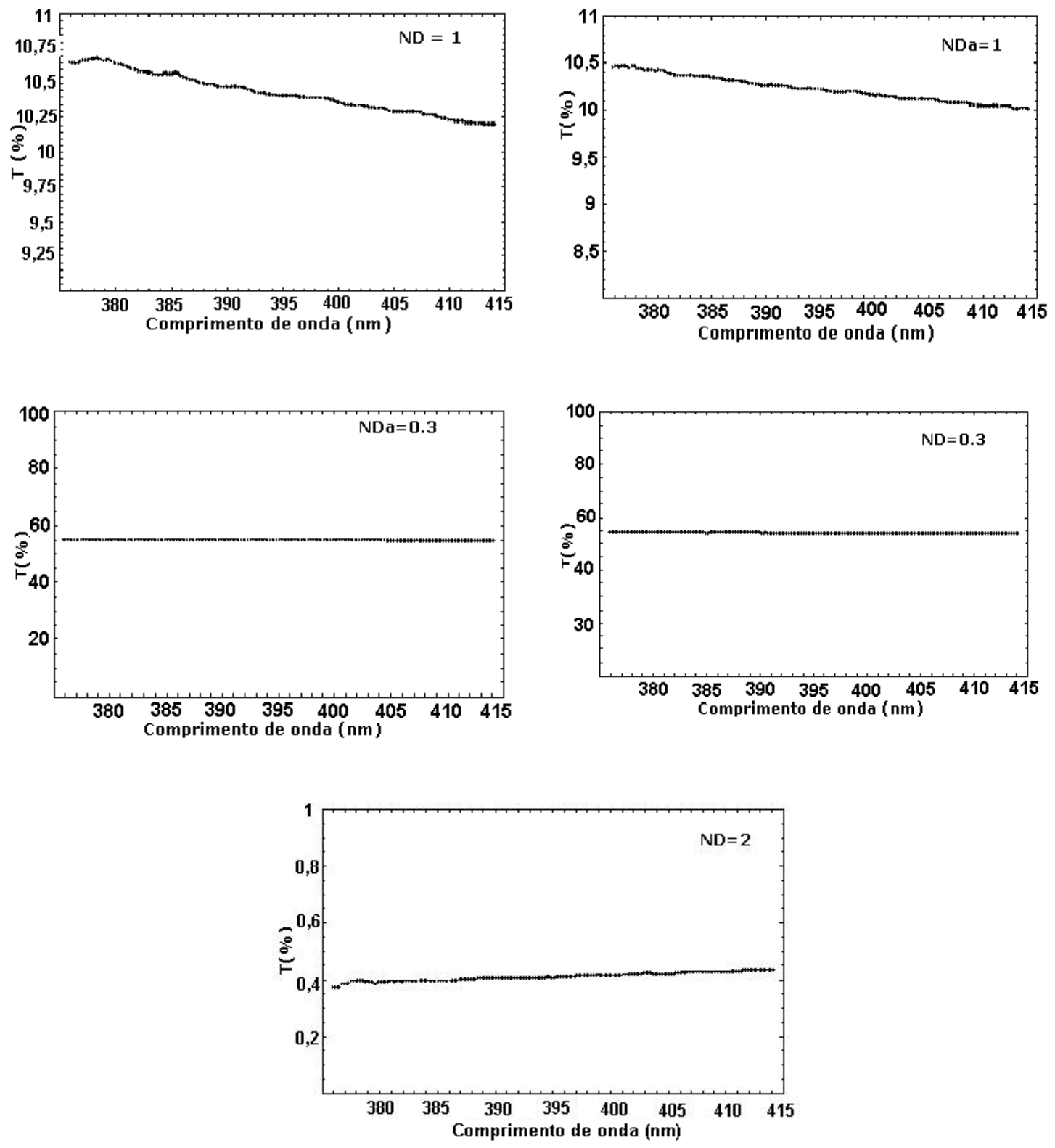

FIGURA 5.12. Perfis dos filtros de densidade neutra utilizados, medidos pelo espectrômetro Perkim Elmer 900.

Uma comparação entre os valores médios de transmissão obtidos pelo método descrito no apêndice A e no espectrômetro Perkim Elmer é apresentada na 
Tabela 9. Para nossos cálculos dentro da metodologia de calibração do HURL , consideramos os valores obtidos pelo Perkim Elmer. O valor de transmissão correspondente ao comprimento de onda do centróide do filtro de interferência foi utilizado para calcularmos a eficiência óptica do sistema.

TABELA 9. Comparação entre a transmissão maxima obtida por dois métodos: com o espectrômero e com o sistema LIDAR. No experimento feito com o LIDAR (Apêndice A), dois sets de dados foram obtidos, um somente coletando fótons em uma única posição da lâmpada e outro com a média de fótons coletados em 5 posições diferentes da lâmpada de tungstênio sobre o telescópio utilizada no experimento.

\begin{tabular}{|ccccc|}
\hline Canal & $\begin{array}{c}\text { Densidade } \\
\text { optica }\end{array}$ & $\begin{array}{c}\text { T\% Perkim } \\
\text { Elmer }\end{array}$ & $\begin{array}{c}\text { T\% pelo LIDAR (anexo } \\
\text { A) }\end{array}$ & $\begin{array}{c}\text { T\% média do LIDAR em } \\
\text { 5 posições diferentes }\end{array}$ \\
\hline $\mathrm{N}_{2}$ & 1 & $10,31 \pm 0,02$ & 11,43 & 12,62 \\
\hline $\mathrm{N}_{2}$ & $1^{*}$ & $10,31 \pm 0,02$ & 11,49 & 12,96 \\
\hline $\mathrm{H}_{2} \mathrm{O}$ & 0,3 & $55 \pm 0,01$ & 62,13 & 57,45 \\
\hline $\mathrm{H}_{2} \mathrm{O}$ & $0,3^{\prime}$ & $54,11 \pm 0,02$ & 57,40 & 55,22 \\
\hline $\mathrm{H}_{2} \mathrm{O}$ & 2 & $0,42 \pm 0,01$ & 0,49 & 0,49 \\
\hline
\end{tabular}

\subsection{Mapeamento do telescópio}

Um mapeamento da area do telescópio foi realizado para determinar-se a homogeneidade de resposta do sistema HURL. Esse experimento consistiu na mudança da posição da lâmpada de tungstênio calibrada sobre a área do telescópio com o auxílio de um motor de passo, coletando dados relativos a taxa de contagens com o registrador de transientes (Licel, Gmbh) no modo contagem de fótons, por 10 segundos em cada posição dessa matriz X,Y (Figura 5.13). A área do espelho primário do telescópio foi dividida em células. Uma célula pode ser definida como uma posição em cima do telescópio com coordenadas $(X, Y)$. O tamanho da célula escolhido foi de $(25 \mathrm{~mm} \times 25 \mathrm{~mm}$ ) baseado em testes preliminares que mostraram que essa resolução era satisfatória o suficiente para observamos os efeitos de borda. O experimento foi realizado para as duas configurações, com filtros de interferência de banda larga e filtros de banda estreita.

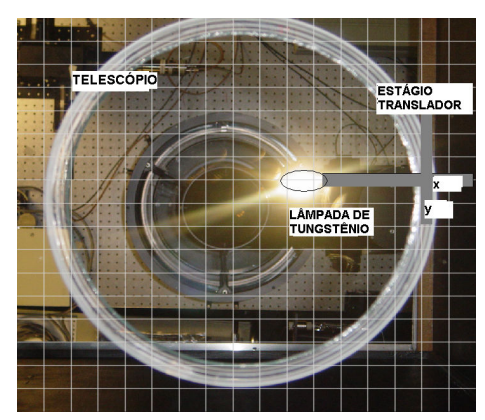

FIGURA 5.13. Esquema do mapeamento experimental. A lâmpada em cima da área dos espelhos primário e secundário. As células são representadas pelos quadrados. 


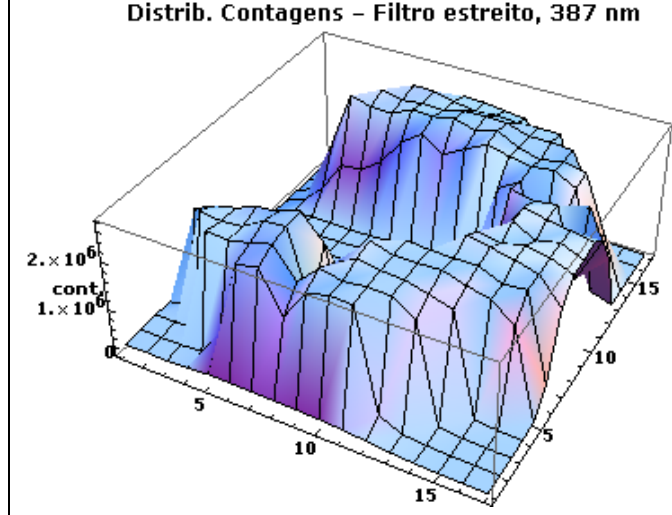

A)

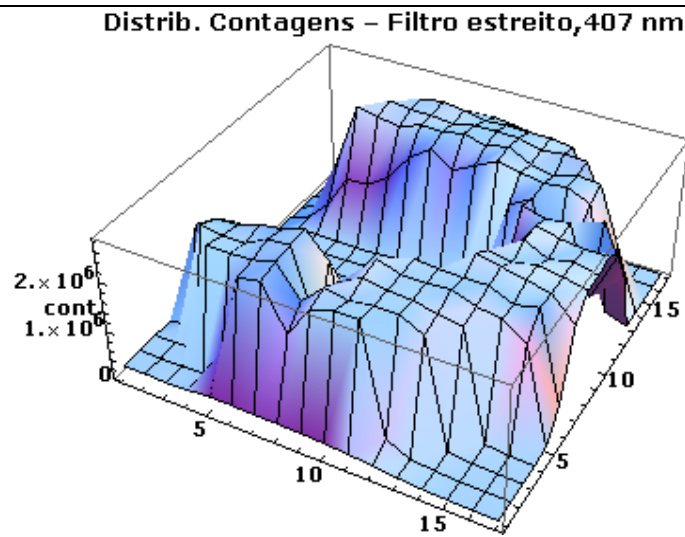

C)

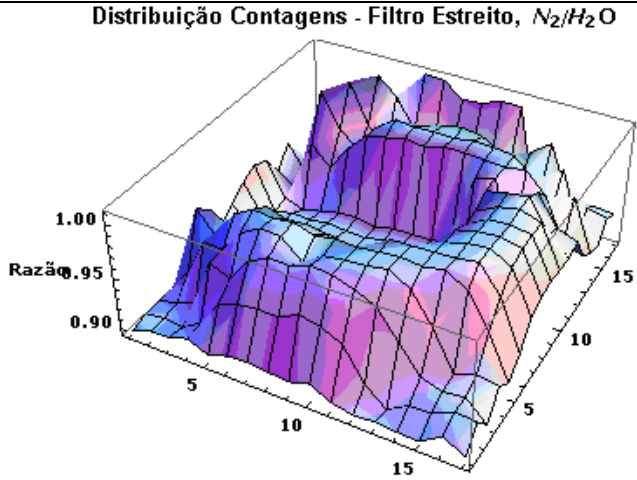

E)

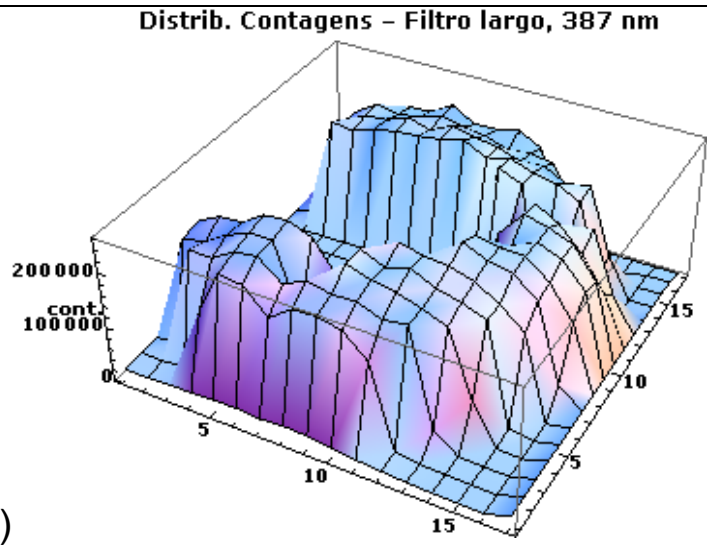

B)

D)

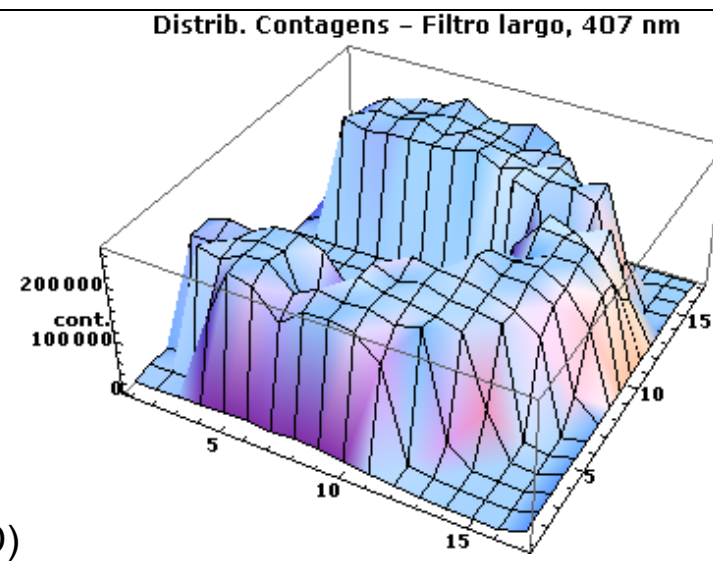

F)

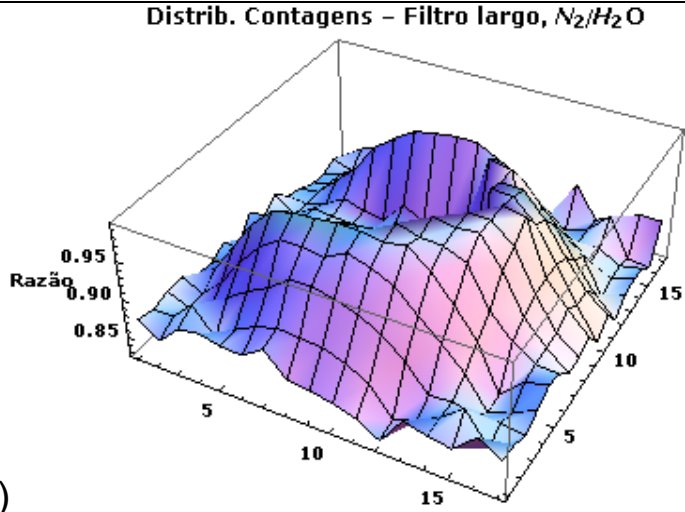

FIGURA 5.14. Distribuição $3 D$ de contagens $A$ ), C), E) para a configuração de filtro estreito e $B), D), F)$ para os filtros de banda larga, obtidos através do mapeamento do telescópio.

Nas Figuras 5.14 é exibida a distribuição de contagens. Nota-se que a taxa de contagem é maior sobre a área exposta do espelho primário. As maiores incertezas foram obtidas nas bordas do telescópio e sobre a área do periscópio. 
Para o cálculo do erro em uma posição particular (célula) no telescópio (janela temporal), utilizamos a soma de contagens de todos os bins (ou canais), pois o sistema Licel digitaliza os dados acumulando contagens em partições de 8000 bins separados. A partir daí calculamos o desvio padrão.

Os resultados deste experimento indicaram que as bordas do telescópio e a região sobre o periscópio mostraram uma aparente diminuição da eficiência enquanto que a área que exibe o sinal "verdadeiro" coletado mostrou uma aparente boa homegeneidade. A Tabela 10 apresenta as faixas de valores dos erros relativos encontrados para os mapeamentos realizados.

TABELA 10 . Incertezas calculadas para o mapeamento.

\begin{tabular}{ccc}
\hline & $\begin{array}{c}\text { Incertezas para a } \\
\text { configuração com filtro } \\
\text { estreito }\end{array}$ & $\begin{array}{c}\text { Incertezas para a configuração com } \\
\text { filtro largo }\end{array}$ \\
\hline$\sigma_{\mathrm{N}_{2}}$ & 17,38 & 426,87 \\
\hline$\sigma_{\mathrm{H}_{2} \mathrm{O}}$ & 17,19 & 444,06 \\
\hline$\sigma_{\text {razão }} \mathrm{N}_{2} / \mathrm{H}_{2} \mathrm{O}$ & $0,081 \rightarrow \underline{8,1 \%}$ & $0,003 \rightarrow \underline{0,3 \%}$ \\
\hline
\end{tabular}

Para efeitos de cálculo de eficiência óptica do sistema, utilizamos a razão do número de contagens, após uma seleção da área do telescópio, excluindo-se bordas e região do periscópio. $\mathrm{Na}$ Tabela 11 abaixo são apresentados os resultados após a seleção para ambas as configurações filtro largo e estreito.

TABELA 11. Resultados de contagens em cada canal, obtidas através do experimento de mapeamento, para as duas configurações de filtros de interferência.

\section{Canais}

\begin{tabular}{|c|c|c|c|c|c|c|}
\hline \multirow[t]{2}{*}{ Canais } & \multicolumn{3}{|c|}{$\begin{array}{l}\text { Contagens } \\
\text { (filtro } \\
\text { estreito) }\end{array}$} & \multicolumn{3}{|c|}{$\begin{array}{c}\text { Contagens } \\
\text { (filtro largo) }\end{array}$} \\
\hline & Min. & Max. & Média & Min & Max. & Média \\
\hline $\mathrm{N}_{2}$ & 3,17 & 346,53 & 148,52 & 2415 & 256182 & 101188 \\
\hline $\mathrm{H}_{2} \mathrm{O}$ & 3,23 & 349,50 & 151,07 & 2761 & 267312 & 109959 \\
\hline $\mathrm{N}_{2} / \mathrm{H}_{2} \mathrm{O}$ & 0,90 & 1,01 & 0,95 & 0,83 & 0,99 & 0,89 \\
\hline $\begin{array}{ll}\mathrm{N}_{2} / \mathrm{H}_{2} \mathrm{O} & \text { com } \\
\text { seleçãa } & \\
\end{array}$ & 0,91 & 1,01 & $\underline{0,98}$ & 0,84 & 0,99 & $\underline{0,92}$ \\
\hline
\end{tabular}

Finalmente, a partir da equação para o cálculo da razão das eficiências (equação 3.54) e com os valores obtidos e apresentados neste capítulo, calculamos as mesmas para as duas configurações de filtros de interferência:

$$
\xi(\lambda) \mathrm{N}_{2} / \xi(\lambda) \mathrm{H}_{2} \mathrm{O} \text { filtro largo+ filtros } \mathrm{ND}^{=}=0,47
$$




$$
\xi(\lambda) \mathrm{N}_{2} / \xi(\lambda) \mathrm{H}_{2} \mathrm{O} \text { filtro estreito }=1,23
$$

Esses valores vão nos ajudar a calcular o coeficiente de calibração. No próximo capítulo abordaremos a obtenção das razões das secções diferenciais de espalhamento Raman que são mais um parâmetro para o cálculo do coeficiente de calibração.

\subsubsection{Mapeamento do telescópio em Julho de 2008}

Em Julho de 2008 um novo mapeamento foi realizado na superfície do telescópio da Howard University com algumas diferenças na configuração do experimento. $\mathrm{O}$ objetivo dessa medida era avaliar a eficiência do sistema com filtros de intereferência largos instalados mas com uma mudança nos filtros de densidade neutra (foram usados filtros $\mathrm{ND}=2,6 \mathrm{em}$ ambos os canais para simplificar a estimativa da eficiência ). Na figura 5.16 e 5.17 são exibidos os resultados obtidos. 


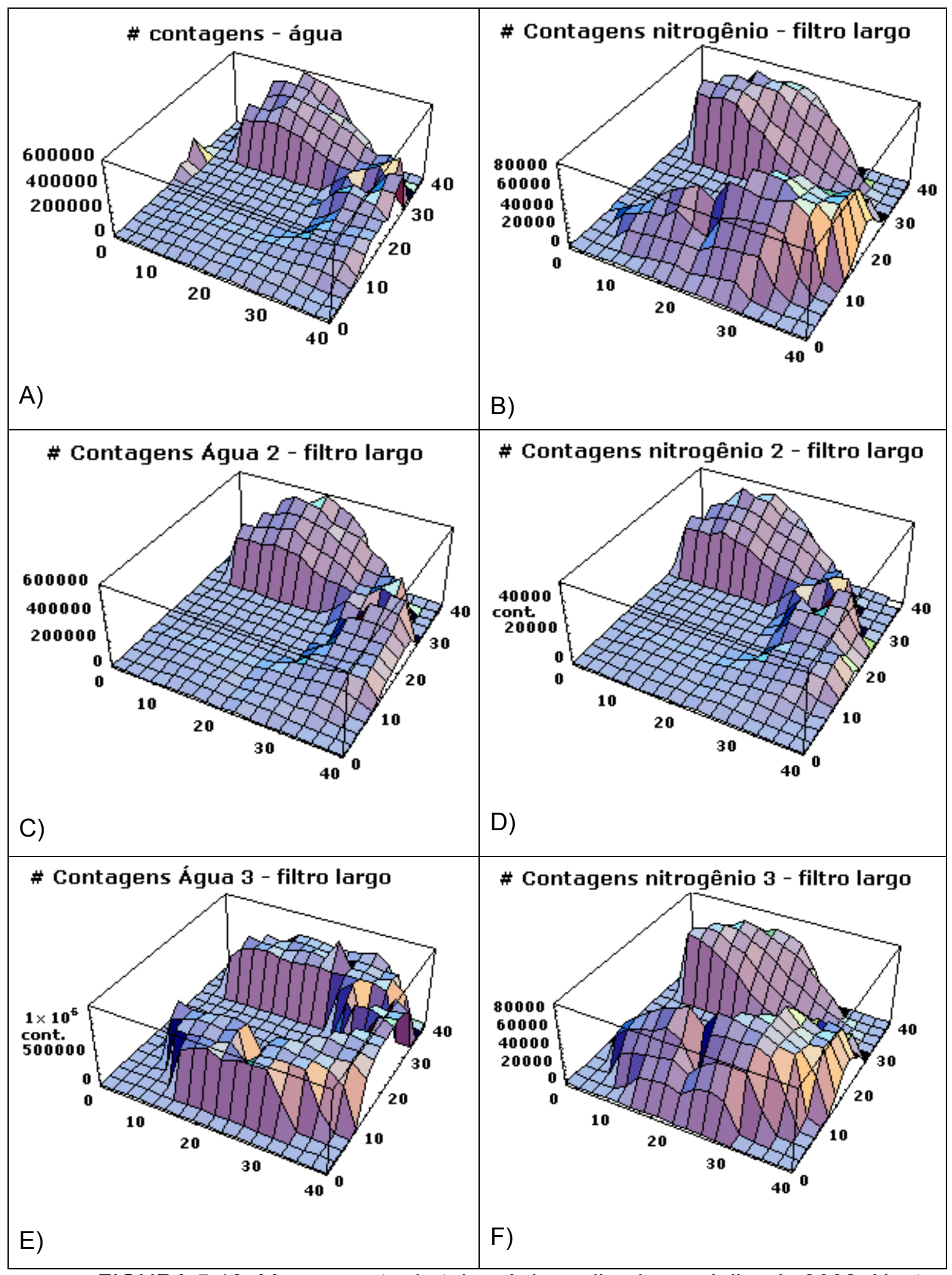

FIGURA 5.16. Mapeamento do telescópio realizado em Julho de 2008. Neste experimento o mapeamento de cada canal foi realizado independentemente, isto é, as leituras de sinal relativas ao vapor d'água $(A, C$ e $E)$ não foram obtidas simultaneamente com as do canal do nitrogênio $(B, D, F)$. 


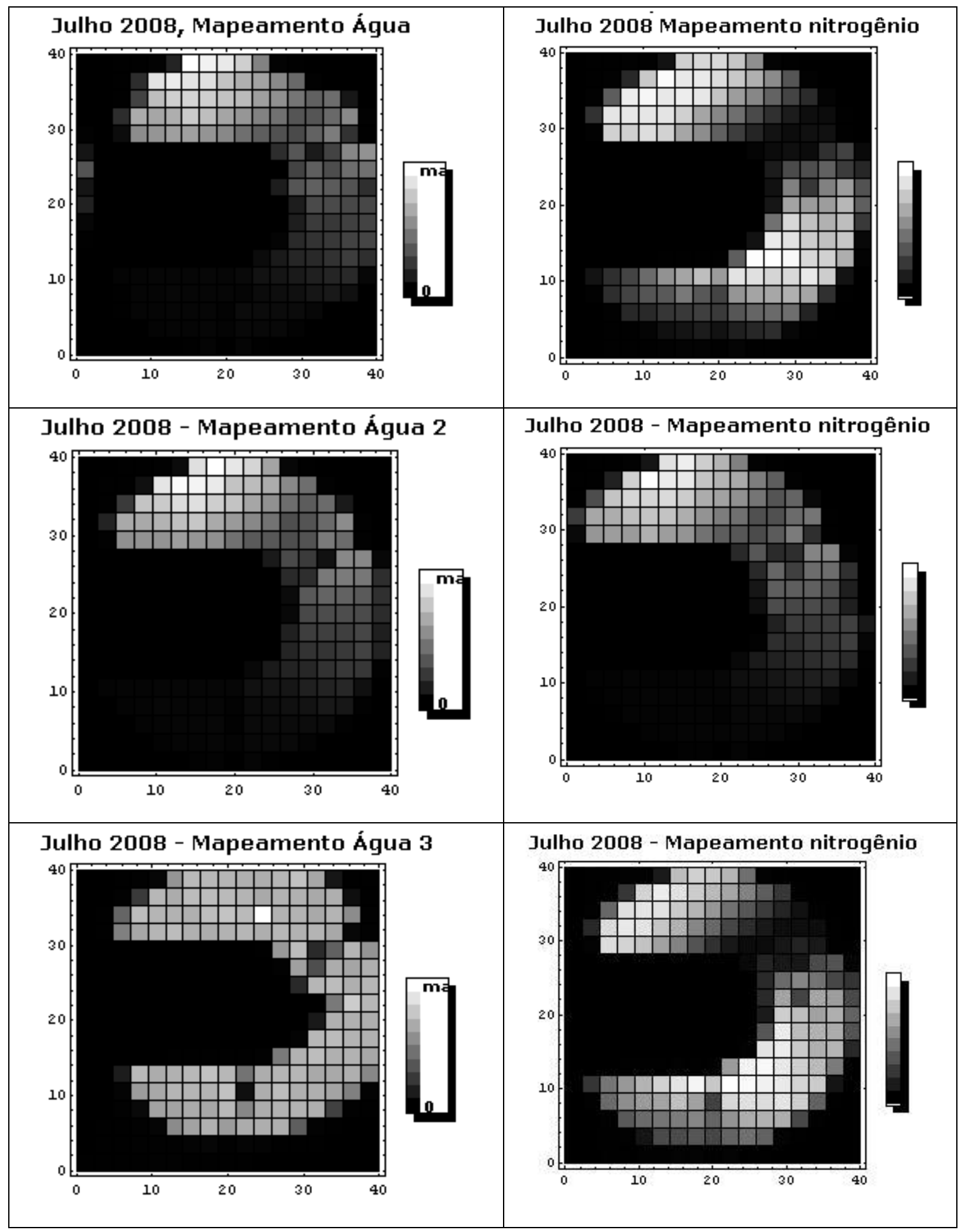

FIGURA 5.17. Superfície do mapeamento do telescópio obtido em Julho de 2008 para os canais de vapor d'água e nitrogênio utilizando filtros de banda larga e filtros de densidade neutra $N D=2,6 \mathrm{em}$ ambos os canais.

As tabelas 12, 13 e 14 exibem os resultados desse experimento. 
TABELA 12 - Taxa de contagens máxima, mínima e média (com 16000 bins por canal em média) para cada um dos 6 mapeamentos realizados em Julho 2008.

\begin{tabular}{|l|c|c|c|}
\hline \multicolumn{1}{|c|}{ Canal } & Max. & Min. & Média \\
\hline Nitrogênio 1 & 84630 & 15 & 20698,7 \\
\hline Nitrogênio 2 & 50172 & 3 & 7641,52 \\
\hline Nitrogênio 3 & 86018 & 28 & 22983,8 \\
\hline Água 1 & 590205 & 45 & 92353,2 \\
\hline Água 2 & 589765 & 51 & 92492,6 \\
\hline Água 3 & $1,2610^{6}$ & 20,93 & 358111 \\
\hline
\end{tabular}

TABELA 13 - Razão das taxas de contagens do nitrogênio/vapor d'água. Leia-se $N$ - canal de nitrogênio e $A$ - canal de vapor d'água.

\begin{tabular}{|l|l|l|l|l|l|l|l|l|l|}
\hline Razão & $\begin{array}{l}\boldsymbol{A 1} \\
\text { Max. }\end{array}$ & $\begin{array}{l}\boldsymbol{A 1} \\
\text { Min. }\end{array}$ & $\begin{array}{l}\boldsymbol{A 1} \\
\text { média }\end{array}$ & $\begin{array}{l}\boldsymbol{A 2} \\
\text { Max. }\end{array}$ & $\begin{array}{l}\boldsymbol{A 2} \\
\text { Min. }\end{array}$ & $\begin{array}{l}\boldsymbol{A 2} \\
\text { média }\end{array}$ & $\begin{array}{l}\boldsymbol{A 3} \\
\text { Max. }\end{array}$ & $\begin{array}{l}\boldsymbol{A 3} \\
\text { Min. }\end{array}$ & $\begin{array}{l}\text { A3 } \\
\text { média }\end{array}$ \\
\hline $\boldsymbol{N 1 x}$ & $\mathbf{0 , 1 4}$ & 0,33 & $\mathbf{0 , 2 2}$ & $\mathbf{0 , 1 4}$ & 0,29 & $\mathbf{0 , 2 2}$ & $\mathbf{0 , 0 7}$ & 0,72 & $\mathbf{0 , 0 6}$ \\
\hline $\boldsymbol{N 2 x}$ & 0,09 & 0,67 & 0,08 & 0,0851 & 0,06 & 0,08 & 0,04 & 0,14 & 0,02 \\
\hline $\boldsymbol{N 3 x}$ & $\mathbf{0 , 1 5}$ & 0,62 & $\mathbf{0 , 2 5}$ & $\underline{\mathbf{0 , 1 5}}$ & 0,55 & $\mathbf{0 , 2 5}$ & $\mathbf{0 , 0 7}$ & 1,34 & $\mathbf{0 , 0 6}$ \\
\hline
\end{tabular}

TABELA 14 - Razão das taxas de contagens nitrogênio e vapor d'água após uma selecão das áreas com maior número de contagem efetiva e da escolha de 4 perfis de razão dos 9 realizados.

\begin{tabular}{|l|l|l|l|c|}
\hline perfil & Média $\mathbf{H}_{\mathbf{2}} \mathbf{O}$ & Média $\mathbf{N}_{\mathbf{2}}$ & $\begin{array}{l}\mathbf{N}_{\mathbf{2}} / \mathbf{H}_{\mathbf{2}} \mathbf{O} \\
\text { média }\end{array}$ & Erro $\sigma_{\text {razão }} \mathbf{N}_{\mathbf{2}} / \mathbf{H}_{\mathbf{2}} \mathbf{O}$ \\
\hline $\mathrm{N} 1 \mathrm{~A} 1$ & 393994 & 56357,1 & 0,14 & $0,44 \%$ \\
\hline $\mathrm{N} 3 \mathrm{~A} 1$ & 404857 & 53623,1 & 0,13 & $0,06 \%$ \\
\hline $\mathrm{N} 3 \mathrm{~A} 2$ & 393740 & 540885 & 0,14 & $0,24 \%$ \\
\hline $\mathrm{N} 1 \mathrm{~A} 2$ & 382784 & 56608,8 & $\underline{\mathbf{0 , 1 5}}$ & $0,66 \%$ \\
\hline
\end{tabular}

Os perfis obtidos com o mapeamento não foram satisfatórios. Possíveis causas:

- A lâmpada de tungstênio não estava funcionando corretamente (ela desligou algumas vezes e a corrente não estava estável);

- Depois do primeiro mapeamento realizado (Agua 3) a configuração do sistema foi alterada ( retiramos os filtros ND) para medirmos vapor d'água atmosférico à noite. Muitos insetos entraram no telescópio e foi necessário "aspirarmos" o telescópio;

- Os filtros ND podem ter sidos deslocados de sua posição original nos mapeamentos subsequentes.

De acordo com a Tabela 2 as razões médias obtidos estão em torno de 0,24 e após uma seleção baseada na área efetiva (tabela 14) obtivemos uma razão de $\sim 0,15$ e são menores que as obtidas com dados anteriores $(\sim 0,91)$. Por essa razão escolhemos os dados obtidos com o mapeamento anterior e que apresentou razão mais próxima de 1 . 


\section{CAPÍTULO 6}

\section{DETERMINAÇÃO DA SECÇÃO DIFERENCIAL DE ESPALHAMENTO RAMAN}

\subsection{Secção Diferencial de espalhamento Raman teórica}

O uso de filtros estreitos (largura a meia altura menor que $1 \mathrm{~nm}$ ) em sistemas LIDAR leva-nos a considerar a dependência de temperatura das linhas do rotacional puro Raman bem como das linhas vibracionais-rotacionais dos canais de nitrogênio e vapor d'água, permitindo a transmissão de somente uma parte dos sinais [Sherlock et al, 1999; Whiteman, 2003(I e II); Adam et al, 2007]. Os coeficientes de retroespalhamento molecular são dependentes de temperatura e não levam em conta essa dependência podendo produzir medidas errôneas em sistemas que empregam filtros estreitos.

Nas figura 6 B) e 6.1 A) são exibidos perfis de secções diferenciais de espalhamento para o vapor d'água sem e com convolução com a eficiência do filtro de transmissão respectivamente. A figura 6.1 B) apresenta a função de dependência com a temperatura calculada. 


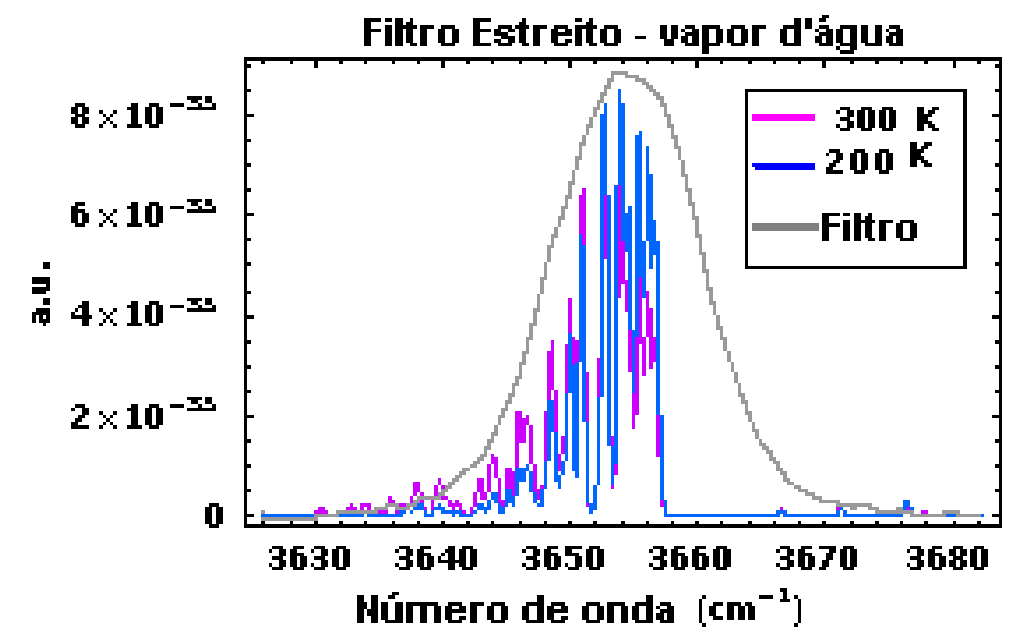

A)

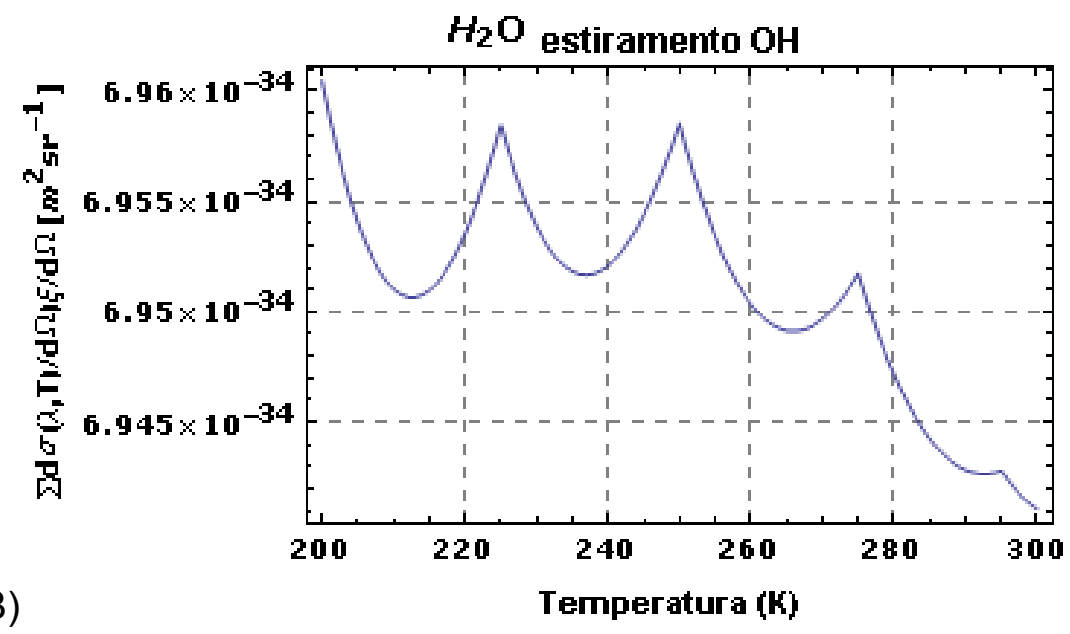

FIGURA 6. A)Representação do espectro Raman para a região de estiramento $\mathrm{OH}$ do vapor d'água simulada a 2 temperaturas, 200 e $300 \mathrm{~K}$. Uma representação do filtro de interferência de banda estreita $\sim 0,25 \mathrm{~nm}$, quando excitado a 354,7 nm, centrado a 407,53 $\mathrm{nm}$ utilizado para detecção do vapor d'água. O eixo y está em unidades arbitrárias. B) Somatória da secção diferencial de espalhamento Raman do vapor d'água. 

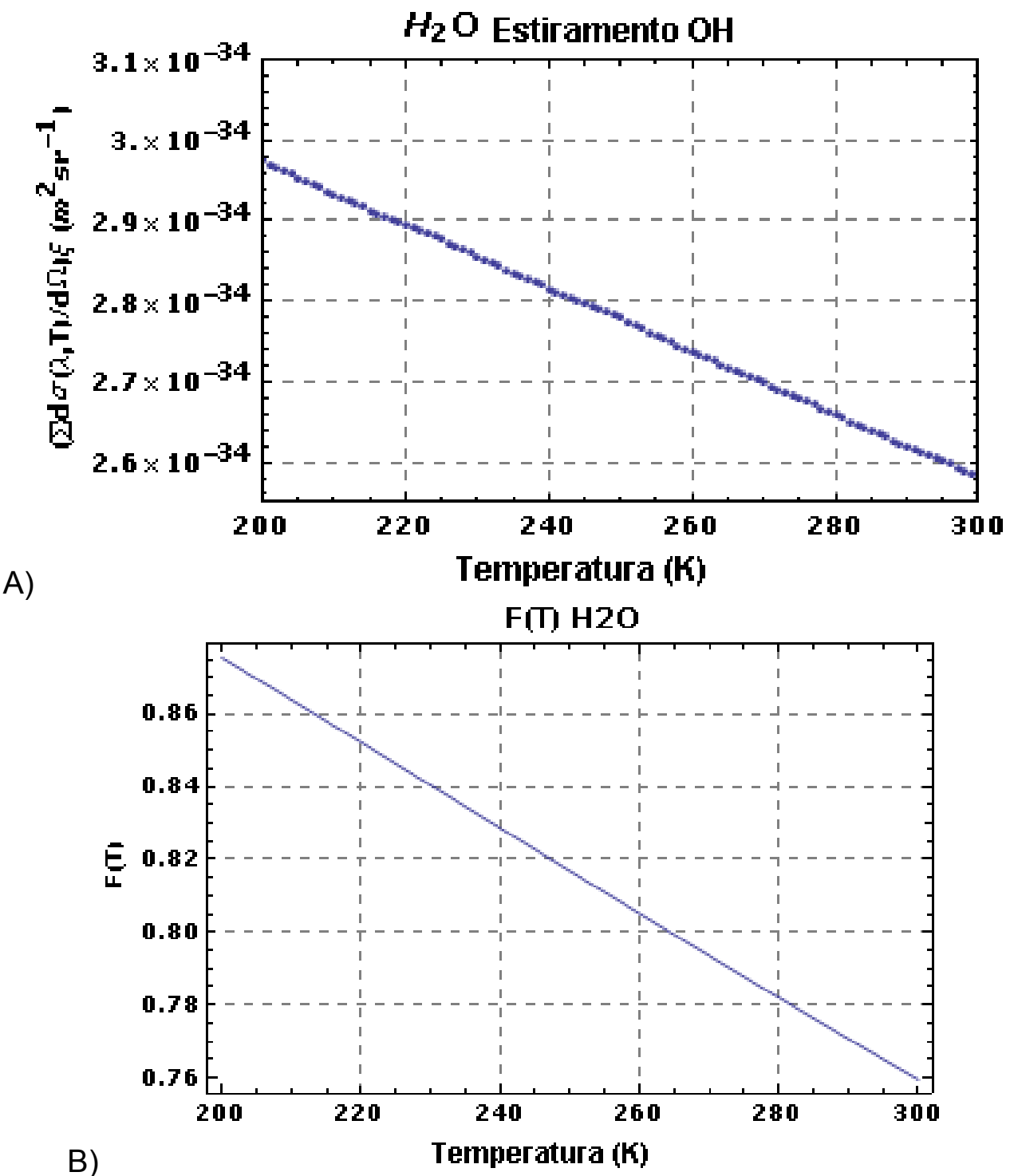

FIGURA 6.1. A) Somatória da secção diferencial de espalhamento vezes a eficiência de transmissão do filtro de banda estreita para temperaturas de 200 a 300 K. B) Função de dependência da secção diferencial de espalhamento Raman do vapor d'água com a temperatura $(F(T))$ utilizando-se um filtro de banda estreita para temperaturas de 200 a $300 \mathrm{~K}$.

Nas figuras 6.2 e 6.3 são apresentadas as secções diferenciais de espalhamento para o vapor d'água com a eficiência do filtro de interferência, calculadas para filtros de banda larga. Observa-se uma quase não dependência com a temperatura ( Figura 6.3 B) da função $F(T)$ para a configuração banda larga o que está de acordo com a teoria. Enquanto que para a secção diferencial de espalhamento total são esperadas serem independentes da temperatura, as linhas individuais de estiramento rotacionais no espectro Raman são dependentes da temperatura e isso deve ser considerado quando filtros estreitos são utilizados 
permitindo a transmissão de somente uma parte dos sinais rotacionais e vibracionais [Sherlock et al, 1999; Whiteman, 2003; Adam et al, 2007]. Já no caso de filtros largos, a transmissão é permitida em uma faixa maior, diminuindo-se drasticamente a dependência com a temperatura.

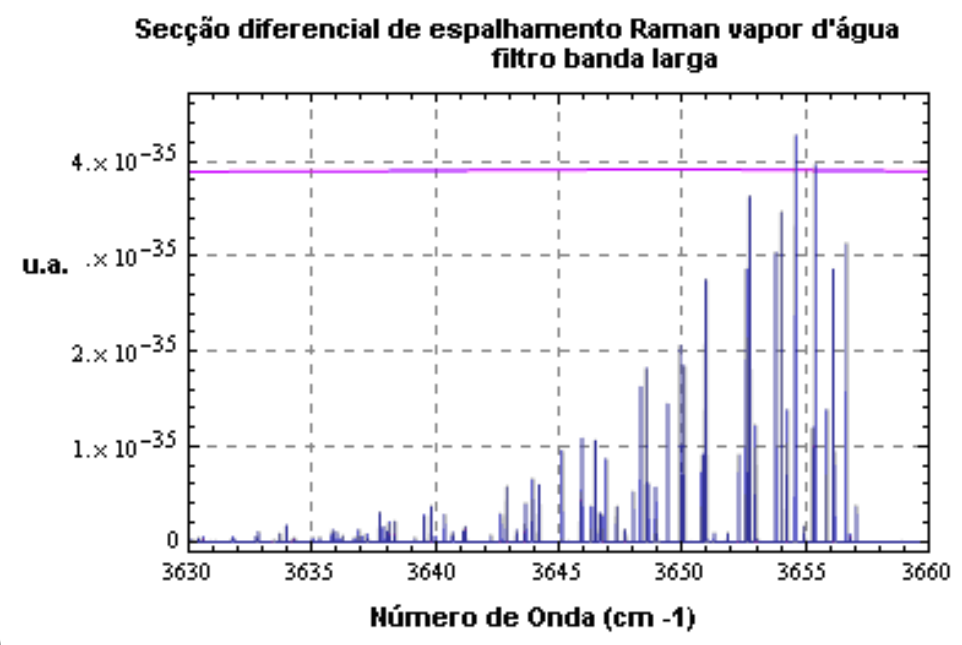

A)

Seção diferencial de espalhamento Raman do vapor d'água - filtro banda larga

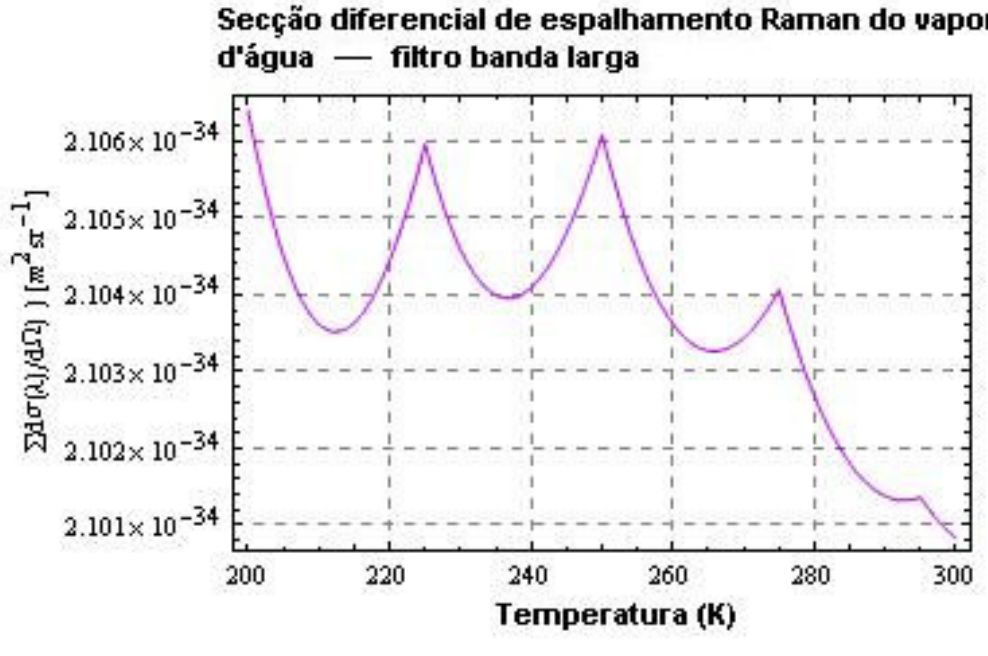

B)

FIGURA 6.2. Secção Diferencial de espalhamento Raman do vapor d'água simulada com a representação do filtro de banda larga $(A)$ e somatória das secções diferenciais de espalhamento Raman do vapor d'água (B). 


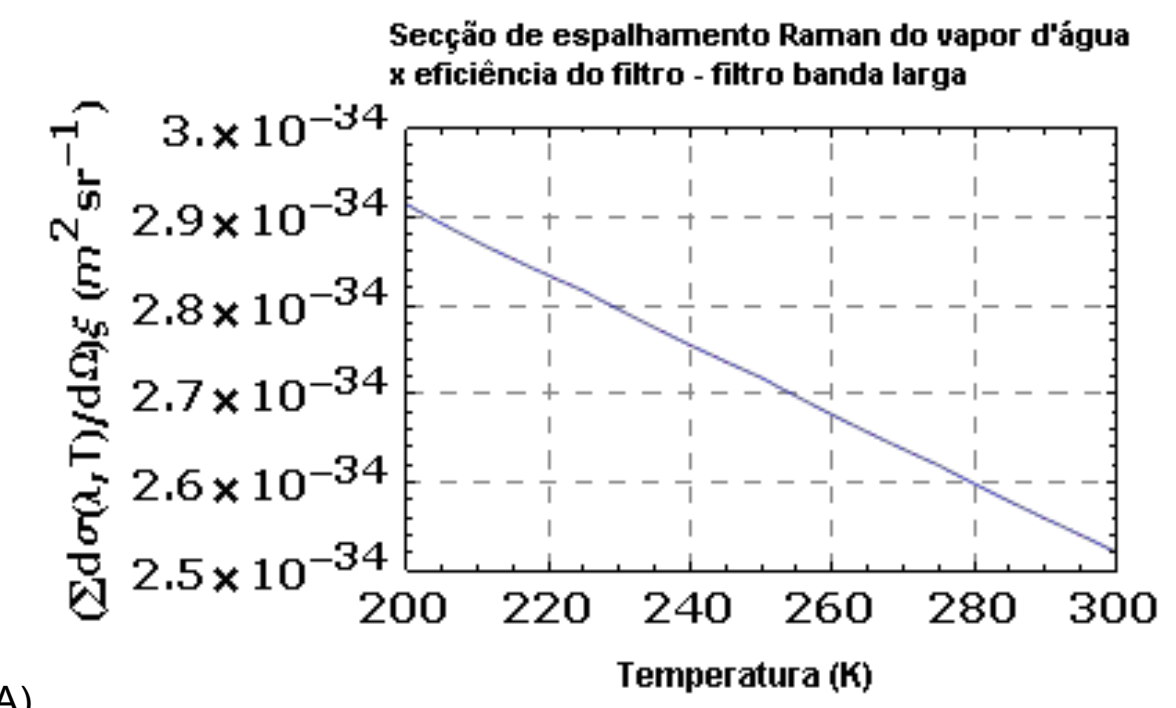

A)

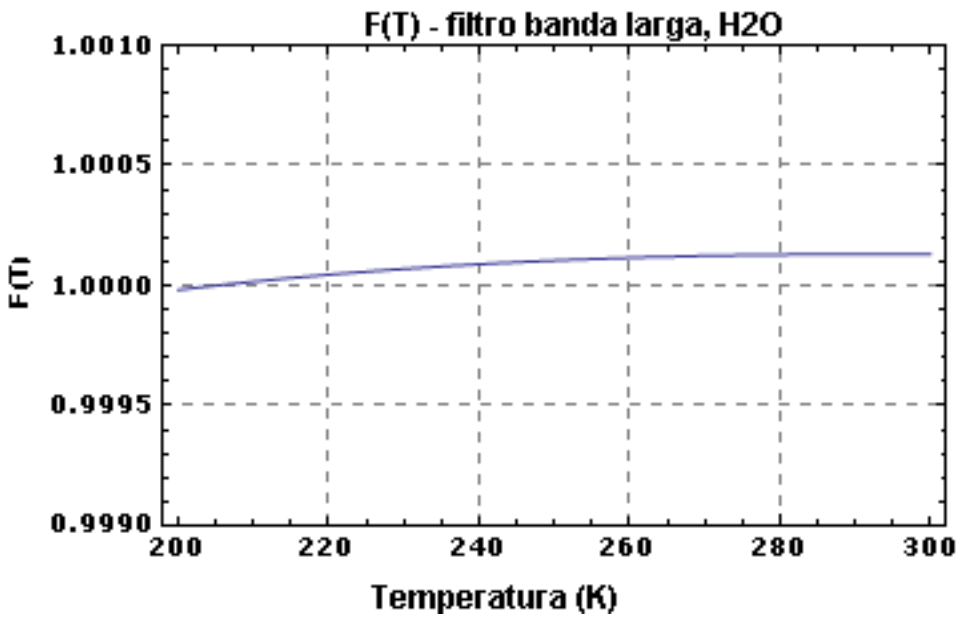

FIGURA 6.3. Somatória das secções diferenciais de espalhamento Raman do vapor d'água vezes a eficiência de transmissão do filtro $(A)$ e função $F(T)$ de dependência da secção diferencial de espalhamento Raman do vapor d'água com a temperatura para a configuração de filtro largo (B).

$\mathrm{Na}$ tabela 15 são apresentados alguns valores obtidos na literatura para a secção de espalhamento differencial do nitrogênio na faixa $Q$. Na última linha apresentamos o valor calculado conforme as equações apresentadas acima e que estão de acordo com a proporcionalidade $1 / \lambda^{4}$. 
TABELA 15. Secção diferencial de espalhamento diferencial do $N_{2}$ na faixa $Q$.

\begin{tabular}{|c|c|c|c|}
\hline $\begin{array}{l}\text { Molécula/tipo de } \\
\text { método }\end{array}$ & $\lambda_{0}(\mathrm{~nm})$ & $\begin{array}{c}\text { Secção } \\
\text { diferencial de } \\
\text { espalhamento } \\
\text { ramo } Q\left(\mathrm{~cm}^{2} / \mathrm{sr}^{-1}\right) \\
\left(\mathbf{1 0}^{-30}\right)\end{array}$ & Referência \\
\hline $\mathrm{N}_{2}$ método téorico & 337,1 & 2,9 & Inaba,1976 \\
\hline $\mathrm{N}_{2}$ experimental & 337,1 & 2,8 & Murphy et al,1981 \\
\hline $\mathrm{N}_{2}$ experimental & 337,1 & 2,9 & Penney et al,1976 \\
\hline $\mathrm{N}_{2}$ experimental & 337,1 & 2,8 & Hyatt et al,1973 \\
\hline $\mathrm{N}_{2}$ teórico & 514,5 & 4,3 & Sherlock et al, 1999 \\
\hline $\mathrm{N}_{2}$ teórico & 337,1 & 2,8 & Measures, 1984 \\
\hline $\mathrm{N}_{2}$ teórico & 354,7 & 2,75 & Calculado com equações 11 e 12 \\
\hline
\end{tabular}

\subsection{Determinação experimental da razão das secções diferenciais de espalhamento Raman utilizando-se uma configuração de filtros de interferência de banda larga}

As intensidades relativas das linhas do espectro Raman do vapor d'água [Avila et al, 1999], $\mathrm{N}_{2}$ e $\mathrm{O}_{2}$ [Herzberg, 1989 e Heaps et al, 1997] agora podem ser modeladas com relativa precisão. Essa habilidade, acoplada com uma medida precisa da razão $\xi\left(\lambda_{N}\right) / \xi\left(\lambda_{H}\right)$ para o sistema LIDAR e uma calibração acurada com relação a outro sensor, poderia potencialmente melhorar o conhecimento da razão das secções diferenciais de espalhamento Raman do $\mathrm{N}_{2}$ e do vapor d'água [Whiteman, $2003(\mathrm{I})$ ].

A partir das equações de razão de mistura do vapor d'água (3) e para o cáculo do fator de calibração, queremos calcular uma razão de secção diferencial de espalhamento experimental. A partir dessa razão, podemos calcular a secção diferencial de espalhamento do vapor d'água já que a secção diferencial de espalhamento do nitrogênio é bem conhecida. $O$ fator de calibração foi calculado a partir da comparação entre o perfil da razão de mistura do vapor d'água do LIDAR Raman e o perfil de uma radiossonda do tipo Stearling, conforme apresentado na figura $6.4 \mathrm{~B})$. 
27 Janeiro 2006 , Razão de Mistura do Vapor d'água com o HURL

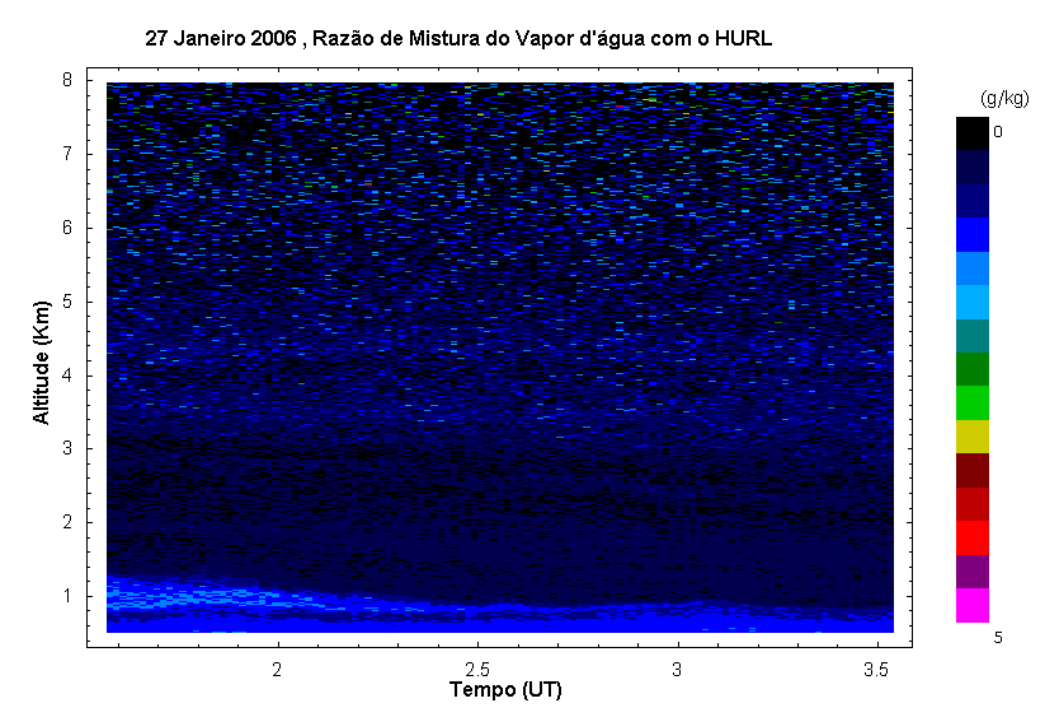

A)

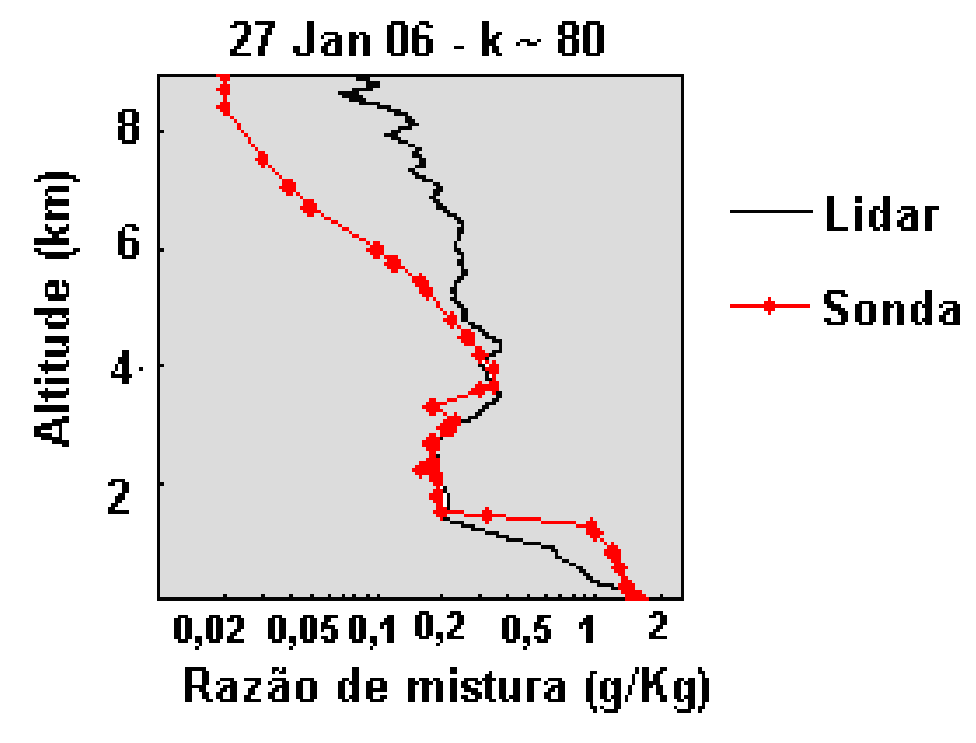

B)

FIGURA 6.4. A) Perfil temporal da razão de mistura de vapor d'água obtido pelo HURL com o uso de filtro largo. B) Razão de mistura do vapor d'água obtida por LIDAR Raman e por radiossondagem no dia 27 de Janeiro de 2006, obtendo-se um fator de calibração igual a 80 , produto da comparação dos dois perfis.

Os dados são exibidos em escala logarítmica. A escala mostra a discrepância entre o LIDAR e a radiossonda no primeiro kilômetro bem como os últimos kilômetros de altitude. Isso pode ser devido a um evento real na atmosfera, ou uma indicação de que a radiossonda necessitava de algum tempo para se equilibrar ao ambiente [Ferrare et al, 1995], ou devido a um overlap incompleto do sistema (o HURL tem overlap em torno de $1,5 \mathrm{~km}$ ). Isolando-se as secções diferenciais de espalhamento a partir da equação 3.53 , obtivemos o valor das razões 
de secção diferencial de espalhamento Raman (nitrogênio/vapor d'água) de $\sim 0,36$. A partir da secção diferencial de espalhamento Raman para o nitrogênio calculada $\sim 2,34 \times 10^{-34} \mathrm{~m}^{2} \mathrm{sr}^{-1}$, do item anterior , estimamos o valor da secção diferencial de espalhamento Raman para o vapor d'água, que foi de $6,54 \times 10^{-34} \mathrm{~m}^{2} \mathrm{sr}^{-1}$.

Outro experimento foi realizado em Julho de 2008, com o lançamento de 6 radiossondagens a menos de 100 metros do sistema HURL da Howard University. A principal motivação era obtermos uma razão de mistura do vapor d'água por uma radiossondagem lançada o mais próximo possível do sistema LIDAR. O resultados dessa comparação são exibidos na figura. 6.5 e 6.6 e descritos nas tabelas 16,17 e 18.

TABELA 16- Parâmetros utilizados na medida da razão de mistura do vapor d'água por LIDAR Raman em 17 de Julho de 2008.

\begin{tabular}{|c|c|c|}
\hline AOT Aeronet & 0,31 & \\
\hline $\begin{array}{l}\text { Potência do laser } \\
\text { inicial }\end{array}$ & $8 \mathrm{~W}$ & \\
\hline $\begin{array}{l}\text { Potência do laser } \\
\text { final }\end{array}$ & $7 \mathrm{~W}$ & \\
\hline $\begin{array}{l}\text { Temperatura } \\
\text { ambiente }\end{array}$ & $71 \mathrm{~F}$ & \\
\hline Condições do tempo & Claro & \\
\hline & & $\begin{array}{l}\text { Ocorreram várias mudanças no sistema. Os } \\
\text { filtros de interferência estreitos para os canais } \\
\text { do vapor d'água e nitrogênio foram substituídos } \\
\text { por filtros de banda larga ( } 5 \mathrm{~nm} \text { para } \mathrm{N}_{2} \text { e } 20 \\
\text { nm para } \mathrm{H}_{2} \mathrm{O} \text {. A janela de vidro presente na } \\
\text { clarabóia foi removida. Durante o dia, } \\
\text { mapeamentos foram realizados do telescópio. }\end{array}$ \\
\hline 17/07/2008 01:59 & $07178 Y 00.001$ & Primeiro arquivo de corrente escura \\
\hline 17/07/2008 02:04 & 07178Y00.006 & Último arquivo de corrente escura \\
\hline 17/07/2008 02:06 & $07178 Y 00.008$ & Primeiro arquivo de dados \\
\hline 17/07/2008 02:26 & & RS92 lançada as 02:26 UT \\
\hline 17/07/2008 04:30 & & RS92 lançada as 04:30 UT \\
\hline 17/07/2008 04:27 & & $\begin{array}{l}\text { Mudança na relação sinal-ruído as 4:25 } \\
\text { UtTaproximadamente. Uma possível causa } \\
\text { poderia ser a presença de uma mariposa no } \\
\text { foco primário do telescópio. Uma mudança no } \\
\text { sinal do vapor d'água também foi observado, } \\
\text { provavelmente devido à deposição de vapor } \\
\text { nos componentes ópticos. }\end{array}$ \\
\hline 17/07/2008 05:59 UT & $07178 Y 00.240$ & Último arquivo de dados. \\
\hline Observações & & $\begin{array}{l}\text { Parte do tecido preto que cobria o telescópio } \\
\text { invadiu a área do espelhos. Muitos insetos foram } \\
\text { encontrados sob o espelho primário. }\end{array}$ \\
\hline
\end{tabular}




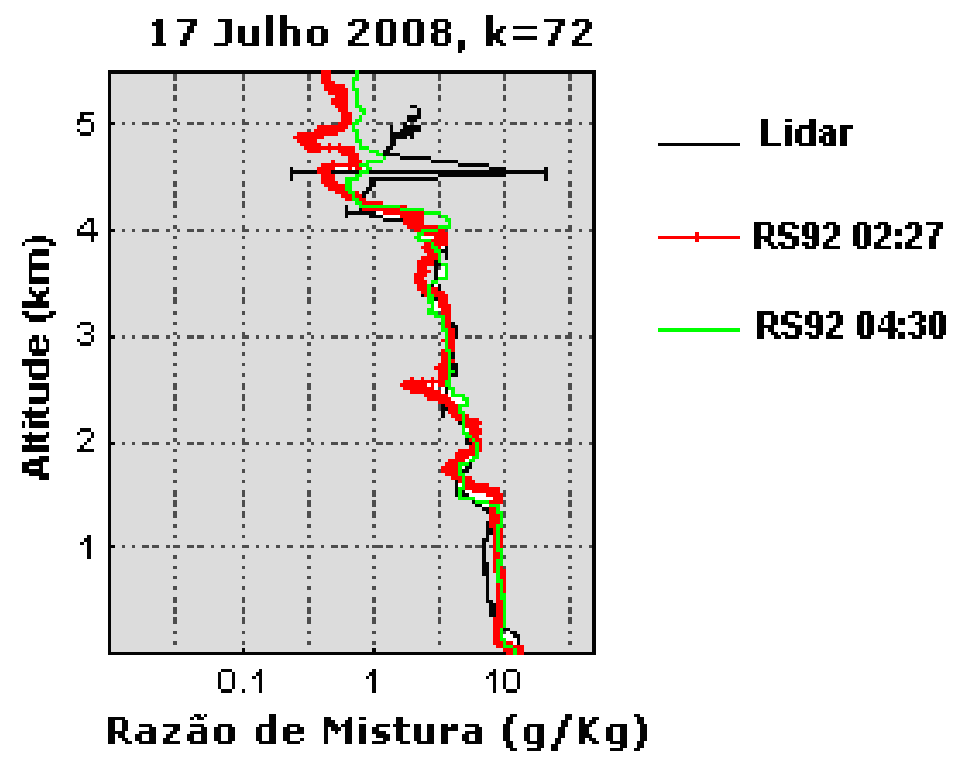

FIGURA 6.5 - Perfis de razão de mistura de vapor d'água obtidos por LIDAR (preto) e por duas radisondas lançadas as 02:27 UT (vermelho) e as 04:30 UT no dia 17/07/2008. 


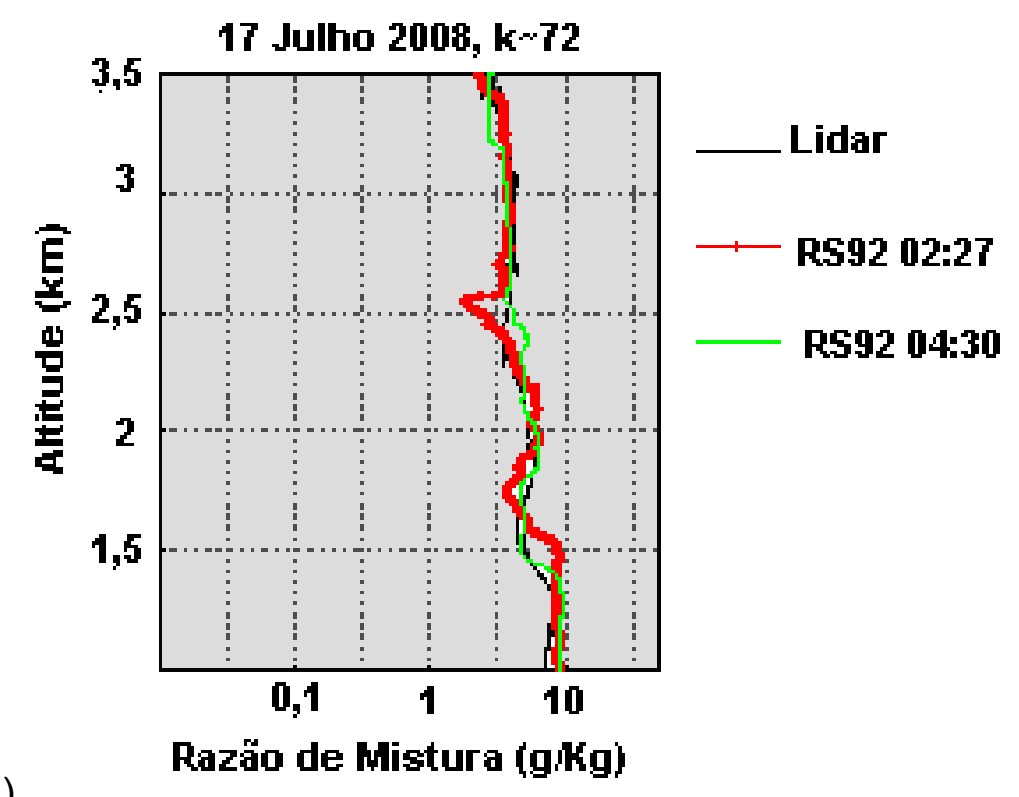

A)

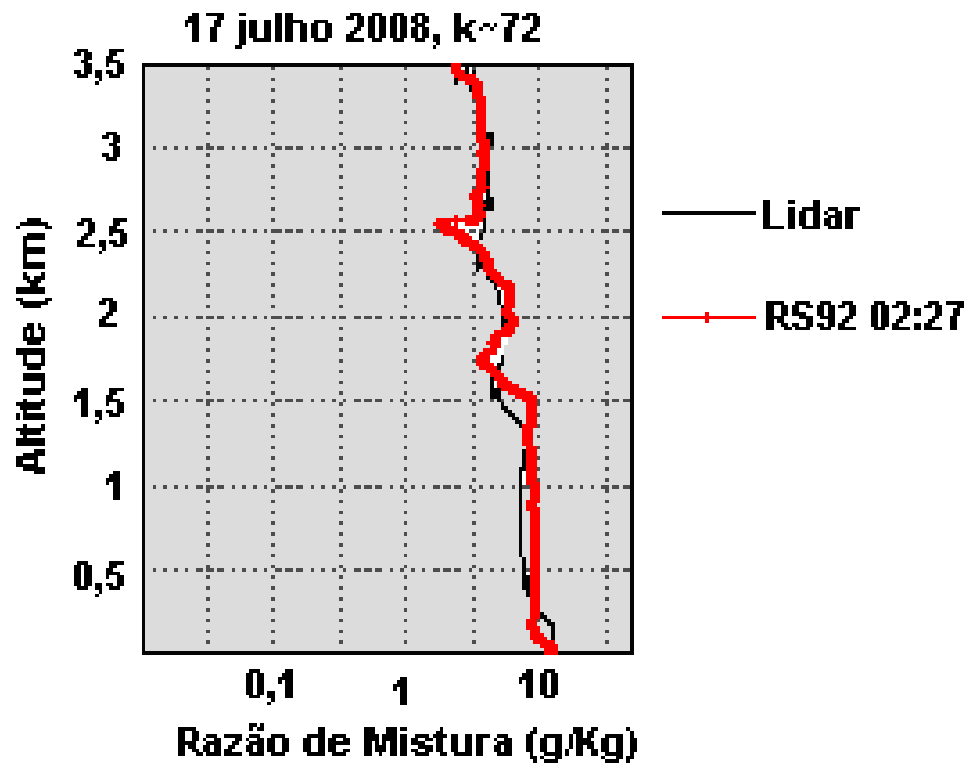

B)

FIGURA 6.6 - A) Perfi de razão de mistura de vapor d'água obtidos por LIDAR (preto) e por duas radisondas lançadas as 02:27 UT (vermelho) e as 04:30 UT (verde) no dia 17/07/2008, com zoom de 1 a 3,5 km. B) Perfil de razão de mistura de vapor d'água obtido por LIDAR Raman em preto (30 min) e pela sonda lançada as 02:27 UT. 
TABELA 17 - Medidas LIDAR dia 18 de Julho de 2008.

\begin{tabular}{|c|c|c|}
\hline AOT Aeronet & --------------- & \\
\hline $\begin{array}{l}\text { Potência do laser } \\
\text { inicial }\end{array}$ & $7,5 \mathrm{~W}$ & \\
\hline $\begin{array}{l}\text { Potência do laser } \\
\text { final }\end{array}$ & $7,3 \mathrm{~W}$ & \\
\hline $\begin{array}{l}\text { Temperatura } \\
\text { ambiente }\end{array}$ & $71 \mathrm{~F}$ & \\
\hline \multirow[t]{2}{*}{ Condições do tempo } & $\begin{array}{l}\text { Parcialmente } \\
\text { nublado }\end{array}$ & \\
\hline & & $\begin{array}{l}\text { Mesmo setup utilizado no dia } 17 \text { de Julho. } \\
\text { Observamos algum problema no controle } \\
\text { remoto do laser. }\end{array}$ \\
\hline $18 / 07 / 200801: 41$ & 07188Y00.001 & Primeiro arquivo de corrente escura \\
\hline $17 / 07 / 200801: 46$ & $07188 Y 00.006$ & Último arquivo de corrente escura \\
\hline $17 / 07 / 200801: 48$ & 07188Y00.008 & Primeiro arquivo de dados \\
\hline 17/07/2008 02:00 & 07188Y00.021 & $\begin{array}{l}\text { Mudança do cristal para otimizar a potência do } \\
\text { laser }\end{array}$ \\
\hline $17 / 07 / 200802: 00$ & & RS92 lançada as 02:00 UT + Ozone \\
\hline $18 / 07 / 200804: 27$ & & RS92 lançada as 4:00T \\
\hline 17/07/2008 05:59 UT & 07188Y00.380 & Último arquivo de dados. \\
\hline
\end{tabular}




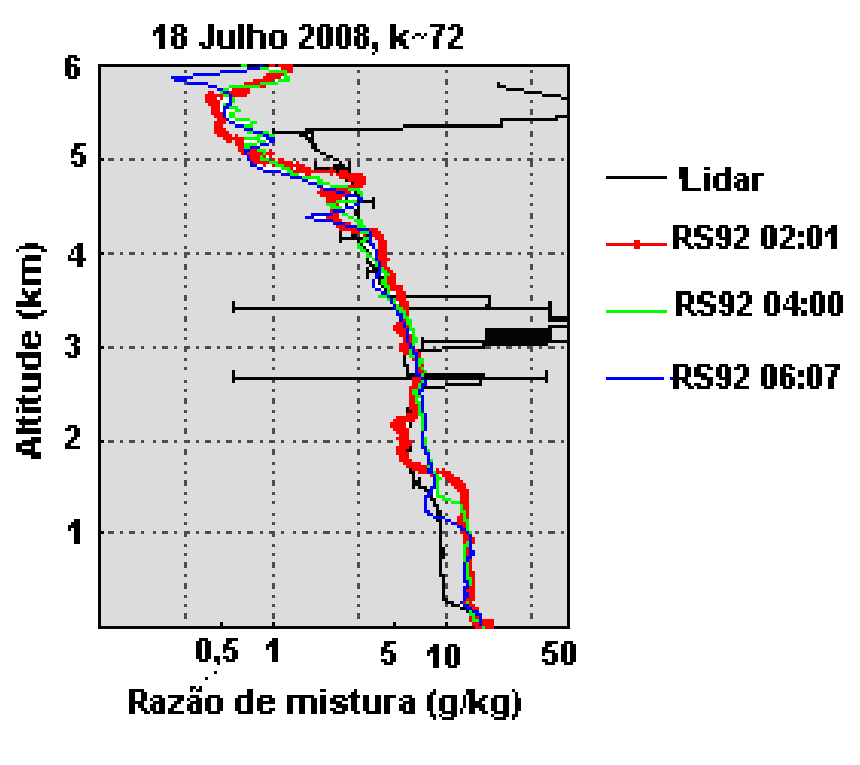

A)

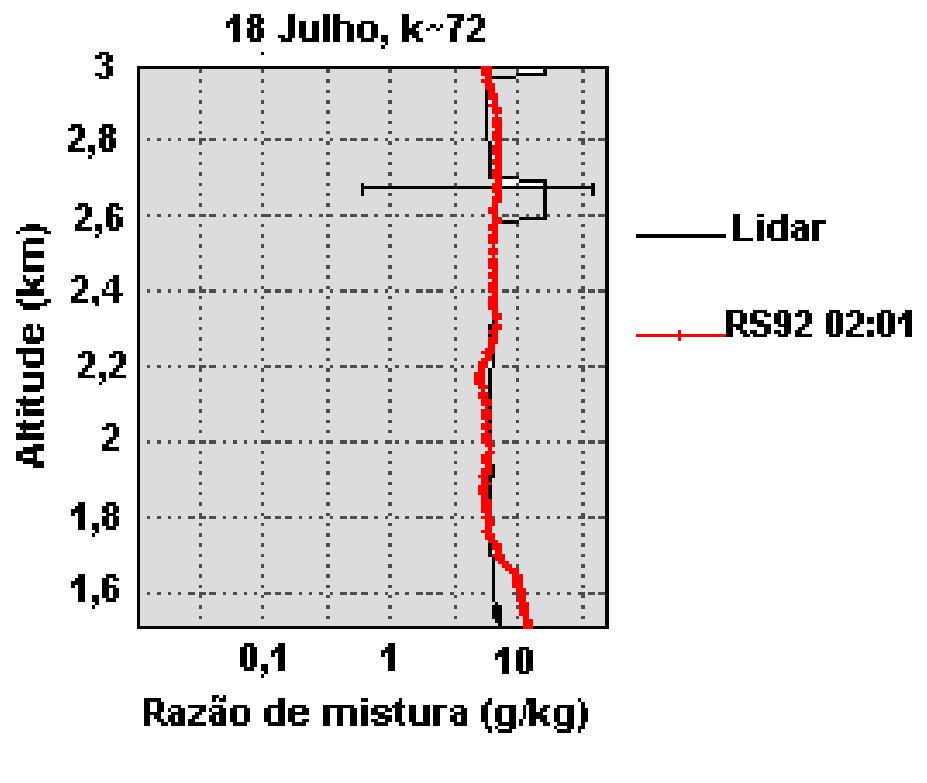

FIGURA 6.7 - A) Perfis de razão de mistura de vapor d'água obtidos por LIDAR (preto) e por três radisondas lançadas as 02:01 UT (vermelho), as 04:00 UT(verde) e as 06:07 UT (azul)no dia 18/07/2008. B) Zoom de 1 a $3 \mathrm{~km}$ do perfil de razão de mistura de vapor d'água obtido por LIDAR Raman em preto (30 min) e pela sonda lançada as 02:01 UT. 
TABELA 18 - Medidas LIDAR em 19 de Julho 2008

\begin{tabular}{|c|c|c|}
\hline AOT Aeronet & --- & \\
\hline $\begin{array}{l}\text { Potência do laser } \\
\text { inicial }\end{array}$ & $8 \mathrm{~W}$ & \\
\hline \multicolumn{3}{|l|}{$\begin{array}{l}\text { Potência do laser } \\
\text { final }\end{array}$} \\
\hline $\begin{array}{l}\text { Temperatura } \\
\text { ambiente }\end{array}$ & $69.8 \mathrm{~F}$ & \\
\hline Condições do tempo & $\begin{array}{l}\text { Parcialmente } \\
\text { nublado }\end{array}$ & \\
\hline Nota & & $\begin{array}{l}\text { Mesma configuração usada em 17/07/2008. O } \\
\text { controle remoto do laser continuava com } \\
\text { problema. }\end{array}$ \\
\hline 19/07/2008 01:48 & $\begin{array}{l}\text { File: } \\
\text { 07198Y00.001 }\end{array}$ & Primeiro arquivo de corrente escura \\
\hline $19 / 07 / 200801: 53$ & 07198Y00.006 & Último arquivo de corrente escura \\
\hline $19 / 07 / 200801: 55$ & 07198Y00.008 & Primeiro arquivo de dados \\
\hline 19/07/2008 02:01 & & RS92 lançada as 02:01 UT \\
\hline 19/07/2008 03:20 & & Inseto pousou no ponto de parada da fibra? \\
\hline 19/07/2008 04:14 & 07198Y00.146 & $\begin{array}{l}\text { Diminuição do sinal } \rightarrow \text { parte do feixe laser } \\
\text { refletido do espelho transmissor no periscópio } \\
\text { estava sendo bloqueada pelo tecido preto. }\end{array}$ \\
\hline 17/07/2008 05:59 UT & .148 & Último arquivo de dados. \\
\hline Observações & & $\begin{array}{l}\text { As 04:16 o laser desligou. Religamos o laser, } \\
\text { mas as 06:18 perdemos o sinal do laser. }\end{array}$ \\
\hline
\end{tabular}




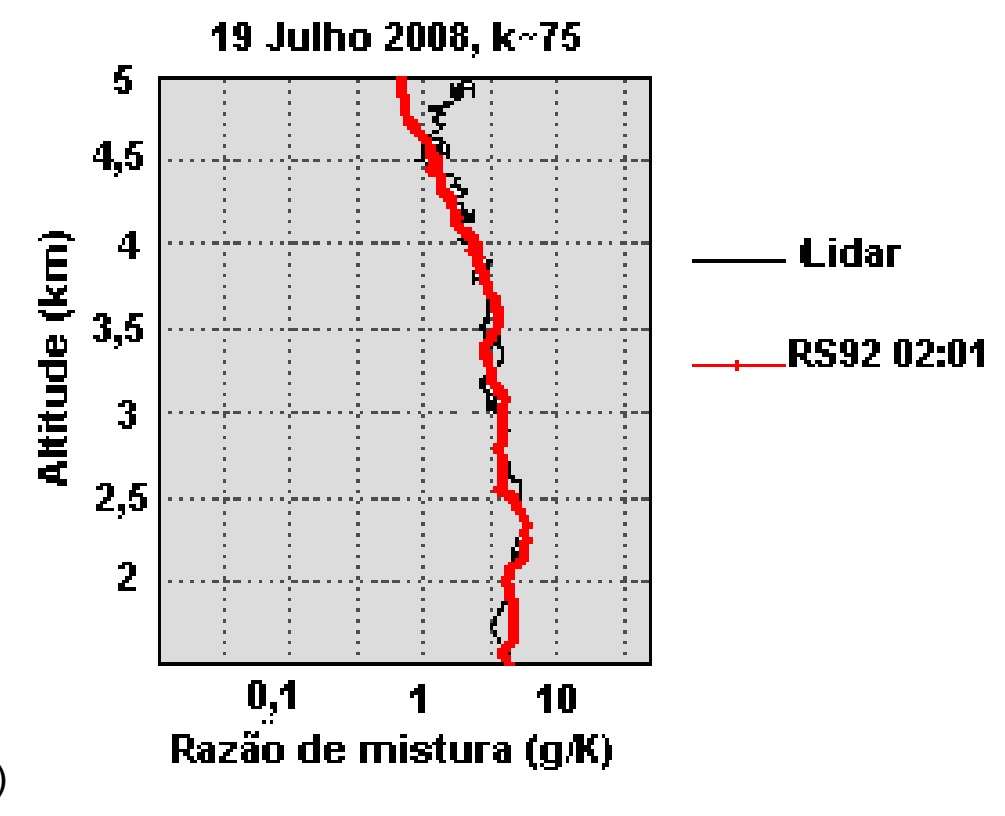

A)

19 Julho 2008, $\mathrm{k}^{\sim 75}$

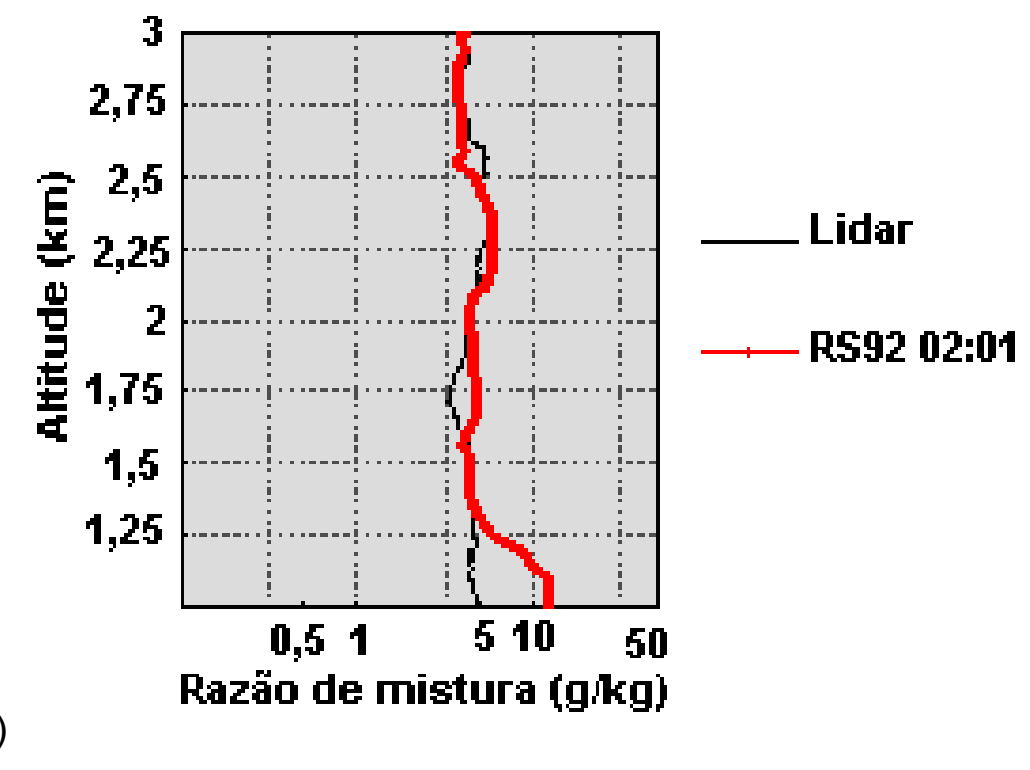

FIGURA 6.8 - A) Perfis de razão de mistura de vapor d'água obtidos por LIDAR (preto) e por 1 radiossonda lançada às 02:01 UT (vermelho) no dia 19/07/2008. B)Zoom de 1 a $3 \mathrm{~km}$ do perfil de razão de mistura de vapor d'água obtido por LIDAR Raman em preto (60 min) e pela sonda lançada as 02:01 UT.

Na tabela 19 são apresentados valores de razão das secções diferenciais de espalhamento do nitrogênio sobre as do vapor d'água utilizados na literatura e obtidos pelo nosso experimento usando filtros largos. 
TABELA 19. Valores de referência para razão das secções diferenciais de espalhamento do nitrogênio e vapor d'água.

\begin{tabular}{|c|c|c|}
\hline$\lambda 0$ & $\begin{array}{c}\left(\mathrm{d} \sigma_{\mathrm{N}} / \mathrm{d} \Omega\right) /\left(\mathrm{d} \sigma_{\mathrm{H}} / \mathrm{d} \Omega\right)- \\
\text { faixaQ }\end{array}$ & Referência \\
\hline $514 \mathrm{~nm}$ & 0,400 & Sherlock et al, 1999. \\
\hline $355 \mathrm{~nm}$ & 0,45 & Whiteman (II), 2003. \\
\hline $331,7 \mathrm{~nm}$ & 0,36 & Measures, 1984. \\
\hline $514 \mathrm{~nm}$ & 0,40 & Penney e Lapp, 1976. \\
\hline $354,7 \mathrm{~nm}$ & $0,40 \pm 0,04$ & $\begin{array}{l}\text { Calculada a partir do modelo de [Avila,2004] para } \\
\mathrm{o} \mathrm{H}_{2} \mathrm{O} \text { e [Weitkamp, 2005] para } \mathrm{N}_{2} \text { e considerada } \\
\text { nesse trabalho. } \mathrm{K} \sim 80\end{array}$ \\
\hline $354,7 \mathrm{~nm}$ & $0,36 \pm 0,03$ & $\begin{array}{l}\text { Obtida experimentalmente com o uso de filtros de } \\
\text { banda larga e } k^{*} \text { obtido por comparação do perfil } \\
\text { com uma radiossonda em Janeiro } 2007 \text {. }\end{array}$ \\
\hline $354,7 \mathrm{~nm}$ & $\mathbf{0 , 3 4} \pm 0,05$ & $\begin{array}{l}\text { Obtida experimentalmente para } \mathrm{k}^{*}=75 \text { em } 19 \text { de } \\
\text { Julho } 2008 \text {. }\end{array}$ \\
\hline $354,7 \mathrm{~nm}$ & $\mathbf{0 , 3 2 \pm 0 , 0 6}$ & $\begin{array}{l}\text { Obtida experimentalmente para } \mathrm{k}^{*}=72 \text { em } 17 \text { e } 18 \\
\text { de Julho de } 2008 \text {. }\end{array}$ \\
\hline
\end{tabular}

Os valores obtidos experimentalmente $(0,36,0,34$ e 0,32$)$ para a razão das secções diferenciais de espalhamento divergem dos obtidos na literatura. Em parte isso se deve ao fato de estarmos utilizando um conjunto de filtros de interferência de banda larga ao invés de filtros estreitos e essa razão é obtida através de um sistema LIDAR específico com suas características. Um conjunto de dados de radiossondagem mais preciso, lançada próxima ao sistema LIDAR ( 100m), foi utilizado para o cálculo das duas últimas razões de secção diferencial de espalhamento. Devido ao fato de que as radiossondas foram lançadas numa distância menor e que os dados LIDAR obtidos apresentaram melhor consistência, adotaremos o valor da razão "experimental" da secção diferencial de espalhamento de 0,32 .

\subsection{Cálculo do fator de calibração para várias configurações}

A partir da equação 3.53, considerando o fator de overlap = 1 [Venable et al, 2005], a eficiência óptica (calculada com filtros de banda larga) $=0,46$ e a razão da secção diferencial de espalhamento obtida experimentalmente, calculamos o fator de calibração.

A tabela 20 mostra os coeficientes de calibração calculados para uma configuração de banda larga e de banda estreita considerando-se a razão das secções diferenciais de espalhamento experimental e a teórica. 
TABELA 20. Fatores de calibração calculados para diferentes configurações.

$\begin{array}{ccccc}\begin{array}{c}\text { Filtros de } \\ \text { interferência }\end{array} & \xi(\lambda) \mathrm{N}_{2} / \xi(\lambda) \mathrm{H}_{2} \mathrm{O} & \left(\mathrm{d} \sigma_{\mathrm{N}} / \mathrm{d} \Omega\right) /\left(\mathrm{d} \sigma_{\mathrm{H}} / \mathrm{d} \Omega\right)- & \mathbf{k}^{*}(\mathrm{r}) & \text { Incerteza } \\ & \text { faixaQ } & & \end{array}$

\begin{tabular}{lllcc}
\hline Banda larga & 0,46 & 0,32 (experimental) & 72 & $10-18 \%$ \\
\hline Banda larga & 0,46 & 0,40 (teórico) & 89 & $10 \%$ \\
\hline Banda estreita & 1,23 & 0,40 (teórico) & 235 & $13 \%$ \\
\hline Banda estreita & 1,23 & 0,32 (experimental) & 192 & $13-18 \%$ \\
\hline
\end{tabular}

No próximo capítulo a propagação de erros para os parâmetros acima é abordada. 


\section{CAPÍTULO 7}

\section{CÁLCULO DE ERROS}

\subsection{Equações para erro na razão de mistura de vapor d'água}

O erro randômico na determinação da razão de mistura de vapor d'água $\omega$ é encontrado por meio de aplicação de fórmulas de propagação de erro padrão [Bevington, 1992] e pode ser representada como:

$$
\begin{gathered}
\frac{\sigma_{\omega}^{2}}{\omega^{2}}=\frac{\sigma_{k^{*}}^{2}}{k^{* 2}}+\frac{\sigma_{R \omega}^{2}}{R_{\omega}^{2}}+\frac{\sigma F x^{2}}{F x}+\frac{\sigma_{\Delta \tau}^{2}}{\Delta \tau^{2}} \\
\frac{\sigma_{\omega}^{2}}{\omega^{2}}=\frac{\sigma_{k^{*}}^{2}}{k^{* 2}}+\frac{\sigma_{F N}^{2}}{F_{N}^{2}}+\frac{\sigma_{F H}^{2}}{F_{H}^{2}}+\frac{\sigma_{P H}^{2}}{P_{H}^{2}}+\frac{\sigma_{P N}^{2}}{P_{N}^{2}}+\frac{\sigma_{\Delta \tau}^{2}}{\Delta \tau^{2}}
\end{gathered}
$$

Sendo que para o fator de calibração $\mathrm{k}$ :

$$
\begin{aligned}
& \frac{\sigma_{K^{*}}^{2}}{k^{2}}=0.485 \frac{\sigma_{O N}^{2}}{O_{N}^{2}}+\frac{\sigma_{O H}^{2}}{O_{H}^{2}}+\frac{\sigma_{d \sigma N / d \Omega}^{2}}{\left[d \sigma_{N} / d \Omega\right]^{2}}+\frac{\sigma_{d \sigma H / d \Omega}^{2}}{\left[d \sigma_{H} / d \Omega\right]^{2}}+\frac{\sigma \xi_{N}^{2}}{\xi_{N}^{2}}+\frac{\sigma \xi_{H}^{2}}{\xi_{H}^{2}} \\
& \frac{\sigma_{\omega}^{2}}{\omega^{2}}=0.485\left[\frac{\sigma_{O N}^{2}}{O_{N}^{2}}+\frac{\sigma_{O H}^{2}}{O_{H}^{2}}+\frac{\sigma_{d \sigma V / d \Omega}^{2}}{\left[d \sigma_{N} / d \Omega\right]^{2}}+\frac{\sigma_{d d H / d \Omega}^{2}}{\left[d \sigma_{H} / d \Omega\right]^{2}}+\frac{\sigma \xi_{N}^{2}}{\xi_{N}^{2}}+\frac{\sigma \xi_{H}^{2}}{\xi_{N}^{2}}\right]+\frac{\sigma_{F N}^{2}}{F_{N}^{2}}+\frac{\sigma_{F H}^{2}}{F_{H}^{2}}+\frac{\sigma_{P H}^{2}}{P_{H}^{2}}+\frac{\sigma_{P N}^{2}}{P_{N}^{2}}+\frac{\sigma_{\Delta \tau}^{2}}{\Delta \tau^{2}}
\end{aligned}
$$

Onde a abreviação $R \omega=P\left(\lambda_{H}, r\right) / P\left(\lambda_{N}, r\right)$ foi usada. A quantificação total da equação 7 requer uma análise de todos os fatores randômicos que estão presentes na calibração da razão de mistura do vapor d'água. A calibração do Raman LIDAR tem se mostrado estável durante longos períodos segundo a literatura [Ferrare et al, 1995; Turner and Goldsmith, 1999; Whiteman I, 2003] quando os componentes do sistemas não são mudados; assim a variância em $\mathrm{k}^{*}$ pode ser considerada pequena. Erros introduzidos por incertezas no termo de transmissão diferencial da razão de mistura do vapor d'água são estudados por [Whiteman, 2003] que diz que utilizando-se a medida da extinção do aerossol por Raman LIDAR em adição ao número de densidade molecular obtido pela radiossonda, é possível mantermos o erro bastante baixo. Assim, o erro randômico na razão dos sinais LIDAR normalmente domina o erro total. Esses erros são quantificados agora pelo uso da estatística de Poisson. 
Lembrando que os termos $P$ na equação 7.1 são atualmente quantidades com background subtraído, podemos re-expressar $\frac{\sigma_{R \omega}^{2}}{R_{\omega}^{2}}$ fazendo-se as seguintes substituições:

$$
\begin{array}{r}
\frac{\sigma_{R_{w}}^{2}}{R_{\omega}^{2}}=\frac{\sigma_{S H}^{2}+\sigma_{B H}^{2}}{\left(S_{H}-B_{H}\right)^{2}}+\frac{\sigma_{S N}^{2}+\sigma_{B N}^{2}}{\left(S_{N}-B_{N}\right)^{2}} \\
\sigma_{R \omega}^{2}=\frac{\left(S_{H}-B_{H}\right)^{2}}{\left(S_{N}-B_{N}\right)^{2}}\left[\frac{\sigma_{S H}^{2}+\sigma_{B H}^{2}}{\left(S_{H}-B_{H}\right)^{2}}+\frac{\sigma_{S N}^{2}+\sigma_{B N}^{2}}{\left(S_{N}-B_{N}\right)^{2}}\right]
\end{array}
$$

Onde é explícito que há erros na determinação do background. Em certas condições, como em altos níveis de backgrounds durante medidas diurnas, essas fontes de erros podem se tornar significativas.

\subsection{Erros calculados para a razão das eficiências de transmissão do sistema LIDAR}

O erro randômico na determinação da razão $\xi\left(\lambda_{H}\right) / \xi\left(\lambda_{N}\right)$ é encontrado através da aplicação de fórmulas padrão de propagação de erros na equação 3.11. A equação resultante pode ser representada como:

$$
\frac{\sigma \xi^{2}}{\xi^{2}}=\frac{\sigma_{I n}^{2}}{I_{I n}^{2}}+\frac{\sigma C_{\text {out }}^{2}}{C_{\text {out }}^{2}}
$$

E é conveniente mencionarmos que

$$
\frac{\sigma_{C_{\text {out }}^{2}}}{C_{\text {out }}^{2}}=\frac{\sigma_{C N}^{2}}{C_{N}^{2}}+\frac{\sigma_{C H}^{2}}{C_{H}^{2}}
$$

Onde I é o sinal medido pelo sistema LIDAR para cada canal. A quantificação desta equação requer análise de cada fator envolvido na determinação da eficiência de transmissão e consequentemente no cálculo do fator de calibração. Para cada razão apresentada na equação 7.6 e 7.7, utilizamos diferentes métodos para obter as incertezas dos mesmos, relativas a cada parte do sistema como explicado nos capítulos anteriores. 


\subsection{Erros relativos e estimados das secções diferenciais de espalhamento Raman para o vapor d'água}

A partir da equação de razão de mistura do vapor d'água (3.52 ) podemos isolar o termo da razão das secções diferenciais de espalhamento como segue:

$$
\frac{d \sigma_{N} / d \Omega}{d \sigma_{H} / d \Omega}=\frac{k}{\omega}+\frac{O_{N}}{O_{H}}+\frac{F_{N}}{F_{H}}+\frac{P_{H}}{P_{N}} \Delta \tau
$$

E para a propagação de erros:

$$
\frac{\sigma_{\frac{d \sigma_{N} / d \Omega}{d \sigma_{H} / d \Omega}}^{2}}{\left[\frac{d \sigma_{N} / d \Omega}{d \sigma_{H} / d \Omega}\right]^{2}}=\frac{\sigma_{k^{*}}^{2}}{k^{2}}+\frac{\sigma_{\omega}^{2}}{\omega^{2}}+\frac{\sigma_{O N}^{2}}{O_{N}^{2}}+\frac{\sigma_{O H}^{2}}{O_{H}^{2}}+\frac{\sigma_{F N}^{2}}{F_{N}^{2}}+\frac{\sigma_{F H}^{2}}{F_{H}^{2}}+\frac{\sigma_{P H}^{2}}{P_{H}^{2}}+\frac{\sigma_{P N}^{2}}{P_{N}^{2}}+\frac{\sigma_{\Delta \tau}^{2}}{\Delta \tau^{2}}
$$

A secção diferencial de espalhamento Raman para o vapor d'água foi inicialmente calculada pelo modelo desenvolvido por Avila et al, 2004 e apresentado no capítulo 6. Para a secção diferencial de espalhamento integrada calculada de $v_{1}$ do vapor d'água fornecido em [Avila,2004] , o erro relativo foi de $8 \%$ com relação aos cálculos feitos por Penney e Lapp. Os valores absolutos são derivados por refinados cálculos $a b$ initio, testados exaustivamente por experimentos Raman como apresentado no três isótopos $\left(\mathrm{H}_{2} \mathrm{O}, \mathrm{HDO}, \mathrm{D}_{2} \mathrm{O}\right)$ [Avila, 2003,2004]. Contudo, é uma estimativa indireta do erro.

Outra estimativa do erro foi feita para a razão das secções diferenciais de espalhamento Raman (nitrogênio/vapor d'água) obtidas de forma experimental, por meio de comparação do perfil de razão de mistura do vapor d'água obtido por um LIDAR Raman com um obtido por radiossondagem. Baseado na equação 3.53 para o cálculo do fator de calibração, estima-se que o erro na razão das secções diferenciais de espalhamento Raman experimentais da água estará em torno de um valor $>10,01 \%$. Consideramos que o erro na razão de mistura do vapor d'água obtido pela radiossonda era de $\sim 10 \%$ para a faixa de 1 a $3 \mathrm{~km}$, que foi a escolhida ou um valor maior para as demais altitudes. Adicionando-se os erros envolvidos da eficiência de transmissão, e no sinal do LIDAR, que influenciam efetivamente a razão de mistura de vapor d'água, obtivemos o valor apresentado.

A estimativa do valor da secção diferencial de espalhamento Raman para o vapor d'água "experimental" difere em 9 a 18\% do valor teórico calculado por [Avila et al]. Contudo, nesse experimento, além de fatores ambientais, um bias observado no perfil de radiossondagem e considerações a respeito das larguras de 
banda dos filtros foram feitas de forma a tentar expressar a leitura do LIDAR Raman em questão para a seç̧ão diferencial de espalhamento Raman do vapor d'água .

Finalmente, para o cálculo dos fatores de calibração, temos duas abordagens. Um fator de calibração $k$ é calculado a partir dos valores de razão de secção diferencial de espalhamento calculados a partir do trabalho de [Avila et al, 2004] e da referência [Weitkamp, 2005], onde consideramos $10 \%$ de erro na secção diferencial de espalhamento do vapor d'água, estimamos um fator de calibração com uma incerteza em torno de 10,33\% para a configuração de filtros de banda larga e de aproximadamente 13\% para a configuração de filtros de banda estreita.

Se consideramos o fator de calibração calculado a partir das seç̧ões diferenciais de espalhamento obtidas experimentalmente, temos uma incerteza no fator de calibração de $\sim 10 \%$ a $18 \%$, se consideramos que ocorre um erro relativo de $18 \%$ em relação ao valor teórico. A estimativa da acurácia do fator de calibração é relativamente complexa, uma vez que não dispomos de dados efetivamente precisos, refinados e conclusivos para estimarmos os valores de razão de secção diferencial de espalhamento Raman experimentais, tratando-se apenas de uma primeira aproximação. 


\section{CAPÍTULO 8}

\section{CAMPANHA WAVES - WATER VAPOR VALIDATION EXPERIMENT}

Como qualquer técnica experimental, medidas de LIDAR são suscetíveis a incertezas experimentais, surgindo das medidas em si e das suposições ou valores imprecisos usados na análise de dados. Essas incertezas dependem de um número de fatores, incluindo o comprimento de onda do laser e outros parâmetros do sistema LIDAR, a luz do sol, a concentração de aerossóis, a validação da calibração do LIDAR, e a incerteza na transmissão atmosférica na localidade do LIDAR. Contudo, uma calibração com outros instrumentos é frequentemente realizada.

Uma campanha de pesquisa em campo, WAVES, foi realizada de 7 de Julho a 10 de Agosto de 2006, na Howard University em Beltsville, Maryland, USA, para a intercomparação entre instrumentos e validação dos dados do satélite AURA com o objetivo de obter um banco estatístico robusto de dados de medidas durante o verão para o vapor d'água, aerosol e gases traçadores para avaliar a acurácia dos instrumentos e dos dados do satélite AURA/Acqua. Uma segunda parte da campanha foi realizada em 2007 no mesmo período e também no outono de 2007. Neste trabalho abordaremos apenas os dados oriundos da WAVES de 2006 onde dados foram coletados pelo HURL e por radiossondagens. Entre os diversos tipos de radiossondas utilizados, escolhemos validar os dados de razão de mistura do vapor d'água do HURL com a sonda CFH ( Cryogenic Frostpoint Hygrometer) pois apresenta uma acurácia melhor que as demais radiossondagens disponíveis no local ( 4\%) [Nasa site, 2007] e com uma tradicional RS-92 com acurácia de $\sim 10 \%$ [Ferrare et al, 1995].

A missão AURA pesquisa a composição, química e dinâmica da atmosfera terrestre além de estudos de ozônio, qualidade do ar e clima. Os Instrumentos do AURA, o HIRDLS, MLS, OMI e TES contém tecnologias avançadas que tem sido desenvolvidas para uso em satélites ambientais. Cada instrumento fornece dados únicos que vão permitir observações globais diárias da camada de ozônio atmosférica, qualidade do ar e parâmetros climáticos chaves. Maiores informações a respeito da missão AURA podem sem encontradas em www.nasa.gov/aura.

Durante a campanha WAVES , 35 passagens do AURA foram cobertas; foram lançadas 143 radiossondagens incluindo $15 \mathrm{CFHs}$ e 35 sondas de ozônio distribuídas em 3 turnos (manhã, tarde e noite); As operações foram coordenadas 
com 6 sistemas LIDAR (4 Raman e 2 de retroespalhamento). Ocorreram colaborações entre agências e Universidades: NOAA, NASA, Departamento de meteorologia, HU, UMBC, Penn State, FOX channel. Dados de LIDAR obtidos durante WAVES foram utilizados neste trabalho, para realizarmos uma comparação com os outros sensores e uma tentativa de validação da nossa técnica de calibração absoluta. A Figuras 8 exibe alguns dos equipamentos disponíveis durante a WAVES 2006.

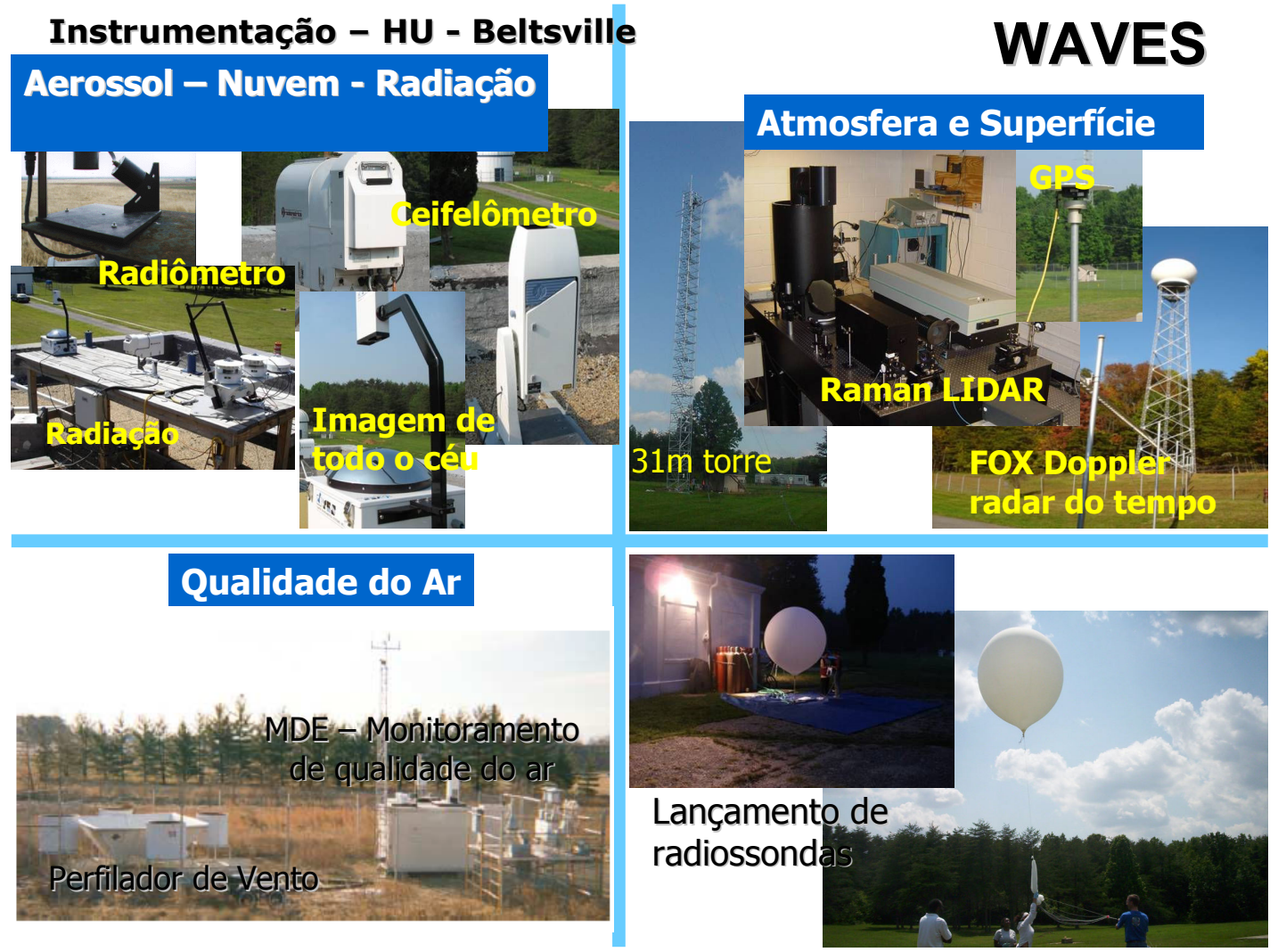

FIGURA 8. Campanha WAVES 2006: instrumentação utilizada durante a campanha de campo em Julho e Agosto de 2006. Para o nosso trabalho, utilizamos dados do microradiômetro, do Raman LIDAR e das radiossondagens RS92 e CFH.

Algumas convenções foram adotadas para os cálculos de pressão de vapor para se comparar a razão de mistura do vapor d'agua provenientes do LIDAR com dados de radiossondagens, as quais medem umidade relativa diretamente. Essas convenções foram estabelecidas baseadas em análises experimentais da campanha AWEX-G [Whiteman, 2006]. Algumas equações são apresentadas seguir. Umidade relativa tem sido definida de diferentes formas [Bohren et al, 1998]. 
A definição tradicional é de que $\mathrm{RH}$ (umidade relativa) é a razão da pressão de vapor atmosférico e, pela pressão de saturação do vapor d'água $e_{s}$ :

$$
R H=\frac{e}{e_{s}}
$$

Para a conversão de umidade relativa em razão de mistura de vapor d'água MR [Waves,2006] adotamos:

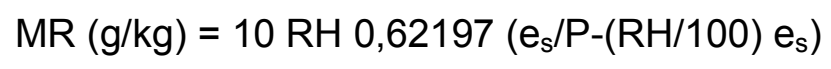

onde $\left(P, e_{s}\right.$ estão em hPa)

\subsection{Dados da WAVES para calibração com outros sensores}

Durante esta campanha dados foram coletados pelo HURL e por radiossondagens. Entre os diversos tipos de radiossondas utilizados, escolhemos validar os dados de razão de mistura do vapor d'água do HURL com a sonda CFH ( Cryogenic Frostpoing Hygrometer) pois apresenta uma acurácia melhor que as demais radiossondagens disponíveis no local ( $\sim \%)$ e com uma tradicional RS-92 com acurácia de $\sim 10 \%$ [Ferrare et al, 1995].

$\mathrm{O} \mathrm{CFH}$ é um pequeno instrumento acoplado a um balão meteorológico, 0 qual mede continuamente vapor d'água entre a superfície e a média estratosfera. É baseado no princípio de espelho resfriado e mede a temperatura de um espelho carregando uma fina camada congelada ou de orvalho, a qual é mantida em equilíbrio com o vapor d'agua do ambiente. O detector sensível a fase óptica mede a refletividade do substrato do espelho e o controlador do microprocessador de fundo regula a temperatura de tal forma que a refletividade do substrato e a camada condensada permaneçam constantes. Sob essa condição a camada condensada no espelho está em equilíbrio térmico com a fase vapor do ar passando sobre o espelho. A temperatura do espelho é então igual ao ponto de orvalho ambiente ou temperatura de ponto de congelamento e a razão de mistura de vapor d'água e a umidade relativa podem ser calculadas dessa observação usando a equação de Clausius Clapeyron [Rogers e Yau,1989].

O CFH normalmente é acoplado ao balão com sondas ECC, GPS e uma radiossonda RS-80, a qual é usada como transmissora de dados. Logo, além da razão de mistura de vapor d'água, cada lançamento de um CFC nos fornece razão 
de mistura de ozônio e pressão atmosférica com a RS80, dados de umidade e temperatura, os quais são usados para determinar altitude, temperatura potencial e razão de mistura de vapor d'água. Na Tabela 21 são apresentadas algumas características do instrumento $\mathrm{CFH}^{1}$ :

TABELA 21 . Parâmetros do instrumento CFH.

\begin{tabular}{|c|c|}
\hline Faixa de medida vertical: & $0 \mathrm{~km} \mathrm{a} \sim 28 \mathrm{~km}$ \\
\hline $\begin{array}{l}\text { Faixa de detecção de ponto de orvalho ou } \\
\text { ponto de congelamento: }\end{array}$ & $>+25 \mathrm{C}$ a $<-95 \mathrm{C}$ \\
\hline Faixa de detecção de razão de mistura: & $>25000$ ppmv a $<0.8 p p m v$ \\
\hline $\begin{array}{l}\text { Incerteza no ponto de orvalho ou ponto de } \\
\text { congelamento: }\end{array}$ & $0.5 \mathrm{C}$ \\
\hline Incerteza na razão de mistura: & $\begin{array}{l}3.5 \% \\
\text { (superfície), } 9 \% \text { (tropopausa), 11\%(28km) }\end{array}$ \\
\hline Resolução vertical: & 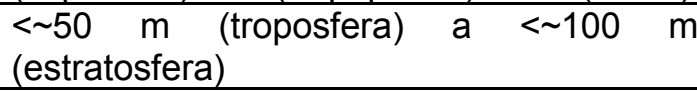 \\
\hline Peso do instrumento $\mathrm{CFH}$ : & $400 \mathrm{~g}$ \\
\hline CFH+ECC+RS80 peso do pacote & $1500 \mathrm{~g}$ \\
\hline
\end{tabular}

Nos arquivos de dados do $\mathrm{CFH}$, a razão de mistura MR foi dada em ppmv (partes por milhão de volume) e temos que converter em $\mathrm{g} / \mathrm{Kg}$ usando a relação:

$$
M R=0,001 p p m v\left(\frac{M W}{M W D}\right)
$$

Onde MW é o peso molecular do vapor d'água e MWD é o peso molecular do ar seco.

A Figura 8.1 mostra o pacote de radiossondagem com um $\mathrm{CFH}$ e uma sonda RS92 acoplado durante o lançamento na WAVES. 


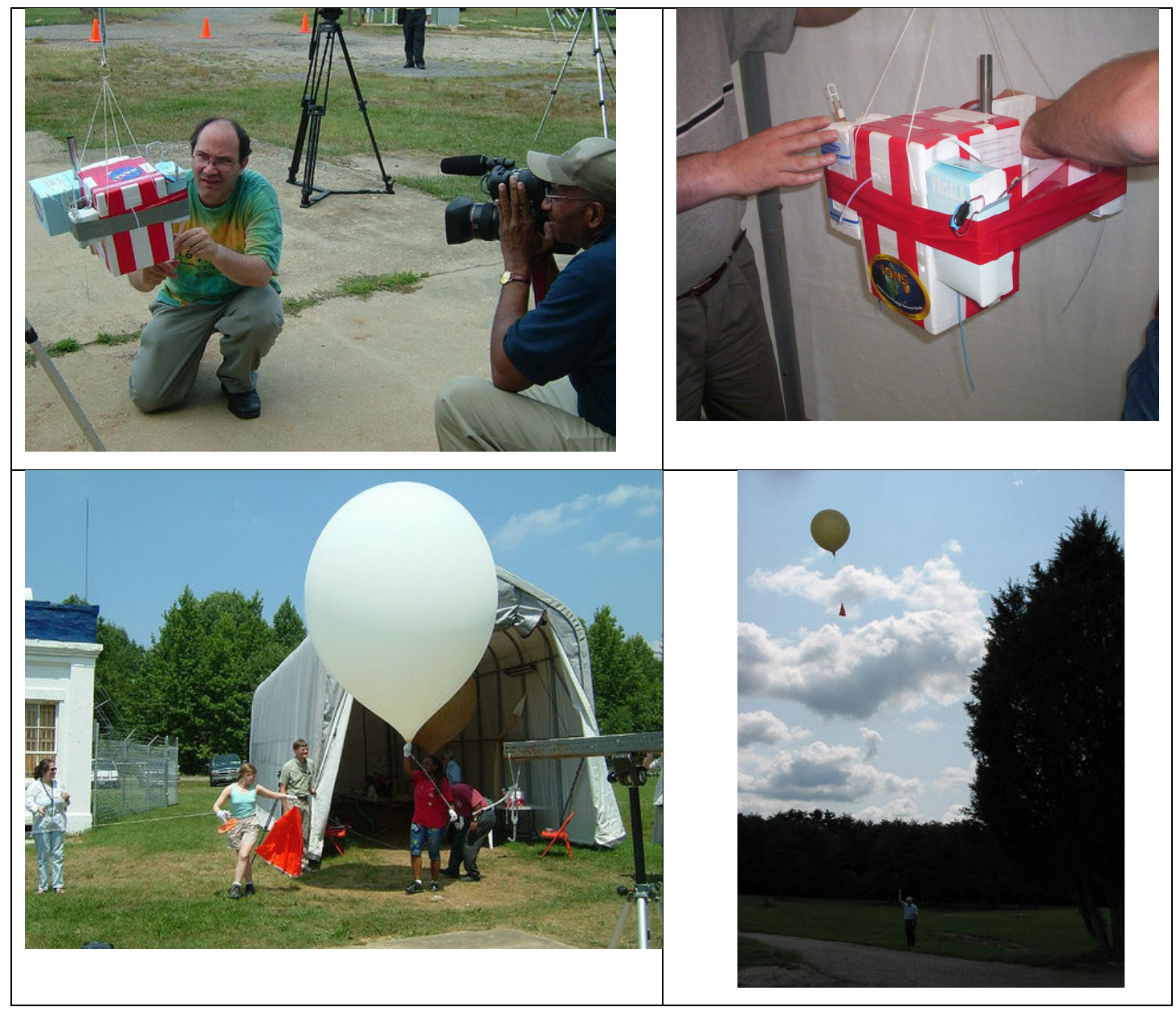

FIGURA 8.1. Pacote de radiossondas (acima) e lançamento do balão meteorológico com as sondas RS92, RS80 e CFH.

Uma comparação dos perfis de razão de mistura do vapor d'água obtidos pelo HURL calibrado de forma independente, HURL calibrado com um microradiômetro, perfil de sonda CFH e da RS 92 foi realizada.

A comparação com perfis calibrados por meio de um microradiômetro (MWR), integrando-se os dados LIDAR para obtermos a coluna de água precipitável, é apresentada nas figuras 8.2, e 8.3.

A comparação com perfis calibrados por meio de um microradiômetro (MWR), integrando-se os dados LIDAR para obtermos a coluna de água precipitável, foi apresentada na figura 8.2. De acordo com as figuras apresentadas acima, observa-se que os dados obtidos por meio da calibração absoluta do LIDAR na região do overlap incompleto $(<1,5 \mathrm{~km})$, não apresentaram um perfil satisfatório. 
Um refinamento no cálculo do coeficiente de calibração seria necessário, levandose em conta a variação da constante de calibração com a altitude.

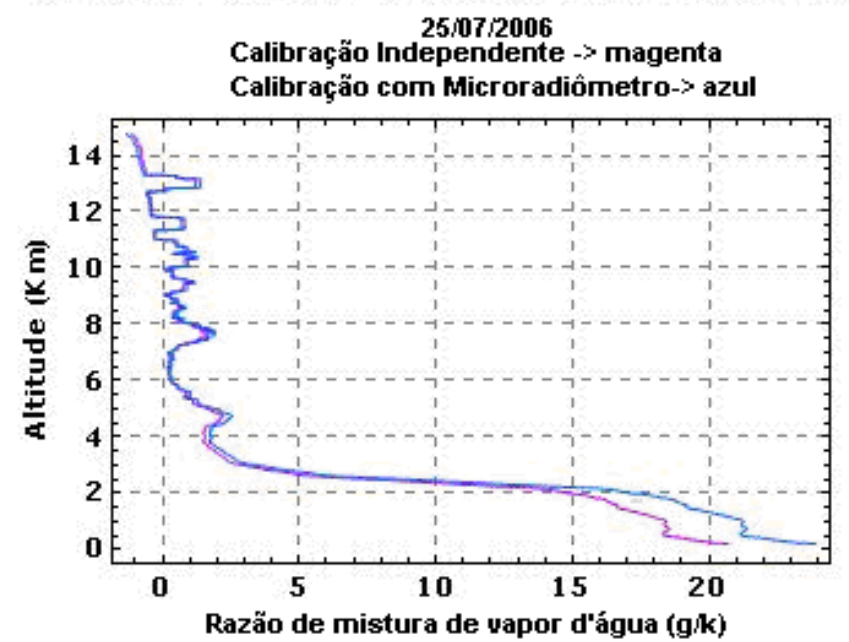

FIGURA 8.2. Comparação da razão de mistura do vapor d'água obtida pelo HURL calibrada de forma independente (em azul) e calibrada com o uso do microradiômetro (em magenta).

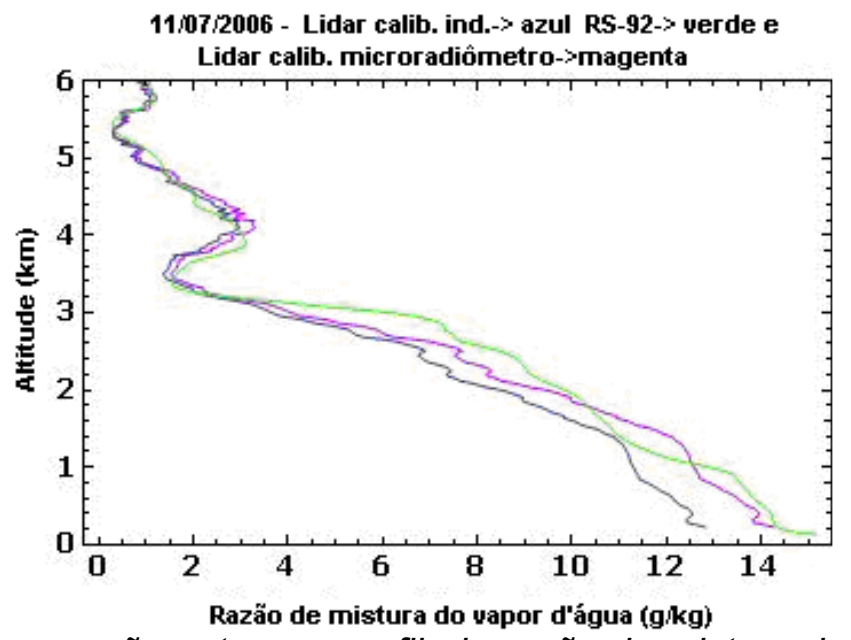

FIGURA 8.3 Comparação entre um perfil de razão de mistura do vapor d'água (á esquerda) obtido pelo HURL calibrado de forma independente (em azul), calibrado com o MWR (magenta) e obtido por uma radiossonda RS-92 (verde) durante a campanha WAVES e depois de feitas as correções da radiossondagem propostas por [Miloshevich, 2006]. 


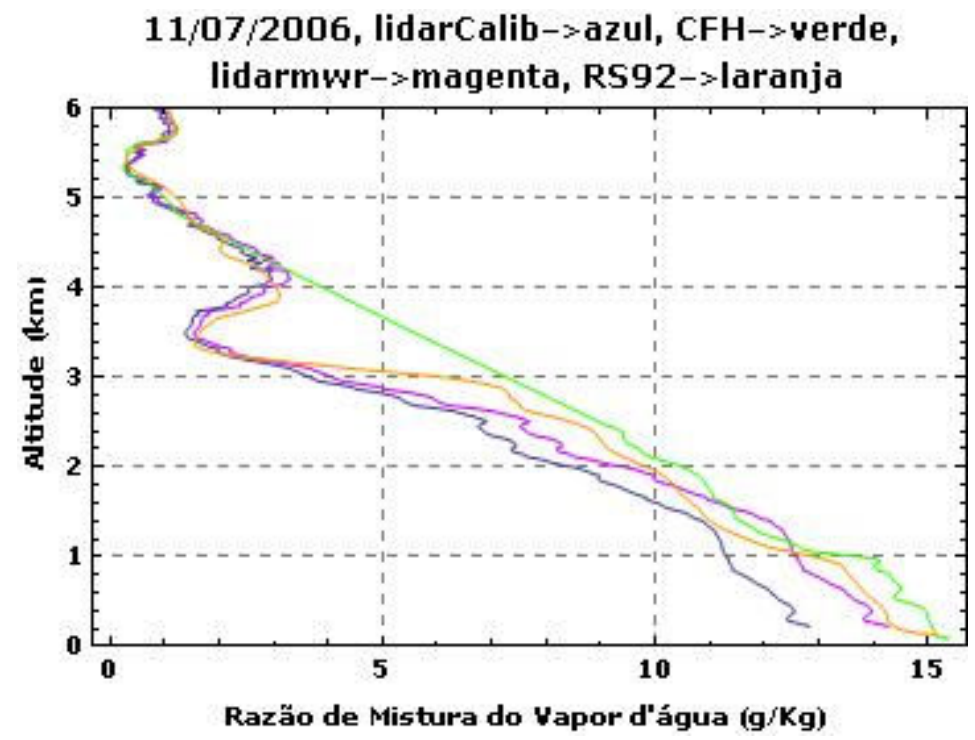

FIGURA 8.4 Comparação entre um perfil de razão de mistura do vapor d'água obtido pelo HURL calibrado de forma independente (em azul), calibrado com o MWR (magenta) e obtido por uma radiossonda RS-92 (laranja) e pelo CFH (verde)) durante a campanha WAVES e depois de feitas as correções da radiossondagem propostas por [Miloshevich, 2006] para o dia 11 de Julho de 2006 as 06:06 UT (tempo de integração de 31 minutos).

De acordo com a figura 8.2 uma discrepância é presente em baixas altitudes provavelmente devido a algum bias da radiossondagem (abaixo de $2 \mathrm{~km}$ ). Esses dados de LIDAR foram corrigidos com a função de dependência com a temperatura, a função de overlap e a função de transmissão. Apesar da relativa grande discrepância apresentada, o perfil de razão de mistura obtido através da técnica de calibração independente apresentou coerência com os perfis.

Os resultados mostraram um bom ajuste entre os dois perfis com um erro relativo em torno de 13\% (LIDAR-MWR/LIDAR). A razão entre os perfis em média estava na faixa de 0,9 . 


\section{CAPÍTULO 9}

\section{CONCLUSÕES PARCIAIS}

Apresentamos um esforço para desenvolver uma metodologia de calibração absoluta para medidas de vapor d'água por LIDAR Raman. O método é baseado em uma análise cuidadosa da eficiência ótica dos componentes do sistema LIDAR. Uma avaliação da homogeneidade espectral do receptor LIDAR foi realizada com o experimento de mapeamento. Os resultados nesse experimento indicaram que as bordas do telescópio e a região em torno da obstrução causada pelo periscópio mostraram uma diminuição na eficiência de transmissão enquanto que a área de recepção do sinal (equivalente a área livre de obstruções no espelho primário) apresentou aparente boa homogeneidade. Uma lâmpada de tungstênio foi utilizada nesse mapeamento. Sua irradiância espectral não obedeceu exatamente a lei da radiação de Planck, logo os valores de irradiância fornecidos pelo fabricante foram utilizados para ajustar uma função polinomial que calcula a intensidade da lâmpada nos comprimentos de onda desejados. Baseado em um estudo de sensibilidade, quantificamos o erro na razão das duas intensidades nos comprimentos de onda de interesse emitidos pela lâmpada, que é necessário para o cálculo do erro do coeficiente de calibração para a razão de mistura de vapor d'água. $O$ erro encontrado foi de $\sim 0,6 \%$.

Duas configurações de filtros de interferência foram utilizadas nesse estudo. Uma com filtros de interferência de banda larga, outra com filtros de banda estreita, os quais foram selecionados de acordo com a dependência (ou não) com a temperatura das secções diferencial de espalhamento Raman do vapor d'água. A equação 3.53 indica uma dependência com a temperatura dada a faixa spectral da configuração de filtro de interferência empregada no experimento. Os filtros de interferência foram avaliados para obtermos as incertezas relativas de transmissão, responsável pelas perdas de luz incidente no sistema, através de espectrômetros e dados disponíveis. Essas incertezas foram de $\sim 0,06 \%$ para a configuração de filtros de banda larga (incluindo os filtros de densidade neutra) e $0,27 \%$ para a configuração de filtros de banda estreita.

Com os valores de incerteza da lâmpada de tungstênio e dos fatores de correção do filtro, as taxas de contagem, a incerteza da eficiência total do sistema 
foi calculada a partir de fórmulas de propagação de erros. Para a configuração de banda larga, obtivemos um erro de $0,51 \%$ e para a de banda estreita, 8,57\%. Esses valores são utilizados no cálculo do erro do fator de calibração absoluta.

Um modelo publicado recentemente [Avila et al, 2004] foi escolhido para calcular as secções diferenciais de espalhamento do vapor d'água, e baseado na literatura, calculamos também as do nitrogênio. A função $F(T)$ mostrou que a secções iferenciais de espalhamento Raman do vapor d'água tem dependência com a temperatura quando utilizamos filtros de interferência estreitos. O mesmo já não ocorreu para filtros largos.

A comparação com a radiossonda RS-92 e o CFH, mostrou que para maiores altitudes (acima do overlap) o perfil de razão de mistura de calibração absoluta coincidiu melhor. A constante de calibração encontrada para o sistema foi coerente com o valor obtido através de uma comparação com uma radiossondagem para configurações de banda larga. Já no caso da configuração de filtro de banda estreita, a 290 K, e a partir da aplicação da fórmula para o cálculo da constante de calibração, para valores de razão de secção diferencial de espalhamento Raman obtidos experimentalmente, obtivemos o valor de 192. Uma sugestão para trabalho futuro seria calcularmos a constante de calibração em função da altitude, uma vez que a temperatura muda em função da altitude.

Outro importante resultado desta pesquisa foi a obtenção/estimativa da razão das secções diferenciais de espalhamento Raman por meio de um experimento. $O$ valor encontrado difere entre 9 até $18 \%$ dos valores encontrados por Penney and Lapp.

Através da aplicação de fórmulas de propagação de erros, encontramos um erro de $10,3 \%$ para a constante de calibração obtida em um sistema com filtros de interferência de banda larga instalados. O erro encontrado para a constante de calibração em um sistema configurado com filtros de intereferência de banda estreita foi de $\sim 13 \%$ considerando no cálculo as secções de espalhamento diferencial Raman calculadas na teoria.

Oferecemos essa técnica como uma alternativa para a calibração de sistemas LIDAR Raman para vapor d'água de forma independente. 


\section{PARTE 2:}

IMPLEMENTAÇÃO DE UM LIDAR RAMAN NO INSTITUTO DE PESQUISAS ENERGÉTICAS E NUCLEARES - IPEN, SÃO PAULO 


\section{CAPÍtULO 10}

\section{O LIDAR DO MUNICÍPIO DE SÃO PAULO - MSP- RAMAN LIDAR}

O Laboratório de Aplicações Ambientais a Laser foi implementado em 2001 [Landulfo et al, 2003], e está localizado no Instituto de Pesquisas Energéticas e Nucleares (IPEN) no Centro de Lasers e Aplicações. O principal instrumento deste laboratório é um sistema de sensoriamento remoto com laser, que opera segundo a técnica de LIDAR [Measures, 1984], e cujo princípio de funcionamento é pelo retroespalhamento elástico de luz coerente (Laser) em aerossóis e moléculas presentes na atmosfera. O comprimento de onda em que o LIDAR opera é $532 \mathrm{~nm}$ (visível), correspondente ao segundo harmônico do laser de Nd:YAG. Este tipo de LIDAR permite a monitoração de poluentes, observando a variação da estrutura vertical da atmosfera, de 300 a 10000 m (25000 à noite). A partir de 2006, incorporou-se ao sistema um módulo adicional que gera o terceiro harmônico da transição fundamental, isto é, um comprimento de onda de $355 \mathrm{~nm}$ (ultravioleta). Esta adição nos permite medir não só a interação elástica, mas também a inelástica através do efeito Raman, que pode ocorrer pela absorção do comprimento de onda emitido pelo laser pelos estados rotacionais/vibracionais das moléculas presentes na atmosfera, e a seguir, vão reemitir em um valor diferente. Sistemas LIDAR que operam com este princípio são chamados de LIDAR Raman, e no nosso caso chamaremos nosso sistema de MSP-Raman LIDAR. Através de medidas LIDAR, elásticas e Raman, pode-se estudar a variação da camada Limite e de Mistura, estudar a dinâmica atmosférica, o retroespalhamento dos aerossóis, estudar a densidade atmosférica através do canal Raman, estudos com tendência climatológica, a exemplo do estudo de aerossóis, em andamento desde 2001, validação de modelos regionais e de qualidade do ar, estudos de perfis de razão de mistura do vapor d'água, e validação de instrumentos a bordo de satélites.

A seguir, é descrito o sistema MSP-Raman LIDAR implementado para medidas de aerossol e vapor d'água.

\subsection{Implementação do MSP- Raman LIDAR}

Com a instalação do módulo gerador do terceiro harmônico do laser (355 nm) Nd:YAG, foi possível implementarmos um sistema LIDAR Raman. Para isso, dois canais foram adicionados ao sistema, um para o nitrogênio (387 nm) e outro para o 
vapor d'água (408 nm), pela instalação de módulos registradores de transiente, espelhos divisores de feixe e filtros de interferência correspondentes para os dois canais. Na Tabela 22 são descritos os principais parâmetros do sistema MSPRaman LIDAR do IPEN, em São Paulo. Esse sistema permite medidas em tempo real de perfis atmosféricos de aerossóis e da razão de mistura do vapor d'água, além de possuir a opção de operar no modo elástico (com emissão a $532 \mathrm{~nm}$ ) para estudos de espalhamento elástico do aerossol, camada limite, etc.

TABELA 22. Parâmetros do sistema MSP-Raman LIDAR

\begin{tabular}{|c|c|}
\hline Geometria & Zenith, geometria coaxial \\
\hline Laser & $\begin{array}{l}\text { Quantel operando no } 3^{\circ} \text { harmônico de } \mathrm{Nd} \text { :YAG, com } 6 \mathrm{~mm} \text { de } \\
\text { diâmetro do feixe, } 20 \mathrm{~Hz} \text {, divergência de } 0,5 \text { mrad, com } \sim 40 \mathrm{~mJ} \text { no } \\
354,7 \mathrm{~nm} \text {, duração do pulso: } 4 \mathrm{~ns} \text {, Energia por pulso } 160 \mathrm{~mJ} \\
\text { (máxima para } 532 \mathrm{~nm} \text { ). }\end{array}$ \\
\hline Telescópio & $\begin{array}{l}\text { Newntoniano, espelho primário com } 300 \mathrm{~mm} \text { de diâmetro, } \mathrm{F}=130 \\
\mathrm{~cm} \text {, Campo de visão variável }(0,5-5 \mathrm{mrad}) \text { com o uso de um } \\
\text { diafragma, Overlarp } \sim 180 \mathrm{~m} \text {, Material do espelho primário: Duran } \\
50 \text { (baixo coeficiente de dilatação térmica) }\end{array}$ \\
\hline Expansor & Expansor de feixe $3 \mathrm{X}$ \\
\hline $\begin{array}{l}\text { Módulo separador } \\
\text { de } \lambda\end{array}$ & $\begin{array}{l}3 \text { canais com filtros de interferência a } 354,7 \mathrm{~nm}, 386,5 \mathrm{~nm} \text { e } 407,5 \\
\text { nm com largura } \sim 0,22 \mathrm{~nm} \text { e outro set com filtros } \sim 20 \mathrm{~nm} \text {. Lente } \\
\text { colimadora, } \mathrm{F}=50 \mathrm{~mm} \text {; Divisores de feixe: } \\
\mathrm{T}>90 \% 387 \text { e } 408 \mathrm{~nm} \text { e R }>90 \% \text { a } 355 \mathrm{~nm} \\
\mathrm{~T}>90 \% \text { a } 408 \mathrm{~nm} \text { e R }>90 \% \text { a } 387 \mathrm{~nm} \\
\mathrm{~T}>90 \% \text { a } 355 \mathrm{~nm}\end{array}$ \\
\hline $\begin{array}{l}\text { PMT - } \\
\text { fotomultiplicadoras }\end{array}$ & $\begin{array}{l}\text { Hamamatsu R7400, Alta voltagem (V) 0-1000, Voltagem } \\
\text { suplementar (V) }+15 \text {, Corrente limite: } 100 \mu \mathrm{A} \text {. }\end{array}$ \\
\hline $\begin{array}{l}\text { Registrador de } \\
\text { transientes - Licel }\end{array}$ & $\begin{array}{l}\text { Modo contagem de fótons (PC) e analógico, taxa máxima de } \\
\text { contagens no modo } P C->250 \mathrm{MHz} \text {, resolução } A / D 12 \text { bits, uso de } \\
\text { trigger }\end{array}$ \\
\hline Software A & $\begin{array}{l}\text { Licel/Labview via placa, rotinas de análise customizadas no } \\
\text { mathematica e outro software desenvolvidos em linguagens de } \\
\text { programação. }\end{array}$ \\
\hline
\end{tabular}




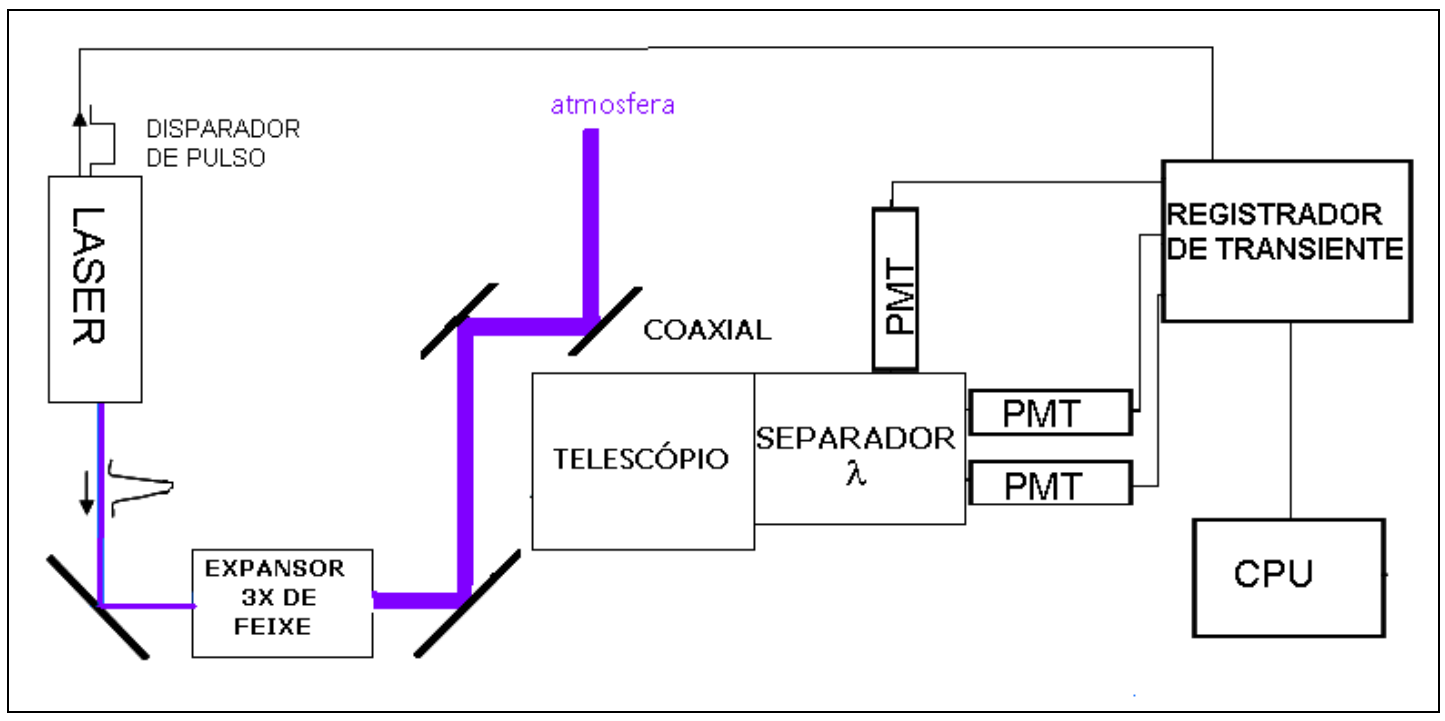

FIGURA 10 . Diagrama de bloco do sistema MSP-Raman LIDAR

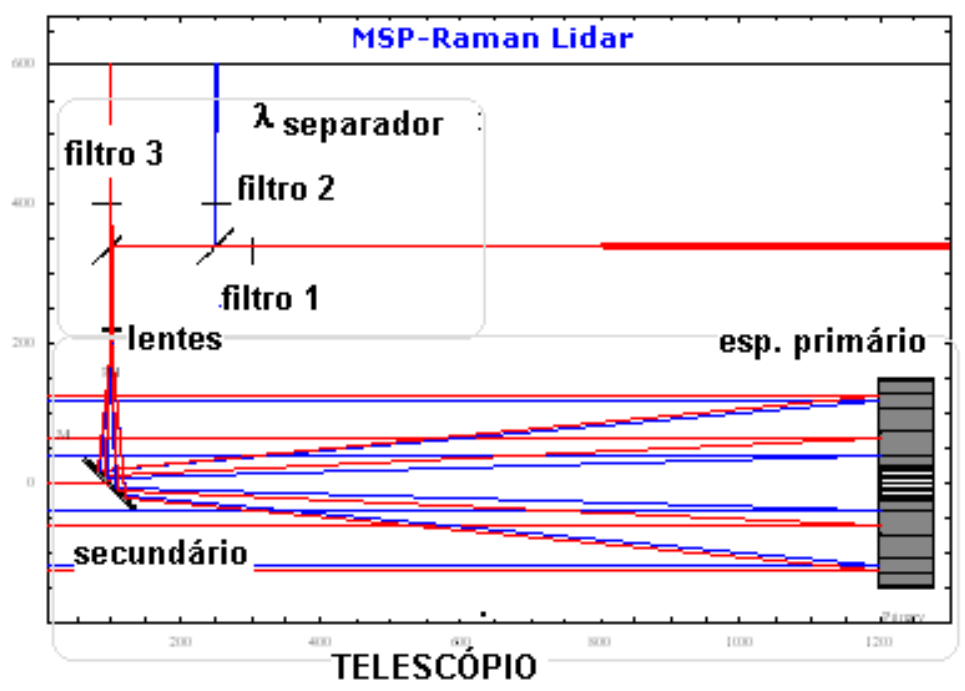

FIGURA 10.1 "Ray-trace" do sistema MSP-Raman LIDAR representando o telescópio e a unidade separadora de comprimento de onda com os três filtros de interferência 1, 2 e 3 correspondendo ao canais 355, 387 e 408 nm. 


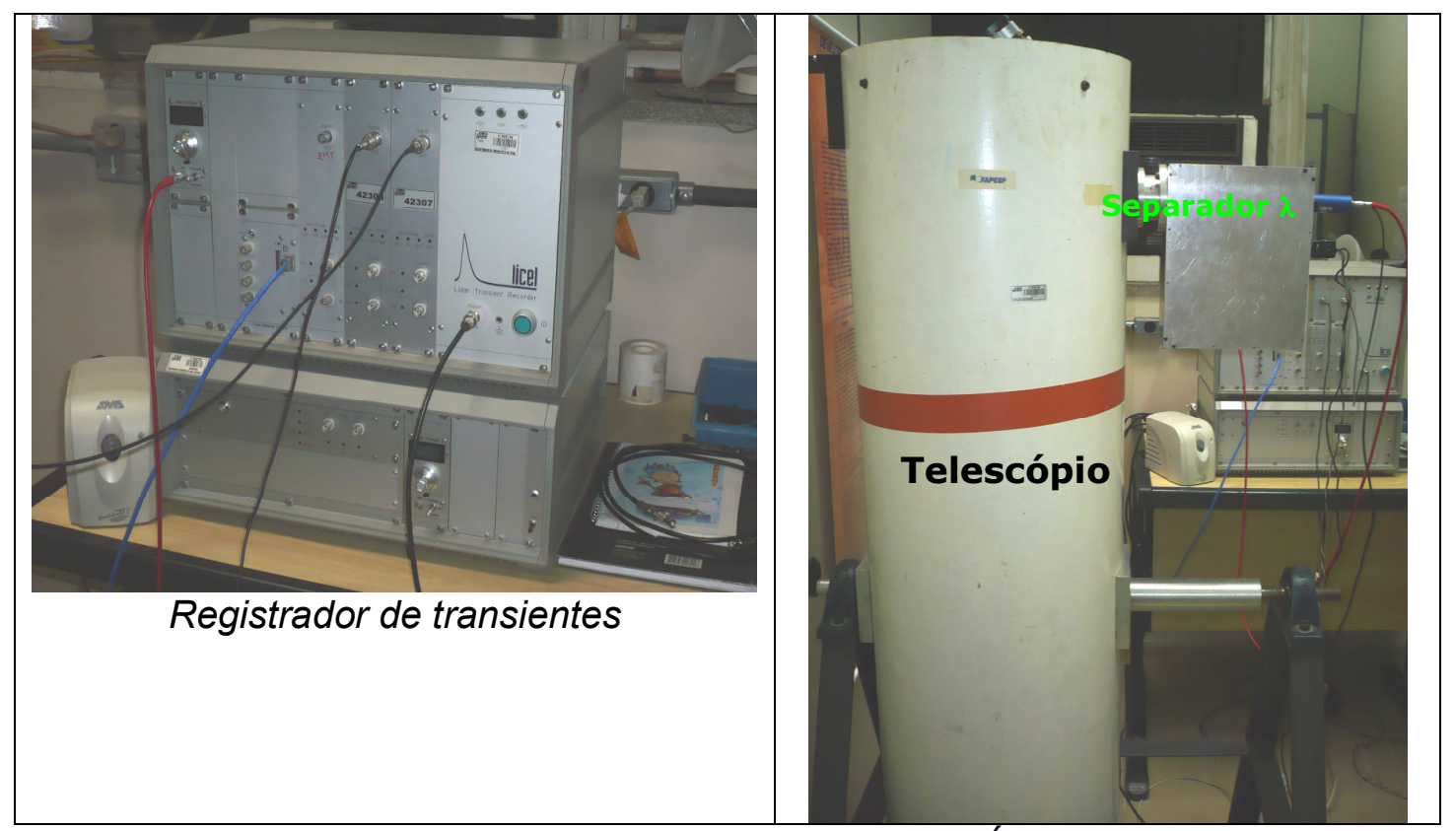

FIGURA 10.2. Fotos do sistema MSP-Raman LIDAR. Á esquerda o registrador de transientes (Licel) e a direita o telescópio e a caixa de detecção ou separador de comprimento de onda $\lambda$.

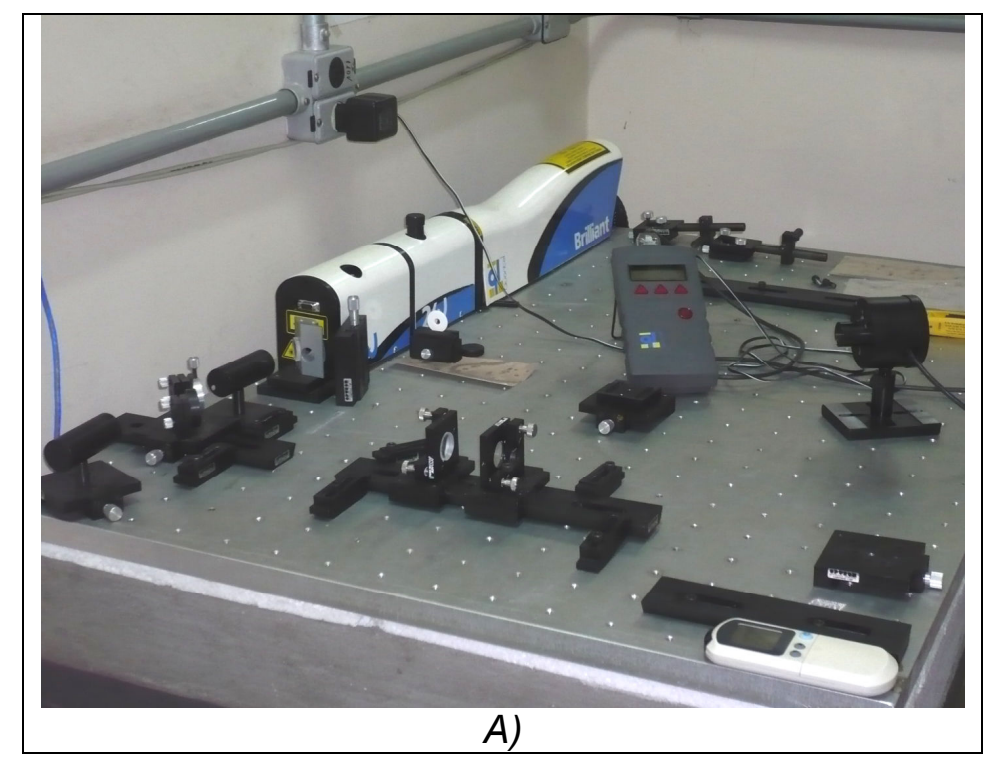

FIGURA 10.3. A) Laser Nd:YAG da Quantel com módulos geradores do segundo e terceiro harmônicos no arranjo ótico com expansor de feixe e espelhos refletores. 


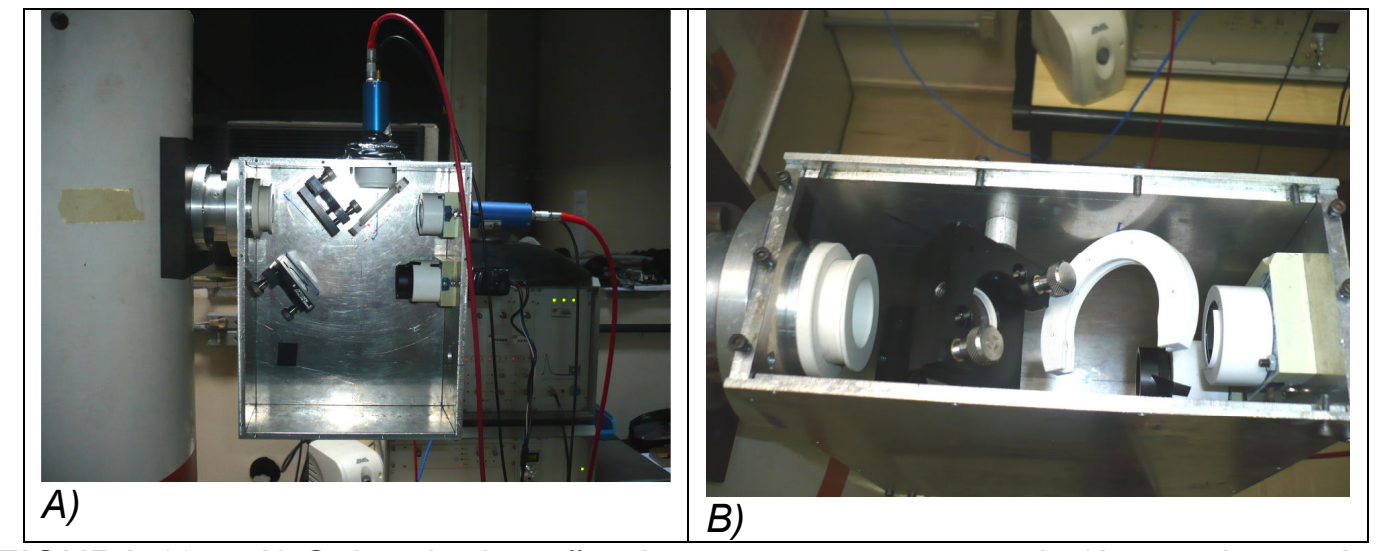

FIGURA 10.4. A) Caixa de deteção aberta com os três canais (água, nitrogênio e aerossol). B) Vista de cima da caixa separadora de comprimento de onda, com filtros de interferência e espelhos divisores de feixe.

\subsection{Formalismo obtenção de perfis de aerossóis por LIDAR Raman}

A razão de espalhamento do aerossol é usada para quantificar a razão do aerossol (ou espalhamento Mie) em relação ao espalhamento molecular. Isso é definido como a razão dos coeficientes de volume de retroespalhamento em relação ao espalhamento total (molecular mais aerossol) para o espalhamento molecular puro e pode ser expressa como:

$$
\begin{aligned}
& \Re\left(\lambda_{L}, r\right)=\frac{\beta_{\pi}^{\text {tot }}\left(\lambda_{L}, r\right)}{\beta_{\pi}^{\text {mol }}\left(\lambda_{L}, r\right)} \\
& \Re\left(\lambda_{L}, r\right)=\frac{\beta_{\pi}^{\text {mol }}\left(\lambda_{L}, r\right)+\beta_{\pi}^{\text {aer }}\left(\lambda_{L}, r\right)}{\beta_{\pi}^{\text {mol }}\left(\lambda_{L}, r\right)} \\
& \mathfrak{R}\left(\lambda_{L}, r\right)=1+\frac{\beta_{\pi}^{\text {aer }}\left(\lambda_{L}, r\right)}{\beta_{\pi}^{\text {mol }}\left(\lambda_{L}, r\right)}
\end{aligned}
$$

Onde o coeficiente de volume retroespalhado molecular $\beta_{\pi}^{\text {mol }}\left(\lambda_{L}, r\right)$ é dado por $\mathrm{N}^{\mathrm{mol}}(\mathrm{r}) \mathrm{d} \sigma_{\mathrm{mol}}(\pi) / \mathrm{d} \Omega$ [Whiteman, 2003, Measures, 1984], $\beta_{\pi}^{\text {aer }}$ é o coeficiente de retroespalhamento do aerossol.

O LIDAR Raman é capaz de quantificar a razão de espalhamento do aerossol de uma maneira mais direta que os sistemas Rayleigh-Mie. O LIDAR Raman mede um sinal que é proporcional à densidade molecular do nitrogênio (ou oxigênio). Esse sinal pode ser usado como uma quantificação direta do denominador da equação 10. Um simples LIDAR Rayleigh-Mie não possui tal sinal e tem que recorrer a métodos de inversão para determinar essa razão.

O cálculo da razão de espalhamento do aerossol a partir do sinal LIDAR é descrito abaixo. A partir das equações de LIDAR Raman para sinais LIDAR com 
backgrounds subtraídos, para comprimentos de onda do laser $\lambda_{L}$ e comprimentos Raman do nitrogênio $\lambda_{N}$, temos:

$$
\frac{P\left(\Delta \lambda_{R}, r\right)}{P\left(\Delta \lambda_{N}, r\right)}=\frac{O_{R}(r)}{O_{N}(r)} \frac{\xi\left(\lambda_{L}\right)}{\xi\left(\lambda_{N}\right)} \frac{F_{R}[T(r)] \beta_{\pi}^{m o l}\left(\lambda_{L}, r\right)+\beta_{\pi}^{\text {aer }}\left(\lambda_{L}, r\right)}{F_{N}[T(r)] N_{N}(r)\left[d \sigma_{N}(\pi) / d \Omega\right]} \exp \left\{-\int_{0}^{r}\left[\alpha\left(\lambda_{L}, r^{\prime}\right)-\alpha\left(\lambda_{N}, r^{\prime}\right) d r^{\prime}\right.\right.
$$

O coeficiente de espalhamento Raman para moléculas de $\mathrm{N}_{2}$ é $\beta_{\pi}^{N}\left(\lambda_{L}, r\right)=N_{N}(r) d \sigma_{N}(\pi) / d \Omega$ e é proporcional ao coeficiente de retroespalhamento Rayleigh para o ar porque $\mathrm{N}_{2}$ é bastante misturado na baixa atmosfera. Esse fator pode ser expresso como:

$$
\beta_{\pi}^{N}\left(\lambda_{L}, r\right)=C_{N} \beta_{\pi}^{m o l}\left(\lambda_{L}, r\right)
$$

Se o sinal Raman o $\mathrm{O}_{2}$ for usado para normalizar a razão de espalhamento, a equação seria:

$$
\beta_{\pi}^{0}\left(\lambda_{L}, r\right)=C_{0} \beta_{\pi}^{m o l}\left(\lambda_{L}, r\right)
$$

O fator de proporcionalidade $C_{N}$ na equação 10.1 pode ser calculado para 0 uso de diferentes fontes de laser, escalonando os valores da secção diferencial de espalhamento para $337,1 \mathrm{~nm}$ [Measures, 1984] e pelo fato do $\mathrm{N}_{2}$ e do $\mathrm{O}_{2}$ formarem $\sim 0,78$ e 0,21 da atmosfera respectivamente, logo:

$$
\begin{aligned}
& C_{N}\left(\lambda_{L}=351\right) \cong 0,78 \frac{d \sigma_{N}(\pi) / d \Omega\left(\lambda_{L}=351\right)}{d \sigma_{m o l}(\pi) / d \Omega\left(\lambda_{L}=351\right)} \cong 0,78 \frac{2,9 \times 10^{-30}}{3,3 \times 10^{-27}} \cong 6,9 \times 10^{-4} \\
& C_{N}\left(\lambda_{L}=355\right) \cong 0,78 \frac{d \sigma_{N}(\pi) / d \Omega\left(\lambda_{L}=355\right)}{d \sigma_{m o l}(\pi) / d \Omega\left(\lambda_{L}=355\right)} \cong 0,78 \frac{2,8 \times 10^{-30}}{3,2 \times 10^{-27}} \cong 6,8 \times 10^{-4} \\
& C_{N}\left(\lambda_{L}=532\right) \cong 0,78 \frac{d \sigma_{N}(\pi) / d \Omega\left(\lambda_{L}=532\right)}{d \sigma_{m o l}(\pi) / d \Omega\left(\lambda_{L}=532\right)} \cong 0,78 \frac{4.6 \times 10^{-31}}{6.3 \times 10^{-28}} \cong 5,7 \times 10^{-4} \\
& C_{O}\left(\lambda_{L}=351\right) \cong 0,21 \frac{d \sigma_{o}(\pi) / d \Omega\left(\lambda_{L}=351\right)}{d \sigma_{m o l}(\pi) / d \Omega\left(\lambda_{L}=351\right)} \cong 0,21 \frac{3,9 \times 10^{-30}}{3,3 \times 10^{-27}} \cong 2,5 \times 10^{-4} \\
& C_{O}\left(\lambda_{L}=355\right) \cong 0,21 \frac{d \sigma_{o}(\pi) / d \Omega\left(\lambda_{L}=355\right)}{d \sigma_{m o l}(\pi) / d \Omega\left(\lambda_{L}=355\right)} \cong 0,21 \frac{3,7 \times 10^{-30}}{3.2 \times 10^{-27}} \cong 2,4 \times 10^{-4} \\
& C_{0}\left(\lambda_{L}=532\right) \cong 0,21 \frac{d \sigma_{o}(\pi) / d \Omega(\lambda=532)}{d \sigma_{m o l}(\pi) / d \Omega(\lambda=532)} \cong 0,21 \frac{6,5 \times 10^{-31}}{6,3 \times 10^{-28}} \cong 2,2 \times 10^{-4}(10 .
\end{aligned}
$$


Equações 10.1 e 10.2 podem ser combinadas para expressar $\mathfrak{R}\left(\lambda_{L}, r\right)$. $O$ resultado é

$$
\Re\left(\lambda_{L}, r\right)-1=\frac{\beta_{\pi}^{\text {aer }}\left(\lambda_{L}, r\right)}{\beta_{\pi}^{\text {mol }}\left(\lambda_{L}, r\right)}=C_{N}\left(\lambda_{L}\right) F_{N}[T(r)] \times \frac{O_{N}(r) \xi\left(\lambda_{N}\right) P\left(\Delta \lambda_{R}, r\right)}{O_{R}(r) \xi\left(\lambda_{L}\right) P\left(\Delta \lambda_{N}, r\right)} \Delta \tau\left(\lambda_{N}, \lambda_{L}, r\right)-F_{R}[T(r)]
$$

Uma expressão similar pode ser derivada pelo uso do sinal Raman do oxigênio como sinal normalizador na razão de espalhamento. Inserindo os termos de overlap e eficiências da equação 10.11 em um novo termo, $C^{*} N\left(\lambda_{L}, r\right)$ temos:

$$
\begin{gathered}
\Re\left(\lambda_{L}, r\right)-1=C_{N}^{*}\left(\lambda_{L}, r\right) F_{N}[T(r)] \frac{P\left(\Delta \lambda_{L}, r\right)}{P\left(\Delta \lambda_{N}, r\right)} \times \Delta \tau\left(\lambda_{N}, \lambda_{L}, r\right)-F_{R}[T(r)] \\
C_{N}^{*}\left(\lambda_{L}, r\right)=C_{N}\left(\lambda_{L}\right) \frac{O_{N}(r) \xi\left(\lambda_{N}\right)}{O_{R}(r) \xi\left(\lambda_{L}\right)}
\end{gathered}
$$

As funções de sensibilidade a temperatura $F_{R}(r), F_{O}(r)$ e $F_{N}(r)$ em geral quantificam a seç̧ão diferencial de espalhamento efetiva molecular consistente como uso de um termo de eficiência óptica monocromática $\xi(\lambda X)$ na equação LIDAR. Um filtro de banda estreita transmite menos linhas Raman rotacionais (ou vibracionais-rotacionais) e assim menos da secção diferencial de espalhamento total.

10.2.1 Equações de erros da razão de espalhamento do aerossol

A componente randômica do erro na determinação de $\mathfrak{R}\left(\lambda_{L}, r\right)$ é dada pela aplicação de fórmulas padrão de propagação de erro [Bevington, 1992] na equação 10.12;

$$
\begin{aligned}
& \frac{\sigma_{\Re}^{2}}{\mathfrak{R}^{2}}=\frac{\sigma_{C_{N}^{* 2}}^{2}}{C_{N}^{* 2}}+\frac{\sigma_{A}^{2}}{A^{2}}+\frac{\sigma_{\Delta \tau^{2}}^{2}}{\Delta \tau^{2}}, \\
& \sigma_{\mathfrak{R}}^{2}=T^{2}\left(\frac{\sigma_{C_{N}^{*}}^{2}}{C_{N}^{* 2}}+\frac{\sigma_{F_{N}}^{2}}{F_{N}^{2}}+\frac{\sigma_{A}^{2}}{A^{2}}+\frac{\sigma_{\Delta \tau}^{2}}{\Delta \tau^{2}}\right)+\sigma_{F_{R}}^{2}
\end{aligned}
$$

Onde a seguinte notação foi utilizada:

$$
\begin{gathered}
T=C_{N}^{*}\left(\lambda_{L}, r\right) F_{N}[T(r)] A \Delta \tau\left(\lambda_{N}, \lambda_{L}, r\right) \\
A=\frac{P\left(\Delta \lambda_{R}, r\right)}{P\left(\Delta \lambda_{N}, r\right)}
\end{gathered}
$$

Onde A representa a razão do sinais LIDAR com background subtraídos. 
É conhecido que a atmosfera oferece uma ferramenta de calibração natural que permite calibrações precisas da razão de espalhamento [Whiteman, II, 2003]. Erros no termo de transmissão diferencial podem ser mantidos baixos através da medida direta da extinção do aerossol. Quantificar o erro envolvido nas funções de sensibilidade com a temperatura $F_{n}(T)$ é complexo pois o erro está relacionado com o fomato da banda passante do filtro, a temperatura atmosférica e o espectro da espécie molecular que está sendo medida. Contudo, estima-se que o efeito de ambas funções dependentes de temperatura no cálculo da razão de espalhamento seja da ordem de 10\% [Whiteman, II, 2003]. A incerteza no cálculo da funções dependentes da temperatura pode ser menor que 10\%, implicando que a contribuição da dependência com a temperatura do balanço total de erro pode estar abaixo de 1\%. Em geral, o erro randômico no cálculo da razão de espalhamento é tipicamente dominado pela incerteza na razão dos sinais LIDAR. Portanto, quantificar o erro padrão na razão de espalhamento do aerossol como sendo determinado pelo erro randômico nos sinais LIDAR é uma boa aproximação [Whiteman, II, 2003]. As equações são:

$$
\begin{aligned}
\frac{\sigma_{\mathfrak{R}}^{2}}{\mathfrak{R}^{2}} \cong \frac{\sigma_{s L}^{2}+\sigma_{B L}^{2}}{\left(S_{L}-B_{L}\right)^{2}}+\frac{\sigma_{S N}^{2}+\sigma_{B N}^{2}}{\left(S_{N}-B_{N}\right)^{2}} \\
\sigma_{\Re}^{2}=\frac{\left(S_{L}-B_{L}\right)^{2}}{\left(S_{N}-B_{N}\right)^{2}}\left[\frac{\sigma_{s L}^{2}+\sigma_{B L}^{2}}{\left(S_{L}-B_{L}\right)^{2}}+\frac{\sigma_{S N}^{2}+\sigma_{B N}^{2}}{\left(S_{N}-B_{N}\right)^{2}}\right]
\end{aligned}
$$

Onde os subscritos $\mathrm{L}$ e $\mathrm{N}$ referem-se ao sinais do Laser e do deslocamento de comprimento de onda do nitrogênio respectivamente.

\subsection{Calibração atmosférica da razão de espalhamento do aerossol}

A atmosfera oferece uma ferramenta de calibração natural para determinar o fator $C_{N}{ }^{*}\left(\lambda_{L}, r\right)$ na equação 10.12. Russell et al [Russell et al., 1979, 1982] demonstraram que, em condições não vulcânicas e na ausência de poeira desértica e nuvens, existe um pouco de aerossóis presentes na troposfera livre (acima da camada limite mas abaixo da tropopausa). Eles mostraram que o valor mínimo para a razão de espalhamento do aerossol $\mathfrak{R}_{\min }(\lambda)$ para o comprimento de onda de 690 $\mathrm{nm}$ não foi maior que 1.02. Utilizando-se este valor de $\mathfrak{R}_{\text {min }}(\lambda)$ e uma dependência de $\lambda^{-4}$ para espalhamento Rayleigh e assumindo-se uma dependência $\lambda^{-k}$ no coeficiente de espalhamento do aerosol (considerado constante em função da faixa) 
implica que o fator pode ser determinado. O escalonamento em comprimento de onda dos coeficientes de retroespalhamento Rayleigh e Mie pode ser expresso:

$$
\begin{aligned}
& \frac{\beta_{\pi}^{\text {mol }}\left(\lambda_{1}, r\right)}{\beta_{\pi}^{\text {mol }}\left(\lambda_{2}, r\right)}=\left(\frac{\lambda_{2}}{\lambda_{1}}\right)^{4} \\
& \frac{\beta_{\pi}^{\text {aer }}\left(\lambda_{1}, r\right)}{\beta_{\pi}^{\text {aer }}\left(\lambda_{2}, r\right)}=\left(\frac{\lambda_{2}}{\lambda_{1}}\right)^{k}
\end{aligned}
$$

Dado que a razão de espalhamento do aerosol no comprimento de onda $\lambda_{1}$ é

$$
\mathfrak{R}\left(\lambda_{1}, r\right)=1+\frac{\beta_{\pi}^{\text {aer }}\left(\lambda_{1}, r\right)}{\beta_{\pi}^{\text {mol }}\left(\lambda_{1}, r\right)}
$$

As equações de 10.20 a 10.22 podem agora ser usadas para escalonar a razão de espalhamento para diferentes comprimentos de onda. Portando para $\lambda_{2} a$ seguinte equação se aplica:

$$
\mathfrak{R}\left(\lambda_{2}, r\right)=1+\frac{\left(\lambda_{1} / \lambda_{2}\right)^{k} \beta_{\pi}^{\text {aer }}\left(\lambda_{1}, r\right)}{\left(\lambda_{1} / \lambda_{2}\right)^{4} \beta_{\pi}^{\text {mol }}\left(\lambda_{1}, r\right)}=1+\frac{\beta_{\pi}^{\text {aer }}\left(\lambda_{1}, r\right)}{\left(\lambda_{1} / \lambda_{2}\right)^{4-k} \beta_{\pi}^{\text {mol }}\left(\lambda_{1}, r\right)}
$$

O coeficiente de retroespalhamento do aerossol é facilmente determinado por

$$
\beta^{\text {aer }}\left(\lambda_{L}, z\right)=\beta_{\pi}^{m o l}\left(\lambda_{L}, z\right)\left[\Re\left(\lambda_{L}, z\right)-1\right]
$$

Em termos de coeficiente de retroespalhamento, o qual fornece a intensidade da luz retroespalhada por fóton incidente, os aerossóis troposféricos induzem mais altos valores do que as nuvens cirrus. Em termos de razão de espalhamento do aerossol, a razão de espalhamento da nuvem é maior que para os aerossóis troposféricos [Whiteman, II, 2003].

A razão da extinção do aerossol sobre o retroespalhamento é um importante parâmetro óptico que pode fornecer informação sobre a natureza física dos aerossóis. Por exemplo, quantificar essa razão é útil para o estudo de crescimento de aerossóis como uma função da umidade relativa [Ansmann, 1992].

\subsection{Medidas de aerossóis com o MSP-Raman LIDAR}

Desde Dezembro de 2006, os canais do espalhamento elástico a $355 \mathrm{~nm}$, o do nitrogênio a $387 \mathrm{~nm}$ e do vapor d'água $(408 \mathrm{~nm})$ foram instalados permitindo 
medidas simultâneas do sinal LIDAR nesses 3 canais. As Figuras 10.5 e 10.6 exibem perfis de coeficientes de extinção e retroespalhamento bem como da razão LIDAR definida como a razão entre eles, durante alguns dias de 2008. Através de uma rotina desenvolvida, e não se levando em conta nos cálculos o fator de dependência com a temperatura, foram calculados os coeficientes de retroespalhamento, extinção e razão LIDAR, exibidos a seguir. 


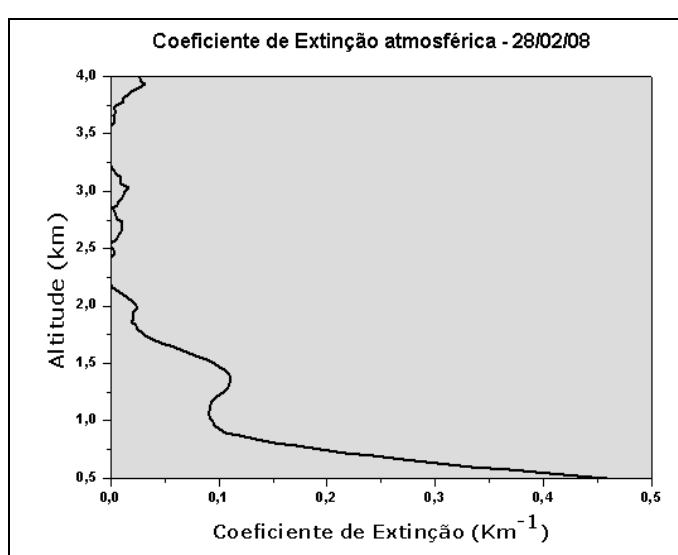

A)

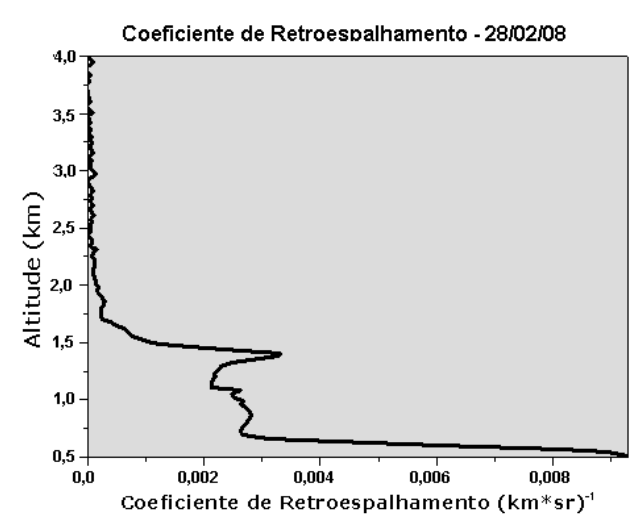

C)

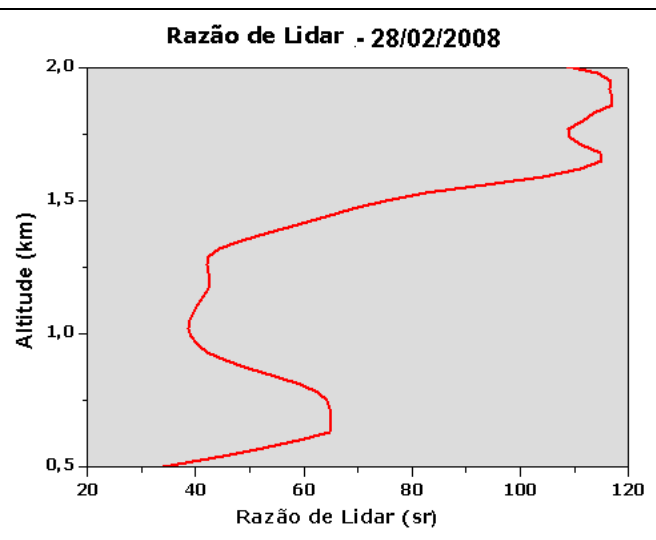

E)

FIGURA 10.5. Perfis associados a aerossóis dos dias 10 de Janeiro e 28 de Fevereiro de 2008. A e B) exibem o coeficiente de extinção do aerossol em função da altitude para um perfil de 1 hora aproximadamente, resolução 30 metros; $C$ e $D$ ) Coeficiente de retroespalhamento do aerossol ; $E$ e F) razão de LIDAR em função da altitude.

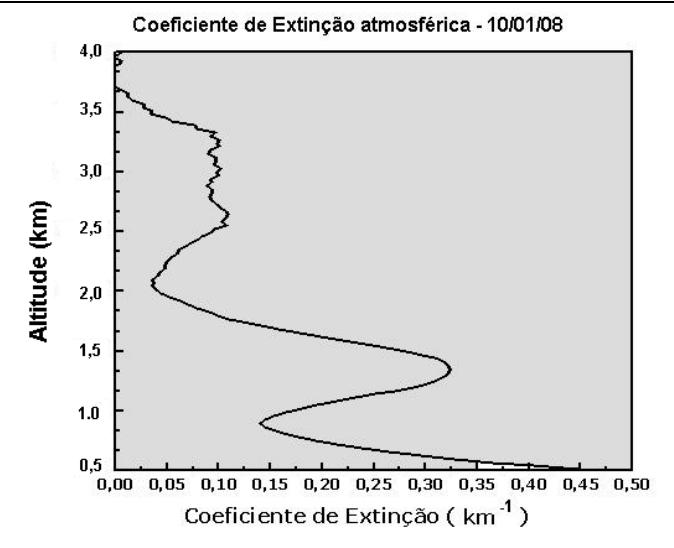

B)

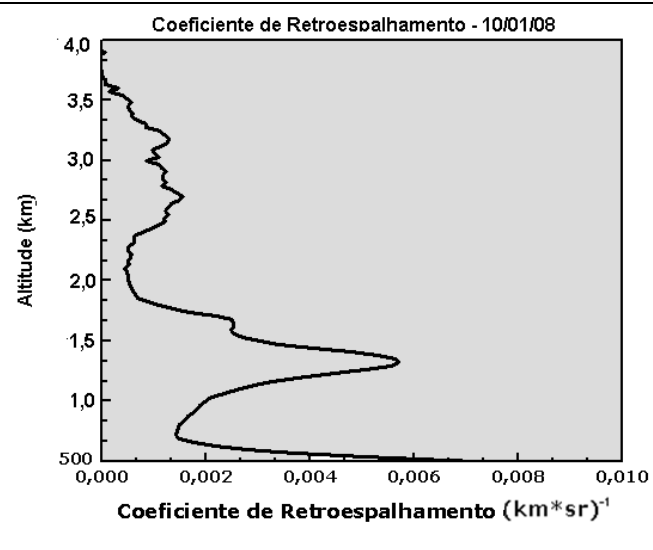

D)

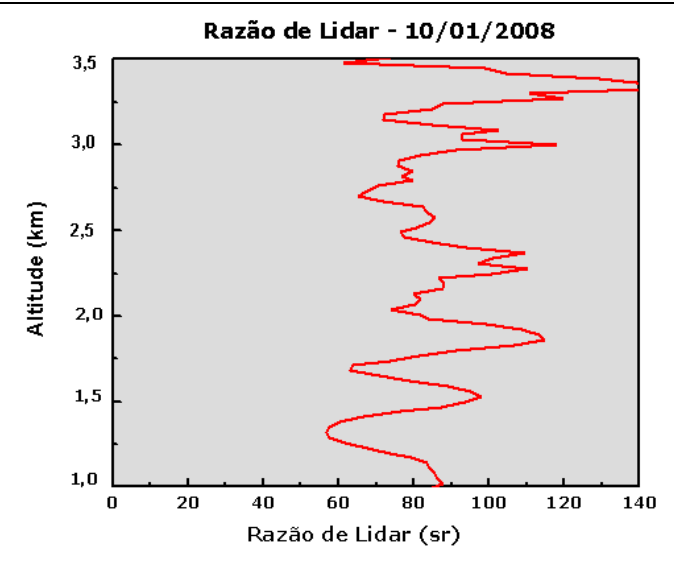

F) 

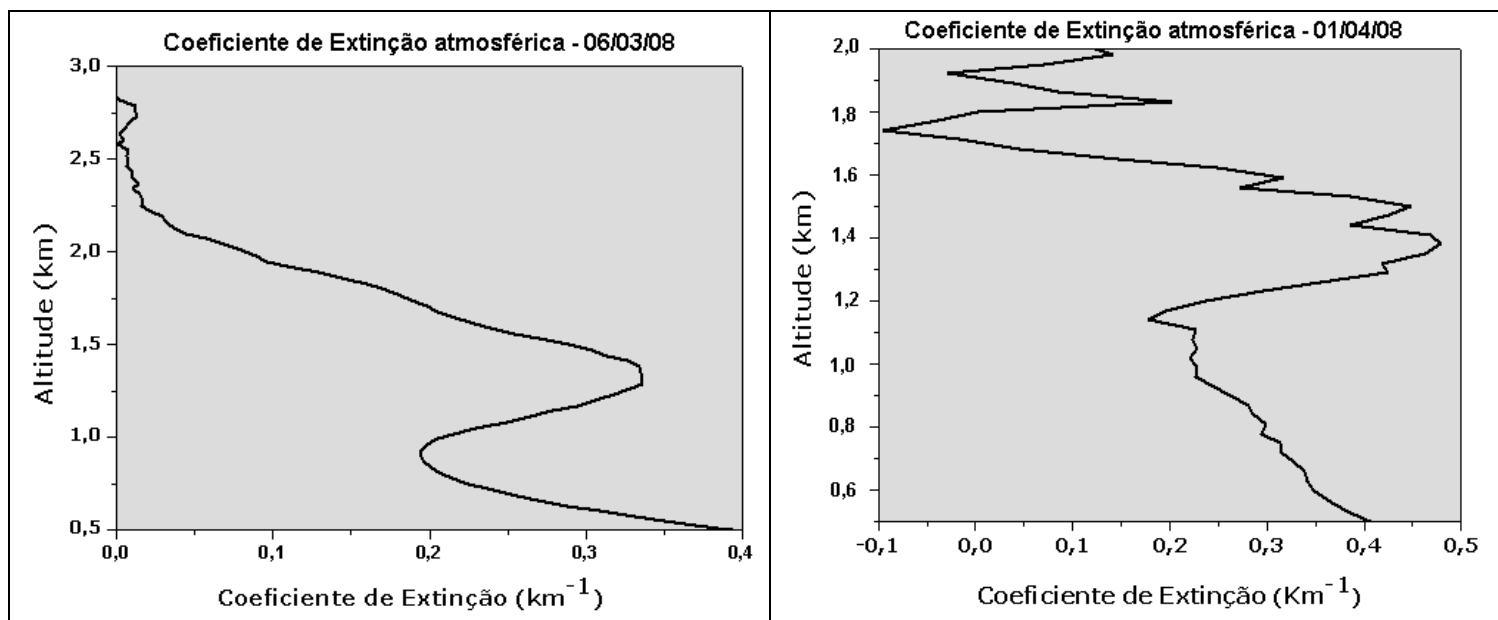

A)

B)

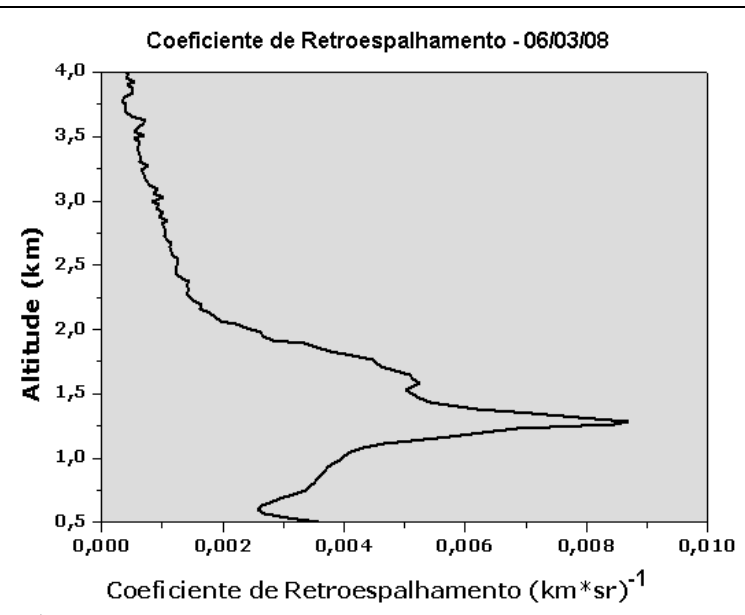

C)

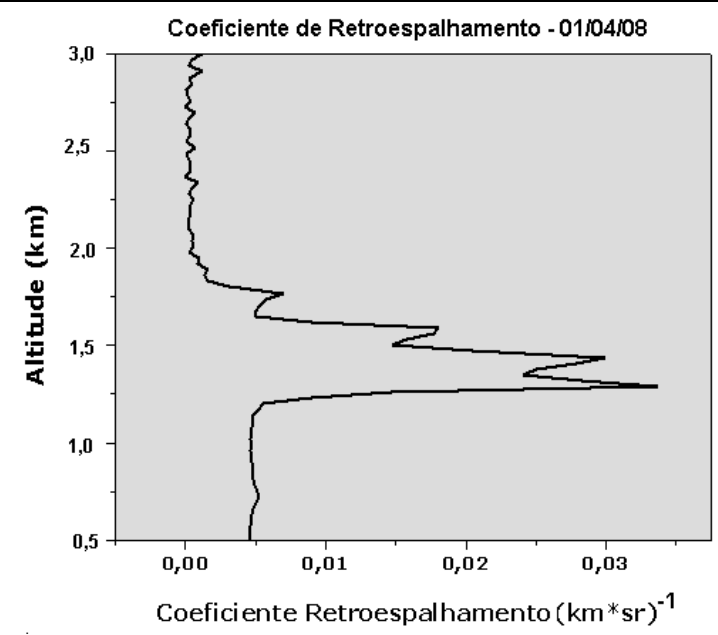

D)

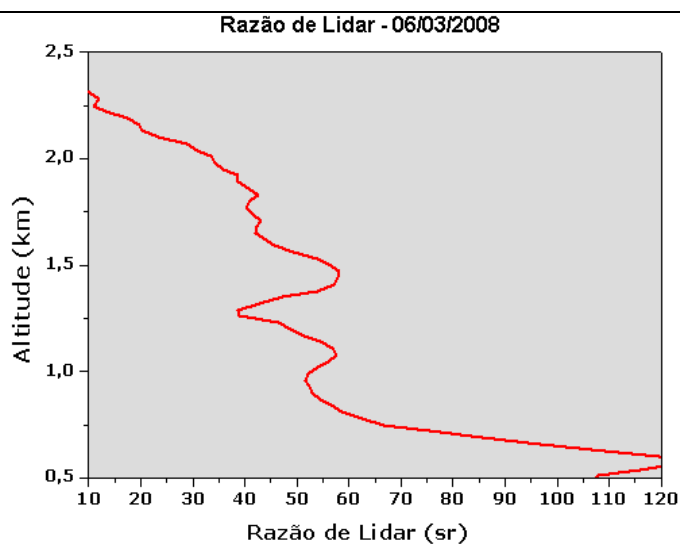

E)

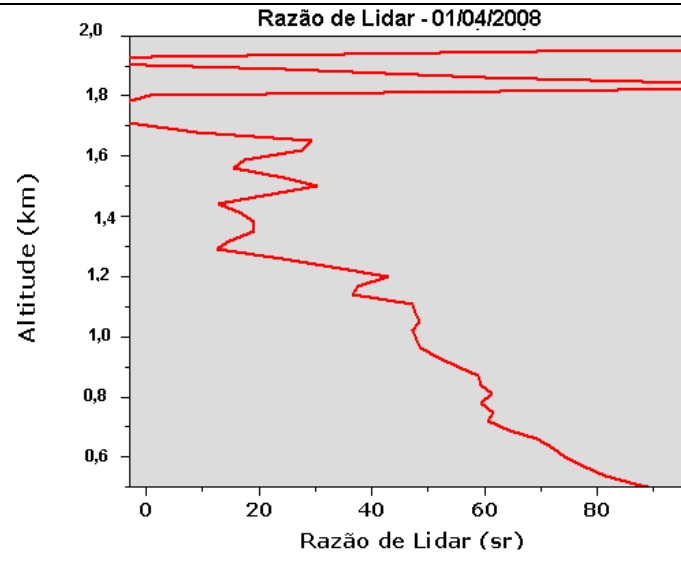

F)

FIGURA 10.6 .Perfis associados a aerossóis dos dias 06 de Março e 01 de Abril de 2008. A e B) exibem o coeficiente de extinção do aerossol em função da altitude 
para um perfil de 1 hora aproximadamente, resolução 30 metros; $C$ e D) Coeficiente de retroespalhamento do aerossol ; $E$ e F) Razão de LIDAR em função da altitude.

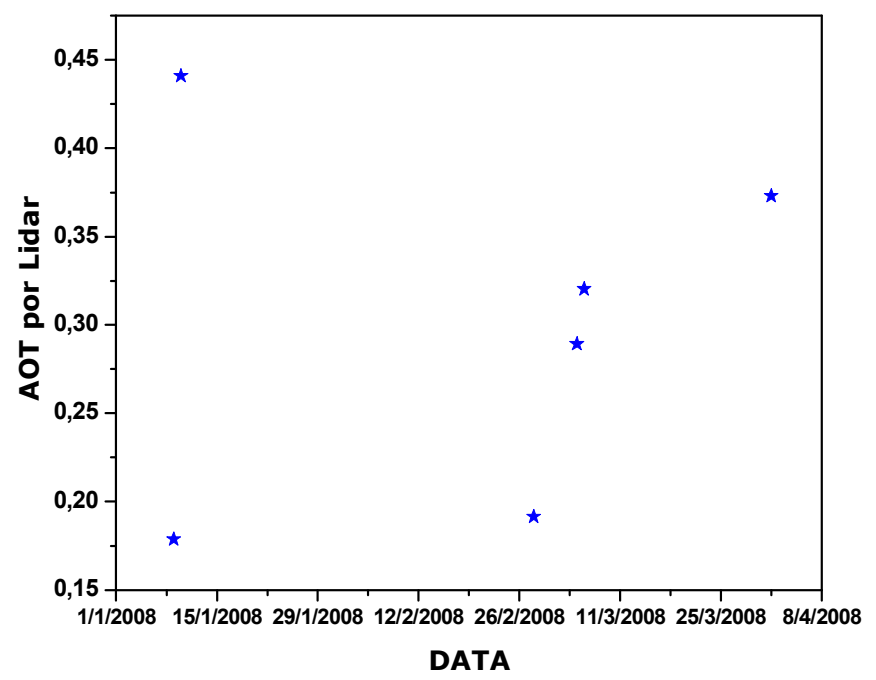

FIGURA10.7. Espessura óptica atmosférica do aerosol obtida através da integração do perfil de extinção do aerossol obtido pelo MSP LIDAR Raman nas datas descritas.

A Figura 10.7 exibe a espessura óptica atmosférica (AOT) determinada a partir da integração dos perfis de extinção do aerossol calculados a partir do sinal LIDAR Raman do MSP LIDAR Raman para alguns dias do ano de 2008. Observase uma variação significativa nos valores de AOT em função da incidência de chuvas, típicas nessa época de ano. AOT obtidas pelo fotômetros solares ainda não estão disponíveis no site da Aeronet para realizarmos uma comparação. 


\section{CAPITULO 11}

\section{CONCLUSÕES FINAIS}

Este trabalho abordou vários objetivos propostos. Entre eles, apresentamos um esforço para desenvolver uma metodologia de calibração absoluta para medidas de vapor d'água por LIDAR Raman, baseado em uma análise cuidadosa da eficiência ótica dos componentes do sistema LIDAR. Uma avaliação da homogeneidade espectral do receptor LIDAR foi realizada com o experimento de mapeamento. Os resultados nesse experimento indicaram que as bordas do telescópio e a região em torno da obstrução causada pelo periscópio mostraram uma diminuição na eficiência de transmissão enquanto que a área de recepção do sinal (equivalente a área livre de obstruções no espelho primário) apresentou aparente boa homogeneidade. Uma lâmpada de tungstênio foi utilizada nesse mapeamento. Sua irradiância espectral não obedeceu exatamente a lei da radiação de Planck, logo os valores de irradiância fornecidos pelo fabricante foram utilizados para ajustar uma função polinomial que estima a intensidade da lâmpada nos comprimentos de onda utilizados nesse estudo. Baseado em um estudo de sensibilidade, quantificamos o erro na razão das duas intensidades da lâmpada, referentes aos comprimentos de onda de interferência dos canais do vapor d'água e nitrogênio, que é necessário para o cálculo do coeficiente de calibração do LIDAR Raman no cálculo da razão de mistura de vapor d'água. $\mathrm{O}$ erro encontrado na irradiância espectral foi de $\sim 0,5 \%$ considerando-se um filtro estreito.

Duas configurações de filtros de interferência foram utilizadas. Uma com o objetivo de estudar-se a dependência com a temperatura das secções diferenciais de espalhamento Raman (especialmente as secções diferenciais de espalhamento Raman do vapor d'água) onde utilizamos filtros de interferência de banda estreita, e no caso em que foram instalados filtros de interferência de banda larga, objetivamos a estimativa de secções diferenciais de espalhamento Raman do vapor d'água de forma experimental, e sem consideramos fatores de influência/dependência com a temperatura, uma vez que filtros largos ( $19 \mathrm{~nm}$ para o canal do vapor d'água) permitem a detecção de uma vasta gama de comprimentos de onda, sendo menos suscetíveis a efeitos de mudança da temperatura. 
Fatores de calibração foram calculados, para ambas configurações de filtros de interferência (estreitos ou largos) e considerando as secções diferenciais de espalhamento Raman calculadas através de modelos escolhidos, publicados na literatura e as estimadas experimentalmente. Notamos uma grande incerteza nas secções diferenciais de espalhamento Raman obtidas experimentalmente, em grande parte devido a problemas na comparação dos perfis de razão de mistura de vapor d'água obtidos por radiossondagem e por LIDAR Raman (HURL). Um bias foi detectado, além do fato de que a radiossonda ter sido lançada a mais de $100 \mathrm{~km}$ de distância do LIDAR em questão. Como uma primeira aproximação, esses dados foram utilizados, na tentativa de implementarmos uma metodologia de obtenção/estimativa de uma secção diferencial de espalhamento Raman para o vapor d'água experimental, considerando-se que as do nitrogênio são bem conhecidas. Em Julho de 2008, esse experimento foi refeito com o lançamento de 7 radiosonda a aproximadamente 20 metros de distância do sistema Lidar, gerando resultados de comparação mais confiáveis com um erro relativo estimado em 9 a $18 \%$ das razões das secções de choque Raman experimentais em relação as publicadas na literatura.

Através da análise cuidadosa da eficiência óptica do sistema do LIDAR Raman, do cálculo de sua razão para canais do nitrogênio e vapor d'água, foi possível estimarmos de forma mais precisa sua incerteza. Estimando-se que a secção diferencial de espalhamento Raman do vapor d'água através do modelo teórico oferecia um valor mais confiável e preciso, calculamos o fator de calibração, que é determinante na incerteza associada a razão de mistura do vapor d'água. $O$ valor obtido de incerteza de $\sim 10,33 \%$, viabiliza esta técnica como uma alternativa a técnicas de calibração independente do LIDAR Raman. Contudo, uma validação é fortemente sugerida, por meio de comparação de perfis de razão de mistura de vapor d'água calibrados com essa técnica e com outros sensores, onde todos os parâmetros de medidas LIDAR são rigorosamente controlados e conhecidos. Esse é o escopo do trabalho futuro a ser desenvolvido, desta vez no sistema LIDAR Raman presente no Brasil, em São Paulo. Referentes aos erros estimados, ressaltamos a necessidade de uma quantidade maior de dados obtidos para validação com outros métodos de calibração.

Outra parte deste trabalho, foi o aprendizado da técnica LIDAR Raman, dos cálculos envolvidos tanto para a obtenção de perfis de razão de mistura de vapor 
d'água como para perfis de aerossóis atmosféricos e sua aplicação no Laboratório de Aplicações Ambientais a Laser (LAAL), localizado no IPEN em São Paulo. A implementação de canais adicionais nos sistema LIDAR de retroespalhamento existente no LAAL possibilitou que o sistema se tornasse um LIDAR Raman. As primeiras medidas de aerossóis foram abordadas neste trabalho, bem como os valores de espessura óptica atmosférica calculados. Os cálculos não levaram em conta a dependência com a temperatura das secções diferenciais de espalhamento Raman. Apesar do canal para o vapor d'água já estar em funcionamento, uma rotina de glue apropriada é necessária para que possamos implementar uma rotina completa de cálculo da razão de mistura do vapor d'água para esses dias medidos. A próxima etapa, descrita em detalhes no próximo capítulo, será aplicarmos a metodologia de calibração independente no MSP-LIDAR Raman do IPEN, possibilitando um maior controle e autonomia de operação do sistema em relação ao sistema disponível utilizado durante do estágio de doutorado (HURL). O sistema MSP-LIDAR Raman estava previsto para operar com os três canais (elástico, nitrogênio e vapor d'água) um ano antes do ocorrido, razão pela qual não houve tempo hábil para implementar a calibração nesse sistema. 


\section{CAPÍTULO 12}

\section{SUGESTÕES PARA TRABALHOS FUTUROS}

De acordo com o trabalho realizado até o presente, algumas etapas são sugeridas para trabalhos futuros dando continuidade a implementação do MSPRaman LIDAR. São elas:

- Implementar o procedimento de "glue" dos dados de vapor d'água atmosférico obtidos pelo MSP-Raman LIDAR por meio de uma rotina desenvolvida em alguma ferramenta como o software Mathematica, por exemplo ou Labview;

- Obter medidas de vapor d'água atmosférico de forma contínua com o MSP-Raman LIDAR e calibrar essas medidas pela método de calibração independente e/ou por comparação com outro sensor. Sugestão para o emprego de outro sensor seria o CIMEL que pode fornecer o perfil de umidade através de um dos comprimentos de onda disponíveis ou do uso de uma radiossonda lançada próxima do sistema. Com essas medidas contínuas de vapor d'água será possível estudar os fenômenos envolvidos com a presença de vapor d'água atmosférico na atmosfera da cidade de São Paulo;

- Refazer o calibração independente, mas desta vez para o sistema MSP-Raman LIDAR, caracterizando os filtros e todo o sistema óptico, realizando o mapeamento do telescópio utilizando a lâmpada de tungstênio.

- Apesar do sistema MSP-Raman LIDAR já estar em operação para medidas de nitrogênio e vapor d'água, uma rotina de análises customizada será necessária.

- Implementar um arranjo óptico para tornar o MSP-Raman LIDAR um instrumento com multi comprimentos de onda. A idéia seria enviar ao mesmo tempo o laser no $355 \mathrm{~nm}$ e no $532 \mathrm{~nm}$ coletando os sinais de retorno do nigrogênio, vapor d'água e Raman elástico correspondentes. 


\section{CAPÍTULO 13}

\section{LISTA DE PUBLICAÇÕES}

Artigos publicados em Jornais Indexados

1. E. Landulfo, C.A. Matos, A.S. TORRES. Uehara, P. Sawamura, Air Quality Assessment using a Multi-Instrument Approach and Air Quality Indexing in the City of São Paulo, Brazil, Atmospheric Research, Volume 85, Issue 1, July 2007, Pages 98-111.

2. E. Landulfo, A. Papayannis, A. S. TORRES, S.T. Uehara, L. M. V. Pozzetti, C. Al. Matos , P. Sawamura, W.M. Nakaema, W. Jesus, A Four Year LIDAR/Sunphotometer Aerosol Study at São Paulo, Brazil, in Press, Journal of Atmospheric and Oceanic Technologies, In Press, 2008.

3. E. Landulfo, E. G. Larroza, A.S. TORRES, F.S. Lopes, R. Costa, W.C. Jesus Midterm pollution monitoring with a backscattering lidar, sunphotometer, and air quality indexing stations. Proc. SPIE, Vol. 7111, 71110P, 2008.

DOI:10.1117/12.800213

\section{Artigos apresentados em Conferências Internacionais}

1. P. Sawamura, E. Landulfo, S. T. Uehara, W. Jesus, L. M. V. Pozzetti, A.S. TORRES, C A Matos. AEROSOL PROPERTIES DERIVED FROM LIDAR/SUNPHOTOMETRY, A FOUR YEAR SYSTEMATIC STUDY OVER THE CITY OF SAO PAULO, BRAZIL In: 23rd International laser Radar Conference, 2006, Nara, Japão. Reviewed and Revised Papers Presented at the 23rd ILRC. , 2006. p.783 -

2. E. Landulfo, A. Papayannis, A.S. TORRES, A. Z. Freitas, L.M.V. Pozzetti, J. Zeferino, P. Sawamura, A. R. Biral, E. Lima, R. F. Souza, Aerosol Measurements with Ipen's LIDAR System during the TROCCIBRAS 2004 Campaign In: 3rd Workshop LIDAR measurements in Latin America, 2005, Popayan. LIDAR measurements in Latin America. , 2005. v.x.

3. E. Landulfo, P. Sawamura, S. T. Uehara, W.M. Nakaema, A.S. TORRES, F. Lopes, C. A. Matos, W. Jesus, LIDAR/photometry studies at São Paulo in the 20032005 period, Brazil In: SPIE 2007, 2007, San Diego. LIDAR Remote Sensing for Environmental Monitoring VIII, Proc. of SPIE. BELLINGHAM: SPIE, 2007. v.6681. p.668105-1 - 668105-11.

4. C. A. Matos, E. Landulfo, W.M. Nakaema, S. T. Uehara, P. Sawamura, A.S. TORRES, Determination methods of the mixed layer height using a LIDAR system in the city of São Paulo In: IV Workshop of LIDAR Measurements in Latin America, 2007, Ilhabela. Abstracts of works presented at the 4th Workshop of LIDAR Measurements in Latin America. , 2007. p.11.

5. A.S. TORRES, E. Landulfo, D. N. Whiteman, D. Venable, Evaluation of the 
Optical Efficiency of a Raman LIDAR System towards a Water Vapor Raman LIDAR Calibration In: VI Workshop of LIDAR Measurements in Latin America, 2007, Ilhabela. Abstracts of works presented at the IV Workshop of LIDAR Measurements in Latin America, IIhabela, Brazil. , 2007. p.9 .

6. E. Landulfo, A. Papayannis, A.S. TORRES, S. T. Uehara, L.M.V. Pozzetti, C.A. Matos, P. Sawamura, W.C. Jesus, A Four Year LIDAR Activities at São Paulo, Brazil In: 7th ISTP, Boulder, CO, US, Proceedings for the 7 th ISTP. , 2006.

7. E. Landulfo, A.S. TORRES, P. Sawamura, C. A. Matos, W. Jesus, S. T. Uehara. LIDAR Activities at Sao Paulo, Brazil In: Poster Session - Universite Joseph Fourier, 2006, Grenoble. Workshop of atmospheric sciences, 2006.

8. S. T. Uehara, E. Landulfo, W. Jesus, P. Sawamura, A.S. TORRES, C. A. Matos, The real-time LIDAR technique used on air polution monitoring In: International Brazil-Japan Workshop in Energy, Environment and Sustainable Developing, Campinas, Brazil Proceedings of : III International Brazil-Japan Workshop in Energy, Environment and Sustainable Developing. , 2005.

9. E. Landulfo, A. Z. Freitas, A. Papayannis, R. F. Souza, L. M. V. Pozzetti, E. Lima, A. R. Biral, A.S. TORRES, C. A. Matos, P. Sawamura, LIDAR MEASUREMENTS WITH IPEN'S AEROSOL LIDAR DURING THE TroCCiBras 2004 CAMPAIGN In: HIBISCUS-TroCCiBras-TROCCINOX workshop, 2004, Bauru. Proceedings of HIBISCUS-TroCCiBras-TROCCINOX workshop. , 2004. v.1.

10. A.S.TORRES, E. Landulfo, D. Whiteman, D. Venable. Water Vapor Raman LIDAR Independent Calibration. In: $24^{\text {th }}$ International laser Radar Conference, 2008, Boulder, CO, USA. Reviewed and Revised Papers Presented at the $24^{\text {th }}$ ILRC, 2008 .

11. E. Landulfo, A.S. Torres, E. Larroza, F.J. S. Lopes, W.M. Nakaema, S.T. Uehara, W. De Jesus, P. Sawamura, A. M. Carrilo, M. P. P. M. Jorge, R. Mariani, G. Mariano. Midterm Aerosol Vertical Profiling Over an Urban Area (São Paulo, Brazil), Aerosol et atmospheric Optics: isual Air Quality Radiation. Air and Waste Management Association's, Moab, UT, 2008.

\section{Artigos publicados em Jornais Nacionais}

1. S T Uehara, P Sawamura, TORRES, A. S., L M V Pozzetti, W Jesus, E Landulfo. Estudo da variação da Camada Limite Planetária com o sistema LIDAR em tempo real In: IV Workshop Brasileiro de Micrometeorologia, 2005, Santa Maria. Revista Ciência e Natura - Revista do Centro de Ciências Naturais e Exatas. , 2005. v.Esp. p.181 - 185

2. W Jesus, S T Uehara, P Sawamura, TORRES, A. S., L M V Pozzetti, C A Matos, E Landulfo. Evolução em Tempo Real da Camada Limite Planetária com o sistema LIDAR e simulação numérica In: IV Workshop Brasileiro de Micrometeorologia, Santa Maria. Revista Ciência e Natura. , 2005. v.Esp. p.357 - 360. 


\section{Conferências Nacionais}

\section{A.S. TORRES}

Filmes de óxido de silício obtidos pela reação de silana e diclorosilana por deposição química a vapor por plasma de alta densidade acoplado indutivamente (ICP-CVD) In: XXVI Encontro Nacional de Física da matéria Condensada, Caxambu. Anais do XXVI Encontro Nacional de Física da matéria condensada. , 2003.

\section{A.S. TORRES,}

Filmes de oxido de silício obtidos pela reação da silana e da diclorosilana por deposição química a vapor por plasma de alta densidade acoplado indutivamente (ICP-CVD) In: XXV Encontro Nacional de Física da Matéria Condensada, CaxambuMG. XXV Encontro Nacional de Física da Matéria Condensada. , 2002.

\section{A.S. TORRES,}

Deposição Química a Vapor de Óxido de Silício assistida por Plasma de Alta Densidade Acolpado Indutivamente (ICP-CVD) In: VI Encontro Brasileiro de Física dos Plasmas, Campos do Jordão. $6^{\circ}$ Encontro Brasileiro de Física dos Plasmas. São Paulo: Sociedade Brasileira de Física, 2001. p.22 - 22

4. A.S. TORRES, Deposição química a vapor de óxido de silício por ICP-CVD In: III Congresso de TEcnologia, FATEC-SP, São Paulo. III Congresso de TEcnologia - FATEC-SP. , 2001.

5. C. A. Matos, A.S. TORRES,E. Landulfo, W.M. NAKAEMA, S. T. Uehara, P. Sawamura, W. Jesus. Estudo de Camada Limite Planetária com o uso de um LIDAR de Retroespalhamento em São Paulo, Brazil In: XIII Simpósio Brasileiro de Sensoriamento Remoto, Florianopolis. Anais do XIII Simpósio Brasileiro de Sensoriamento Remoto. , 2007.

6. W.M. Nakaema, A.S. TORRES, C. A. Matos, P. Sawamura, S. T. Uehara, W. Jesus, M.F. Andrade, M.A. Yamasoe, O.R.S. Ccoyllo, N.M.P. Leme, E Landulfo. ESTUDO DA EVOLUCAO DA CAMADA LIMITE PLANETARIA E PROPRIEDADES OPTICAS DE AEROSSOIS DURANTE A CAMPANHA DE POLITICAS PUBLICAS MODELOS DE QUALIDADE FOTOQUIMICOS EM SAO PAULO/SP In: XIV Congresso Brasileiro de Meteorologia, Florianopolis. XIV Congresso Brasileiro de Meteorologia , 2006.

7. A.S. TORRES, E Landulfo, Nakaema, W. M. Implementação de um LIDAR Raman no IPEN - Instituto de Pesquisas Energéticas e Nucleares, São Paulo, Brasil In: XIV Congresso Brasileiro de Meteorologia, 2006, Florianópolis. Anais do XIV Congresso Brasileiro de Meteorologia , 2006.

\section{Participação em eventos}

Participação na campanha de campo WAVES - Water Vapor Experiment (no time de lançamento de radiossondagens)em Beltsville, MD, US - Jullho 2006. (2 meses). 


\section{ANEXO 1}

\section{EXPERIMENTO COM FILTROS DE DENSIDADE NEUTRA NO HURL}

Esse experimento visa determinar a transmissão dos filtros de densidade neutra, escolhidos com base no valor de densidade óptica calculada para serem instalados no sistema HURL, trazendo a taxa de contagem de fótons para o regime linear, quando filtros de interferência de banda larga forem utilizados. Para isso, dois experimentos foram realizados. Um por meio de medidas da taxa de contagem pelo sistema LIDAR HURL, fazendo-se uma estimativa da transmissão óptica a partir da taxa de contagem, e outro experimento com medidas de transmissão dos filtro por um espectrômetro.

Em suma, caracterizamos todos os filtros de densidade neutra (ND), depois medimos a taxa de contagem do HURL com os mesmos instalados, segundo a configuração descrita a seguir.

\section{A.1 Caracterização dos filtros ND}

A transmissão foi medida em todos os filtros ND pelo espectrômetro Digikron DK 480 1 1 2 Meter disponível no Goddard Space Flight Center- NASA (Figura A1).

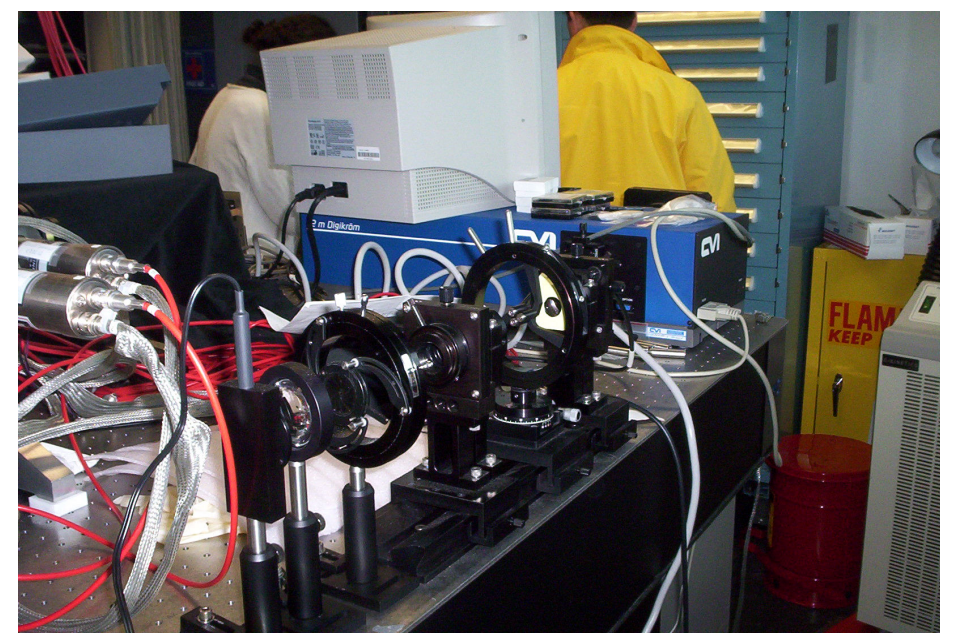

FIGURA A1. Espectrômetro Digikron e sistema de lentes.

Procedimento com o espectrômetro: 
- Calibração usando uma lâmpada de mercúrio, banda única obtendo-se a transmissão total em um intervalo próximo ao pico de interesse. Checar o fator de calibração que o espectrômetro fornece (a partir do desvio entre o pico medido e o correspondente teoricamente). Esse fator corrige as medidas realizadas.

- Com a lâmpada de mercúrio e banda larga, medindo a transmissão para cada filtro de interferência, subtraindo-se linhas de base, normalizando dados com filtro e sem o filtro.

Manipulação dos dados: correção das linhas de base, da transmissão total e do fator de calibração obtido com a etapa de uso da lâmpada de mercúrio de banda única.

\section{A.2. Medidas da taxa de contagem com o HURL}

Abaixo são descritos os filtros ND utilizados no experimento:

Filtro A: valor nominal de densidade óptica igual a 3

Filtro B e Filtro C: densidade óptica nominal igual a 2

Filtro D e Filtro E: densidade óptica nominal igual a 1

Filtro F e Filtro G: densidade óptica nominal igual a 0,3.

Procedimento no canal do vapor d'água $\mathrm{H}_{2} \mathrm{O}$

1. Insira o filtro de interferência largo e o filtro ND A. Verifique se a taxa de contagem do HURL sob incidência da lâmpada de tungstênio é < $2 \mathrm{MHz}$. Quantifique acuradamente a taxa de contagem.

2. Insira o filtro $B$ (e depois $F$ e $\circ G$ individualmente) em adição ao filtro $A$. Quantifique acuradamente a taxa de contagem nessas configurações e estime a transmissão de cada filtro.

Procedimento no canal do $\mathrm{N}_{2}$

1. Insira o filtro de interferência largo e o filtro ND C. Verique se a taxa de contagem medida pelo HURL, sob incidência da lâmpada de tungstênio é < $2 \mathrm{MHz}$. Quantifique a taxa de contagem acuradamente para essa configuração.

2. Insira filtro $D$ em adição ao filtro $C$. Depois, retire $O D$ e insira $o$ filtro $E$. Quantifique acuradamente a taxa de contagem nessa configuração para cada cada filtro adicionado depois do filtro $\mathrm{C}$. 


\section{REFERÊNCIAS BIBLIOGRÁFICAS}

ADAM, M., VENABLE, D., CONNELL, R., WHITEMAN, D.N., DEMOZ, B.B., Performance of the Howard University Raman LIDAR during 2006 WAVES campaign, J. Optoelec. Advanced Materials, v. 9, n. 11, p. 3522-3528, 2007.

ANSMANN, A.; RIEBESELL, M., and WEITKAMP, C. Measurement of atmospheric aerosol extinction profiles with a Raman LIDAR. Optics Letters, v. 15, n. 13, p. 746-748, 1990.

ANSMANN, A.; WANDINGER, U.; RIEBESELL, M.; WEITKAMP, C. and MICHAELIS, W. Independent measurement of extinction and backscatter profiles in cirrus clouds by using a combined Raman elastic-backscatter LIDAR. Applied Optics, v. 31, n. 33, p. 7113-7131., 1992.

ARSHINOV, Y.F.; BOBROVNIKOV, S.M.; ZUEV, V.E. and MITEV, V.M. AtmosphericTemperature Measurements Using a Pure Rotational Raman LIDAR, Applied Optics, v.22, n. 19, p. 2984-2990, 1983.

AVILA, G.; FERNANDEZ, J.M.; MATE, B.; TEJEDA, G. And MONTERO, S. Rovibrational Raman Cross Sections of Water Vapor in the $\mathrm{OH}$ Stretching Region. J. Mol. Spectrosc., v. 196, n. 1, p. 77-92, 1999.

AVILA, G.; TEJEDA, G.; FERNÁNDEZ, J.M. and MONTERO, S. The rotational Raman spectra and cross sections of $\mathrm{H}_{2} \mathrm{O}, \mathrm{D}_{2} \mathrm{O}$, and HDO. Journal of Mol. Spectroscopy, v. 220, p. 259-275, 2003.

AVILA, G.; TEJEDA, G.; FERNÁNDEZ, J.M. and MONTERO, S. The Raman spectra and cross-sections of the $\mathrm{v}_{2}$ band of $\mathrm{H}_{2} \mathrm{O}, \mathrm{D}_{2} \mathrm{O}$, and HDO. J. Mol. Spectroscopy, v. 233, p. 166-180, 2004.

AVILA, G.; TEJEDA, G.; FERNÁNDEZ, J.M. and MONTERO, S. The Raman spectra and cross-sections of $\mathrm{H}_{2} \mathrm{O}, \mathrm{D}_{2} \mathrm{O}$, and $\mathrm{HDO}$ in the $\mathrm{OH} / \mathrm{OD}$ stretching regions. J. Mol. Spectroscopy, v. 228, p. 38-65, 2004.

BARRY, R.G., CHORLEY, R.J. Atmosphere, Weather and Climate (7th edition), Routledge (London), 409 p., 1998.

BATES, D.R. Rayleigh-scattering by air. Planet. Space Sci., v. 32, p. 785790, 1984.

BEHRENDT A. Temperature measurements with LIDAR, LIDAR, range-resolved optical remote sensing of the atmosphere, editor C. Weitkamp, Springer, 273306, 2005.

BEVINGTON, P.R. AND ROBINSON, D.K. Data reduction and Error Analysis for the Physical Sciences (McGraw-Hill), New York, 1992.

BISSON, S.E.; GOLDSMITH, J.E.M. and MITCHELL, M.G. Narrow-band, narrow fieldof-view Raman LIDAR with combined day and night capability for tropospheric watervapor profile measurements. Applied Optics, v. 38, n. 9, p. 1841-1849, 1999.

BOHREN, C.F.; HUFFMAN, D. Absorption and Scattering of Light by Small Particles Wiley Science Paperback Series, 1998. 
BROWELL, E.; WILKERSON, T.D.; McILRATH, T.J. Water vapor diffential absorption LIDAR development and evaluation. Applied Optics, 1979.

CLEMESHA, B.R., KENT, G.S., WRIGHT, R.W.H. Journal of Applied Meteorology, v. 6, p. 386-395, 1966.

CLEMESHA, B.R., KENT, G.S., WRIGHT, R.W.H. Laser Probing the Lower Atmosphere, Nature, 209, p. 184-185, 1966.

COONEY, J. Measurements of the Raman component of Laser Atmospheric backscatter, Applied Physics Letters, v. 12, n. 2, p. 40-42, 1968.

COONEY, J.A., ORR, J., TOMASETTI, C. Measurements separating the gaseous and aerosol components of laser atmospheric backscatter, Nature(London) 224, 10981099, 1969.

ELTERMAN, L. Seasonal trends of temperature, density and pressure to $67.6 \mathrm{~km}$ obtained with the searchlight probe technique. Journal of Geophysical Research Atmospheres, v. 59, n. 3, p. 351-358, 1954.

FERRARE, R.A.; MELFI, S.H.; WHITEMAN, D.N.; EVANS, K.D.; SCHMIDLIN, F.J., and STARR, D.I. A Comparison of Water Vapor Measurements made by Raman LIDAR and Radiosondes, J. Atmos. Oceanic Tech., v.12, n. 6, 1995, p. 1177-1195, 1995.

FIOCCO, G.; SMULLIN, L.D. Detection of Scattering Layers in the Upper Atmosphere (60-140 km) by Optical Radar. Nature, v. 199, p. 1275-1276,1963.

FLAMANT, C., PELON, J. Advances in Atmospheric Remote sensing with LIDAR, Spriger-Verlag, Berlin, 31, 1997.

HAUCHCORNE, A.; CHANIN, M.L.; KECKHUT,P. Climatology and trends of the middle atmospheric temperature $(33-87 . \mathrm{km})$ as seen by Rayleigh LIDAR over the south of France, Journal of Geophysical Research-Atmospheres, 1991.

HEAPS, W.S.; BURRIS, J.; FRENCH, J.A. LIDAR technique for remote measurement of temperature by use of vibrational-rotational Raman spectroscopy. Appl. Opt. v. 36, p. 9402-9405, 1997.

HERZBERG, G. Molecular Spectra and Molecular Structure, vol. 1 Spectra of Diatomic Molecules, 658 pp. , New York, Van Nostrand Reinhold, 1950.

HERZBERG, G. Molecular Spectra and Molecular Structure, vol. 2 Infrared and Raman Spectra of Polyatomic Molecules, 632 pp. , New York, Van Nostrand Reinhold , 1945.

HINKLEY, E. D. (Ed.). Laser monitoring of the atmosphere. Berlin, New York, Springer-Verlag, 1976. (Topics in applied physics, 14).

HOCHENBLEICHER, J.G.; KIEFER, W.; BRANDMULLER, J., A laboratory for a resonance Raman LIDAR system, Applied Spectrocospy, v. 30, n. 5, p. 528-531, 1976.

INABA, H.; KOBAYASHI, T. Laser-Raman Radar for Chemical Analysis of Polluted Air, Nature, v. 224, p. 170-172, 1969. 
INABA, $\mathrm{H}$. Detection of atoms and molecules by Raman scattering and resonance fluorescence. Laser monitoring of the atmosphere, Springer-Verlag, p. 153-236, 1976.

LANDULFO, E.; PAPAYANNIS, A.; ARTAXO, P.; CASTANHO, A.D.A.; FREITAS, A.Z.; SOUZA, R.F.; VIEIRA JUNIOR, N.D.; JORGE, M.P.M.P.; SÁNCHEZ-CCOYLLO, O.R. and MOREIRA, D.S. Synergetic Measurements of Aerosols over São Paulo, Brazil using LIDAR, Sunphotometer and Satellite Data During the Dry Season, Atmospheric Chemistry and Physics, v. 3, p. $1523-1539,2003$.

LARCHEVÊQUE, G. Development of the Jungfraujoch multi-wavelength LIDAR system for continuous observations of the aerosol optical properties in the free troposphere. PhD thesis presented at École Potythecnique Federal de Lausanne, 2002.

LAVORATO, M. Et al. Advances in Atmospheric Remote sensing with LIDAR, Springer-Verlag, Berlin,91, 1997.

LAZZAROTTO, B. Ozone and Water Vapor Measurements by Raman LIDAR in the Planetary Boundary Layer. Thesis n. 2351, Tese (Doutorado), Ecole Polytechnique Federale de Lausane. 2001.

LEONARD, D.A. Observation of Raman Scattering from the Atmosphere using a Pulsed Nitrogen Ultraviolet Laser, Nature, v. 216, p. 142-143, 1967.

LILLESAND, T.M. and KIEFER, R.W. Remote Sensing and Image Interpretation. 2nd edition, John Wiley \& Sons Publishers, 1987. a

LONG, D.A. The Raman Effect: A Unified Treatment of the Theory of Raman Scattering by Molecules, John Wiley \& Sons, 2002.

LONG, D.A. Raman Spectroscopy, McGraw Hill, 1977.

MAIMAN, T.H. Stimulated Optical Emission in Ruby. Journal of the Optical Society of America, v. 50, n. 11, p. 1134-1134,1960.

MANSHARAMANI, N. Greenhouse Effect-LIDAR Techiques: A State of Art Report. Vidya Art Press, Jakhan, Dehradun, 2006.

MANUAL Optronics, Manual da calibração da lâmpada de Tungstênio modelo S-990 , Optronics, 2005.

MC CLUNG, F.J.; HELLWORTH, R.W. Giant Optical Pulsations from Ruby. Journal of Applied Physics, v. 33, p. 828-829, 1962.

MEASURES, R. M. Laser Remote Sensing Fundamentals and Applications, Krieger Publishing Company, 1984.

MELFI, S.H.; LAWRENCE, J.D.; McCORMICK, M.P. Observation of Raman Scattering by Water Vapor in the Atmosphere, Applied Physics Letters, v. 15, n. 9, p. 295297, 1969.

MILOSHEVICH, L., VOEMEL, H.,WHITEMAN, D.N., LESHT, B., SCHMIDLIN, F.J., RUSSO,F., J. Geophys. Res., v.111, doi: 1029/2005JD6083, 2006.

MURPHY, W.F. Intensities of rotation and vibration-rotation Raman transitions in asymmetric top molecules. J. Raman Spectroscopic 11, 339-345, 1981. 
NASA site: http://www.espo.nasa.gov/docs/ave-costarica2/cfh.pdf, Acesso em 20 de Outubro de 2007.

OPTICA SOFTWARE, http://www.opticasoftware.com/ Acesso em 12/2006.

PECK, E.R., REEDER, K. Dispersion of air. J. Opt. Soc. Am, v 62, p. 958-962, 1972.

PENNEY,C.M, PETERS, R.L.ST., LAPP, M. Absolute rotational Raman cross sections for $\mathrm{N}_{2}, \mathrm{O}_{2}$, and $\mathrm{CO}_{2}$. Journal of Optical Soc. America, v. 64, n. 5, p. 712-716, 1974.

PENNEY, C.M.; LAPP, M. Raman-scattering cross-section for water vapor. J. Opt. Soc. Am. V.66, p. 422-425, 1976.

RENAUT, D.; CAPITINI, R. Boundary-Layer Water Vapor Probing with a Solar-Blind Raman LIDAR: Validations, Meteorological Observations and Prospects, Journal of Atmospheric and Oceanic Technology, v. 5, n. 5, p. 585-601, 1988.

Report of calibration of One Standard of Spectral Irradiance OL 200M, S/N: S990. Optronic Laboratories, Inc. 2000.

ROGERS, R.R., YAU, M.K. A Short Course in Cloud Physics. ButterworthHeinemann, 3. ed., 1989.

ROSEN, H.; ROBRISH, P.; CHAMBERLAIN, O. Remote detection of pollutants using resonance Raman scattering, Applied Optics, v. 14, n. 11, p. 2703-2706, 1975.

RUSSEL, P.B.; SWISSLER, T.J. and MCCORMICK, M.P. Methodology for error analysis and simulation of LIDAR aerosol measurements. Applied Optics, v.18, n. 22, p. 3783-3797, 1979.

RUSSEL, P.B. et al. Journal of Geophysics Research 79,36, 5555, 1974.

SCHAWLOW, A.L.; TOWNES, C.H. Infrared and Optical MASERS. Physical Review, v. 112, n. 6. p. 1940-1949, 1958.

SEINFELD, J.H.; PANDIS, S.P. Atmospheric chemistry and physics.I John Wiley, Sons, 1998.

SHE, C.Y.; YU, J.R. and CHEN, H. Observed thermal structure of a midlatitude mesopause. Geophys. Res. Lett. v. 20, p. 567-570, 1993.

SHERLOCK, V.; GARNIER, A.;HAUCHECORNE, A. and KECKHUT, P. Implementation and validation of a Raman LIDAR measurement of middle and upper tropospheric water vapor. Applied Optics, v. 38, n. 27, p. 5838-5850, 1999.

SHERLOCK, V.; HAUCHERCONE, A.; LENOBLE, J. Methodology for the independent calibration of Raman backscatter water-vapor LIDAR systems. Applied Optics v. 38 n. 27, p. 5816-5837, 1999.

TARNIEWICZ, J.; BOCK, O.; PELON, J. and THOM, C. Raman LIDAR for external GPS path delay calibration devoted to high accuracy height determination. Phys. and Chem. Of the Earth, v. 27, p. 329-333, 2002. 
TELLER, E.; JARHRB, D. Chemical Physics, v. 9 , n. 2, p. 43, 1934.

TORRES, A.S., LANDULFO, E., WHITEMAN, D.,VENABLE, D. Water Vapor Raman LIDAR Independent Calibration. In: $24^{\text {th }}$ International laser Radar Conference, 2008, Boulder, CO, USA. Reviewed and Revised Papers Presented at the $24^{\text {th }}$ ILRC, 2008.

TROY, C. T. et al. Where it all begins. Photonics Spectra, Environment April Issue, p. 101,1998.

TURNER, D.D., GOLDSMITH, j.E.M. J. Atmos. Ocean. Tech., 16, p. 1062, 1999.

UCHIUMI, M. et al. DIAL measurement of Ch4, CO2, CO and NO2 using a tunable IR source based on the Ti:Sapphire laser, in $\mathbf{1 7}^{\text {th }}$ ILRC, Senday, Japan, 1994.

VAUGHAN, G.; WAREING, D.P.; PEPLER, L.; THOMAS, L. and MITEV, V., Atmospheric-temperature measurements made by rotational Raman-scattering. Applied Optics v.32, n.15, p. 2758-2764, 1993.

VAUGHAN, G.; WAREING, D.P.; THOMAS, L. Humidity measurements in the free troposphere using Raman backscatter. Q.J.R. Meteorol. Soc., v. 114, pp. 14711484, 1988.

VENABLE, D., CONNEL, R. The development of the Howard University Raman LIDAR. $2^{\text {nd }}$ Symposium of LIDAR Atmospheric Applications.- AMS, 2005.

VLADUTESCU, D.V., GROSS, B., WU, Y., GLILERSON, A., MASHARY, F., AHMED, S. GPS calibrated multiwavelength water vapor Raman LIDAR measurements to assess urban aerosol hygroscopicity. Proceeding of SPIE 2007, v. 6750, 2007.

WAVES web site, http://ecotronics.com/LIDAR-misc/waves.htm. Acesso em: $12 / 08 / 2007$.

WATER VAPOR in the Climate System. Special Report. December 1995. Disponível em: http://www.agu.org/sci soc/mockler.html. Acesso em: 04 ago. 2004.

WEITKAMP, C. LIDAR: Range-Resolved Optical Remote Sensing of the Atmosphere. Springer, 2005.

WHITEMAN, D.N. Examination of the traditional Raman LIDAR technique. I. Evaluating the temperature-dependent LIDAR equations. Applied Optics, v. 42, n. 15, p. 2571-2592, 2003.

WHITEMAN, D.N. Examination of the traditional Raman LIDAR technique. II. Evaluating the ratios of water vapor and aerosols. Applied Optics v. 42, n.15, p. 2593-2608, 2003.

WHITEMAN, D.N.; DEMOZ, B.; DI GIROLAMO, P.D.; COMER, J.; VESELOVSKII, I.; EVANS, K.; WANG, Z.; CADIROLA, M.; RUSH, K.; SCHWEMMER, G.; GENTRY, B.; MELFI, S.H.; MIELKE, B.; VENABLE, D. and VAN HOVE, T. Raman LIDAR measurements during the International $\mathrm{H} 2 \mathrm{O}$ Project. Part I: Instrumentation and Analysis Techniques. J. Atmospheric and Oceanic Technology, v. 23, p. 157-169, 2006.

WHITEMAN, D.N.; EVANS, K.D.; DEMOZ, B.; STARR, D.O'C.; TOBIN, D.; FELTZ, W.; JEDLOVEC, G.J.; GUTMAN, S.I.; SCHWEMMER, G.K.; CADIROLA, M.; MELFI, S.H. and SCHMIDLIN, F.J. Raman LIDAR measurements of water vapor and cirrus clouds 
during the passage of hurricane Bonnie", J. of Geophys. Res., v. 106, n. D6, p. 5211-5225, 2001.

WHITEMAN, D.N.; RUSSO, R.; DEMOZ, B.; MILOSHEVICH, L.M.; VESELOVSKII, I.; HANNON, S.; WANG, Z.; VOMEL, H.;, SCHMIDLIN, F.; LESHT, B.; MOORE, P.J.; BEEBE, A.S.; GAMBACORTA, A. and BARNET, C. Analysis of Raman LIDAR and radiosonde measurements from the AWEX-G field campaign and its relation to Aqua validation. Journal of Geophysical Research, v. 111, D09S09, 2006.

ZUEV, V.E. Laser Beams in the atmosphere, Consultants Bureau, New York, 1982. 